\title{
Klaus Koszinowski
}

\section{Die von präfigierten Verben abgeleiteten Substantive in der modernen serbokroatischen Standardsprache}

Eine Untersuchung zu den Präfixen do, iz, na, za

Verlag Otto Sagner München · Berlin · Washington D.C.

Digitalisiert im Rahmen der Kooperation mit dem DFG-Projekt „Digi20“

der Bayerischen Staatsbibliothek, München. OCR-Bearbeitung und Erstellung des eBooks durch den Verlag Otto Sagner:

http://verlag.kubon-sagner.de

( bei Verlag Otto Sagner. Eine Verwertung oder Weitergabe der Texte und Abbildungen, insbesondere durch Vervielfältigung, ist ohne vorherige schriftliche Genehmigung des Verlages unzulässig.

«Verlag Otto Sagner» ist ein Imprint der Kubon \& Sagner GmbH. 


\section{Slavistische Beiträge}

BEGRÜNDET VON ALOIS SCHMAUS

HERAUSGEGEBEN VON JOHANNES HOLTHUSEN UND JOSEF SCHRENK

REDAKTION: PETER REHDER

Band 100 
KLAUS KOSZINOWSKI

\section{DIE VON PRÄFIGIERTEN VERBEN ABGELEITETEN SUBSTANTIVE IN DER MODERNEN SERBOKROATISCHEN STANDARDSPRACHE}

Eine Untersuchung zu den Präfixen do, iz, na, za 


\section{Bovortaonse}

Otas:avioliction

Acinanon

ISBN 3-8769C-112-Y

Copyright by Verlag Otto Sagner, München 1976 Abteilung der Firma Kubon und Sagner, München Druck: Alexander Großmann

8 München 19, Ysenburgstraße $7^{I}$ 


\section{EINLEITUNG}

1. Ziel der Arbeit............................... 11

2. Untersuchungsgrundlage.......................... 13

3. Literatur zur Problematik der Arbeit............... 14

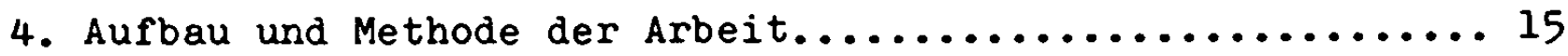

a) Zur Theorie der Funktionen der Verbalpräfixe........ 15

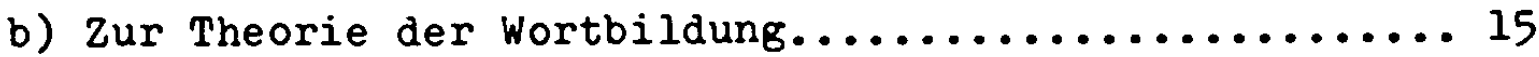

c) Zur Klassifikation des Materials................ 16

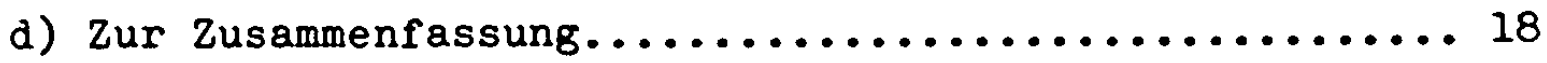

5. Zur Abgrenzung des Materials.................... 18

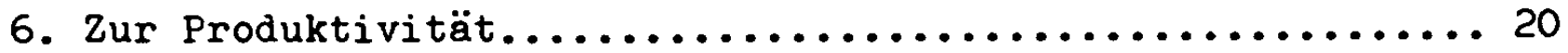

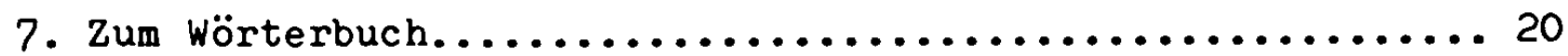

ERSTER TEIL

I. ZUR THEORIE DER VERBALPRAFIXE................... 23

1. Die Funktionen der Verbalpräfixe............... 23

2. Exkurs: Zur Frage des Aspekts................ 28

3. Die lexikalische Funktion........................ 31

4. Die modifizierende Funktion..................... 34

5. Die rein perfektivierende Funktion.............. 38

II. ZUR THEORIE DER WORTBILDUNG................... 4 7

1. Der Begriff der onomasiologischen Kategorie........47

2. Verfahren der morphologischen Wortbildung......... 51

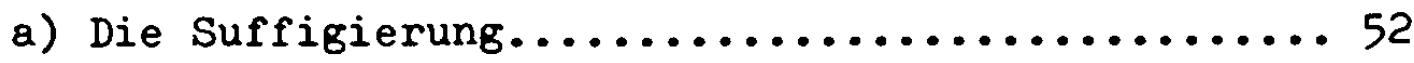

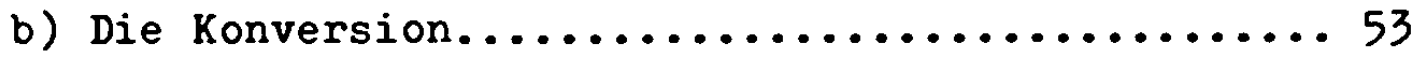

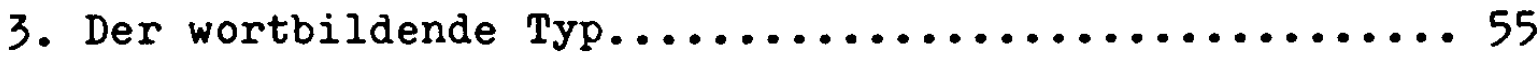

4. Die wortbildende Kategorie................... 58

ZWEITER TEIL

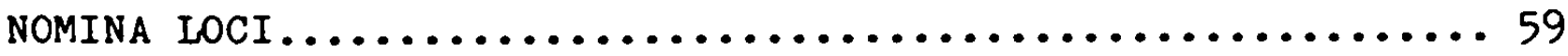

Allgemeine Vorbemerkungen........................ 59

Material.................................66

A. Lexikalische Funktion........................66 66

AA. Nomina loci von Verben mit dem Präfix do-.........66 66 
AB. Nomina loci von Verben mit dem Präfix iz-....... 66

AC. Nomina loci von Verben mit dem Präfix na-........ 68

AD. Nomina loci von Verben mit dem Präfix za-........ 70

B. Modifizierende Funktion.......................... 72

BC. Nomina loci von Verben mit dem Präfix na-....... 72

BD. Nomina loci von Verben mit dem Präfix za-....... 73

C. Rein perfektivierende Funktion.................... 73

CB. Nomina loci von Verben mit dem Präfix iz-........ 73

a) iz- als reihendes Präfix................. 73

CC. Nomina loci von Verben mit dem Präfix na-........ 75

a) na- als reihendes Präfix................. 75

CD. Nomina loci von Verben mit dem Präfix za-........ 76

a) za- als reihendes Präfix................ 76

Schlussbemerkungen.............................. 77

NOMINA INSTRUMENTI............................. 80

Allgemeine Vorbemerkungen......................... 80

Material................................... 86

A. Lexikalische Funktion........................... 86

AA. Nomina instrumenti von Verben mit dem Präfix do-... 86

AB. Nomina instrumenti von Verben mit dem Präfix iz-... 87

AC. Nomina instrumenti von Verben mit dem Präfix na-... 89

AD. Nomina instrumenti von Verben mit dem Prëfix za-... 92

B. Modifizierende Funktion........................ 95

BA. Nomina instrumenti von Verben mit dem Präfix do-... 95

BC. Nomina instrumenti von Verben mit dem Präfix na-... 96

C. Rein perfektivierende Funktion..................... 97

CB. Nomina instrumenti von Verben mit dem Präfix iz-... 97

a) $\underline{i z}$ - als reihendes Präfix................... 97

CC. Nomina instrumenti von Verben mit dem Präfix na-... 98

a) na- als reihendes Präfix.................. 98

b) na- als leeres Präfix.................... 99

CD. Nomina instrumenti von Verben mit dem Präfix za-... 101

a) za- als reihendes Präfix.................. 101

Schlussbemerkungen................................ 104

NOMINA AGENTIS................................... 107 
Allgemeine Vorbemerkungen....................... 107

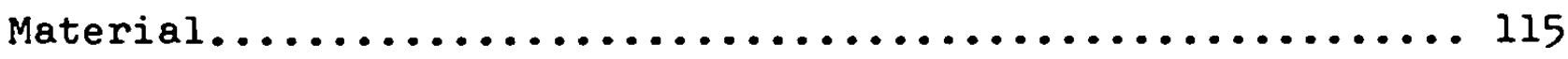

A. Lexikalische Funktion........................ 115

AA. Nomina agentis von Verben mit dem Präfix do-...... 115

$A B$. Nomina agentis von Verben mit dem Präfix iz-..... 117

AC. Nomina agentis von Verben mit dem Präfix na-...... 120

AD. Nomina agentis von Verben mit dem Präfix za-...... 122

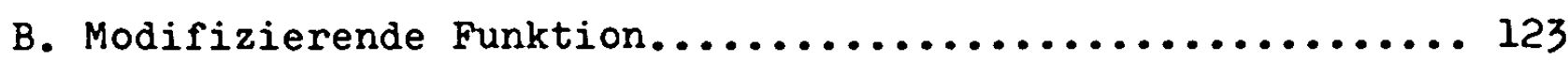

BA. Nomina agentis von Verben mit dem Präfix do-...... 123

BB. Nomina agentis von Verben mit dem Präfix iz-...... 124

BC. Nomina agentis von Verben mit dem Präfix na-...... 124

BD. Nomina agentis von Verben mit dem Präfix za-...... 125

C. Rein perfektivierende Funktion................... 126

CB. Nomina agentis von Verben mit dem Präfix iz-...... 126

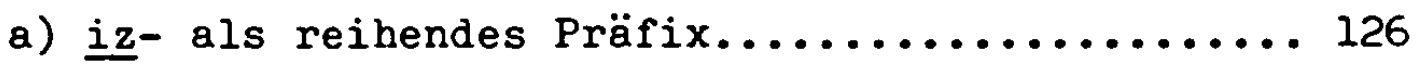

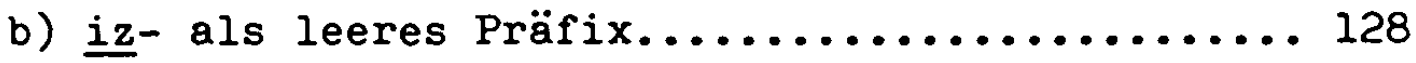

CC. Nomina agentis von Verben mit dem Präfix na-...... 129

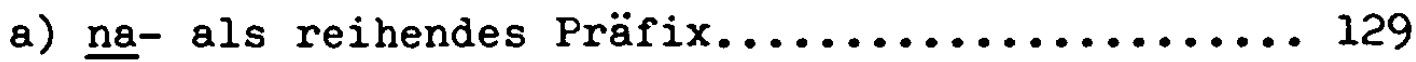

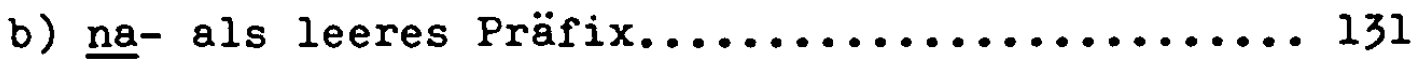

CD. Nomina agentis von Verben mit dem Präfix za-...... 132

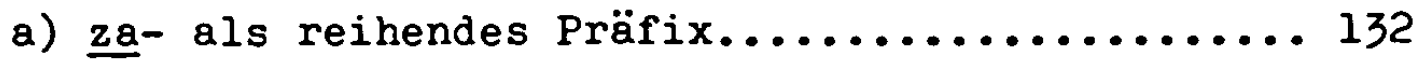

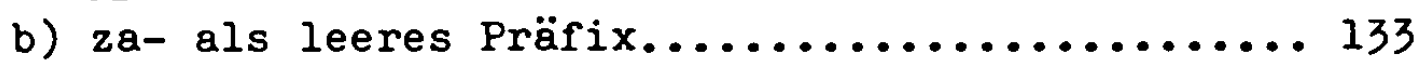

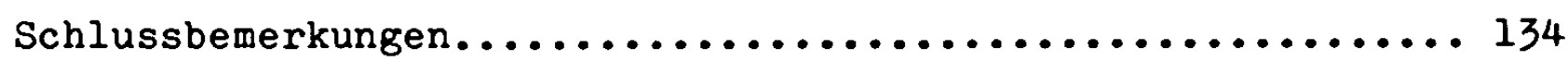

NOMINA RESULTATIVA.......................... 137

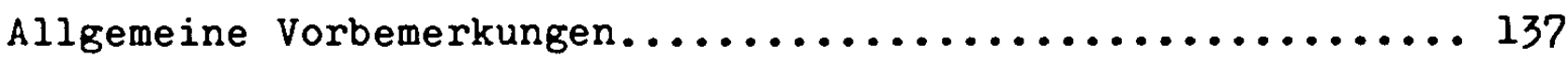

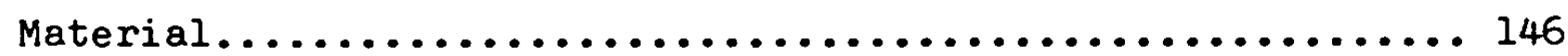

A. Lexikalische Funktion......................... 146

AA. Nomina resultativa von Verben mit dem Präfix do-... 146

AB. Nomina resultativa von Verben mit dem Präfix 프-... 147

AC. Nomina resultativa von Verben mit dem Präfix na-... 149

AD. Nomina resultativa von Verben mit dem Präfix za-... 151

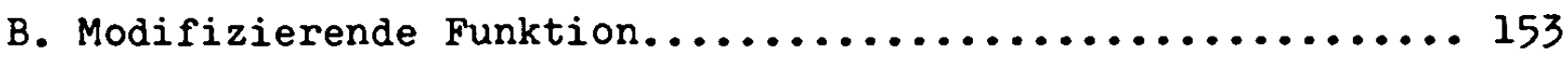

BA. Nomina resultativa von Verben mit dem Präfix do-... 153

BB. Nomina resultativa von Verben mit dem Präfix iz-... 154

BC. Nomina resultativa von Verben mit dem Präfix na-... 155

BD. Nomina resultativa von Verben mit dem Präfix za-.... 157 


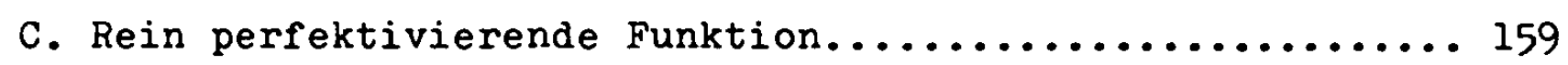

CB. Nomina resultativa von Verben mit dem Präfix iz-... 159

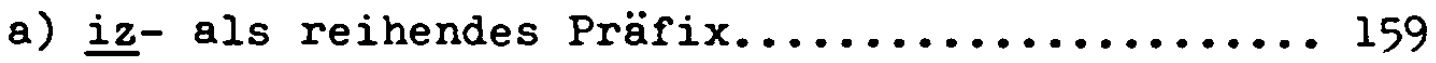

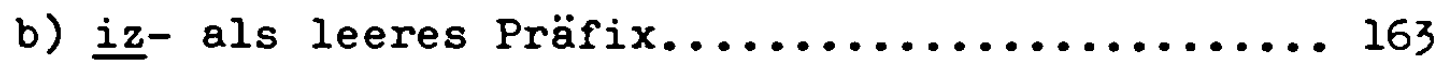

cC. Nomina resultativa von Verben mit dem Präfix na-... 163

a) na- als reihendes Präfix............... 163

b) na- als leeres Präfix................... 166

CD. Nomina resultativa von Verben mit dem Präfix za-... 166

a) za- als reihendes Präfix............... 166

b) za- als leeres Präfix................. 170

Schlussbemerkungen............................ 171

NOMINA ACTIONIS.................................... 174

Allgemeine Vorbemerkungen...................... 174

1. Nomina actionis im engeren Sinne................ 175

2. Verbalsubstantive.......................... 181

Material..................................... 194

1. Nomina actionis im engeren Sinne................. 194

A. Lexikalische Funktion.......................... 194

AA. Nomina actionis im engeren Sinne von Verben mit

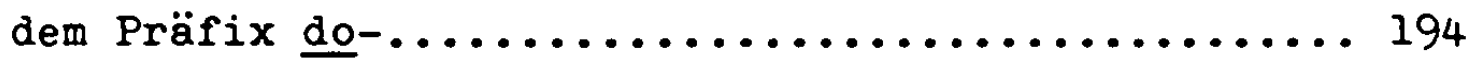

$A B$. Nomina actionis im engeren Sinne von Verben mit

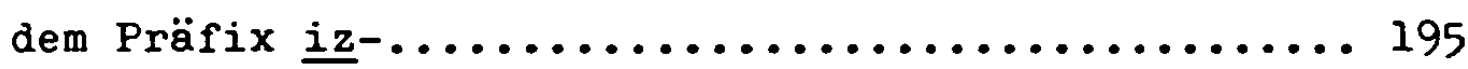

AC. Nomina actionis im engeren Sinne von Verben mit dem Präfix na-......................... 197

AD. Nomina actionis im engeren Sinne von Verben mit dem Präfix za-........................ 199

B. Modifizierende Funktion....................... 201

BA. Nomina actionis im engeren Sinne von Verben mit dem Präfix do-.......................... 201

BB. Nomina actionis im engeren Sinne von Verben mit dem Präfix iz-........................ 202

$B C$. Nomina actionis im engeren Sinne von Verben mit dem Präfix na-......................... 203

BD. Nomina actionis im engeren Sinne von Verben mit

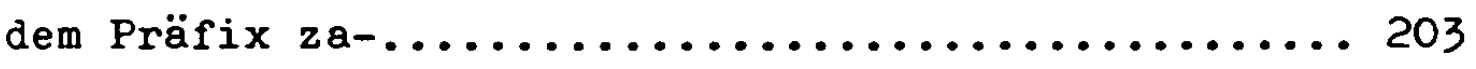

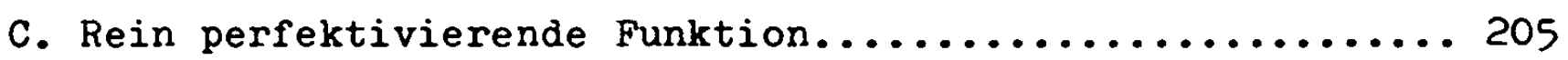

$C B$. Nomina actionis im engeren Sinne von Verben mit

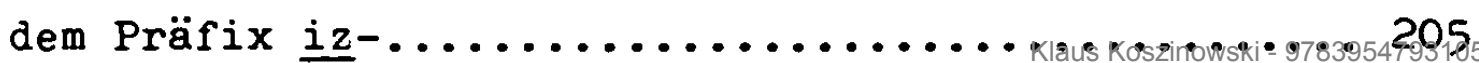




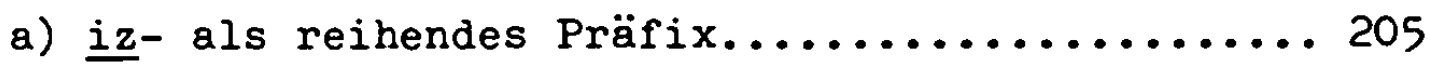

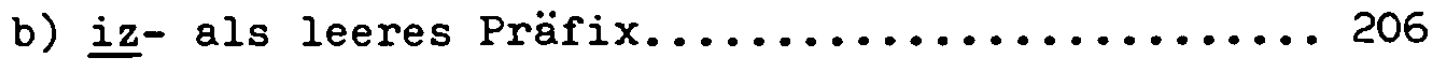
CC. Nomina actionis im engeren Sinne von Verben mit dem Präfix na-............................ 207

a) na- als reihendes Präfix................. 207

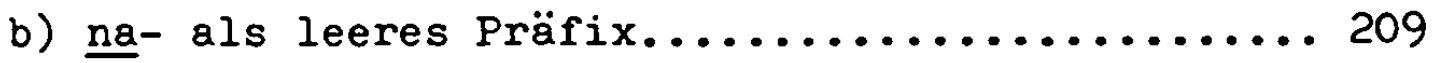

CD. Nomina actionis im engeren Sinne von Verben mit

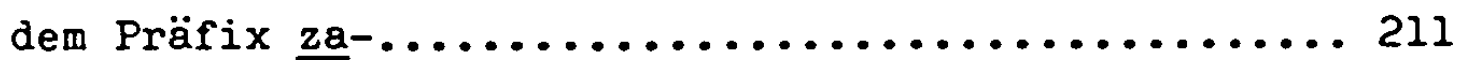

a) za- als reihendes Präfix................211

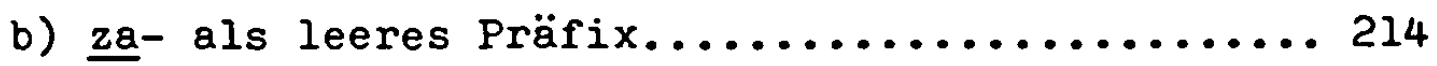

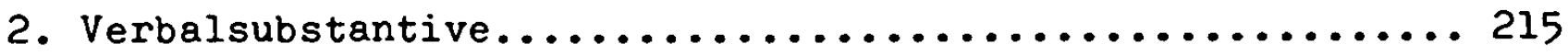

A. Lexikalische Funktion......................... 215

$A A$. Verbalsubstantive von Verben mit dem Präfix do-.... 215

$A B$. Verbalsubstantive von Verben mit dem Präfix iz-.... 218

AC. Verbalsubstantive von Verben mit dem Präfix na-....220

AD. Verbalsubstantive von Verben mit dem Präfix za-.... 222

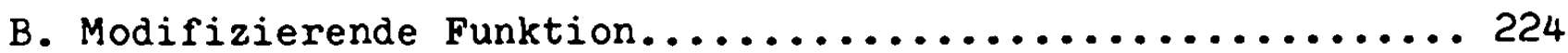

$B A$. Verbalsubstantive von Verben mit dem Präfix do-.... 224

BB. Verbalsubstantive von Verben mit dem Präfix iz-.... 225

$B C$. Verbalsubstantive von Verben mit dem Präfix na-.... 226

BD. Verbalsubstantive von Verben mit dem Präfix za-.... 227

C. Rein perfektivierende Funktion.................. 228

CB. Verbalsubstantive von Verben mit dem Präfix iz-.... 228

a) $\underline{\text { iz }}$ als reihendes Präfix................ 228

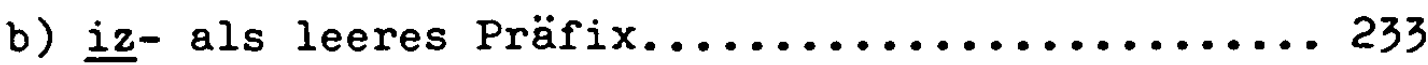

CC. Verbalsubstantive von Verben mit dem Präfix na-.... 235

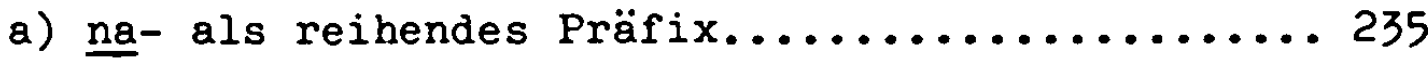

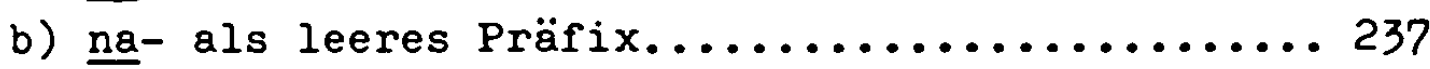

CD. Verbalsubstantive von Verben mit dem Präfix za-.... 238

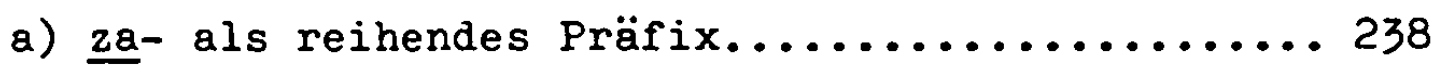

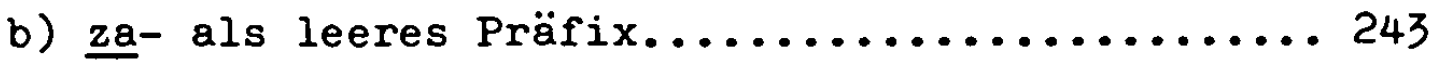

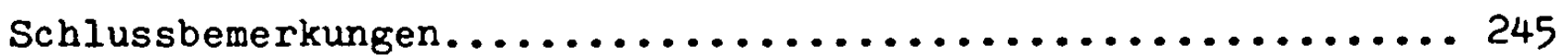

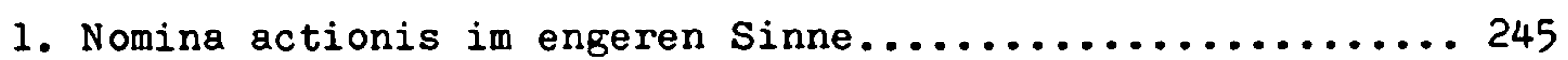

2. Verbalsubstantive......................... 247

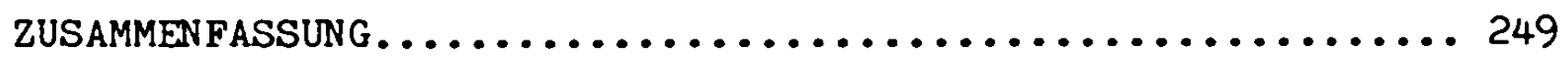

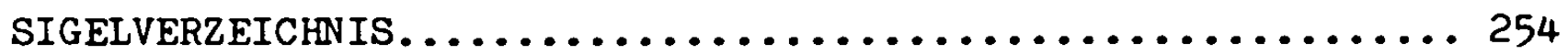

IITERATURVERZEICHNIS. ....................... 257 


\section{0}

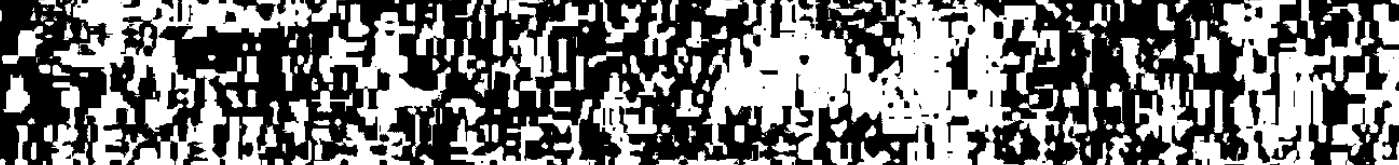

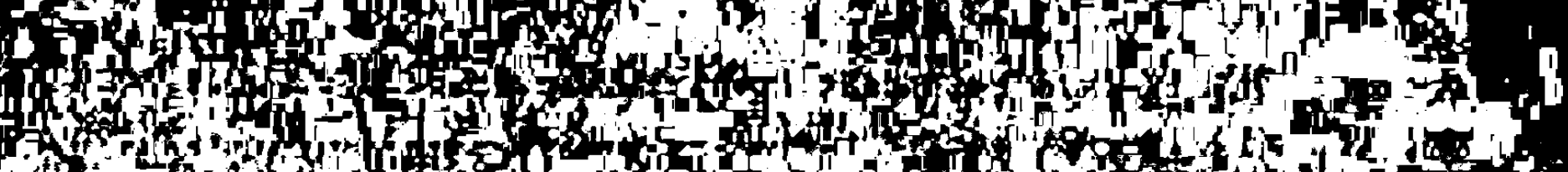

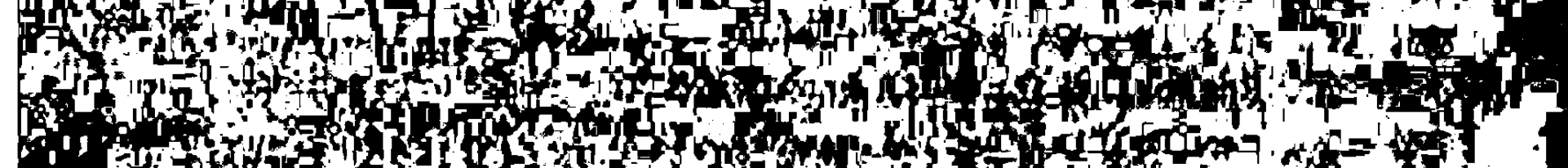

at 7on

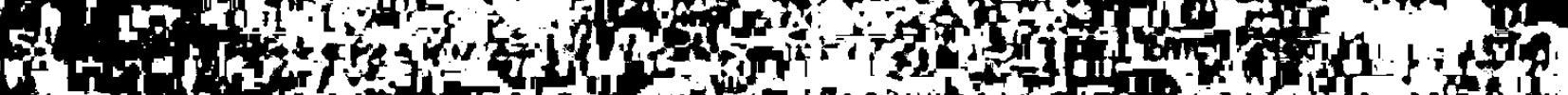

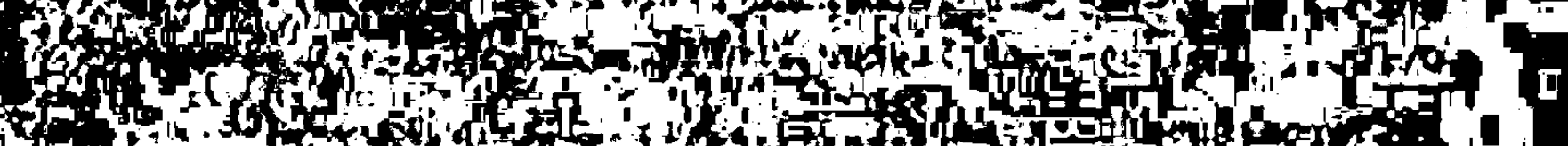
19.

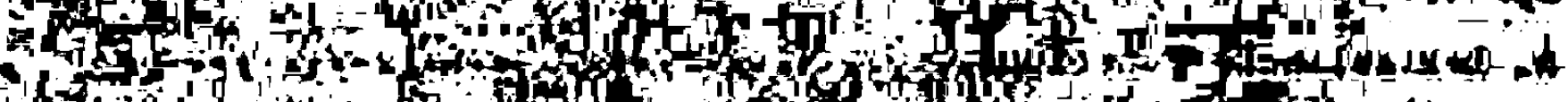

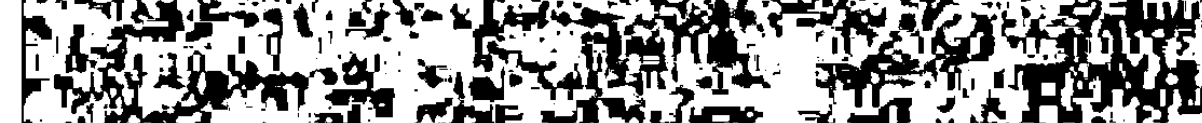

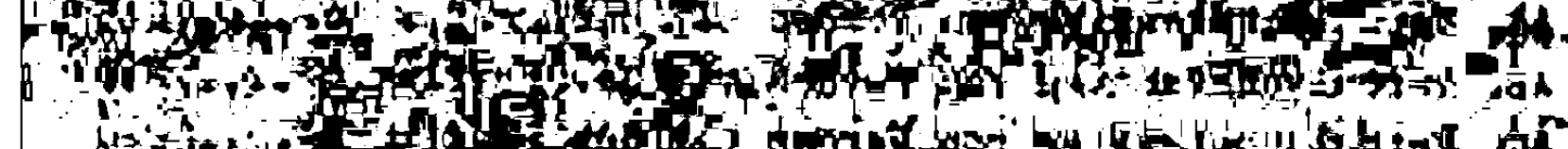

pis

1

i.t.

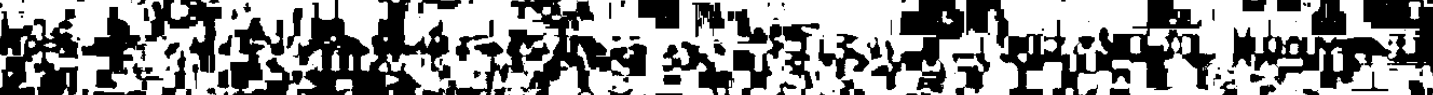

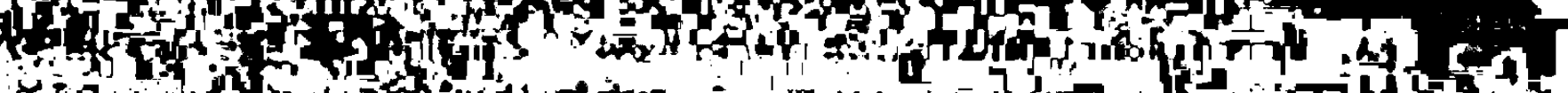

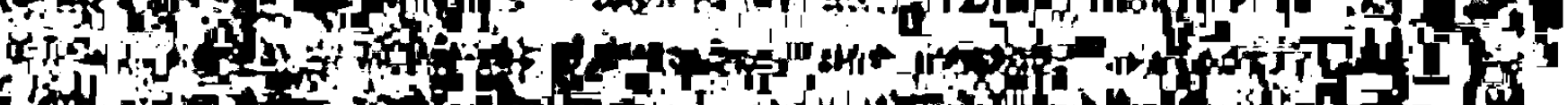

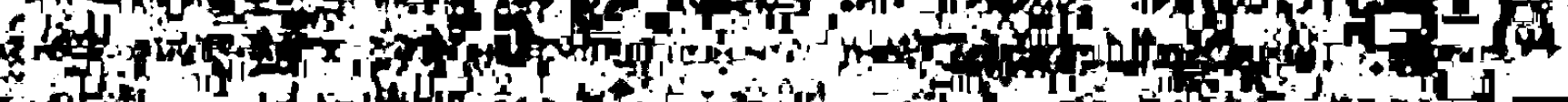

atow

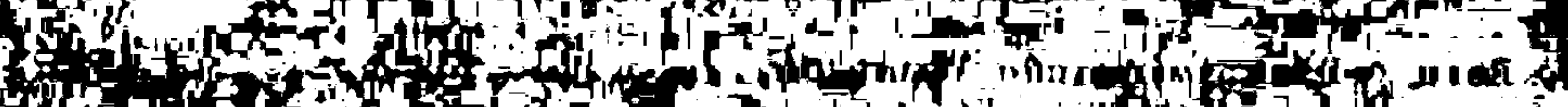

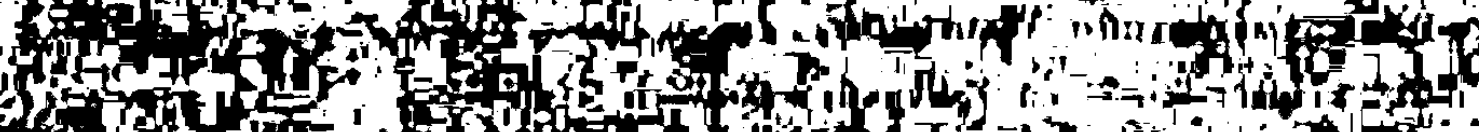

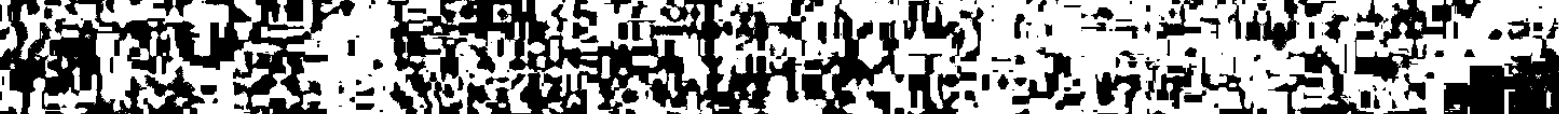

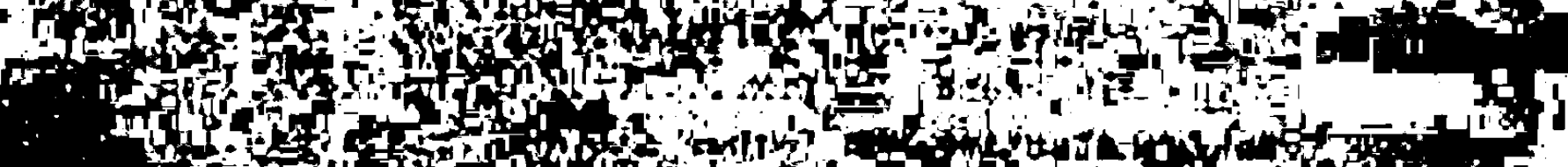

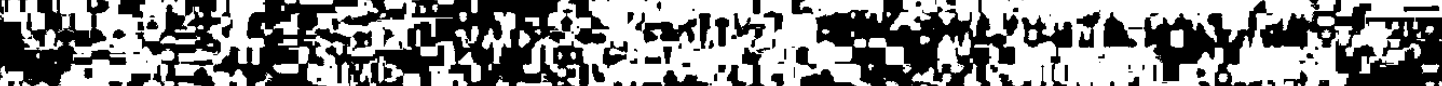

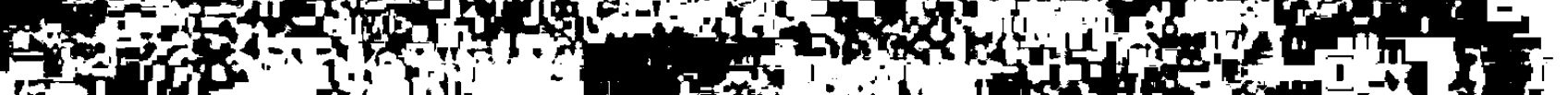

I

Pive

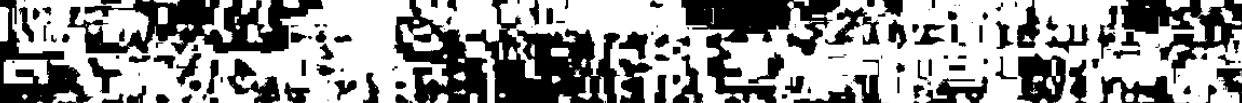

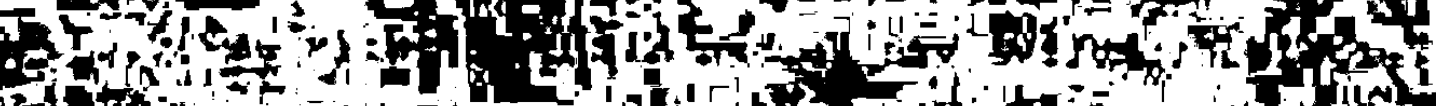

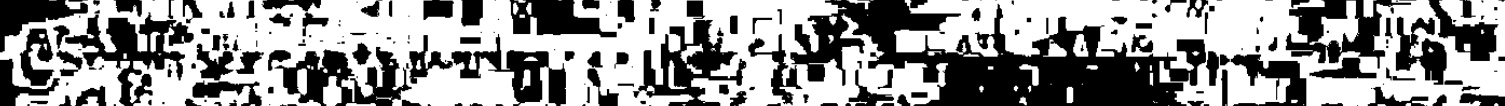

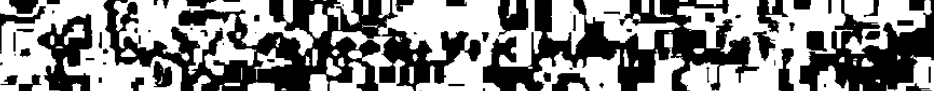

r.

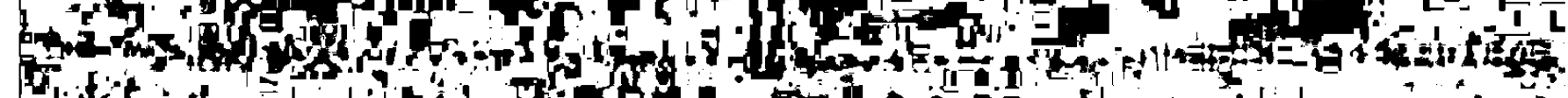

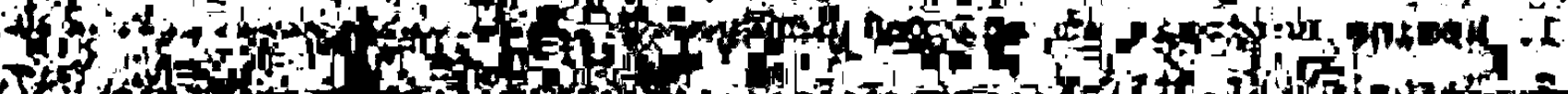

$\therefore y^{3}=3$ mor

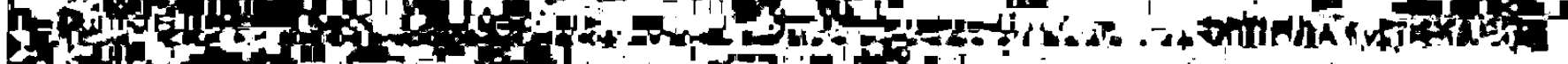

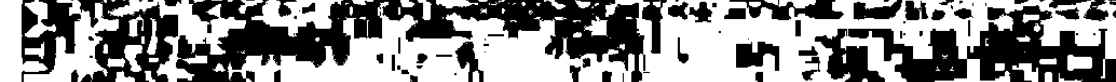

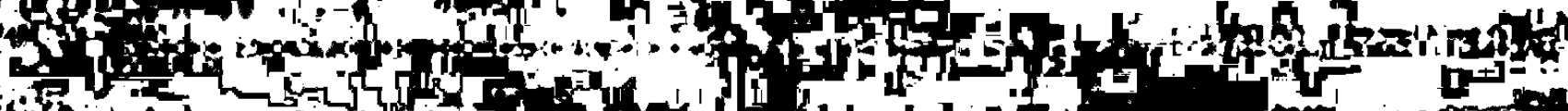

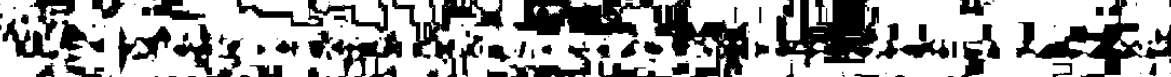
rith

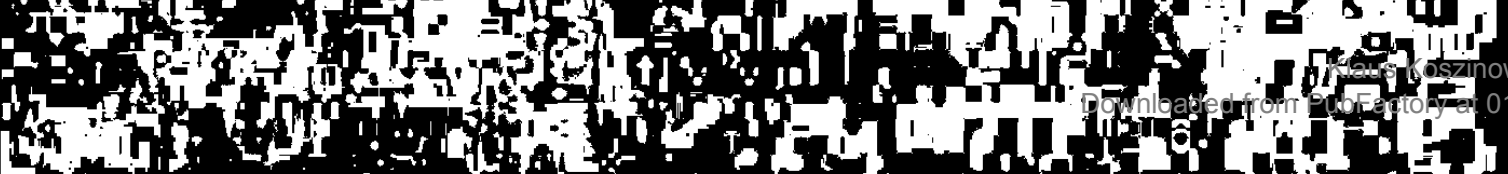

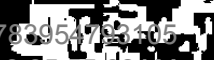




\section{EINLEITUNG}

\section{Ziel der Arbeit}

In den slavischen Sprachen dienen neben Suffixen Präfixe der Ableitung von Wörtern. Während Suffixe hauptsächlich zur Ableitung von Substantiven herangezogen werden, finden Präfixe ihren genuinen Anwendungsbereich in der Ableitung von Verben (neben der wortbildenden Funktion haben sie in Verbindung mit ihnen formbildende, d.h. aspektbildende Funktion).

Substantivische Derivate, bei denen allein das Präfix als wortbildendes Element fungiert, d.h. also Verbindungen von Präfix und unveränderter Form des zugrunde liegenden Substantivs, treten sowohl in den slavischen Sprachen im allgemeinen als auch im Serbokroatischen ${ }^{1}$ im besonderen so selten auf, dass sie für die Wortbildungslehre kein grösseres Interesse darstellen. Es handelt sich bei diesen um solche mit einheimischen Präfixen wie z.B. bez-broj 'Unzahl', nad-moćnost 'Uberlegenheit' und um solche mit Präfixen fremder Herkunft wie z.B. arhi-lopov 'Erzdieb', arhipastir 'Erzpriester'.

Neben den präfigierten Substantiven mit eigentlich wortbildender Funktion des Präfixes weist das Serbokroatische zahlreiche präfigierte Substantive auf, bei denen das Präfix keine wortbildende Funktion ausübt, da es sich um von bereits präfigierten Verben abgeleitete Substantive wie z.B. izdubak 'Aushöhlung', ispljuvak 'Auswurf' handelt, die durch die präfigierten Verben 'izdubiti' und 'ispljuvati' motiviert sind. Substantive dieses Typs erlauben also keine lineare Segmentierung in iz-dub-ak, sondern nur eine hierarchische in (iz-dub)-ak). Das Präfix des Substantivs wird im Rahmen des verbalen Ableitungsstamms in das abgeleitete Substantiv übernommen.

Diese Substantive werden mit Hilfe von Suffixen von der Kategorie des Verbs in die des Substantivs überführt. Ihre Bearbeitung erfahren sie somit allein im Rahmen der mittels Suffigierung abgeleiteten Substantive, d.h. zunächst ohne besondere

1 M. Stevanović, Savremeni srpskohrvatski jezik. Beograd 1964 , S. 444 . 
Berücksichtigung und Hervorhebung des spezifischen Charakters des Präfixes.

Präfigierte deverbale Substantive des oben beschriebenen Typs, genauer gesagt, die Beziehungen, die zwischen den präfigierten Verben und den von ihnen abgeleiteten präfigierten substantiven unter besonderer Berücksichtigung des Charakters des Präfixes herrschen, bilden den Gegenstand des Interesses der vorliegenden Arbeit.

Ziel der vorliegenden Arbeit ist es also festzustellen, ob es zwischen den Präfixen der ableitenden Verben und den von ihnen abgeleiteten Substantiven semantische Zusammenhänge oder sogar Gesetzmässigkeiten gibt, die Ableitungen einer bestimmten onomasiologischen bzw. wortbildenden Kategorie zumindest tendenziell begünstigen, ob nicht die spezifische Funktion und Bedeutung der Präfixe eine Prädisposition zur Ableitung bestimmter onomasiologischer bzw. wortbildender Kategorien darstellt, d.h. ob nicht eine Affinität von den Präfixen der ableitenden präfigierten Verben $z u$ den von ihnen abgeleiteten Substantiven besteht.

Die Fragestellung der Affinität erscheint interessant genug, um notfalls auch ein negatives Resultat in Kauf $z u$ nehmen, dies um so mehr, als - wie bereits erwähnt - dieses spezielle Problem in der slavischen Forschung bisher völlig unbearbeitet geblieben ist.

Es wären die Fragen (1) nach einer semantisch motivierten Affinität und (2) einer quantitativ konstatierten Affinität, bei der also eine direkte semantiscke Motivation nicht $z$ ermitteln ist, zu stellen, wobei bei jeder dieser beiden Fragen Bezug zu nehmen wäre (a) auf die einzelnen Präfixe in einer bestimmten Funktion bzw. Bedeutung, soweit sie vorhanden ist, und (b) generell auf eine bestimmte Präfixfunktion ${ }^{2}$. Für (1) und (2) würden sich dann die folgenden weiteren Fragestellungen ergeben:

1a) Besteht zwischen einem bestimmten Präfix in einer bestimmten Funktion und Bedeutung ${ }^{3}$ (z.B. den Verben mit dem Präfix izin lexikalischer Funktion mit der lokalen Bedeutung '(etwas) von innen nach aussen (bewegen)' wie istočiti 'herausflie-

2 In den einzelnen Schlussbemerkungen wird nur auf die Variante der Affinität eingegangen, die vorliegt.

3 Die für die einzelnen wortbildenden Kategorien in Betracht kommenden Präfixbedeutungen innerhalb der einzelnen Funktionen werden jeweils am Schluss der allgemeinen Vorbemerkungen aufgeführt. 
ssen') und einer bestimmten onomasiologischen bzw. wortbildenden Kategorie (z.B. den nomina loci wie istočnik 'Quelle') eine Affinität der Art, dass nomina loci stets bzw. häufig von diesen Verben abgeleitet werden, während dies bei Verben mit iz- in einer anderen Bedeutung der lexikalischen Funktion nicht oder nur sporadisch der Fall ist?

1b) Besteht generell eine Affinität zwischen einer bestimmten Funktion der Präfixe (z.B. der lexikalischen) und den onomasiologischen bzw. wortbildenden Kategorien schlechthin, eine Affinität der Art also, dass der in la) geschilderte Fall innerhalb einer bestimmten Funktion häufig vorkommt, während er bei einer anderen Funktion weniger häufig ist bzw. überhaupt fehlt?

2a) Von welchen Präfixen in welchen Funktionen und in welcher quantitativen Reihenfolge werden Ableitungen einer bestimmten onomasiologischen bzw. wortbildenden Kategorie gebildet?

2b) Von welchen Präfixfunktionen generell und in welcher quantitativen Reihenfolge werden Ableitungen einer bestimmten onomasiologischen bzw. wortbildenden Kategorie gebildet?

Auf diese Fragen wird nicht immer eindeutig mit 'ja' oder 'nein' geantwortet werden können.

2. Untersuchungsgrundlage

Die Untersuchung wird am Material der modernen serbokroatischen Schriftsprache vorgenommen. (Vgl. Einzelheiten dazu S. $20 \mathrm{f}$ Zur Untersuchung gelangen deverbale präfigierte Substantive mit den Präfixen do-, 프-, na-, za--. Die Auswahl von Ableitungen gerade mit diesen Präfixen ist in erster Linie durch das verwendete Wörterbuch, den "Rečnik srpskohrvatskoga književnog jezika" bedingt, das zur Zeit der Materialsammlung noch nicht vollständig vorlag. (Das erwähnte Wörterbuch ist in kyrillischer Schrift gedruckt, woraus sich das Erscheinen von za- im vorderen Teil des Alphabets erklärt.)

Andererseits wäre eine Bearbeitung von Ableitungen mit allen Präfixen in der hier vorgenommenen Art und Weise für diese Arbeit $z u$ umfangreich gewesen. Zur Dokumentation einer Affinität zwisches Präfix des ableitenden Verbs und von ihm abgeleitetem Substantiv erscheint das bearbeitete Material als ausreichend. Es liesse sicl also auf dieser Grundlage der Schluss ziehen, dass sich diese 
Tendenz prinzipiell auch bei den Ableitungen fortsetzt, die in diesem Rahmen nicht behandelt werden konnten und einer weiteren Arbeit vorbehalten bleiben müssen.

\section{Literatur zur Problematik der Arbeit}

Da in der Wissenschaft die Tendenz vorhanden ist, Ableitungen unter Berücksichtigung der letzten "Stufe in der Ableitungsgeschichte" ( $d . h$. nur die stufe izdub-ak) zu behandeln, fehlt zum Thema dieser Arbeit jede Literatur. Zur eigentlichen Problematik dieser Arbeit konnten weder allgemein slavische noch serbokroatische Abhandlungen gefunden werden.

Zur Frage der formbildenden Funktion des Verbalpräfixes liegen dagegen für die einzelnen slavinen mehr oder weniger umfangreiche Untersuchungen vor. Für das Serbokroatische wird diese Problematik im Rahmen von Grammatiken ${ }^{4}$ abgehandelt. In Verbindung mit dem Aspekt finden sich wertvolle Hinweise zum Verbalpräfix bei Grubor ${ }^{5}$. Mit der Frage der Präfigierung als grammatischem Mittel befasst sich Grickat ${ }^{6}$. Die Autorin geht in ihren Darlegungen von einer Konzeption aus, die auch weitgehend der vorliegenden Arbeit zugrunde liegt. Ihr Material kann leider nur in Einzelfällen zu Vergleichszwecken herangezogen werden, da es sich mit dem hier vorliegenden nicht vollständig deckt.

Eine spezielle Monographie über das Verbalpräfix ist, was die jugoslavischen Slavinen betrifft, bisher nur für das Makedo-

$4 \mathrm{Vgl}$. M. Stevanović, a.a.0., S. $452 \mathrm{ff}$; T. Maretić, Gramatika hrvatskoga ili srpskoga književnog jezika. Zagreb 31963, S. 4loff; I. Brabec, Hraste M., Zivković S., Gramatika hrvatskosrpskoga jezika. Zagreb 51963, S. 164ff; A. Leskien, Grammatik der serbo-kroatischen Sprache. 1. Teil: Lautlehre, Stammbildung, Formenlehre. Heidelberg 1914, S. $327 \mathrm{ff}$. und 474ff; A. Belić, Savremeni srpskohrvatski književni jezik. II. Nauka o gradjenju reči. Beograd 1964, S. 293 - 322.

$5 \mathrm{Dj}$. Grubor, Aspektna značenja. In: Rad Jugoslavenske akademije znanosti i umjetnosti 293, Zagreb 1953, S. 5 - 234; Aspektna značenja II. In: Rad Jugoslavenske akademije znanosti i umjetnosti 295, Zagreb 1953, S. 81 - 284.

6 1. Grickat, Prefiksacija kao sredstvo gramatičke (čiste) perfektizacije. In: JF XXVII, 1966/67, S. 185 - 223; dieselbe, Sta daje za proučavanje glagolske semantike čista (gramatička) perfektizacija putem prefiksacije. In: NJ XVI, 1967, S. 119 126. 
nische ${ }^{7}$ erarbeitet worden.

Für das Slovenische gibt es eine Arbeit über Präfixe und Präpositionen von $\mathrm{Bajec}^{8}$.

4. Aufbau und Methode der Arbeit

Die Arbeit besteht aus zwei Teilen. Der erste Teil ist der Theorie der Funktionen der Verbalpräfixe und der Theorie der Wortbildung gewidmet. Der zweite Teil gibt eine systematische Klassifikation des Materials nach den im ersten Teil erarbeiteten und dargelegten Prinzipien sowie eine Darlegung der sich aus dieser Klassifikation ergebenden Erkenntnisse.

a) Zur Theorie der Funktionen der Verbalpräfixe

- Der Darstellung und Diskussion der verschiedenen Auffassungen von den Funktionen der Verbalpräfixe wird breitester Raum gewährt. Es wird somit die Möglichkeit geschaffen, dem vorliegenden Material eine möglichst adäquate Konzeption zugrunde zu legen.

Der Einteilung der präfigierten Verben nach den Funktionen der Präfixe wird die Konzeption von Poldauf, Vey und Kopečný zugrunde gelegt. Ausserdem werden die Ausführungen von Grickat zu dieser Problematik berücksichtigt. Die Klassifikation der Funktionen der Verbalpräfixe erfolgt in der Arbeit nicht an besonderer Stelle, sondern erscheint im Rahmen der Klassifikation der von präfigierten Verben abgeleiteten Substantive.

b) Zur Theorie der Wortbildung

Das Kapitel zur Theorie der Wortbildung beschränkt sich auf die Darstellung der in der Arbeit verwendeten Wortbildungstheorie. Auf eine Diskussion der verschiedenen Wortbildungstheorien kann aus den unten erwähnten Gründen verzichtet werden. Im übrigen soll die gewählte Wortbildungstheorie lediglich die Grundlage für die Klassifikation der deverbalen präfigierten Substantive bilden, die ihrerseits nur den Rahmen für ein übergeordnetes ziel abgibt.

7 R. Ugrinova-Skalovska, Značenjata na glagolskite prefiksi vo makedonskiot jazik. Skopje I960.

$8 \mathrm{~A}$. Bajec, Besedotvorje slovenskega jezika. IV. Predlogi in predpone. Ljubljana 1959. 
In diesem Sinne ist die Wortbildungstheorie nicht Mittelpunkt und Selbstzweck, sondern Mittel zum Zweck und rechtfertigt somit ihre knappe Abhandlung.

Der Klassifikation der abgeleiteten präfigierten Substantive liegt die Wortbildungstheorie des tschechischen Iinguisten Dokulil ${ }^{9}$ zugrunde, die die Konzeption der strukturell-funktionalen Wortbildung vertritt und beide Aspekte ihrer Problematik, den synchronischen und genetischen, betrachtet. Sie ist unter den zur Zeit vorliegenden die umfangreichste, kurrenteste und ausserdem die slavischen Verhältnisse am besten berücksichtigende Theorie.

Die Theorie wird nur in dem Umfange dargelegt, in dem sie für die Klassifikation des vorliegenden Materials von Bedeutung ist.

c) Zur Klassifikation des Materials

Im zweiten Teil wird das Material nach den einzelnen onomasiologischen Kategorien der nomina loci, nomina instrumenti, nomina agentis, nomina resultativa und nomina actionis (getrennt in nomina actionis im engeren sinne und Verbalsubstantive) bzw. den sie realisierenden wortbildenden Kategorien klassifiziert.

Die Reihenfolge der wortbildenden Kategorien ist bedingt durch den Grad der quantitativ konstatierten Affinität. Die Verbalsubstantive nehmen eine Sonderstellung in dem Sinne ein, dass sie für das Ziel dieser Arbeit wenig oder kaum von Bedeutung sind. ( $V_{g l}$. Zusammenfassung) Die Sonderstellung der Verbalsubstantive wird dadurch betont, dass sie im Rahmen der wortbildenden Kategorie der nomina actionis und auch im Rahmen des zweiten Teils an den Schluss gestellt werden. Nomina actionis im engeren Sinne können wegen der gemeinsamen onomasiologischen Kategorie mit den Verbalsubstantiven nicht getrennt von ihnen an einem anderen Ort der Arbeit aufgeführt werden, obwohl sie nach dem Kriterium der quantitativ konstatierten Affinität an vierter Stelle aufgeführt werden müssten.

Die Darstellung jeder einzelnen Kategorie setzt sich aus allgemeinen Vorbemerkungen, der Darlegung des Materials und

9 M. Dokulil, Tvořeni slov v češtině. 1. Teorie odvozováni slov. Praha 1962; derselbe [u.a.], Tvořeni slov v češtině. 2. Odvozováni podstatných jmen.Praha 1967. Im weiteren werden die Abkürzungen benutzt: Tvořeni slov I, Tvořeni slov II. 
Schlussbemerkungen zusammen.

In den allgemeinen Vorbemerkungen, die jeder wortbildenden Kategorie vorangestellt werden, werden die die gesamte Kategorie betreffenden charakteristischen Merkmale hervorgehoben. Folgende, die jedoch nicht alle gleichzeitig für jede einzelne onomasiologische bzw. wortbildende Kategorie zutreffen müssen, finden dabei Berücksichtigung :

- Abgrenzung der Kategorie gegenüber anderen sowie gegebenenfalls ihre Subkategorisierung;

- Bestimmung der onomasiologischen Kategorie;

- Aufzeigen der wortbildenden Verfahren;

- Angabe über die Häufigkeit des Vorkommens der Ableitungen in bezug auf die Funktionen der Präfixe der ableitenden Verben;

- Angabe der wortbildenden Typen nach deren Formantien, geordnet nach dem Genus und dem Ableitungsverfahren;

- Angabe der Produktivität der wortbildenden Typen für die gesamte wortbildende Kategorie;

- allgemeiner Uberblick über die Produktivität der Ableitungen für die einzelnen Funktionen;

- Angabe der Ableitungsstämme;

- Uberblick über die Häufigkeit der Verwendung der Ableitungsstämme bei den einzelnen Funktionen;

- Angabe der Konjugationen der ableitenden Verben für die einzelnen Funktionen;

- Uberblick über die Ableitungsverfahren, Ableitungsstämme und die Konjugationen für die Ableitungen mit Präfixen in lexikalischer, modifizierender und rein perfektivierender Funktion;

- Angabe des Aspekts der ableitenden Verben für die einzelnen Funktionen;

- Berührungspunkte $z u$ anderen wortbildenden Kategorien;

- Sonstiges (z.B. Frage der Bewahrung der Aspektopposition bei den nomina instrumenti);

- Uberblick über die Präfixbedeutungen der ableitenden Verben für die einzelnen Funktionen.

Die Darlegung des Materials erfolgt in drei Gruppen entsprechend den drei Funktionen der Präfixe der zugrunde liegenden Verben, die wiederum jeweils unterteilt sind nach den Präfixen, mit denen Ableitungen $z u$ der jeweiligen Funktion vorkommen können. Innerhalb der rein perfektivierenden Funktion wird das Material für jedes einzelne Präfix geteilt in Ableitungen mit a) reihenden und b) leeren Präfixen. Der Darlegung des Materials 
zu jedem einzelnen Präfix im Rahmen der einzelnen Funktionen geht unmittelbar ein kurzer Uberblick voraus, der folgende Punkte umfasst:

- Ableitungsverfahren;

- wortbildende Typen anhand ihrer Formantien, ihrer Produktivität (mit Zahlenangabe) und den Bedeutungen der Präfixe der ableitenden Verben (mit Zahlenangabe);

- Ableitungsstämme und Konjugationen;

- Aspekt der Ableitungsstämme.

Das Material selbst wird im Rahmen der einzelnen Funktionen und Präfixe in wortbildenden Typen angeführt, die ihrerseits geordnet sind nach Genera und in alphabetischer ${ }^{10}$ Reihenfolge. Innerhalb eines jeden wortbildenden Typs erfolgt eine weitere feinere Klassifizierung nach 1) den Präfixbedeutungen, 2) dem Aspekt der ableitenden Verben, 3) den Ableitungsstämmen und 4) der Konjugation der ableitenden Verben.

In den Schlussbemerkungen wird festgestellt, welche Variante der Affinität in den einzelnen onomasiologischen bzw. wortbildenden Kategorien vorliegt. Diese Feststellung wird in Ubereinstimmung mit den auf $S$. 12ff. formulierten Fragestellungen getroffen. In einer Tabelle wird das Material in Zahlen dargelegt.

\section{d) Zur Zusammenfassung}

Am Schluss der Arbeit erfolgt ein kurzer Uberblick über den Verlauf der Arbeit sowie eine Zusammenfassung der in den einzelnen Schlussbemerkungen aufgeführten Ergebnisse.

\section{Zur Abgrenzung des Materials}

Untersucht werden nur motivierte präfigierte deverbale Substantive bzw. motivierte präfigierte Verben, d.h. lexikalische Einheiten, deren Wortbildungsstrukturen sowohl in formaler als auch in semantischer Hinsicht durchsichtig sind. Allerdings bereitet das Feststellen der Motiviertheit bei einer Reihe von

10 Die Einordnung der wortbildenden Typen wird in alphabetischer Reihenfolge nach ihren Formantien vorgenommen. Eine andere Möglichkeit der Einordnung wäre nach der Produktivität der wortbildenden Typen. Zugunsten einer grösseren Ubersichtlichkeit wurde die erste Regelung vorgezogen. 
Beispielen grosse Schwierigkeiten, da die Grenzen von der Motiviertheit zur Unmotiviertheit fliessend sind. Auf jeden Fall werden Verben vom Typ nagraditi 'belohnen' und deren Derivate von der Untersuchung ausgeschlossen, die als synchron völlig unmotiviert gelten müssen.

In die Untersuchung werden auch Substantive aufgenommen, die in dem oben erwähnten Wörterbuch als Dialektismen, Archaismen, individuelle Bildungen usw. gekennzeichnet werden, sofern sie motiviert sind. Es hat sich nämlich herausgestellt, dass in dem von der serbischen Verlagsanstalt herausgegebenen wörterbuch z.B. kroatische Varianten als Dialektismen angegeben werden. Auf dieses Problem soll an dieser Stelle aber nicht weiter eingegangen werden. Dieser Sachverhalt hat uns jedoch bewogen, auch das Material mit den oben angeführten Kennzeichnungen zu bearbeiten.

Nicht in die Untersuchung aufgenommen werden präfigierte Substantive, deren zugrunde liegende präfigierte Verben ihrerseits nicht durch Verben motiviert sind, sondern durch Konstruktionen aus Präposition plus Nomen (Substantiv oder Adjektiv) oder Präposition plus Adverb wie z.B. izvešćivanje 'Benachrichtigen' von izvešćivati zu vest, zabradjivanje 'Befestigen unter dem Kinn' von zabradjivati zu brada, zastakljivanje 'Verglasen' von zastakljivati $z$ u staklo, zaglupljivanje 'Verdummen' von zaglupljivati zu glup, iznenadjivanje 'Uberraschung' von iznenadjivati zu iznenada.

Ausserhalb der Untersuchung müssen nomina attributiva bleiben, auch wenn ein grosser Teil von ihnen durch Ableitungsstämme in Gestalt von adjektivierten Partizipien motiviert ist, Ableitungsstämmen also, die letztlich auf Verben zurückzuführen sind. Vom heutigen Standpunkt müssen diese Partizipien als Adjektive angesehen werden. Der deverbale Charakter dieser Adjektive besteht nur formal, nicht jedoch semantisch. Daneben wird eine grosse Anzahl von nomina attributiva von präfigierten Adjektiven abgeleitet, die ihrerseits von Adjektiven abgeleitet sind. Selbst wenn man diejenigen nomina attributiva, deren Ableitungsstämme ursprünglich auf Verben zurückgehen, in die Untersuchung aufnehmen wollte, könnte dies auf keinen Fall mit den Substantiven geschehen, die von originären Adjektiven abgeleitet worden sind. 


\section{Zur Produktivität}

Die Produktivität der wortbildenden Typen wird in den allgemeinen Vorbemerkungen jeweils für die gesamte wortbildende Kategorie angegeben. Die Beurteilung der Produktivität der einzelnen wortbildenden Typen nach 'sehr produktiv', 'weniger produktiv' usw. erfolgt jeweils im Hinblick auf den produktivsten Wortbildungstyp der entsprechenden Kategorie.

In den kurzen Uberblicken über das Material zu jedem einzelnen Präfix im Rahmen der einzelnen Funktionen wird die Produktivität für jeden wortbildenden Typ in Zahlen angegeben.

\section{Zum Wörterbuch}

Die Absicht, die Untersuchung am Sprachmaterial der modernen serbokroatischen Schriftsprache vorzunehmen, schloss von vornherein die Verwendung einer Reihe von wörterbüchern aus.

Es schieden Wörterbücher aus, die das moderne Sprachmaterial der serbokroatischen Sprache nicht enthalten, wie z.B. der "Srpski rječnik" von Karadžić aus dem Jahre 1818 oder der "Rečnik hrvatskoga jezika" von Iveković-Broz, der 1901 erschien.

Andere Wörterbücher erwiesen sich als ungeeignet, weil sie Sprachmaterial aus mehreren Jahrhunderten enthalten, das für die Arbeit $z u$ heterogen ist. Es handelt sich um den "Rečnik hrvatskoga ili srpskoga jezika Jugoslavenske akademije znanosti i umjetnosti" sowie den "Rečnik srpskohrvatskog književnog i narodnog jezika" der serbischen Akademie der Wissenschaften.

Schliesslich wurden in die engere Wahl zwei wörterbücher gezogen, die sich beide durch modernes serbokroatisches Sprachmaterial auszeichnen. Der "Rečnik srpskohrvatskog i nemačkog jezika" von Ristić-Kangrga erschien als ungeeignet, da er naturgemäss nur die deutschen Aquivalente anführt. Für uns war es jedoch wichtig, Aufschluss auch über die innere Form der lexikalischen Einheiten zu bekommen, wie sie nur ein einsprachiges definitorisches wörterbuch geben kann. Diesen Anforderungen kam endlich der "Rečnik srpskohrvatskoga književnog jezika" am weitesten entgegen, der auf Material basiert, das aus Werken der neueren und neuesten Literatur, aus der Publizistik, der Fachliteratur und der wissenschaftlichen Literatur gesammelt wurde. Er dokumentiert das serbokroatische Sprachgut der heutigen Zeit. 
Das bearbeitete Material wurde aus den ersten vier Bänden der Ausgabe der serbischen ${ }^{l l}$ Verlagsanstalt exzerpiert.

11 Das Wörterbuch sollte ursprünglich in seinem ganzen Umfang gemeinsam von der kroatischen und der serbischen Verlagsanstalt bearbeitet, aber getrennt herausgegeben werden. Aus Gründen, auf die in diesem Zusammenhang nicht eingegangen zu werden braucht, wurde die gemeinsame Arbeit am Wörterbuch nach den ersten Bänden eingestellt. Es erscheint heute nur noch in der serbischen Verlagsanstalt. 


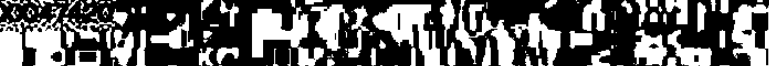

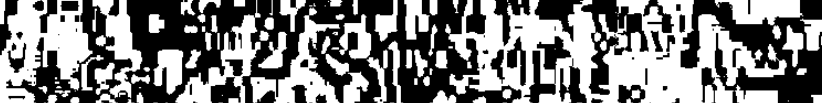

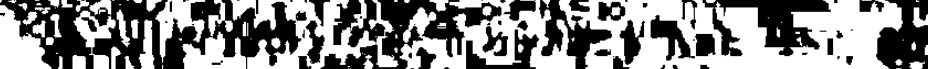

1.

(4)

A

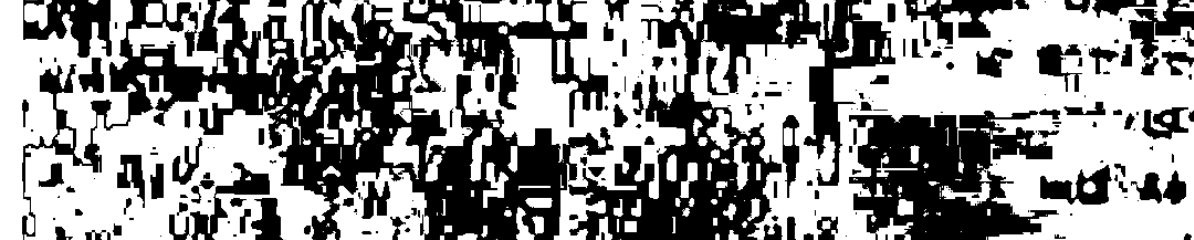

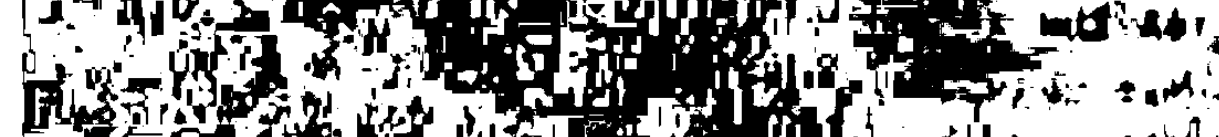

Fon

of

and

dint

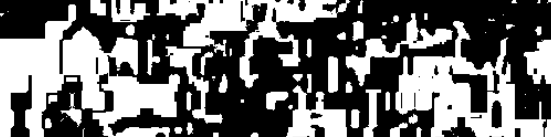

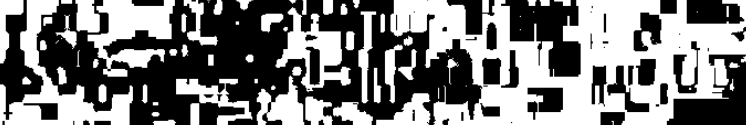

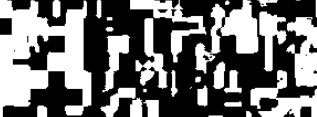

54

thing

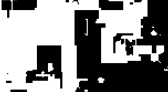

12n'

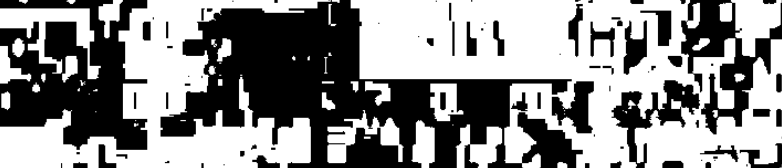

is 1 -

1)

1)

sin.

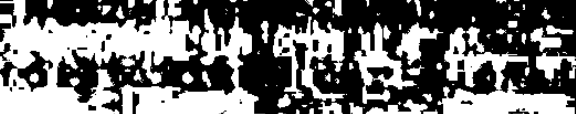

ind in

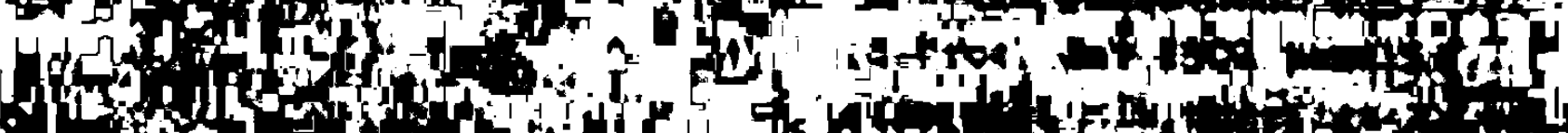

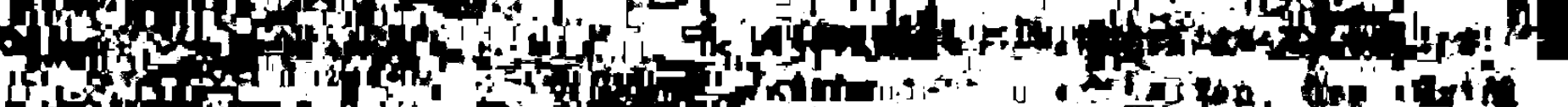
If

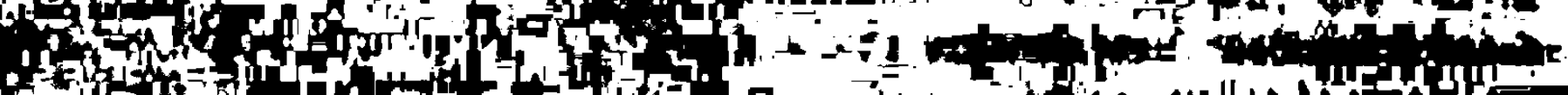

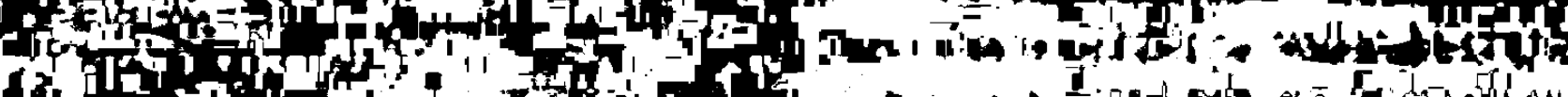
for f 4 n

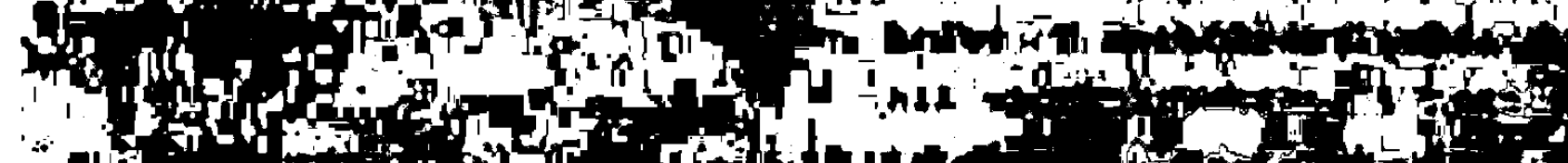

if

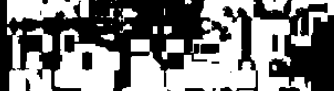

Mf

1,7 fut

(1)

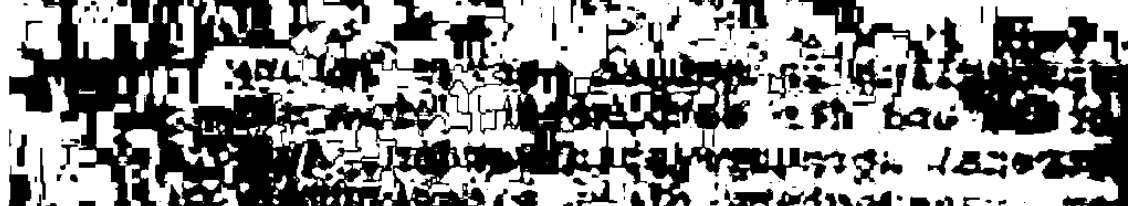

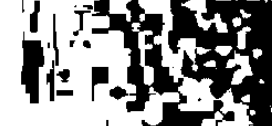

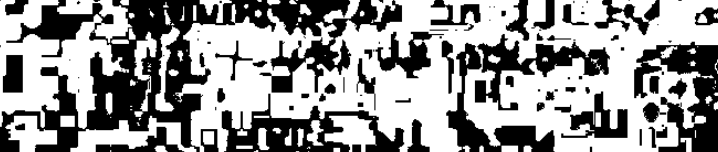
I. A.

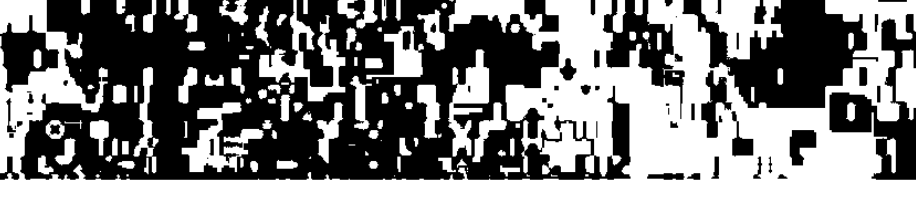

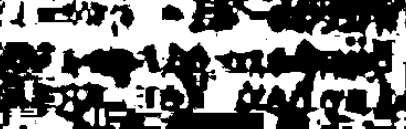

rot

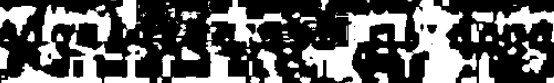

Pith

il. 
ERSTER TEII

I. ZUR THEORIE DER VERBALPRÄFIXE

1. Die Funktionen der Verbalpräfixe

Präfixe dienen neben Suffixen in der serbokroatischen Sprache wie in den slavischen Sprachen allgemein der Ableitung von Wörtern in weitesten Sinne des Wortes. Darunter wird die Bildung eines Wortes auf der Basis eines bereits existierenden Wortes durch Anderung seines morphologischen Baus verstanden ${ }^{12}$. Die Ableitung stellt in den slavischen Sprachen bei der Bildung von neuen Wörtern das häufigste Wortbildungsverfahren dar, und zwar das wortbildende Verfahren der Präfigierung bei der Bildung von Verben und das der Suffigierung bei der Bildung von Substantiven. Eine ähnliche überragende Stellung nimmt bei der Bildung von neuen Wörtern im Deutschen die Komposition ein, d.h. die Zusammensetzung zweier autosemantischer wörter, die ihrerseits für die slavischen Sprachen nur eine relativ geringe Bedeutung hat.

Ableitungsbasis der Präfigierung sind im Serbokroatischen in erster Iinie Verben und in geringerem Umfange Substantive, Adjektive, Adverbien und Pronomen. Da es sich in dieser Arbeit ausschliesslich um Ableitungen von Verben handelt, wird bei der Darlegung des Wesens der Präfigierung und des Präfixes nicht auf solche Besonderheiten eingegangen, die im Zusammenhang mit anderen Wortarten stehen.

Ableitungsbasis der Verbalpräfigierung ist in der Regel das ganze Wort, aufgefasst als Gesamtheit der Wortformen, in unserem Fall das einfache oder (in sehr geringem Umfange) schon präfigierte Verb ${ }^{13}$. Der Typ der Präfigierung, dessen Ausgangsbasis

12 Vgl. M. Dokulil, Trořeni slov I, S. 22.

13 Das einfache Verb der Ableitungsbasis ist in der Regel imperfektiv und wird durch Hinzufügen eines Präfixes perfektiv. Einfache imperfektive Verben bleiben auch nach der Verbindung mit einem Präix imperfektiv, wenn es sich um die indeterminierte Form von Doppelzeitwörtern handelt wie z.B. nositi - donositi 'tragen - herbeitragen', voziti - dovoziti 'fahren, befördern

- herbeiführen, zufuhren'. Ist das einfache Verb der Ablei- 
ein ganzes Wort ist und der charakteristisch ist für die Ableitung von Verben (nositi - do-nositi 'tragen - herantragen', vlačiti - za-vlačiti 'ziehen, schleppen - hineinziehen', kopati is-kopati 'graben - ausgraben') und nur in geringem Masse für die von Substantiven (pra-baba 'Urgrossmutter', pra-domovina 'Urheimat' u.a.) wird in der Terminologie Dokulils "reine Präfigierung" 14 genannt. Auf andere Typen der präfixalen Ableitung soll nicht eingegangen werden, da sie in Verbindung mit dem Verb keine Rolle spielen.

Vor das Verb wird das Präfix gesetzt, das die lexikalische Bedeutung des zugrunde liegenden Wortes in einer grossen Anzahl der Fälle 15 ändert, seinen grammatischen Charakter jedoch unverändert lässt, mit Ausnahme des Verbalaspekts. In der Regel wird durch Hinzufügen eines Präfixes an ein einfaches unpräfigiertes Verb der Aspekt desselben geändert. Das Präfix hat also keine grammatische, d.h. wortartzuordnende Funktion wie das Suffix. Die Wortart bleibt die gleiche wie im einfachen, nicht abgeleiteten Verb. Ob jedoch das Präfix auf Grund seiner Funktionen im abgeleiteten Verb einen Einfluss auf die Zuordnung der von präfigierten Verben abgeleiteten Substantive zu den einzelnen wortbildenden Kategorien besitzt, soll erst im Verlaufe der Arbeit untersucht werden. (s. Affinität S. $12 f f$. )

Zu den Präfixen gibt es im allgemeinen homonyme Präpositionen. Eine Ausnahme bilden im Serbokroatischen ${ }^{16}$ lediglich die Präfixe pa-, pre-, pro- und raz-, die bereits im Altslavischen nicht mehr in Form einer Präposition vorkommen.

Der Umstand, dass Präfixe eine autonomere stellung im Wort einnehmen als Suffixe, die semantisch und formal mit dem gegebenen Stamm eng verbunden sind ${ }^{17}$, dass sie sich leichter abtrennen lassen als Suffixe und dass ihnen in der Mehrzahl homonyme Präpo-

tungsbasis perfektiv, dann bleibt es auch nach der Verbindung mit einem Präfix perfektiv wie z.B. dići - podići 'heben - erheben', vrći - navrći 'stellen, legen - auflegen', pasti napasti 'fallen - anfallen'.

14 Reine Präfigierung liegt dann nicht vor, wenn der Ableitungsbasis kein ganzes Wort zugrunde liegt, sondern z.B. ein Wortstamm. M. Dokulil, Tvořeni slov I, S. 54 .

15 Uber Präfixe, die nicht die lexikalische Bedeutung des Grundworts ändern, wird weiter unten abgehandelt.

16 T. Maretić, Gramatika..., a.a.0., S. 411.

17 M. Dokulil, Tvořeni slov I, S. 147. 
sitionen entsprechen, die ihrerseits ein selbständiges, wenn auch synsemantisches Wort darstellen und sich aus autosemantischen Wörtern - Adverbien ${ }^{18}$ - entwickelten (Suffixe dagegen gibt es per definitionem niemals als selbständiges Wort), führte Forscher wie z.B. Trávniček ${ }^{19}$ zu der Annahme, die Präfigierung für eine Sondergattung der Komposition zu halten.

Von den angeführten Kriterien dürfte die Verfechter der Auffassung der Präfigierung als einer Sondergattung der Komposition in erster Linie wohl das zu ihrer Annahme bewegt haben, dass Präfixe in der Mehrzahl im Gegensatz zu Suffixen auch ausserhalb der Verbindung mit dem Ableitungsstamm bzw. der ganzen lexikalischen Einheit als selbständiges, wenn auch synsemantisches Wort als Präposition - vorkommen können.

Die Tatsache allerdings, dass Präfixe, wie oben gezeigt wurde, nicht durchweg über Parallelen unter den Präpositionen verfügen, während Glieder eines Kompositums so gut wie immer, auch ausserhalb dieses Kompositums, als autosemantische Wörter existieren, zeigt, dass zwischen den Wortbildungsverfahren der Ableitung und der Komposition ein fundamentaler Unterschied besteht. Nicht zuletzt dieser Sachverhalt veranlasst Dokulil zu der Feststellung, "...dass die Verbindung mit synsemantischen Wörtern prinzipiell unterschiedlich von einer Verbindung mit autosemantischen wörtern ist" 20 .

Gegen die Auffassung von der Präfigierung als einer Sondergattung der Komposition spricht ferner, dass Präfixe und Präpositionen semantisch nicht identisch sind und dass Präfixe ihre eigene semantische Entwicklung durchgemacht haben. Die Semantik der Präfixe und ihre Funktionen werden im Grunde erst durch die Analyse der präfigierten wörter bestimmt ${ }^{21}$.

Ein weiteres wesentliches Argument gegen diese Auffassung ist nach Dokulil 22 auch die Tatsache, dass Präfixe wie Suffixe

$18 \mathrm{M}$. Dokulil, Tvořeni slov I, S. 23. Vgl. auch A, Belić, 0 jezičkoj prirodi i jezičkom razvitku. Beograd 21958, S. 131.

19 F. Trávniček, Mluvnice spisovné češtiny. I. Praha 31951, S. 393.

20 M. Dokulil, a.a.0., S. 147.

21 E. Sekaninová, Slovesná predpona do- v ruštine a slovenčine. In: CR XVI, 1971, S. 193.

22 M. Dokulil, a.a.0., s. 147. Vgl, auch W. Fleischer, Wortbildung der deutschen' Gegenwartssprache. Leipzig 1969, S. 64. Im Deutschen wird $z$.B. 'Werk' als Substantiv 'Werk' und Ableitungssuffix -werk(-) zur Bildung von Kollektiva: Mauerwerk Gemâuer, Backwerk - Gebäck, Buschwerk - Gebüsch u.a. verwen- 
ihre lexikalische Bedeutung verlieren und eine rein grammatische Funktion annehmen können, was für die Glieder eines Kompositums völlig ausgeschlossen ist.

Wie die angeführten Argumente gezeigt haben, sind die Unterschiede zwischen der Präfigierung und der Komposition so beträchtlich, dass die Präfigierung kaum für eine Sondergattung der Komposition gehalten werden kann. Andererseits hat sich gezeigt, dass zwischen der Suffigierung, die als Ableitungsverfahren par excellence gilt, und der Präfigierung Unterschiede bestehen. Die Unterschiede werden noch deutlicher, wenn z.B. auch Präfixe in Betracht gezogen werden, die nur der Ableitung von Substantiven dienen, worauf aber in diesem Zusammenhang nicht eingegangen werden soll. (Beispiele s. S. 1l)

Aus diesem Grunde wird bei der Wertung der Verbalpräfigierung in der vorliegenden Arbeit in Ubereinstimmung mit den Anschauungen von Dokulil 23 , Horeckýt $y^{24}$ und Sekaninová25 davon ausgegangen, dass die Präfigierung ein Spezialfall der Ableitung ist.

Das Verfahren der Präfigierung kann sich auch wiederholen. So werden z.B. von folgenden doppelt präfigierten Verben Substantive abgeleitet: vezati - do-vezati - na-do-vezati - nadovezivanje 'binden - anbinden - anbinden - Anbinden'; ići - ob-ićci za-ob-ići - zaobilaženje, zaobilazak 'gehen - herumgehen umgehen, Umweg machen - Umgehen, Umweg'; stati - o-stati - izo-stati - izostajanje, izostanak 'sich hinstellen - bleiben fehlen, ausbleiben - Ausbleiben, Fehlen'; liti - na-liti - do-naliti - donalevanje 'giessen - vollgiessen - zu-, vollgiessen $\mathrm{Zu}$, Vollgiessen'. Dabei kann festgestellt werden, dass von einer bereits präfigierten Ableitungsbasis am häufigsten Verben mit dem Präfix na- abgeleitet werden, wobei bei dem der Arbeit zugrunde liegenden Material das Präfix der bereits präfigierten Ableitungsbasis in der Mehrzahl der Fälle do- ist, weniger häufig sind Ableitungen mit den Präfixen za-, iz- und do- von bereits präfigierten Verben. Das zweite Präfix fügt den präfigierten Verben in der Mehrzahl der Fälle keine neue Bedeutung hinzu. Auf diese

det. Als Ableitungssuffix bei Adjektiven erscheint z.B. -los in 'lieblos' u.a., das als Substantiv 'Los' verwendet wird.

23 M. Dokulil, Tvořeni slov I, S. 23.

24 J. Horecký, Slovotvorná sústava slovenčiny. Bratislava 1959, S. 55 .

25 E. Sekaninová, Slovesná predpona do-..., a.a.o., S. 193. 
Weise können Bildungen von absoluter Synonymie realisiert werden. Die Bedeutung des Präfixes hat nach dem Zusammenwachsen mit dem Verb zu der ursprünglichen räumlichen, die es mit den Präpositionen ohne $\mathrm{Zweifel}$ gemeinsam hat, noch weitere hinzubekommen ${ }^{26}$, und zwar Bedeutungen der Aktionsart, die die Art und Weise des Verlaufs der Handlung charakterisieren, und die grammatische Bedeutung $^{27}$. So weist z.B. das Präfix za- neben der räumlichen Bedeutung '(etwas) hinter (etwas stellen)' (za-baciti 'hinterwerfen', za-ići 'hintergehen') die Aktionsartbedeutung 'eine Handlung beginnen' (za-veslati 'anfangen zu rudern', za-pevati 'anfangen $z u$ singen' und die grammatische Bedeutung auf (za-daviti 'erwürgen', za-docniti 'verspäten').

Auf der Basis der Analyse der Semantik des präfigierten Verbs als einer Verbindung von Präfix und Verbbasis lassen sich die Funktionen des Präfixes bestimmen. In Abhängigkeit vom Einfluss des Präfixes auf die Verbbasis lassen sich folgende drei Funktionen des Präfixes unterscheiden:

1. Das Präfix spezifiziert das, was man das externe Bedeutungspotential des zugrunde liegenden Verbs nennen könnte. So kann z.B. ein Verb, das eine Bewegung im Raum bezeichnet, ohne dass entsprechende Raumangaben in seiner internen Semantik explizit vorhanden sind, durch entsprechende präfigierte Derivate im Hinblick auf diese potentielle Bedeutungsdimension spezifiziert werden. Das Präfix übt hier eine lexikalische Funktion aus. 2. Das Präfix spezifiziert den Ablauf in der Zeit, der generell eine interne Komponente der Bedeutung der Wortart Verb darstellt. Das Präfix übt hier eine modifizierende Funktion aus.

3. Das Präfix bewirkt keine Anderung der lexikalischen, sondern lediglich der grammatischen Bedeutung. Das Präfix übt eine rein perfektivierende Funktion aus.

Das Präfix übt neben der lexikalischen und modifizierenden Funktion auch immer zugleich eine perfektivierende aus, wenn das

26 A. Leskien, Grammatik der serbo-kroatischen Sprache. 1. Teil: Lautlehre, Stammbildung, Formenlehre. Heidelberg 1914, S. $475 \mathrm{ff}$. A. Belić, o jezičkoj prirodi i jezičkom razvitku. Beograd 21958, S. 131; I. Grickat, Nekoliko zapažanja o glagolskom vidu. In: Pitanja književnosti i jezika IV u. V, B, 1957/58, S. $38 \mathrm{ff}$. R. Ugrinova - Skalovska, Značenjata na glagolskite prefiksi vo makedonskiot jazik. Skopje 1960, S. $5 \mathrm{ff}$. W. Fleischer, Wortbildung der deutschen Gegenwartssprache. Leipzig 1969, s. 72.

27 Weiteres dazu in dem Abschnitt über die rein perfektivierende Funktion. 
der Ableitung zugrunde liegende Verb imperfektiv ist. Ein und dasselbe Präfix kann in Verbindung mit verschiedenen Simplizia alle drei Funktionen ausüben.

Bevor auf die einzelnen Funktionen der Präfixe näher eingegangen wird, soll zunächst die hier vertretene Auffassung vom Aspekt dargelegt werden.

\section{Exkurs: Zur Frage des Aspekts}

Die Verbindung von Präfigierung und Aspektkategorie ist durch die Tatsache gegeben, dass die Präfigierung eines der Hauptverfahren ${ }^{28}$ der morphologischen Realisierung des perfektiven Aspekts ist. In der Regel wird, wie gesagt, durch Anfügen eines Präfixes an ein imperfektives einfaches Verb der perfektive Aspekt dieses Verbs gebildet.

Die Kategorie des Aspekts wird nicht einheitlich betrachtet. Die unterschiedliche Betrachtung des Aspekts bedingt zum Teil verschiedene Auffassungen von den Funktionen des Präfixes, da deren Bestimmung in erster Iinie von der Auffassung des Aspekts abhängt. Bevor daher auf die festgesetzten drei Funktionen des Präfixes näher eingegangen wird, muss meine Auffassung vom Aspekt dargelegt werden. Das soll in Form einer kurzen Gegenüberstellung $\mathrm{zu}$ anderen Auffassungen geschehen.

Eine für lange Zeit vorherrschende Meinung über den Aspekt geht auf die Konzeption des Slavisten Miklosich ${ }^{29}$ zurück, der von der Analyse des perfektiven Aspekts ausging und sein Hauptmerkmal in der Vollendung oder Abgeschlossenheit der Handlung sah. Als Vertreter dieser Konzeption können u.a. Stojanovic 30 und Diels 31 genannt werden.

\section{Allerdings erklären Vollendung oder Abschluss der Handlung}

28 Neben der Präfigierung dient in den slavischen Sprachen die Suffigierung der Verwirklichung der Aspektkorrelation. Sie dient vor allem der Bildung von sekundären Imperfektiven. In beschränktem Umfange ist auch der Ablaut als sekundäres charakteristikum produktiv. völlig unproduktiv ist in diesem Zusammenhang das Verfahren des Suppletivismus.

29 F. Miklosich, Vergleichende Grammatik der slavischen Sprachen. IV. Bd. Syntax. Heidelberg 1926, S. 276 u. 279.

$30 \mathrm{Lj}$. Stojanović, 0 značenju i upotrebi glagolskih oblika u rečenicama. In: JF II, 1921 , S. 188.

31 P. Diels, Altkirchenslavische Grammatik. Heidelberg ${ }^{2}{ }_{1963}$, S. 225 . 
noch nicht ganz den perfektiven Aspekt, da eine solche Auffassung andere Phasen der Handlung ausser acht lässt. Wie Braun 32 ausführt, drücken Zeitwörter nur in seltensten Fällen aus, dass eine Handlung zum Abschluss gelangt ist. Bei einer Definition des perfektiven Aspekts muss berücksichtigt werden, dass dieser nicht nur einzelne Phasen, sondern den gesamten Verlauf der Handlung einschliesst.

Einige Forscher gingen vom imperfektiven Aspekt aus und erblickten im Begriff der Dauer der Verbhandlung das Hauptkriterium. Diese Annahme impliziert, dass dem perfektiven Aspekt als dem Gegenteil des imperfektiven jede Dauer der Verbhandlung fehle. Vertreter dieser Auffassung waren z.B. Brugmann 33 , Leskien 34 , Meillet ${ }^{35}$, Vondrák ${ }^{36}$, Maretic ${ }^{37}$.

Ebenfalls nicht den ganzen Verlauf der Handlung berücksichtigten Forscher wie Trávniček 38 und Doroszewski ${ }^{39}$, die das wesentliche Merkmal des perfektiven Aspekts in der Punktualität oder in dem momentanen Charakter erblickten.

Eine isolierte Stellung in der Aspektforschung nimmt Koschmieder 40 ein, der den Gegensatz der beiden Aspekte in der Richtungsbezogenheit sieht. Er definiert den perfektiven Aspekt als Ausdruck für den Zeitrichtungsbezug von der Zukunft in die Vergangenheit und den imperfektiven Aspekt umgekehrt. Diese Gedanken über den Aspekt lassen sich nicht mit unserer Auffassung vereinbaren.

Von grosser Bedeutung für das Verständnis der Perfektivität

32 M. Braun, Grundzüge der slawischen Sprachen. Göttingen 0.J., S. 96.

$33 \mathrm{~K}$. Brugmann - B. Delbrück, Grundriss der vergleichenden Grammatik der indogermanischen sprachen. Strassburg 1913, S. 79.

34 A. Leskien, Handbuch der altbulgarischen Sprache. Heidelberg 81962 , S. 172 .

35 A. Meillet, Linguistique historique et linguistique générale. Paris 1948, S. $183 \mathrm{ff}$.

36 W. Vondrák Vergleichende slavische Grammatik. I-II. Göttingen 21924-1928, S. 370 .

37 T. Maretić, Gramatika..., a.a.0., S. 442.

38 F. Trávniček, Studie o českém vidu slovesném. Praha 1923, S. 1.

39 W. Doroszewski, o znaczeniu dokonanym osnów czasownikowych (słownych) w jezyku polskim. In: PF X, S. 208; vgl. auch S. $195 \mathrm{ff}$.

40 E. Koschmieder, Zeitbezug und Sprache. Ein Beitrag zur Aspekt - und Tempusfrage. Leipzig und Berlin 1929, S. $34 \mathrm{ff}$. 
wurde die Ansicht de Saussures, der den perfektiven Aspekt als einen Vorgang charakterisierte, der "in seiner Gesamtheit" 41 ausgedrückt wird. Der Begriff von der "Gesamtheit" wurde Ausgangspunkt für die Bestimmung der Perfektivität überhaupt. So definierte Dostál den Verbalaspekt auf der Basis dieses Begriffs als "die Fähigkeit des Verbs, die Stellung des Sprechers zum wirklichen Geschehen auszudrücken, zur Handlung (oder zur Vorstellung jenes Geschehens), die als Ganzes aufgefasst wird oder umgekehrt" 42 .

Auf der Basis des Begriffs der "Gesamtheit" bestimmte Isačenko den perfektiven Aspekt als merkmalhaltiges, starkes Glied und den imperfektiven Aspekt als merkmalloses Glied der Aspektkorrelation ${ }^{43}$. Den Aspekt versteht er bei ansonsten völliger semantischer Identität von Ausgangsverb und abgeleitetem Verb und lediglichem Unterschied der grammatischen Aspektbedeutung als grammatische Kategorie 44.

Mit dem Begriff der "Gesamtheit" wurde ein wichtiges Merkmal des perfektiven Aspekts erfasst. Ein weiteres wesentliches Merkmal, und zwar das des "erreichten Resultats", das gerade für eine richtige Wertung der Verben mit rein perfektivierendem Präfix von grosser Bedeutung ist, muss meines Erachtens zur Charakterisierung des Aspektbegriffs hinzugefügt werden. Braun weist auf die grosse, häufig aber unterschätzte Bedeutung der Verwendung des perfektiven Aspekts "im Hinblick auf das Ergebnis" 45 für den Sprachgebrauch hin. Koschmieder stellt fest, dass die Mehrzahl der slavischen perfektiven Ableitungen "resultative Vollendungsbedeutung" 46 hat. Das perfektive Glied der Aspektkorrelation wird daher in der vorliegenden Arbeit folgendermassen definiert: Der perfektive Aspekt bezeichnet eine Handlung in ihrer Gesamtheit und im Hinblick auf ihr Resultat. Der imperfektive Aspekt entbehrt eines Hinweises auf die Gesamtheit der Handlung und die Vorstellung des Erreichens des Resultats.

41 F. de Saussure, Grundfragen der allgemeinen Sprachwissenschaft. Paris 21967, S. 139.

42 A. Dostál, Studie o vidovém systému v staroslověnštině. Praha 1954, S. 18.

43 A. V. Isačenko, Die russische Sprache der Gegenwart. Teil I. Formenlehre. Halle (Saale) 1962, S. 350.

44 Ebenda, S. 417.

45 M. Braun, Grundzüge..., a.a.0., s. 97.

46 E. Koschmieder, Zeitbezug..., a.a.0., s. 3 ? 


\section{Die lexikalische Funktion}

Präfixe mit lexikalischer Funktion verändern die Bedeutung der Verbbasis so stark, dass eine neue lexikalische Einheit entsteht. Präfixe mit lexikalischer Funktion qualifizieren, wie Isačenko ${ }^{47}$ schreibt, das Verb, an das sie angefügt werden, sozusagen von aussen; sie verursachen derart wesentliche qualitative Anderungen des Ausgangsverbs, dass sich präfigierte Verben dieses Typs von ihm sowohl in semantischer als auch in grammatischer Hinsicht losreissen und selbständige Verblexeme bilden. Verben mit lexikalischen Präfixen und deren Simplizia bilden keine Aspektpaare. So entstehen durch Hinzufügen der Präfixe do-, iz-, na-, za- an die Verben skakati 'springen', krcati 'laden', vlačiti 'ziehen, schleppen', bosti 'stechen' die neuen lexikalischen Einheiten doskakati 'herbeispringen', iskrcati 'ausladen', navlačiti 'überziehen', zabosti 'hineinstossen'.

Die Existenz der lexikalischen Funktion in der oben angeführten Definition wird von allen Wissenschaftlern anerkannt. Unterschiedliche Ansichten bestehen lediglich in bezug auf die Wahl der Kriterien, die der Bestimmung der lexikalischen Funktion der Präfixe dienen. Dabei lassen sich zwei grundlegend verschiedene Auffassungen feststellen. Diejenigen Forscher, die neben der lexikalischen Funktion auch die rein perfektivierende Funktion der Präfixe anerkennen, gehen bei der Bestimmung der lexikalischen Funktion der Präfixe allein von der inhaltlichen Beziehung aus, die zwischen dem Präfix und der Verbbasis herrscht. Ein formales Kriterium wird für die Bestimmung der Funktion des Präfixes nicht herangezogen. Diese Auffassung vertreten u.a. Wissenschaftler wie: Jacobsohn ${ }^{48}$, Dostál ${ }^{49}$, Poldauf ${ }^{50}$, Němec ${ }^{51}$, Peciar ${ }^{52}$,

47 A. V. Isačenko, Grammatičeskij stroj russkogo jazyka v sopostavlenii s slovackim. Morfologija, II. Bratislava I960, S. $222-223$.

$48 \mathrm{H}$. Jacobsohn, Aspektfragen. In: IF LI, 1933, S. 295. Er meint, dass die lexikalische Perfektivierung eines imperfektiven Simplex wohl in allen indogermanischen Sprachen vorhanden ist.

49 A. Dostál, Studie o vidovém..., a.a.0., S. 256.

50 I. Poldauf, Spojováni s předponami při tvořeni dokonavých sloves $v$ češtine. In: SS XV, 1954, S. 50.

51 I. Nèmec, Vývojové problémy soudobé nauky o vidu. In: SI XXVIII, i959, S. 317.

52 S. Peciar, Funkcie slovesnej predpony na- v slovenčine. In: JC XVIII, 1967 , S. 138. 
Sekaninová 53 , Horeckýy ${ }^{54}$ Bogusławski ${ }^{55}$, vinogradov ${ }^{56}$, Tichonov 57 , Ugrinova-Skalovska 58 , Grickat ${ }^{59}$.

Die andere Auffassung vertreten im allgemeinen die Linguisten, die in der Präfigierung ausschliesslich einen Wortbildungsvorgang sehen, d.h. für die es keine "leeren" Aspektpräfixe gibt $^{60}$. Sie ziehen für die Bestimmung der lexikalischen Funktion, als deren Resultat neue lexikalische Einheiten entstehen, ein formales Kriterium heran, und zwar schliessen sie von der Existenz eines sekundären Imperfektivs auf die lexikalische Funktion des Präfixes. Wenn also zum Verb russ. razorvat' 'zerreissen' das sekundäre Imperfektiv razryvat' oder zu russ. otorvat' 'abreissen' das sekundäre Imperfektiv otryvat' gebildet wird, dann handelt es sich nach Meinung dieser Forscher bei den Präfixen raz- und otum solche mit lexikalischer Funktion. Wenn jedoch zu Verben wie z.B. russ. zakričat' 'losschreien' und russ. zaigrat'61 'anfangen zu spielen' keine sekundären Imperfektive gebildet werden, handelt es sich bei za- nicht um ein Präfix mit lexikalischer, sondern mit modifizierender Funktion. Als Hauptvertreter dieser Auffassung können Isačenko ${ }^{62}$, Stender-Petersen 63 , Kartsevski ${ }^{64}$,

53 E. Sekaninová, Miesto prefixácie vo vidovom systéme slovanského slovesa. In: SISl V, 1970, S. 33.

$54 \mathrm{~J}$. Horecký, 0 tvoreni slovies predponami. In: SR XXII, 1957 , S. 148.

55 A. Bogusławski, Perfektivnye glagoly v russkom jazyke. In: SI XXXII, 1963, S. 24.

56 V. V. Vinogradov, Sovremennyj russkij jazyk. Morfologija. Moskva 1952, S. 312.

57 A. N. Tichonov, Zametki o vtoričnoj imperfektivacii glagolov s čisto vidovymi pristavkami, Trudy Uzbekskogo gosudarstvennogo universiteta imeni Ališera Navoi, Novaja serija No. 92 , Slavjanskij sbornik, Samarkand 1958, S. 61, (zit. nach K. Ivanova, Desemantizacijata na glagoinite predstavki v súvremennija bülgarski knižoven ezik, Sofija 1966, S. 19.).

58 R. Ugrinova-Skalovska, Značenjata na glagolskite prefiksi..., a.a.0., S. 27 .

59 I. Grickat, Prefiksacija kao sredstvo..., a.a.0., S. 187.

60 Eine Ausnahme bildet Kopečný. Er versteht die Präfigierung nicht ausschliesslich als Wortbildungsvorgang. Zu Verben mit lexikalischem Präfix muss seiner Meinung nach ein sekundäres Imperfektiv gebildet werden. F. Kopečný, Bemerkungen zu zwei Arbeiten über die schlechthin perfektivierenden Vorsilben im Tschechischen. In: ZfSI IV, 1959, S. 113.

61 Alle russischen Beispiele sind nach Isačenko zitiert. A. V. Isačenko, Grammatičeskij stroj..., a.a.0., S. 222 - 223.

62 Nach Isačenko und Stender-Petersen dient das sekundäre Imperfektiv als Beweis für die Anwesenheit einess semantisshep $p_{93105}$ 
Kuryłowicz ${ }^{65}$ und Maslov ${ }^{66}$ genannt werden.

Der vorliegenden Darstellung der lexikalischen Funktion der Präfixe liegt die Auffassung der Forscher zugrunde, die auch die rein perfektivierende Funktion der Präfixe anerkennen. Meines Erachtens kann bei der Bestimmung der lexikalischen Funktion des Präfixes nur von der semantischen Beziehung ausgegangen werden, die zwischen der Verbbasis und dem Präfix herrscht.

Das sekundäre Imperfektiv kann nach meiner Meinung nicht als Beweis für das Vorhandensein der lexikalischen Funktion des Präfixes im Serbokroatischen angeführt werden, selbst wenn, wie es im Serbokroatischen der Fall ist, zu der überwiegenden Mehrzahl der perfektiven präfigierten Verben mit lexikalischer Funktion ein sekundäres Imperfektiv gebildet werden kann, und daher der Schluss naheliegen könnte, diese Erscheinung als Beweis für das Vorhandensein der lexikalischen Funktion des Präfixes heranzuziehen; denn ebenso können Beispiele angeführt werden, die gegen diese Auffassung sprechen 67 . Keine sekundären Imperfektive werden z.B. gebildet $z u$ izdahnuti '1. aushauchen, 2. sterben', ishlapiti 'auslüften', nagaziti 'festtreten', nalepiti 'ankleben', zagaziti 'hineinwaten'. Damit kann letztlich gezeigt werden, dass, wie

Unterschiedes $z$ wischen dem einfachen und dem präfigierten Verb. Das Aspektpaar kann nach deren Meinung folglich nur mit dem perfektiven Verb und dem imperfektiven sekundären Verb gebildet werden, da allein diese beiden die gleiche Realbedeutung aufweisen. A. V. Isačenko, Die russische Sprache..., a.a.0., S. 385.

63 A. I. Stender-Petersen, O funkcijach glagol'nych pristavok v russkom jazyke. In: SI XII, 1933, S. 327.

$64 \mathrm{~S}$. Kartsevski (Karcevskij), Etudes sur le système verbal du russe contemporain. II. Mécanisme des aspects. In: SI I, 1922, S. $496 \mathrm{ff}$.

$65 \mathrm{~J}$. Kuryłowicz, Pochodzenie słowiańskich aspektów czasownikowych. In: Sbornik prací I. Sjezdu slovanskych filologú v Praze 1929. II. Přednášky. Praha 1932, S. 572.

$66 \mathrm{Ju}$. S. Maslov, Morfologija glagol'nogo vida v sovremennom bolgarskom literaturnom jazyke. Moskva-Leningrad 1963, S. 5. Nach Maslov musste das Fehlen der absoluten lexikalischen Identität zwischen den Gliedern ähnlicher "Paare" notwendigerweise zur Entstehung von sekundären Imperfektiven führen.

67 Gegen die Auffassung, das sekundäre Imperfektivum für die Bestimmung der lexikalischen Funktion des Präfixes heranzuziehen, spricht auch die Tatsache, dass das sekundäre Imperfektiv im Serbokroatischen auch zu perfektiven Verben mit Präfixen der modifizierenden Funktion und relativ häufig als Synonym auch zu perfektiven Verben mit Präfixen der rein perfektivierenden Funktion gebildet wird. 
Sekaninová ${ }^{68}$ schreibt, die Qualität des selbständigen lexikalischen Präfixes nicht durch das Vorkommen des sekundären Imperfektivs bedingt wird.

4. Die modifizierende Funktion 69

Verbalpräfixe weisen neben der lexikalischen Funktion zur Bildung neuer lexikalischer Einheiten eine Funktion auf, die der Modifizierung der Bedeutung des Ausgangsverbs hinsichtlich des Verlaufs der Handlung bzw. der Art und Weise des Ablaufs der Handlung dient. Diese Präfixe werden seit Agrell ${ }^{70}$ aktionsartbildend genannt.

Präfixe mit lexikalischer und modifizierender Funktion sind durch die gemeinsame Aufgabe verbunden, eine Bedeutungsveränderung der Verbbasis hervorzurufen, die auf ihrer semantischen Verengung ${ }^{71}$ beruht.

Der Unterschied zwischen den beiden Funktionen besteht in der verschiedenen Realisierung der semantischen Verengung der Bedeutung des Ausgangsverbs. Während mittels der lexikalischen Präfixe, wie weiter oben gezeigt wurde, der Handlungsablauf gewissermassen von seiner äusseren Seite charakterisiert wird, wird mit den modifizierenden Präfixen die Aufmerksamkeit auf ein inneres Merkmal ${ }^{72}$ des Verlaufs der Verbhandlung des Ausgangsverbs konzentriert und seine individuelle Semantik unberührt gelassen.

Die Handlung, die z.B. durch die Verben nakotiti 'viel hekken' und zaorati 'anackern' ausgedrückt wird, ist vollständig mit der Handlung identisch, die durch die Simplizia kotiti 'hecken' und orati 'pflügen' ausgedrückt wird. Die Besonderheit der Bedeutung der Verben mit modifizierendem Präfix besteht lediglich in der Konzentrierung der Aufmerksamkeit auf eine Phase usw. der durch die Ausgangsverben kotiti und orati ausgedrückten Handlung.

Der Begriff der Aktionsarten wird in der Wissenschaft verschieden weit gefasst. So umfasst der von Maslov ${ }^{73}$ verwendete

68 E. Sekaninová, Miesto prefixácie..., a.a.0., S. 25.

69 Für dieselbe Erscheinung wird auch der Begriff "Aktionsart" verwendet.

70 S. Agrell, Aspektänderung und Aktionsartbildung beim polnischen Zeitworte. Lund 1908, S. 78.

71 A. V. Isačenko, Grammatičeski.j stroj..., a.a.0., S. 222.

72 Ebenda, S. 223. 
Begriff der Aktionsarten sowohl Verben, die mit Hilfe wortbildender Mittel gebildet werden (wie z.B. Präfixe, Suffixe, Präfixe in Verbindung mit einem Reflexivsuffix) als auch Verben, die nicht abgeleitet sind und demnach keinerlei wortbildende Charakteristik aufweisen, wie z.B. solche der statalen Aktionsart (russ. stojat' 'stehen', spat' 'schlafen', plakat' 'weinen'), der multiplikativen (russ. kolot' 'stechen', lizat' 'lecken', kapat' 'tropfen'), der evolutiven (russ. pisat' 'schreiben', šit' 'nähen', idti 'gehen'). Die vorliegende Darstellung berücksichtigt nur Aktionsartbildungen, die durch das wortbildende Mittel der Präfigierung abgeleitet werden.

Ein Unterschied ist nicht nur zwischen den Aktionsartbildungen und den Bildungen mit lexikalischen Präfixen zu konstatieren, sondern auch zwischen den Aktionsartbildungen und der Kategorie des Aspekts. Verben, die mittels modifizierender Präfixe perfektiviert werden, sind keine völlig selbständigen Verben, sie bleiben in Korrelation zu den Ausgangsverben. Das Verhältnis, das zwischen den ableitenden und den abgeleiteten Verben besteht, kann jedoch nicht als rein aspektal bezeichnet werden, da Verben des Typs nakotiti und zaorati, die mittels Präfixe perfektiviert worden sind, noch eine ergänzende Aktionsartbedeutung der "ausreichenden Menge" und des "Handlungsbeginns" enthalten.

Auf den Umstand - der heute übrigens in der Wissenschaft allgemein anerkannt ist - dass ein grundsätzlicher Unterschied zwischen der Kategorie des Verbalaspekts ${ }^{74}$ und der Kategorie der Aktionsarten 75 gemacht werden muss, wies zuerst der schwedische Linguist Agrell hin. Er versteht unter dem Aspekt "die beiden Hauptkategorien des slawischen Zeitwortes, die unvollendete und die vollendete Handlungsform (das Imperfektivum und das Perfektivum)" und unter dem Begriff der Aktionsart Bedeutungsfunktionen, "die genauer ausdrücken, wie die Handlung vollbracht wird, die Art und Weise ihrer Ausführung markieren" 76 .

Eine genaue Abgrenzung dieser beiden Kategorien stösst jedoch wegen der fehlenden ausgearbeiteten Kriterien auf Schwie-

$73 \mathrm{Ju}$. S. Maslov, Morfologija glagol'nogo vida..., a.a.o., s. 6 .

74 Diese wird als grammatische, paradigmatische Kategorie verstanden (jedes Verb ist im Hinblick auf den Aspekt charakterisiert).

75 Diese wird als Wortbildungskategorie aufgefasst, die mehr oder weniger produktiv ist.

76 S. Agrell, Aspektänderung und Aktionsartbildung...., a.a.0., S. 78 . 
rigkeiten. Diese Tatsache hat zur Folge, dass der Begriff der Aktionsart entsprechend der jeweils vorliegenden Auffassung vom Aspekt weiter oder enger gefasst werden kann. Während wir die präfigierten Verben, deren Präfix das Resultat der Handlung anzeigt, gemäss der oben gegebenen Definition des Aspekts, nach der die Resultativität ein Merkmal des perfektiven Aspekts ist, in die Kategorie der reinen Präfigierungen einordnen, zählt sie z.B. Isačenko 77 entsprechend seiner Auffassung vom Aspekt, nach der die Resultativität kein Merkmal des perfektiven Aspekts ist, zur resultativen Aktionsart.

Aber nicht nur die Abgrenzung der Aktionsart zur Kategorie des Aspekts bereitet Schwierigkeiten. Auch hinsichtlich einiger formaler Kriterien zur Bestimmung der Aktionsarten bestehen bei den Autoren teilweise unterschiedliche Auffassungen. So bestehen vor allem unterschiedliche Ansichten über die Rolle des sekundären Imperfektivs bei der Bestimmung der Aktionsarten. Nach Isačenko, der über Aktionsarten nur in bezug auf Verben spricht, die mittels der wortbildenden Verfahren der Präfigierung (z.B. zu russ. čitat' 'lesen' die delimitative Aktionsart počitat' 'ein bisschen, eine Weile lesen') und Suffigierung (z.B. zu russ. ipf. čitat' 'lesen' die iterative Aktionsart ipf. čityvat' 'zu lesen pflegen') von selbständig existierenden Verben (meist Simplizia) abgeleitet sind, stellt die Zugehörigkeit zu einem einzigen Aspekt das formale Hauptmerkmal der Aktionsarten dar 78 . Aktionsarten sind seiner Meinung nach immer Perfektiva oder Imperfektiva tantum 79. Für Isačenko wären demnach nur in Verben wie skr. zaveslati 'anfangen $z u$ rudern' oder zapevati 'anfangen $z u$ singen' alle Voraussetzungen für das Vorhandensein der Aktionsart gegeben, da $z u$ diesen Verben keine sekundären Imperfektiva gebildet werden, nicht jedoch in Verben wie zaorati 'anackern' oder zažeti 'anfangen zu ernten', da zu diesen die sekundären Imperfektiva zaoravati bzw. zažinjati gebildet werden 80 . Wie jedoch aus den Bei-

77 A. V. Isačenko, Grammatičeskij stroj..., a.a.0., s. $242 \mathrm{ff}$. 78 A. V. Isačenko, Die russische Sprache..., a.a.0., s. 386.

79 Ebenda, S. 387ff. Für Stender-Petersen sind semantische Kriterien und das Fehlen des sekundären Imperfektivs massgebend für die Bestimmung der Aktionsart. A. I. Stender-Petersen, o funkcijach glagol'nych pristavok..., a.a.0., S. 332.

80 Isačenko stellt jedoch selber wiederholt Abweichungen von dieser Regel fest. "In Einzelfällen sind sekundäre Bildungen des imperfektiven Aspekts möglich: russ. naigrat'sja - naigryvat'sja, nastojat'sja - nastaivat'sja." A.V. Isačenko, Grammatičeskij stroj..., a.a.O., S. 246 . Klaus Koszinowski- 9783954793105 
spielen hervorgeht, drückt das Präfix za- in zaorati und zažeti ebenso deutlich den Beginn der Handlung aus wie in zaveslati bzw. zapevati. Das sekundäre Imperfektiv kann daher meiner Meinung nach kein Kriterium für die Bestimmung der Aktionsart sein. Eine grosse Anzahl von Aktionsartbildungen könnte durch dieses Kriterium nicht erfasst werden. Die Mehrzahl der Sprachforscher argumentiert in diesem Sinne und lehnt daher das Vorhandensein oder Fehlen eines sekundären Imperfektivs als Kriterium zur Bestimmung der Aktionsart ab. Zu diesen Forschern zählen u.a. Maslov ${ }^{81}$, Bondarko $^{82}$, Sekaninová 83 und Ivanova 84 .

Es muss jedoch eingeräumt werden, dass zu Aktionsartbildungen, die mittels der Präfigierung gebildet und dadurch zugleich perfektiviert worden sind, wesentlich weniger sekundäre Imperfektiva gebildet sind als $z u$ lexikalischen oder rein aspektalen Bildungen. Nicht zuletzt dieser Umstand führte nach Meinung von Maslov dazu - die Situation hinsichtlich der sekundären Imperfektiva ist im Russischen ähnlich wie im Serbokroatischen -, dass Isačenko in der Abwesenheit des sekundären Imperfektivs einen Beweis für das Vorhandensein einer Aktionsart erblickte. Auch wenn in zahlreichen Fällen bei Fehlen des sekundären Imperfektivs eine Aktionsart konstatiert werden kann, kann meines Erachtens nicht von diesem formalen Kriterium ausgegangen werden, da in ebenso vielen Fällen das Gegenteil nachgewiesen werden kann. So muss bei der Bestimmung der Aktionsarten allein von semantischen Kriterien ausgegangen werden, und zwar von den spezifi-

81 Maslov verbindet die Aktionsarten der abgeleiteten Verben nicht mit der "Aspektdefektheit (vidovaja defektivnost'). Ju. S. Maslov, Morfologija glagol'nogo vida..., a.a.0., s. 7 . Für ihn ist bei der Bestimmung der Aktionsarten neben einer Bedeutungsmodifizierung in bezug auf den Handlungsablauf eine spezifisch gerichtete wortbildende Aktivität wichtig (z.B. werden von statalen Verben beschränkt-dauernde gebildet: russ. postojat' 'eine Zeitlang stehen', poplakat' 'eine Zeitlang, ein wenig weinen' u.a., aber keine semelfaktiven, und von multiplikativen - gerade semelfaktive: russ. kol'nut' 'stechen', liznut' 'lecken' u.a.) und u.a. "bestimmte Besonderheiten des syntaktischen Gebrauchs"; ebenda, S. 6.

82 A. V. Bondarko, Rez.: zu A. V. Isačenko, Grammatičeskij stroj... In: Vja 1962, 5, S. 140.

83 E. Sekaninová, Miesto prefixácie..., a.a.0., S. 24.

84 Ivanova bemerkt, dass bei Anwendung dieses Kriteriums in der bulgarischen Sprache von einer ganzen Reihe grundlegender Aktionsarten nicht gesprochen werden könnte, da hier die sekundäre Imperfektivierung ein generalisierter Prozess ist. K. Ivanova, Desemantizacijata na glagolnite predstavki..., a.a.0., S. 15 . 
fischen Bedeutungsmodifikationen, die das Präfix der Bedeutung des Ausgangsverbs verleiht.

5. Die rein perfektivierende Funktion

Unter der reinen Präfigierung ist zu verstehen, dass mit Hilfe von Verbalpräfixen eine rein aspektale Beziehung zwischen dem unpräfigierten imperfektiven Verb und dem präfigierten perfektiven Verb hergestellt wird. Verbalpräfixe, die lediglich den Aspekt des Ausgangsverbs ändern, seine lexikalische Bedeutung aber unverändert lassen, werden grammatische Präfixe, rein aspektale Präfixe, reihende 85 oder leere Präfixe 86 genannt.

Von der Möglichkeit, dass Präfixe ihre ursprüngliche räumliche Bedeutung teilweise oder ganz verlieren können und zu einem Zeichen der Perfektivierung der Handlung werden, schreibt schon Brugmann 87 . Diese Auffassung vertreten, auch wenn sie nicht die einzig anerkannte ist, mit kleineren oder grösseren Abwandlungen eine grosse Anzahl von Wissenschaftlern, von denen nur einige genannt werden sollen, so z.B. Stender-Petersen 88 , Dostál 89 , Němec 90 , Koschmieder 91 , słoński 92 , Bogusławski 93 , Tichonov' 94 ,

85 J. Poldauf, Spojováni s předponami..., a.a.0., s. 49 - 65 .

$86 \mathrm{M}$. Vey, Les préverbes "vides" en tchèque moderne. In: RES XXIX, 1952 , S. 82 .

87 K. Brugmann, B. Delbrück, Grundriss..., a.a.0., s. 147.

88 A. I. Stender-Petersen, O funkcijach glagol'nych pristavok..., a.a.0., S. 332 . Für den Autor ist das sekundäre Imperfektiv in der Mehrzahi der Fälle ein Beweis für das Vorhandensein der rein aspektalen Beziehung zwischen den Verben eines Aspektpaars.

89 A. Dostál, Studie o vidovém..., a.a.0., S. 255.

90 I. Němec, Vłyvojové problémy..., a.a.0., s. 317.

91 E. Koschmieder, Nauka o aspektach czasownika polskiego w zarysie. Próba syntezy. Wilno 1934, S. 17. Zu einem perfektiven Verb vom Typ poln. zrobić braucht seiner Meinung nach wegen der Existenz der imperfektiven Dublette robić kein sekundäres Imperfektivum gebildet $z u$ werden. Vgl. dazu auch E. Koschmieder, Zeitbezug..., a.a.0., s. $28 \mathrm{ff}$. u. 37.

92 st. Słoński, Funkcje prefiksów werbalnych w jezyku starosłowiańskim (starobułgarskim). Warszawa 1937, S. 5.

93 A. Bogusławski, Prefiksacja czasownikowa..., a.a.0., S. 113; derselbe, Prefiksalne pary aspektowe a semantyka prefiksalna czasownika rosyjskiego. In: SIOr IX, I960, S. 139 - 175.

94 A. N. Tichonov, Zametki o vtoričnoj imperfektivacii..., a.a.0., S. 19; derselbe, Cistovidovye pristavki v sisteme russkogo vi-

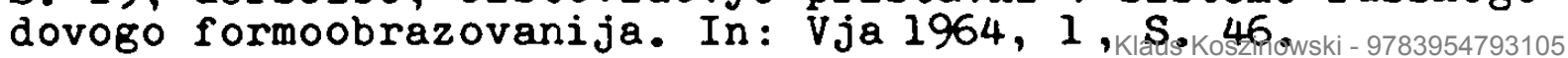


Vinogradov 95 , Pauliny 96 , Horecký9 97 , Peciar ${ }^{98}$, Sekaninová99, Ivanova 100 , Ugrinova-Skalovskal01, Grickat ${ }^{102}$.

So ändern z.B. in den Verben izjednačiti 'gleichmachen', iznicati 'aufkeimen', islužiti 'ausdienen', napisati 'schreiben, aufschreiben', naduvati 'aufblasen', narušiti 'zerstören', zamiriti 'beschwichtigen', zasaditi 'anpflanzen' die Präfixe iz-, na-, za- lediglich den Aspekt, fügen aber keine neue Bedeutung hinzu. Wie die angefühten Beispiele zeigen, wird der Begriff der "rein aspektalen Präfixe" in dieser Arbeit weiter gefasst, als dies häufig der Fall ist. Unter diesen Begriff werden nicht nur Präfixe subsumiert, die im abgeleiteten Verb keinerlei Eigenbedeutung haben, wie z.B. in islužiti, narušiti und zamiriti, sondern auch Präfixe, die in gewisser Hinsicht eine lexikalische Bedeutung im abgeleiteten Verb haben, die mit der des imperfektiven Verbs kongruiert, wie z.B. in iznicati, napisati und zasaditi. Mit diesem weiter gefassten Begriff der rein aspektalen Präfixe befinden wir uns in Ubereinstimmung mit den Auffassungen von Vey, Poldauf, Kopečný und Grickat.

Ausserdem sei hervorgehoben, dass davon ausgegangen wird, dass die Resultativität ein Merkmal der Perfektivität im Aspektpaar ist. Autoren, die die Resultativität nicht für ein Merkmal der Perfektivität halten, schliessen die Möglichkeit der Bildung von Aspektkorrelationen mittels der Präfigierung aus. Diese halten rein aspektale Präfixe für Träger der "allgemeinen resul-

95 V. V. Vinogradov, Sovremennyj russkij jazyk..., a.a.0., s. 312.

96 E. Pauliny, Odvodzovanie slovies podl'a slovesného vidu.

In: Slovo a tvar IV, $1950, \mathrm{~s} .91$.

97 J. Horecký, O tvoreni slovies..., a.a.0., s. 148.

98 S. Peciar, Funkcie slovesnej predpony na-..., a.a.0., S. 148; derselbe, $K$ problému čisto vidových predpon. In: JC XIX, 1968, S. 216. Kriterium für die rein grammatische Aspektfunktion ist für ihn das Fehlen einer sekundären imperfektiven Form.

99 E. Sekaninová, Miesto prefixácie..., a.a.0., S. 33; dieselbe, Analýza sémantiky komponentov $v$ predponovom slovese. In: Kapitoly ze srovnávaci mluvnice ruské a ceské. III. Praha 1968, S. 232 - 286; dieselbe, Strukturálno-sémantická analýza slovies s predponou na- v slovenčine. In: JC XXI, 1970, S. $26-$ 35; dieselbe, Slovesná predpona do-..., a.a.0., S. 193 - 199.

$100 \mathrm{~K}$. Ivanova, Desemantizacijata na glagolnite predstavki..., a.a.0., S. 33 .

101 R. Ugrinova-Skalovska, Značenjata na glagolskite prefiksi..., a.a.0., S. 27 .

102 I. Grickat, Prefiksacija kao sredstvo..., a.a.0., S. 185 223; dieselbe, Sta daje za proučavanje... 126 . 
tativen" Aktionsart ${ }^{103}$. Diese Linguisten sehen nur die Suffigierung als Mittel zur Bildung der reinen Aspektkorrelation an, d.h. ihrer Meinung nach kann nur durch das Mittel der Suffigierung die semantische Identität, die zwischen den beiden Gliedern eines Aspektpaars vorherrschen muss, realisiert werden ${ }^{104}$. Nach dieser Auffassung wären nur Korrelationen wie izvršiti - izvršivati 'ausführen' reine Aspektpaare. Vertreter dieser Auffassung sind z.B. Kartsevski 105 , Maslov ${ }^{106}$, Isačenko 107 , Kuryłowicz ${ }^{108}$. Es erhebt sich nun die Frage, ob es irgendwelche Kriterien gibt, nach denen man sich bei der Beurteilung der rein perfektivierenden Funktion des Präfixes richten kann. Da es nämlich in den slavischen Sprachen keine speziellen Aspektpräfixe gibt - wie etwa im Gotischen 109 _, also ein und dasselbe Präfix ein imperfektives Verb entweder lediglich perfektivieren oder aber perfektivieren und gleichzeitig eine Anderung seines lexikalischen Gehalts hervorrufen kann, wie etwa za- in zakretati 'ein-, umdrehen', bzw. perfektivieren und gleichzeitig eine innere Modifizierung seiner Handlung bewirken kann, wie etwa za- in zaorati 'anackern',

103 A. V. Isačenko, Grammatičeskij stroj..., a.a.0., S. 298; Ju. S. Maslov, Rol' tak nazyvaemoj perfektivacii i imperfektivacii v processe vozniknovenija slavjanskogo glagol'nogo vida. In: Issledovanija po slavjanskomu jazykoznaniju, Moskva 1961, S. $165 \mathrm{ff}$.

104 Wie Tichonov für das Russische nachgewiesen hat, sind jedoch auch Glieder der suffixalen Aspektkorrelation semantisch nicht immer identisch. Allgemein kann die semantische Identität etwas häufiger bei Aspektpaaren konstatiert werden, die mittels der Suffigierung gebildet werden als bei denen, die mittels der Präfigierung gebildet werden. Ein prinzipieller Unterschied besteht also zwischen der Aspektkorrelation, die mittels reiner Aspektpräfixe realisiert wird, und der, die mittels der Suffigierung realisiert wird, nicht. Vgl. A. N. Tichonov, Cistovidovye pristavki..., a.a.0., s. 45 u. 52.

$105 \mathrm{~S}$. Kartsevski, Etudes sur le système verbal..., a.a.0., S. 496 u. 497.

$106 \mathrm{Ju}$. S. Maslov, Morfologija glagol'nogo vida..., a.a.0., S. 4ff; derselbe, Rol' tak nazyvaemoj..., a.a.0., S. i6?.

107 A. V. Isačenko, Die russische Sprache..., a.a.0., S. 359; derselbe, Grammatičeskij stroj..., a.a.o., s. 172; derselbe, Slovesný vid, slovesná akce a obecný charakter slovesného děje. In SS XXI, I960, S. 12.

108 Kuryłowicz hält neben Suffixen in geringem Umfange auch Präfixe für formale Mittel zur Bildung der Aspektkorrelation. J. Kuryłowicz, Pochodzenie..., a.a.0., S. 572.

109 Das Präfix ga-, das die grundlegende Bedeutung des Verbs nicht ändert, dient lediglich zur Perfektivierung. J. Kuryłowicz, Pochodzenie..., a.a.0., S. 572 
ist die Bestimmung der rein perfektivierenden Funktion eines Präfixes nicht immer einfach.

Vey unterscheidet zwei Grundsätze, nach denen man sich bei der Beurteilung des rein perfektivierenden Präfixes richten kann, und zwar den der Analogie und den der Subsumption 110 .

Unter dem Grundsatz der Analogie versteht Vey, dass sich bestimmte rein perfektivierende Präfixe mit imperfektiven Verben verbinden können, die unter einen bestimmten gleichgearteten Sachbereich fallen ${ }^{11}$. So werden Verben, die unter den Sachbereich des "Schreibens, Zeichnens u. ä." fallen, mit dem Präfix na- präfigiert: napisati 'schreiben', nacrtati 'zeichnen'. Tätigkeitsbezeichnungen, die unter den Sachbereich des "Tötens" fallen, werden mit dem Präfix za-präfigiert, so z.B. zaklati 'erstechen', zadaviti und zagušiti 'erwürgen'. Verben, die unter den Sachbereich des "Auftragens einer Schicht auf eine Oberfläche" fallen, werden mit dem Präfix na- präfigiert, so z.B. namazati 'beschmieren', nasapuniti 'einseifen', našminkati 'schminken'll2.

Unter dem der Subsumption versteht Vey, dass ein imperfektives Verb, das lediglich perfektiviert werden soll, mit einem Präfix versehen wird, dessen lexikalischer Inhalt bereits in dem des betreffenden imperfektiven Verbs enthalten ist. "Die Vorsilbe", wie Kopečný bemerkt, "beinhaltet dabei eine mehr oder minder bestimmte Vorstellung, unter die sich der konkrete Inhalt des betreffenden Imperfektivums gut subsumieren lässt"ll3. So steht z.B. dem Inhalt des Präfixes iz-, das die Bedeutung "aus, heraus, (eine Bewegung) aus der. Innern heraus" enthält, durchaus mit dem Inhalt der Verben bljuvati 'brechen' und nicati 'hervorkeimen' in Einklang. Mit dem Inhalt des Präfixes na- in der Bedeutung von

110 M. Vey, Les préverbes "vides"..., a.a.0., S. 82 - 107.

111 Bogusławski weist übrigens nach, dass schon Agrell auf diesen Sachverhalt hingewiesen hat. A. Bogusławski, Prefiksacja czasownikowa..., a.a.0., S. 113 .

112 Bogusławski gibt einen Uberblick über solche typischen Sachbereiche im Russischen. Verben, die unter den Sachbereich des Schreibens bzw. Tötens fallen, werden im Russischen ebenfalls mit den Präfixen na- bzw. za- verbunden. Bei einer eingehenden Gesamtanalyse der serbokroatischen präfigierten Verben liessen sich sicherlich noch einige andere sachbereiche feststellen, die in beiden Sprachen das gleiche Präfix erfordern. A. Bogusławski, Prefiksacja czasownikowa..., a.a.0., S. Il3ff.

113 F. Kopečný, Bemerkungen zu zwei Arbeiten..., a.a.0., s. 113. 
"(einen Gegenstand) auf (den anderen stellen)" stimmt durchaus der Inhalt des Verbs nizati 'auffädeln, aufreihen' überein und mit der Bedeutung des Präfixes za- "von allen Seiten (umfassen)" steht die Bedeutung des Verbs rubiti 'säumen, einsäumen' in Einklang.

Das Problem der Präfixe mit rein perfektivierender Funktion wird später von dem tschechischen Linguisten Poldauf aufgegriffen und weiter bearbeitet ${ }^{114}$. Poldauf räumt prinzipiell die Möglichkeit ein, dass unpräfigierte Verben mittels eines Präfixes perfektiviert werden können, ohne dass durch das Präfix eine semantische Anderung hervorgerufen wird ${ }^{15}$. Er unterscheidet $z w i s c h e n$ "leeren" und "reihenden" Präfixen, wobei es sich um leere Präfixe dann handelt, wenn die Bedeutung des Präfixes nicht mit der des Verbs vereinbar ist, ( $z . B$. ist das Präfix pro- in čech. promluvit 'sprechen, an-' ein leeres Präfix, weil pro- ein Durchdringen ausdrückt, Durchdringen und Sprechen aber nicht miteinander vereinbar sind) und um "reihende" dann, wenn die Bedeutung des Präfixes mit der des Verbs kongruiert, es also dem Verb keine neue Bedeutung hinzufügt ${ }^{116}$ (z.B. fügt das Präfix pro- 'durch' in čech. pro-vrtat 'durchbohren' dem Verb keine neue Bedeutung hinzu, es hebt nur eine bezeichnende Charakteristik hervor). Bei den reihenden Präfixen ist die Bedeutung klar, es ist bekannt, warum sie zur Perfektivierung herangezogen wurden. Bei der Präfigierung anderer Verben mit ähnlicher Bedeutung wird auf dasselbe Präfix zurückgegriffen, das sie in eine abstrakte semantische Kategorie einführt, sie unter eine allgemeinere Bedeutung reiht und deshalb von Poldauf als "reihend" bezeichnet wird"17. So reiht z.B. das Präfix na- die Verben rasti 'anwachsen', dolaziti 'steigen' und ticati 'anschwellen' unter die allgemeinere Bedeutung des 'Anschwellens', wo narasti, nadolaziti, naticati nur besondere Fälle sind.

Bei den leeren Präfixen ist es vom heutigen standpunkt der Sprachentwicklung aus unklar, warum gerade sie zur Perfektivierung herangezogen wurden; sie sind unmotiviert.

Die Zweiteilung der rein aspektalen Präfixe in reihende und

114 Poldauf weist darauf hin, dass er sich mit genau derselben Frage, wie sie Vey darlegt, schon im Jahre 1942 befasst hat. I. Poldauf, Spojování s předponami..., a.a.0., s. 51 .

115 Ebenda, S. 50.

116 Ebenda, S. 50.

117 Ebenda, S. 5lff. 
leere bringt in Hinblick auf ihre Funktion keine neuen Gesichtspunkte. Global betrachtet sind die Präfixe, die nach der Konzeption von Vey Präfixe mit rein perfektivierender Funktion sind, es auch nach der von Poldauf. So hält Kopečný zwar die Unterscheidung zwischen reihenden und leeren Präfixen in gewissem Sinne für berechtigt, betont aber, dass auch die letzteren lediglich perfektivierend sind. Ausserdem ist nach Ansicht Kopečnǵs die für grammatische Zwecke belanglose Grenzziehung zwischen reihenden und leeren Präfixen wegen der meist fehlenden objektiven Anhaltspunkte schwierig ${ }^{118}$.

Meiner Ansicht nach stellt die Einführung des Begriffs der reihenden Präfixe in den Komplex der Präfixe mit rein perfektivierender Funktion prinzipiell eine positive Erweiterung des Bereichs der reinen Perfektivierung mittels der Präfigierung dar, da mit diesem Begriff tatsächlich zahlreiche Verbalpräfixe erfasst werden können, die trotz ihrer konkreten Bedeutung in Verbindung mit dem Ausgangsverb eine unzweifelhaft rein perfektivierende Funktion ausüben. Es kann also gezeigt werden, dass sich die Ausübung der rein perfektivierenden Funktion nicht nur auf Präfixe beschränkt, die im abgeleiteten Verb keine konkrete Bedeutung aufweisen.

Für Poldauf hebt das reihende Präfix das charakteristische Merkmal der Verbbedeutung heraus, wodurch es semantisch redundant wird und im abgeleiteten Verb lediglich eine rein perfektivierende Funktion ausübt wie auch das leere Präfix. In bezug auf die Affinität jedoch wird ein Unterschied zwischen den reihenden und leeren Präfixen festgestellt werden können. Es wäre denkbar, dass sich die reihenden Präfixe ähnlich verhalten wie die lexikalischen, da sowohl die lexikalischen als auch die reihenden Präfixe konkreten Inhalt haben, wobei allerdings durch erstere ein neues Bedeutungselement dem Inhalt des Simplex hinzugefügt wird, während bei letzteren lediglich eine bestimmte Komponente des Simplexinhalts noch einmal herausgehoben wird.

Die Einführung des Begriffs der reihenden Präfixe in den Bereich der Präfixe mit rein perfektivierender Funktion bringt aber auch einige Schwierigkeiten mit sich, die in der Abgrenzung zu den leeren und lexikalischen Präfixen liegen. Wegen fehlender objektiver Kriterien kann es zu subjektiven Entscheidungen hinsichtlich der Klassifizierung dieser Präfixe kommen.

118 F. Kopečný, Bemerkungen zu zwei Arbeiten..., a.a.0., S. 113. 
Die Möglichkeit einer Realisierung der reinen Aspektbeziebung zwischen dem imperfektiven und perfektiven Verb mittels Präfigierung erkennt auch die jugoslavische Linguistin Grickat 119 an. Dabei müssen ibrer Meinung nach die beiden folgenden grundlegenden Momente beachtet werden. "I) Zur reinen Perfektivierung des Simplex kann es dank einer bestimmten Koinzidenz zwischen der lexikalischen Bedeutung des Simplex und des ausgewählten Präfixes kommen. 2a) Bei der reinen Perfektivierung durch ein gewisses Präfix kommt es vor, dass durch diesen Akt nur ein Bedeutungssegment des Simplex erfasst wird, während - um das gleiche Ziel zu erreichen - für ein anderes Segment ein anderes Präfix notwendig ist... b) Bei der reinen Perfektivierung wird durch diesen Akt nur ein Bedeutungssegment des Präfixes erfasst" ${ }^{120}$ (aus dem Original übersetzt).

Hinsichtlich der Auffassung der Realisierung der reinen Perfektivierung mittels Präfixe, durch die eine semantische Koinzidenz von Präfix und Simplex hergestellt werden kann, steht sie in Einklang mit denen von Vey, Poldauf und Kopečný. Das Simplex versteht die Autorin als polysemantische Einheit, mit potentiellen, häufig aber nicht ausgedrückten Bedeutungsnuancen. Jedem dieser nicht ausgedrückten Bedeutungsnuancen des Simplex räumt sie das Recht auf eine eigene präfixale Perfektivierung ein ${ }^{12 l}$, was z.B. beim Verb 'roniti' mit den Bedeutungen 'sich unter der Wasseroberfläche befinden' und '〈immer tiefer〉 unter die Wasseroberfläche tauchen' mit dem Präfix za- bei der ersten Bedeutung und mit $u$ - bei der zweiten geschieht ${ }^{122}$. Der Grund für die Bildung von mehreren rein aspektalen perfektiven Korrelaten zum Simplex wird darin gesehen, dass auf diese Weise wenigstens bei den perfektiven $A b l e i t u n g e n$ verschiedene Bedeutungsnuancen ausgedrückt werden können, die im Simplex unausgedrückt bleiben ${ }^{123}$.

Zum Beweis der Existenz der reinen Präfigierung wurde immer wieder versucht, objektive Kriterien ins Feld zu führen, so das

119 I. Grickat, Prefiksacija kao sredstvo..., a.a.0., S. 185 - 223; dieselbe, Sta daje za proučavanje..., a.a.0., S. 119 - 126.

120 I. Grickat, Prefiksacija kao sredstvo..., a.a.0., s. 193. 121 I. Grickat, Sta daje za proučavanje..., a.a.0., s. 120.

122 Ebenda, S. 120.

123 1. Grickat, Prefiksacija kao sredstvo...., a.a.0., s., 197. F. Kopečný, Dvě nové práçe prostě vidových prededponách $v$ čštinè. In: SS XVII, 1956, s. 30 . 
Fehlen eines sekundären Imperfektivs ${ }^{124}$. Wenn also zu pisati napisati kein sekundäres Imperfektiv gebildet wird, läge demnach reine Perfektivierung vor und umgekehrt: wenn es z.B. zu koristiti - iskoristiti 'ausnutzen' das sekundäre Imperfektiv iskorišćavati gibt, könne kein reines Aspektpaar vorliegen, denn, so wird argumentiert, wenn sich die beiden Glieder des reinen Aspektpaars genau decken, eine in sich abgeschlossene vollständige Aspektkorrelation darstellen, sei die Bildung eines sekundären Imperfektivs überflüssig ${ }^{125}$.

Ein Blick auf die Situation in der makedonischen und bulgarischen Sprache zeigt jedoch, dass das Vorhandensein oder Fehlen eines sekundären Imperfektivs kein zuverlässiges Kriterium für eine Bewertung der Beziehungen zwischen Simplex und abgeleitetem präfigierten Verb sein kann. Im Makedonischen und Bulgarischen gibt es zu fast jedem perfektiven präfigierten Verb ein sekundäres Imperfektiv ${ }^{126}$, besonders im Bulgarischen kann dieser Vorgang als generalisiert betrachtet werden 127 .

Im Bulgarischen können zur Feststellung der Beziehungen zwischen Simplex, primärer und sekundärer Ableitung auch syntaktisch

124 Hier können vor allem angeführt werden: Stender-Petersen, Koschmieder, Peciar und in beschränktem Masse auch Kopečny. A. I. Stender-Petersen, 0 funkcijach glagol'nych pristavok..., a.a.0., S. 332; E. Koschmieder, Nauka o aspektach..., a.a.0., S. $230 ;$ S. Peciar, Funkcie slovesnej predpony na-..., a.a.0., S. 148. Kopečný ist der Auffassung, dass zu präfigierten Verben mit lediglich perfektivierendem Präfix kein sekundäres Imperfektiv gebildet zu werden braucht, da es sich bei dem präfigierten Verb lediglich um die perfektive Parallele zu dem imperfektiven unprafigierten Verb handelt. Er räumt jedoch ein, dass zu Verben mit diesen Präfixen bisweilen "unorganische" sekundäre Imperfektiva auftreten können. Ein sekundäres Imperfektiv erwartet er jedoch bei Bildungen mit dem reihenden Präfix. Aber auch bei präfigierten Verben mit dem reihenden Präfix können, wie er bemerkt, Ausnahmen vorkommen. Wie man sieht, lassen sich aus dem Vorhandensein oder Fehlen des sekundären Imperfektivs keine allgemeingültigen Schlüsse für die Bestimmung der rein perfektivierenden Funktion des Präfixes ziehen. F. Kopečný, Dvě nové práce..., a.a.0., S. 30; derselbe, Bemerkungen zu zwei Arbeiten..., a.a.o., s. ils.

125 Ebenda, S. 114.

126 R. Ugrinova-Skalovska, Značenjata na glagolskite prefiksi..., a.a.0., S. 11 .

$127 \mathrm{~K}$. Ivanova, Desemantizacijata na glagolnite predstavki..., a.a.0., S. 28. Die Tendenz zur Generalisierung der Bildung des sekundären Imperfektivs existiert nach ihrer Meinung in allen Slavinen. Vgl. K. Ivanova, Razvoj $i$ upotreba na vtoričnite nesvürš̀eni glagoli v novobŭlgarskija knižoven ezik. In: Izvestija na Instituta za bulgarski ezik pri BAN XV, Sofija 1968, S. 55. 
funktionelle Kriterien verwendet werden. In dem Fall, dass zwischen Simplex und primärer Ableitung eine Aspektkorrelation besteht, kann die sekundäre Ableitung, d.h. das sekundäre Imperfektiv, nur zum Ausdruck der iterativen Handlung und des historischen Präsens verwendet werden, nicht jedoch zum Ausdruck des regulären Präsens ${ }^{128}$.

Aber auch dieses Kriterium erweist sich, wie die Autorin einräumt, in zahlreichen Fällen als nicht ganz brauchbar und kann daher nur relativ zur Lösung des Problems beitragen ${ }^{129}$.

Im Serbokroatischen lässt sich das sekundäre Imperfektiv ebenfalls nicht als Beweis für das Vorhandensein von rein aspektalen Beziehungen zwischen Simplex und primärer Ableitung heranziehen, da zu der Mehrzahl der von mir untersuchten präfigierten Verben mit den Präfixen iz-, na-, za-, die u.a. die rein perfektivierende Funktion anzeigen, ein sekundäres Imperfektiv gebildet ist. Es kann vermutet werden, dass sich diese Tendenz auch bei den Verben mit den hier nicht bearbeiteten Präfixen fortsetzt.

Unter den Begriff der rein perfektivierenden Präfixe werden in der vorliegenden Arbeit sowohl "reihende" als auch "leere" Präfixe subsumiert. Die reihenden Präfixe werden im Sinne der Konzeption Poldaufs verstanden, nach der das Präfix lediglich ein charakteristisches Bedeutungsmerkmal des Ausgangsverbs hervorhebt.

Bei der Feststellung der rein perfektivierenden Funktion wird allein von den semantischen Beziehungen ausgegangen, die zwischen den Präfixen und deren entsprechenden Verbbasen herrschen. Reine Aspektkorrelationen liegen nicht nur dann vor, wenn es kein sekundäres Imperfektiv gibt, sondern auch dann, wenn ein solches sekundäres Verb vorhanden ist ${ }^{130}$, unter der Voraussetzung, dass es völlig synonym mit dem einfachen unpräfigierten Verb ist, wobei die Kriterien zur Ermittlung einer solchen völligen Synonymie den wörterbüchern nicht zu entnehmen sind.

$128 \mathrm{~K}$. Ivanova, Desemantizacijata na glagolnite predstavki..., a.a.0., S. 33 .

129 Ebenda, S. $33 f f$.

130 Die Frage, inwieweit im Serbokroatischen die Tendenz besteht, wie etwa im Russischen, eine der beiden imperfektiven Formen zu verdrängen - im Russischen ist es zumeist das sekundäre Imperfektiv - ist meines Wissens noch nicht eingehend untersucht worden. Grickat konstatiert lediglich, dass es im Serbokroatischen Fälle gibt, dass ein imperfektives Glied langsam verloren gehen kann. I. Grickat, Prefiksacija kao sredstvo..., a.a.0., S. 189. Vgl. für das Russische: A. N. Tichonov, Cistovidovye pristavki..., a.a. . . . S. 47 . 
II. ZUR THEORIE DER WORTBILDUNG

1. Der Begriff der onomasiologischen Kategorie

Die modernen Theorien zur slavischen Wortbildung basieren direkt oder indirekt auf der These des polnischen Linguisten Jan Rozwadowski ${ }^{131}$ von der formalen und semantischen Dichotomie der abgeleiteten und zusammengesetzten Wörter. Diese war nach Meinung von Furdik "ein geeigneter Ausgangspunkt für die Erforschung der Funktionen der zwei grundlegenden Elemente der wortbildenden Struktur: der wortbildenden Basis... und des wortbildenden Formans bei abgeleiteten Wörtern, der zwei wortbildenden Basen bei Komposita"132 (aus dem Original übersetzt).

Dokulil betont in seiner Wortbildungstheorie ${ }^{133}$ die Notwendigkeit, beim Versuch der Aufdeckung des Systems der Lexik das Wort in seiner Komplexität als einen Komplex mit semantischer und formaler Seite 134 aufzufassen. Er weist also auf die grosse Bedeutung hin, die auf der Dialektik der Beziehung von Form und Inhalt für die Kohäsion und Festigkeit des Netzes der wortbildenden Beziehungen beruht, wobei die Bedeutung die primäre Rolle spielt.

Das grundlegende Element der Wortbildungstheorie Dokulils ist der Begriff der onomasiologischen Kategorien ${ }^{135}$, die die Begriffsinhalte generell strukturieren. Er versteht darunter mit anderen Worten "die fundamentalen Umrissstrukturen der Denkinhalte..., die in der gegebenen Sprache eine entsprechende kategorielle (isomorphe) Ausdrucksweise besitzen, die mit den Benennungsarten der Sprache in Einklang stehen und die auch als Grundlage und Grundriss der Benennungen dienen, die durch besondere

131 J. Rozwadowski, 0 dwuczłonowości wyrazów. In: 0 zjawiskach i rozwoju jezyka. Wydanie II, pomnożone. Kraków 1950, S. 143 155.

$132 \mathrm{~J}$. Furdik, o súčasných smeroch slovotvorného výskumu. In: JC XX, 1969, S. 64.

133 M. Dokulil, Tvořeni slov I, S. 179.

134 Horálek zeigt sich in seiner Rezension zu Dokulils Theorie der Wortbildung darüber überrascht, dass die Werke Rozwadowskis nicht im Literaturverzeichnis aufge führt sind. K. Horálek, Rezension zu M. Dokulil, Tvoření slov I. In: RS XXIII, 1964, S. 108.

135 M. Dokulil, Tvoření slov I, S. 29. 
morphologische bzw. syntaktische Mittel verwirklicht werden" 136 .

Die onomasiologischen Kategorien, die ganz von der Form des Wortes bzw. der lexikalischen Einheit abstrahiert sind, stellen in gewisser Weise ein Bindeglied zwischen der aussersprachlichen Erscheinung, die benannt werden soll, und der Sprache dar, die diese Erscheinung auf eine bestimmte Weise ausdrücken soll.

Buzássyová sieht den Vorteil dieses Begriffs in seiner Anwendbarkeit auf die Strukturierung des Inhalts der Benennung überhaupt, d.h. der gesamten Lexik ${ }^{137}$.

Die Struktur der onomasiologischen Kategorie setzt sich aus zwei Elementen zusammen, und zwar aus dem bestimmten Element, das Dokulil die "onomasiologische Basis"138, und dem bestimmenden Element, das er "onomasiologisches Merkmal"139 nennt. Die onomasiologische Basis ordnet die $z u$ benennende Erscheinung in eine bestimmte Begriffsklasse ein, das onomasiologische Merkmal, das differenzierende Merkmal, spezifiziert die Erscheinung im Rahmen dieser Klasse. Eine onomasiologische Struktur ist nur motivierten Benennungen eigen.

Die dichotomische Struktur auf der onomasiologischen Ebene hat ihre genaue Entsprechung auf der wortbildenden Ebene, wo sie sich aus der wortbildenden Basis und dem wortbildenden Suffix des abgeleiteten Wortes zusammensetzt 140 .

Die grundlegenden Bauelemente der onomasiologischen Strukturen sind die Elementarkategorien der Substanz, der Eigenschaft, der Handlung und der Umstandsbestimmung, von denen jede als onomasiologische Basis und als onomasiologisches Merkmal fungieren kann. Die Kategorie der Substanz wird so z.B. bestimmt: 141 1. durch ihre Beziehung zu einem anderen Begriff derselben Kategorie, also der Kategorie der Substanz..., z.B. zastavnik 'Fahnenträger' ;

2. durch die Beziehung zu einem Begriff aus der Kategorie der

136 M. Dokulil, Zur Theorie der Wortbildung. In: WZUL XVII, 1968, S. 207.

137 K. Buzássyová, Rezension zu: M. Dokulil, Tvoření slov I u. II. In: JC XX, 1969, S. 98.

138 M. Dokulil, Tvořeni slov I, S. 29.

139 Ebenda, S. 29.

140 Dokulil ersetzt das Suffix durch den weiteren Begriff "Formans", worunter er die Einheit von wortbildendem Affix, morphologischem Paradigma und lautlicher Alternation versteht. Ebenda, S. 69.

141 Ebenda, S. 32. 
Eigenschaft, 2.B. slepac 'Blinder, blinder Mensch';

3. durch die Beziehung $z u$ einem Begriff aus der Kategorie der Handlung, z.B. izgradilac 'einer, der erbaut';

4. durch die Beziehung zu einem Begriff der Art und Weise- oder Umstandsbestimmung des Grundmerkmals (d.h. der Eigenschaft oder Handlung), z.B. nedeljnik (=nedeljni list) 'Wochenblatt'. Analog werden die Kategorien der Eigenschaft, der Handlung und der Umstandsbestimmung bestimmt.

$\mathrm{Da}$ das in der vorliegenden Arbeit enthaltene Wortmaterial lediglich aus substantivischen Ableitungen von Verbalstämmen besteht, diesen Benennungen also die Kategorie der Substanz, die durch das onomasiologische Merkmal der Handlung bestimmt ist, zugrunde liegt, werden onomasiologische Kategorien, bei denen die Substanz durch andere Merkmale charakterisiert ist, in der weiteren Darstellung der Theorie nicht mehr berücksichtigt.

Während die onomasiologische Basis immer einfach, d.h. nicht zusammengesetzt, ist (sich nur durch den verschiedenen Grad der Verallgemeinerung unterscheidet - z.B. Substanz, lebendes Wesen, Mensch ${ }^{142}$ ), kann das onomasiologische Merkmal sowohl einfach als auch zusammengesetzt sein ${ }^{143}$. Die onomasiologischen Kategorien können nach dem Charakter des onomasiologischen Merkmals weiter differenziert werden.

Die onomasiologische Kategorie des "Trägers" der Handlungsbeziehung ist durch ein einfaches, aber innerlich differenziertes Merkmal charakterisiert. Dokulil trifft hier eine Unterscheidung zwischen der Grundmodifikation und den abgeleiteten Modifikationen. "Die Grundmodifikation dieser Beziehung ist die Beziehung des Handlungsträgers, die bei einer intransitiven Handlung stattfindet; vgl. Ständer = was steht, Läufer = wer oder was läuft. Abgeleitete Modifikationen sind dann: die Beziehung des Agens zu einer Tätigkeit: Lehrer ist dadurch charakterisiert, dass er lehrt; die Beziehung des Mittels zu einer Tätigkeit: Deckel = etwas, was zum Decken dient; die Beziehung des Resultats zu einer Handlung: Heft = was geheftet ist" 144 .

"Alle diese Modifikationen", wie Dokulil ausführt, "die auf einer Differenzierung der Beziehung des Trägers der Handlung

142 Ebenda, S. 29.

143 Ebenda, S. 29.

144 M. Dokulil, Zur Theorie der Wortbildung..., a.a.0., s. 208. 
beruhen, überkreuzen sich untereinander" ${ }^{145}$.

Die Spezifizierung der onomasiologischen Basis innerhalb der verschiedenen Grundkategorien, z.B. bei der Subkategorie des Ortes, die bestimmt wird durch ihre Beziehung $z u$ einer anderen Substanz, einer Eigenschaft, einer Handlung oder Umstandsbestimmung, sowie die Spezifizierung der onomasiologischen Verbindung, z.B. bei der des Mittels zu einem Zweck, die vorkommen kann zwischen den Kategorien der Substanz, die durch die Kategorie der Handlung bestimmt ist (čech. rfpadlo 'Stecheisen') oder durch die Kategorie der Substanz selbst (čech. řepák 'Messer zum Beschneiden von Rüben'), führen $z u$ den komplexen onomasiologischen Kategorien ${ }^{146}$.

Dokulil unterscheidet drei Typen von onomasiologischen Kategorien. Den weiter oben angeführten Grundtypus der onomasiologischen Kategorien, der darauf beruht, "... dass die Erscheinung einer Begriffskategorie nach ihrer unmittelbaren oder auch mittelbaren Beziehung $z u$ einem Element derselben oder einer anderen Begriffskategorie definiert wird"147, bezeichnet Dokulil als Mutationstyp.

Neben dem Mutationstypus unterscheidet Dokulil noch den Transpositionstypus und den Modifikationstypus.

Das Wesen des Transpositionstypus, wobei nur auf die Substantivierung Bezug genommen wird, der eine Sonderstellung innerhalb der onomasiologischen Grundkategorien einnimmt, wird darin gesehen, "...dass hier eine Erscheinung, die man im Einklang mit der widergespiegelten Wirklichkeit normalerweise als ein abhängiges Merkmal auffasst, nun als absolut oder relativ unabhängig betrachtet wird"148. Beim Transpositionstypus kommt es zu keiner Anderung der lexikalischen Bedeutung des abgeleiteten Wortes, sondern lediglich zu einer Anderung der Wortart.

Im Rahmen dieser Arbeit hat der Transpositionstypus grösste Bedeutung bei der Vergegenständlichung der Handlung, also bei der Bildung von Verbalsubstantiven und nomina actionis im engeren Sinne, z.B. istovarivanje/ istovar von ipf. istovarivati/ pf. istovariti 'Ausladen'.

Das Wesen des Modifikationstypus, der im Rahmen der vorlie-

145 M. Dokulil, Tvořeni slov I, S. 35.

146 Ebenda, S. 41.

147 M. Dokulil, Zur Theorie der Wortbildung..., a.a.0., s. 209. 148 Ebenda, S. 209. 
genden Arbeit keine Rolle spielt, beruht darauf, "dass... zum Inhalt des gegebenen Ausgangsbegriffs ein ergänzendes, modifizierendes Merkmal hinzugefügt wird. Zwischen dem der Ableitung zugrunde liegenden Worte und dem abgeleiteten wort besteht dann eine privative Opposition, in der das Grundwort als merkmalloses, das abgeleitete Wort dann als merkmalhaltiges Glied der Opposition auftritt..."149.

2. Verfahren der morphologischen Wortbildung

In diesem Kapitel werden die wortbildenden Verfahren der Suffigierung und der Konversion beschrieben, mit deren Hilfe die onomasiologische Struktur eines bestimmten Begriffsinhalts im Rahmen einer Einwortbenennung realisiert wird urd die bei der $\mathrm{Ab}-$ leitung der Substantive des vorliegenden Materials Verwendung finden.

Durch die onomasiologische Struktur sind zugleich einige Elemente der sie realisierenden Benennung festgelegt, und zwar durch die onomasiologische Basis der grundlegenden und modifizierten onomasiologischen Kategorien der Wortartrahmen des Wortes und durch das onomasiologische Merkmal das Ausgangswort, die wortbildende Grundlage des abzuleitenden Wortes. Wird ein Wort auf der Grundlage einer einzigen Wortbildungsbasis gebildet, so handelt es sich im weitesten Sinne des wortes um ein abgeleitetes wort.

Unter der Ableitung wird ein morphologischer Prozess verstanden, der auf der Bildung von Wörtern beruht, die von bereits vorhandenen Wörtern oder Wortformen mit Hilfe wortbildender Mittel abgeleitet sind.

Die wortbildende Grundlage der Ableitung kann dreierlei Form haben: "sie kanr nämlich sowohl einerseits ein ganzes (ableitendes) Wort sein, andererseits nur ein Teil davon, der sog. wortbildende (Ableitungs-) Stamm, als auch schliesslich eine (ableitende) Wortform"150 (aus dem Original übersetzt).

Bei der Suffigierung und der Konversion, den wortbildenden Verfahren also, die der Bildung der Ableitungen des hier vorlie-

149 Ebenda, S. 209.

150 M. Dokulil, Tvořeni slov I, S. 51. 
genden Materials zugrunde liegen, ist der Ausgangspunkt der Ableitung ein Ableitungsstamm, der immer präfigiert, d.h. von Verben gebildet ist, die bereits ihrerseits mit Hilfe eines Präfixes abgeleitet worden sind.

\section{a) Die Suffigierung}

Die Ableitung mit Hilfe von Suffixen ist sowohl für die slavischen Sprachen im allgemeinen als auch für das Serbokroatische im besonderen sehr typisch, und zwar bei den Nomina, während sie in sehr beschränktem Masse bei Verben zur Geltung kommt.

Das Wesen des wortbildenden Verfahrens der Suffigierung besteht darin, dass an den Ableitungsstamm ein wortbildendes Suffix angehängt wird. Durch das Anfügen des Suffixes an den Ableitungsstamm erhält man den abgeleiteten Stamm, jedoch noch keine neue lexikalische Einheit. "Die Bildung des Wortes als neue lexikalische Einheit wird erst durch die grammatische Formierung dieses Wortes als Vertreter einer bestimmten Wortart vollendet, indem man es innerhalb dieser Wortart zum bestimmten Paradigma einordnet" ${ }^{151}$ (aus dem Original übersetzt). Das Suffix bestimmt jedoch häufig von vornherein das Paradigma oder grenzt wenigstens mehr oder weniger eng seine Auswahl ab. Wenn man z.B. vom Verb istražiti 'untersuchen' ein neues Wort mit der Bedeutung des Ausführenden einer Handlung mit dem Suffix -nik- bildet (istražnik 'einer, der untersucht'), dann ist dadurch schon das Paradigma des abgeleiteten Wortes und damit auch die morphologische Kategorie des Genus (in diesem Fall des maskulinen) vorherbestimmt.

Das Paradigma ist mit dem stammbildenden Suffix häufig derart eng verbunden, dass im Sprachbewusstsein die beiden Elemente gewöhnlich gar nicht unterschieden werden. In der Praxis wird vom wortbildenden Suffix gesprochen, das in der Form des Nominativs (bzw. Infinitivs) angeführt ist ${ }^{152}$. Die eigentlich wortbildende Rolle des Paradigmas tritt z.B. bei der Bildung von wörtern mit Konversion deutlicher hervor als bei der mit Suffigierung ${ }^{153}$.

Das Suffix weist manchmal - vor allem in Verbindung mit dem Paradigma - auf eine bestimmte Mutations-, Transpositions- oder auch Modifikationskategorie hin. Das Suffix -telj weist im Serbo-

151 Ebenda, S. 54.

152 Ebenda, S. 57.

153 Ebenda, S. 57. 
kroatischen wie im Tschechischen ${ }^{154}$ eindeutig auf die Zugehörigkeit des gegebenen Begriffs zur Klasse von Personen, die eine bestimmte Tätigkeit ausüben (izgonitelj 'einer, der austreibt'), im Sinne der onomasiologischen bzw. wortbildenden Kategorie der nomina agentis.

Die Mehrzahl der Suffixe weist jedoch nicht in eindeutiger Weise auf eine bestimmte onomasiologische bzw. wortbildende Kategorie, sie sind mehrdeutig. So weisen z.B. Suffixe wie -ač und $-1(0)$ einerseits auf Personen, die eine Handlung ausüben und zur onomasiologischen bzw. wortbildenden Kategorie der nomina agentis gehören, und andererseits auf Sachen, die zur Ausübung einer Tätigkeit dienen und als solche in die onomasiologische bzw. wortbildende Kategorie der nomina instrumenti eingeordnet werden, so z.B. došaptač 'einer, der zuflüstert' und izbijač 'Stosseisen', naklapalo 'einer, der plaudert' und nabadalo 'Pfrieme'.

b) Die Konversion

Uber das Wesen des Wortbildungsvorgangs der Konversion gehen die Ansichten der Forscher heute noch auseinander. Es wird hier nicht auf die verschiedenen Ansichten der Forscher zum Begriff der Konversion eingegangen, sondern der Bearbeitung des Materials die Auffassung zu diesem Wortbildungsvorgang von Dokulil zugrunde gelegt, die auf der Bearbeitung dieses Problems in den slavischen Sprachen beruht und konsequent die Ansichten Smirnickijs 155 fortsetzt. Die Einbeziehung der slavischen Sprachen in die Erörterung des Wesens der Konversion bringt eine wesentliche Erweiterung der Auffassung dieses Begriffs mit sich, der ursprünglich am englischen Sprachmaterial erarbeitet wurde und dessen Wesen allein in der Anderung der Wortart gesehen wurde ${ }^{156}$.

Dokulil definiert den Begriff der Konversion folgendermassen: "Wir verstehen also die Konversion (im genetischen Sinne) als Bildung eines neuen wortes auf der Basis eines in der Sprache schon existierenden ohne seinen stammbildenden Umbau, d.h. allein

I54 Ebenda, S. 61.

155 A. I. Smirnickij, Tak nazyvaemaja konversija i čeredovanie zvukov $v$ anglijskom jazyke. In: Inostrannye jazyki $v$ škole $1953,5,5.21-31$; derselbe, Po povodu konversii v anglijskom jazyke. In: Inostrannye jazyki v škole 1954, 3 , S. $12-24$.

156 M. Dokulil, Zur Frage der Konversion und verwandter Wortbildungsvorgänge und -beziehungen. In: TLP III, 1968, S. 215. 
durch die Anderung seines Paradigmas oder - wie wir sagen - durch die Anderung seiner morphologischen Charakteristik"157 (aus dem Original übersetzt). An anderer Stelle ergänzt er die gegebene Definition durch den Hinweis, "...dass der Paradigmawechsel von Lautalternationen begleitet werden kann, gleichgültig, ob sie phonologisch abhängig sind oder nicht"158.

Unter der Konversion wird also kein blosser Funktionswechsel ein und desselben Wortes verstanden, sondern die tatsächliche Entstehung eines neuen Wortes als lexikalisch-grammatische Einheit. Die Konversion, die eindeutig der morphologischen Ebene angehört, ist ein Mittel der Wortbildung, das keine spezifischen wortbildenden Affixe zur Bildung eines neuen Wortes heranzieht, sondern das als einziges wortbildendes Mittel den Wortart- bzw. Paradigmawechsel verwendet, der damit die Funktion eines selbständigen Formans ausübt.

Es wird nun noch kurz auf die Frage der Wechselbeziehung von Konversion als einem wortbildenden Mittel und Transposition als einem Typ der onomasiologischen Kategorie - wobei in diesem Rahmen nur auf Substantive Bezug genommen wird - eingegangen. Es besteht nach Dokulil 159 zumindest die Tendenz, dass die Konversion der Realisierung der Wortarttransposition auf der morphologischen Ebene den Vorzug gibt und umgekehrt, dass die Transposition ihren adäquaten Ausdruck in der Konversion findet. Anderseits wird aber die Wortarttransposition nicht nur durch Konversion, sondern auch insbesondere durch suffigierung realisiert. In dem vorliegenden Material werden die Verbalsubstantive und ein grosser Teil der nomina actionis im engeren Sinne, die als Resultat des Prozesses der Nominalisierung des Verbs entstehen, mittels Suffigierung gebildet, so z.B. izgonjenje zu izgoniti 'Hinaustreiben', izrinuce zu izrinuti 'Hinauswerfen', nalivak zu naliti 'Anguss'.

Von den in dieser Arbeit behandelten von präfigierten Verben abgeleiteten Substantiven wird nur ein Teil der nomina actionis im engeren Sinne sowie ein Teil der nomina instrumenti, nomina loci und nomina resultativa mittels Konversion abgeleitet, wobei letztere jedoch durch semantische Anderung aus nomina actionis im engeren Sinne entstehen, wie z.B. istok 'Herausfliessen', istovar 'Ausladen', zatak 'Stöpsel', nagib 'Abhang', izrez 'Ausschnitt'.

157 M. Dokulil, Tvořeni slov I, S. 63.

158 M. Dokulil, Zur Frage der Konversion..., a.a.0., s. 215.

159 Ebenda, S. 224ff. u. $234 \mathrm{ff}$. 
Die Konversion wechselt in diesen Fällen den Wortartrahmen des Wortes aus, wobei der lexikalische Inhalt des Wortes derselbe bleibt.

Der Wortartwechsel wird bei einer Reihe von nomina actionis im engeren Sinne, nomina instrumenti, nomina loci und nomina resultativa von Lautalternationen begleitet. Es handelt sich dabei um Alternationen von Konsonanten und Vokalen.

Alternationen bei Konsonanten:

k//č doskok zu doskočiti 'Herbeispringen', iskorak zu iskoračiti

'Schritt vorwärts oder zur Seite'

$k / / c ́$ isek $z u$ iseći 'Ausschnitt', istok $z u$ isteći 'Herausfliessen', narok zu nareći 'Schicksal'

$\mathrm{g} / / \check{z}$ izlog zu izložiti 'Schaufenster', nalog zu naložiti 'Anordnung, Auftrag'.

Alternationen bei Vokalen:

o//e ispon zu ispeti 'Hervorwölbung', narok zu nareći 'Schicksal' o//i izbor zu izbirati 'Wahl', izvor zu izvirati 'Quelle' oj//i naboj zu nabiti 'gestampfte Erde; Gegenstand zum Stampfen', napoj zu napiti 'Getränk'

$\circ j / / a$ zastoj zu zastati 'Stocken, Stauung'.

\section{Der wortbildende Typ}

Der Begriff des wortbildenden Typs bildet nach Ansicht von Furdik ${ }^{160}$ gemeinsam mit dem Problem der Stellung der Wortbildung die umstrittenste Frage auf dem Gebiet der Wortbildung. "Prinzipiell wird die Existenz der wortbildenden Typen", wie Furdik weiter ausführt, "anerkannt, wenn auch in der Abgrenzung des wortbildenden Typs sehr wesentliche Unterschiede sind"161 (aus dem Original übersetzt).

Es kann hier nicht auf die Diskussion darüber eingegangen werden, welches die wesentlichen Merkmale des Begriffs wortbildender Typ sind. Der wortbildende Typ wird in der Interpretation und Auffassung von Dokulil übernommen.

Während mit der Einführung der onomasiologischen Kategorie die Begriffsgrundlage der sprachlichen Benennung gelegt wurde, die im wesentlichen durch bestimmte Begriffsstrukturen gebildet

160 J. Furdik, 0 súčasných smeroch..., a.a.0., s. 77.

161 Ebenda, S. 77. 
ist, die in den wechselseitigen Beziehungen von bestimmtem zu bestimmendem Element stehen, mit anderen Worten: mit dem Begriff der onomasiologischen Kategorie die nichtsprachliche Ebene tangiert ist, wird mit der Einführung des Begriffs des "wortbildenden Typ" zum eigentlich wortbildenden Aspekt des Benennungsvorgangs, d.h. zur Realisation der onomasiologischen Struktur übergegangen.

Der wortbildende Typ stellt das Klassifikationselement dar, nach dem das Material der abgeleiteten Substantive im Rahmen der wortbildenden Kategorie systematisch klassifiziert wird.

Der wortbildende Typ enthält nach Dokulil die drei folgenden Komponenten:

"A. Die Ebene, die durch die Einheit der onomasiologischen Struktur gegeben ist (die z.B. Bezeichnungen des Trägers einer Eigenschaft, die von Adjektiven und Substantiven abgeleitet sind, nomina agentis und nomina actoris verbindet);

B. Die Ebene, die durch die Einheit des lexikalisch-grammatischen Charakters der Basis gegeben ist (z.B. die Ebene der Deverbativa, die Ebene der Denominativa mit den Unterebenen der Desubstantiva und Deadjektiva).

C. Die Ebene, die durch die Einheit des Formans gegeben ist (innerhalb derselben Wortart) (z.B. die Ebene von Wörtern mit dem Formans -ec, die eine Reihe von wortbildenden Typen einschliesst)" 162 (aus dem Original übersetzt).

Innerhalb des wortbildenden Typs können Untertypen unterschieden werden, die diesen weiter präzisieren. "Weniger allgemeine wortbildende Begriffe - wortbildende Untertypen - fügen zu diesen konstitutiven Merkmalen weitere hinzu, am häufigsten eine spezifische semantische Klasse abgeleiteter wörter oder einen semantischen oder wortbildenden Charakter ableitender wörter usw." 163 (aus dem Original übersetzt).

Auf der Grundlage der gegebenen Definition wird das gesamte Material der Ableitungen von Verben mit den Präfixen do-, iz-, na-, za- in der serbokroatischen Sprache nach seinen wortbildenden Typen gegliedert und klassifiziert, wobei das spezifische Merkmal das Formans ist.

Das bedeutet konkret, dass z.B. innerhalb der Kategorie der nomina agentis ein Typ mit Hilfe des Suffixes -ač abgeleitet wird,

162 M. Dokulil, Trořeni slov I, S. 73. 163 Ebenda, S. 75. 
zu dem Substantive gehören wie iznosač 'einer, der etwas hinausträgt', istovarač 'einer, der etwas auslädt', izlagač 'einer, der etwas hinauslegt, ausstellt'; ein zweiter mit dem Suffix -ac, ein dritter mit dem Suffix -nik usw.

Analog wird das gesamte Material nach wortbildenden Typen gegliedert.

Innerhalb der so definierten wortbildenden Typen wird eine weitere Einteilung und engere Systematisierung in Untertypen nach der Art des Verbalstamms vorgenommen, und zwar nach dem Grundstamm ${ }^{164}$, dem Stamm des Partizip Präteritum Aktiv, dem Infinitivstamm und dem Stamm des Partizip Präteritum Passiv. Es muss allerdings betont werden, dass keinesfalls alle angeführten Arten des Verbalstamms in einer onomasiologischen bzw. wortbildenden Kategorie vorkommen müssen, es jedoch können. Im allgemeinen hat jede Kategorie einen für sie typischen Verbalstamm zur Ableitung zur Verfügung, um den sich bisweilen ein oder zwei für diese Kategorie weniger typische gruppieren. So werden Verbalsubstantive ausschliesslich vom Stamm des Partizip Präteritum Passiv abgeleitet, nomina agentis dagegen überwiegend vom Grundstamm und daneben auch vom Stamm des Partizip Präteritum Aktiv und vom Infinitivstamm.

Das bedeutet, dass z.B. der wortbildende Typ der nomina agentis, der mit Hilfe des Suffixes -ač gebildet wird, in weitere Untertypen geteilt wird, und zwar in einen mit Grundstamm, in einen mit dem Stamm des Partizip Präteritum Aktiv und in einen dritten mit Infinitivstamm usw. 165

Eine weitere Unterteilung des wortbildenden Typs erfolgt nach den Konjugationen der ableitenden Verben ${ }^{166}$.

Die gesamte Gliederung des wortbildenden Typs mit seinen Untertypen sieht dann wie folgt aus:

Formans (-ač, -ac usw.)

Verbalstamm (Grundstamm, Infinitivstamm usw. Konjugation.

164 Unter dem Grundstamm wird der Infinitivstamm minus dem Klassenmerkmal verstanden. Der Grundstamm z.B. von kupiti ist kup-iti. Vgl. V. Smilauer, Novočeské tvoření slov. Praha 1971 , S. 10 u. 19.

165 Die Reihenfolge der Ableitungsstämme ist mit ihrer Produktivität identisch, gemessen am gesamten Material der vorliegenden Arbeit.

166 Es wird die Klassifikation der Verben verwendet, die der Grammatik von Brabec [u.a.] zugrunde liegt. I. Brabec, M. Hraste, S. Zi vković, Gramatika..., Do a a O. O. Prom PubFactory at 01/10/2019 05:55:03AM 
4. Die wortbildende Kategorie

Dem wortbildenden Typ übergeordnet ist der Begriff der wortbildenden Kategorie, die sich von ihm nur durch die Abstraktion von einem bestimmten Formans unterscheidet. "Allgemeinere wortbildende Begriffe entstehen dann durch Abstraktion von einem dieser drei konstitutiven Merkmale. Wenn wir von einem bestimmten Formans abstrahieren, erhalten wir die wortbildende Kategorie"167 (aus dem Original übersetzt). So gehören z.B. zur wortbildenden Kategorie der nomina agentis ausser dem wortbildenden Typ mit dem Formans -ač (iznosač 'einer, der hinausträgt') die wortbildenden Typen mit dem Formans -ac, -nik usw.

Innerhalb der wortbildenden Kategorie können ebenso wie innerhalb des wortbildenden Typs wortbildende Subkategorien unterschieden werden. "Allerdings können auch hier verschiedene wortbildende Subkategorien zur Geltung kommen, die den wortbildenden Untertypen übergeordnet sind, keineswegs aber den Typen (z.B. können innerhalb der Kategorie der nomina agentis Subkategorien von Benennungen zur Geltung kommen, die von Verben abgeleitet sind..., innerhalb... dieser dann eine Klasse von Benennungen von imperfektiven Verben und eine Klasse von Benennungen von perfektiven Verben" 168 (aus dem Original übersetzt).

Darüber hinaus wird das Material innerhalb des wortbildenden Typs nach den Präfixbedeutungen - soweit solche vorhanden sind - der den Ableitungen zugrunde liegenden Verben gegliedert.

Demzufolge kann das Klassifikationsschema des wortbildenden Typs noch durch die wortbildenden Subkategorien des Aspekts der ableitenden Verben sowie die Präfixbedeutungen ergänzt werden und hat dann folgende Gestalt:

Formans (-ač, -ac usw.)

Präfixbedeutung

Aspekt (perfektiver oder imperfektiver)

Verbalstamm (Grundstamm, Infinitivstamm usw.)

Konjugation.

167 M. Dokulil, Tvořeni slov I, S. 75.

168 Ebenda, S. 75. 
ZWEITER TEIL

NOMINA LOCI

\section{Allgemeine Vorbemerkungen}

Unter nomina loci werden allgemein Substantive verstanden, die einen Ort im weitesten Sinne des Wortes bezeichnen, an dem eine Handlung stattfindet oder der in irgendeiner Beziehung zu einer Handlung steht. Der Begriff der Handlung wird in dem Sinne aufgefasst, wie er für die Beschreibung der nomina actionis gegeben worden ist s.u.

Die in der vorliegenden Arbeit analysierten nomina loci sind deverbale Ableitungen, die eine räumliche Konkretisierung des Begriffs der Handlung darstellen ${ }^{169}$, so z.B. doskočište 'Ort, auf den man beim Sprung landet', izlog 'Schaufenster', ishodište 'Ausgangspunkt', iskrcalište 'Ausladeplatz', nahodište 'Fundort', namataonica 'Fabrikabteilung, wo etwas aufgewickelt wird', zaseda 'Hinterhalt', zavojište 'Verbandsplatz'.

Die onomasiologische Kategorie der nomina loci gehört zu den komplexen Kategorien ${ }^{170}$, deren Wesen darin besteht, dass die onomasiologische Basis einerseits die verschiedenen onomasiologischen Grundkategorien nicht generell sondern spezifiziert enthält, d.h. im vorliegenden Fall nicht die Substanz schlechthin, sondern deren Subkategorie des Ortes bezeichnet, und andererseits bestimmt wird durch ihre Beziehung zu einer anderen Substanz, einer Eigenschaft, einer Handlung oder Umstandsbestimmung.

In dem vorliegenden Material ist lediglich die Beziehung der onomasiologischen Basis zur Handlung realisiert, also der Typ iskrcalište 'Ort, wo ausgeladen wird'. Substantive wie doletište 'Anflugplatz', doskočište, ispasište 'Weide' $u_{.} a_{\text {. }}$, die vom Grundstamm abgeleitet sind und neben sich nomina actionis im engeren Sime haben (dolet 'An-, Zuflug', doskok 'Ansprung, der letzte Teil des

\footnotetext{
169 W. Doroszewski, Nomina loci jako kategoria slowotwórcza. In: Slavia 31, 1962, S. 346.

170 M. Dokulil, Tvoření slov I, S. 41.
} 
Sprungs', ispaša 'Weiden'), die von denselben Verben abgeleitet sind, erlauben neben der Motivation durch die Ort - Handlungsbeziehung auch die durch die Beziehung eines Ortes zu einer Substanz, die wir jedoch für eine sekundäre halten, da nur selten neben nomina loci auch entsprechende nomina actionis im engeren Sinne vorhanden sind.

Auf der wortbildenden Ebene werden nomina loci durch das wortbildende Verfahren der Suffigierung realisiert. Neben diesen auf diese Weise gebildeten Substantiven sind einige mittels des wortbildenden Verfahrens der Konversion gebildete maskuline und feminine nomina actionis im engeren sinne vorhanden, die durch Bedeutungsübertragung lokale Bedeutung erhalten haben. Die Konversion zählen wir bei der Ableitung von nomina loci zu den uneigentlichen Mitteln. Es handelt sich um Substantive mit hartem stammauslautendem Konsonanten und der Endung $\varnothing$ im Nominativ Singular wie z.B. izlaz, nagib 'Abhang', zaklon und mit hartem stammauslautendem Konsonanten und der Endung -a im Nominativ Singular wie z.B. istoka 'Quelle', zastava 'Hinterhalt beim Viehdiebstahl', zaseda 'Hinterhalt'.

Zu nomina loci, die mit Hilfe der Konversion gebildet worden sind, werden nur Substantive gezählt, die vom heutigen standpunkt in erster Linie lokale Bedeutung haben. Substantive, die die lokale Bedeutung als sekundäre Bedeutung haben, werden nicht in diese wortbildende Kategorie aufgenommen. Sie werden nach ihrer primären Bedeutung in die entsprechende Kategorie eingeordnet.

Nomina loci werden von Verben mit den Präfixen do-, iz-, na-, za- in lexikalischer Funktion, von Verben mit den Präfixen na-, za- in modifizierender Funktion und von Verben mit den Präfixen iz-, na-, za- in rein perfektivierender Funktion ${ }^{171}$ abgeleitet. Folgende Formantien finden bei der Ableitung von nomina loci Verwendung:

Maskulina: I. 172 -ac, -ak, -jak, -nik, -ut(a)k II. 172 -HK- $\varnothing^{173}$ Feminina: I. $-b(a),-i c(a),-i n(a),-\operatorname{nic}(a),-\operatorname{otin}(a)$ II. $-\mathrm{HK}-\mathrm{a} 173$

Neutra: I. $-i s ̌ t(e),-j(e)$.

171 Nomina loci sind in rein perfektivierender Funktion nur von Verben mit reihenden Präfixen abgeleitet.

172 Nach "I" stehen die wortbildenden Typen, deren Ableitungen mittels des wortbildenden Verfahrens der Suffigierung gebildet werden; nach "II" stehen die wortbildenden Typen, deren Substantive mittels des wortbildenden Verfahrens der Konversion gebildet werden. 
Nach der Produktivität ergibt sich für die gesamte wortbildende Kategorie der nomina loci folgendes Bild:

Maskulina: I. b) weniger produktiv: -ak, -nik, d) ganz unproduktiv: -ac, -jak, -ut(a)k, II. a) sehr produktiv: -HK- $\varnothing$

Feminina: I. b) weniger produktiv: -in(a), c) unproduktiv: -nic(a)

d) ganz unproduktiv: $-b(a),-i c(a),-o t i n(a)$

II. b) weniger produktiv: $-\mathrm{HK}-\mathrm{a}$

Neutra: I. a) sehr produktiv: -išt(e), d) ganz unproduktiv: -j(e).

Der neutrale wortbildende Typ mit dem Formans -išt(e) bildet den Kern der Kategorie der nomina loci.

Nomina loci werden generell ganz überwiegend von Verben mit Präfixen der lexikalischen Funktion abgeleitet, wobei die maskulinen Substantive vor den neutralen und femininen geringfügig überwiegen.

In relativ geringem Masse sind nomina loci von Verben mit Präfixen der rein perfektivierenden Funktion abgeleitet.

In ganz geringem Masse sind nomina loci von Verben mit Präfixen der modifizierenden Funktion abgeleitet. Es kommen lediglich die wortbildenden Typen mit den Formantien -nik, -in(a) und mit $-H K-\varnothing$ vor.

Nomina loci werden am häufigsten von Verben mit dem Präfix iz- in lexikalischer Funktion gebildet. Mit geringem Abstand folgen nomina loci mit dem Präfix za-, in grösserem Abstand folgen nomina loci mit den Präfixen na- und do- ebenfalls in lexikalischer Funktion.

Nomina loci sind nur mit einem bzw. zwei Beispielen von Verben mit den Präfixen na- und $z a-$ in modifizierender Funktion abgeleitet.

Nomina loci, die von Verben mit Präfixen der rein perfektivierenden Funktion abgeleitet werden, werden vor allem von denen mit dem Präfix iz- vor denen mit den Präfixen za- und na- gebildet.

Betrachtet man die wortbildende Kategorie der nomina loci als eine Einheit, dann sind die zahlreichsten Ableitungen die von Verben mit dem Präfix iz-.

Die Ableitungsbasis der nomina loci wird im allgemeinen vom

$173-H K-\varnothing$ steht in verkürzter Ausdrucksweise für maskuline Substantive mit hartem stammauslautendem Konsonanten und der Endung - $\varnothing$ im Nominativ Singular (Deklinationsmuster "rad"); -HK-a steht für feminine substantive mit hartem stammauslautendem Konsonanten und der Endung -a im Nominativ Singular (Deklinationsmuster "žena"). 
Grundstamm und ganz selten vom Infinitivstamm bzw. vom Stamm des Partizip Präteritum Aktiv gebildet.

Der Stamm des Partizip Präteritum Aktiv wird in ganz geringem Masse zur Ableitung von Substantiven mit dem Formans -išt(e) verwendet, so z.B. ispiralište 'Ort, an dem man auswäscht'. Das Element -l- wird dabei allgemein als zum Ableitungsstamm zugehörig gewertet. Auf die Richtigkeit dieser Annahme weisen Beispiele hin, die von anderen Partizipien abgeleitet sind, so z.B. im Slovakischen von der Form des Partizip Präteritum Passiv bei Substantiven wie: spalenisko, zhorenisko, stavenisko ${ }^{174}$. Neben dieser für allgemein richtig gehaltenen Deutung des Elements - l- in Wörtern vom Typ 'ispiralište' äussern einige Wissenschaftler 175 die Vermutung, dass es sich dabei um eine Agglutination der Suffixe $-10\left(^{*}-d 10,-10\right)$ und -isko handeln könnte ${ }^{176}$.

Nomina loci, die mit Hilfe der Suffigierung gebildet sind, sind durch Verben aller Konjugationen mit Ausnahme derer der zweiten motiviert. Den Kern der Ableitungsbasis bilden Verben der 4. und 5. Konjugation.

Nomina loci, die mit Hilfe der Konversion gebildet sind, sind durch Verben aller Konjugationen mit Ausnahme derer der 3. und 6. motiviert. Den Kern der Ableitungsbasis bilden ebenfalls Verben der 4. und 5. Konjugation.

Die nomina loci nach dem Ableitungsverfahren, dem Ableitungsstamm und der Konjugation.

A. Lexikalische Funktion

I. Suffigierung

1. Grundstamm

Maskulina: 4., 5. Konjugation

Feminina: 4., 5. Konjugation

Neutra: 4., 5., 1., 3., 6. Konjugation

2. Stamm des Partizip Präteritum Aktiv

174 J. Horecký, Slovotvorná sústava..., a.a.0., s. 129.

175 A. Meillet, Etudes sur l'étymologie et le vocabulaire du vieux slave. II. Paris 1961, S. 350 - 351; derselbe, Le slave commun. Paris 1924, S. 365; W. Vondrák, Vergleichende slavische Grammatik..., a.a.0., S. 622; T. Szymanski, Słowotwórstwo rzeczownika w bułgarskich tekstach XVII - XVIII wieku. Wrocław-Warszawa-Kraków 1968, S. 62ff.

176 Nomina loci vom Typ 'ispiralište' werden unter dem Gesichtspunkt klassifiziert, dass das Element - 1 - in diesen Substantiven zum Ableitungsstamm gehört, da noch nicht vollständig geklärt ist, ob hier eine Agglutination der Suffixe - lo und -isko stattgefunden hat. 
Feminina: 5. Konjugation

Neutra: 5. Konjugation

II. Konversion

Maskulina: 4., 5., 2. Konjugation

Feminina: 4., 5., 1. Konjugation.

B. Modifizierende Funktion

I. Suffigierung

1. Grundstamm

Feminina: 5. Konjugation

3. Infinitivstamm

Maskulina: 5. Konjugation

II. Konversion

Maskulina: 4. Konjugation.

C. Rein perfektivierende Funktion

I. Suffigierung

1. Grundstamm

Maskulina: 1. Konjugation

Feminina: 5. Konjugation

Neutra: 1., 4. Konjugation

2. Stamm des Partizip Präteritum Aktiv

Neutra: 1., 5. Konjugation

II. Konversion

Maskulina: 5.,2., 4. Konjugation

Feminina: 4. Konjugation.

Nomina loci werden generell sowohl von perfektiven als auch von sekundär imperfektiven Verben abgeleitet, wobei Ableitungen von perfektiven Verben ükerwiegen.

Nomina loci, die mittels der Suffigierung von Verben mit Präfixen der lexikalischen Funktion abgeleitet sind, basieren in fast gleichem Masse auf perfektiven und sekundär imperfektiven Verben. Die entsprechenden ncmina loci, die mittels der Korversion abgeleitet sind, basieren ebenfalls in fast gleichem Masse auf perfektiven und sekundär imperfektiven Verben.

Nomina loci, die mittels der Suffigierung von Verben mit Präfixen der modifizierenden und rein perfektivierenden Funktion abgeleitet sind, basieren mit einer Ausnahme bei Ableitungen von Verben mit Präfixen der rein perfektivierenden Funktion auf perfektiven Verben. Nomina loci, die mittels der Konversion von 
Verben mit Präfixen der modifizierenden Funktion abgeleitet sind, basieren auf perfektiven Verben und die, die mittels der Konversion von Verben mit Präfixen der rein perfektivierenden Funktion abgeleitet sind, basieren mit zwei Ausnahmen ebenfalls auf perfektiven Verben.

Nomina loci, und zwar vorwiegend die, die mit Hilfe der Konversion abgeleitet sind, haben neben der primären lokalen Bedeutung eine sekundäre Handlungsbedeutung wie z.B. izlazak 'Ausgang; Hinausgehen', izlaz 'Ausgang; Hinausgehen', zalet 'l. Ort, zu dem Bienen gewöhnlich fliegen; Flugrichtung, 2. Anlauf', izliv 'Ort, von dem etwas herausläuft; Herauslaufen'.

Einige wenige Substantive weisen eine sekundäre instrumentale Bedeutung auf wie z.B. ispust 'Ventil', zaklon 'Schirm, Schild'.

Unter dem Gesichtspunkt der Bedeutung der Präfixe der ableitenden Verben ergibt sich für das Vorkommen der nomina loci folgendes Bild:

In lexikalischer Funktion werden nomina loci von Verben mit nachstehenden Präfixen und ihren Bedeutungen 177 abgeleitet: do- Il 'bis zu (einem bestimmten Ort gelangen)' (doskočište 'Ort, auf dem man beim Sprung landet' von doskočiti 'herbeispringen');

L3 'bis zu (etwas gelangen)' (dočka 'Ort, an dem der Jäger auf das Wild wartet' von dočekati 'erwarten');

iz- $L l$ ' (etwas) von innen nach aussen (oder) von unten nach oben (bewegen)' (istovarište 'Ausladeplatz' von istovariti 'ausladen');

na- Il '(einen Gegenstand) auf (einen anderen stellen)' (nahodište 'Fundort' von nahoditi 'finden');

za- Ll '(etwas) hinter (etwas stellen)' (zavojište 'Verbandsplatz' von zaviti 'verbinden');

L2 '(umfassen) von allen Seiten' (zaliv 'Bucht' von zalivati 'begiessen');

L3 ' (umfassen) der äusseren Hülle' (zamladnik 'entzündete Stelle an kranker Zahnwurzel' von zamladiti se 'zuheilen'); L4 'eine Stellung einnehmen' (zaseda 'Hinterhalt' von zasedati 'sich in den Hinterhalt legen');

177 Die Klassifikation der Präfixbedeutungen in lexikalischer und modifizierender Funktion basieren auf den Ausführungen von M. Stevanović, Savremeni srpskohrvatski jezik..., a.a.0., S. $453 \mathrm{ff}$. und die der Bedeutungen der reihenden Präfixe auf den Darlegungen von 1. Grickat, Prefiksacija kao sredstvo..., a.a.0., S. $185-223$. 
In modifizierender Funktion werden nomina loci von Verben mit nachstehenden Präfixen und ihren Bedeutungen abgeleitet:

na- MI '(eine Handlung) in ausreichendem Masse (ausführen)' (nakopanik 'ausgespülter Weg, der mit Erde beschüttet wird, die von der Seite weggegraben wird' von nakopati 'genug ausgraben');

za- MI '(eine Handlung) beginnen' (zakopina 'Land, das einer zuerst anfing zu bearbeiten' von zakopati 'angraben');

In reihender Funktion werden nomina loci von Verben mit nachstehenden Präfixen und ihren Bedeutungen abgeleitet: Das Präfix iz- kann in Zusammensetzung mit Verben in der Bedeutung (RI) 'von weg, heraus' und in der Bedeutung (R2) 'ausführen bis zum Erreichen des Ziels, bis zur Ausschöpfung der Möglichkeit' mit seinen jeweiligen Bedeutungsnuancen reihende Funktion ausüben. Die Bedeutungsnuancen der Bedeutung $R l$ sind: Rld 'ausschneiden' (izrezotina 'Ort, an dem etwas ausgeschnitten wird' von izrezati 'ausschneiden'); Rli 'verschwinden' (ispasište 'Weide' von ispasti 'abweiden'); Rlj 'Restgruppe' (z.B. izbeglište 'Ort, wo sich Flüchtlinge aufhalten' von izbeći 'flüchten'); Die Bedeutungsnuancen der Bedeutung R2 sind: R2a 'versehen mit einem neuen Gepräge' (izderina 'Hohlweg' von izderati 'zerrei$\left.\operatorname{ssen}^{\prime}\right)$;

Das Präfix na- kann in Zusammensetzung mit Verben in der Bedeutung (RI) 'stellen eines Gegenstandes auf einen anderen' und in (R2) der 'Augmentation' mit seinen jeweiligen Bedeutungsnuancen reihende Funktion ausüben. Die Bedeutungsnuancen der Bedeutung RI sind: RId 'Restgruppe' (z.B. nakapnica 'Zisterne' von nakapati 'auf-, eintropfen');

Die Bedeutungsnuancen der Bedeutung $R 2$ sind: $R 2 b$ 'Nahrung in ausreichender Menge geben' (napajalište 'Tränke' von napajati 'tränken');

Das Präfix za- kann in Zusammensetzung mit Verben in der Bedeutung (RI) 'hinter etwas gehen' und in (R2) 'einen neuen Zustand einnehmen' mit seinen jeweiligen Bedeutungsnuancen reihende Funktion ausüben. Die Bedeutungsnuancen der Bedeutung $R I$ sind: Rla 'umdrehen' (zaokret 'Krümmung, Kurve' von zaokretati 'wenden'); RIb 'umfassen eines Teils oder des Ganzen' (zahvata 'ein Stück Land, das der Nachbar vom Nachbarn anackert' von zahvatiti 'fassen'); RIh 'töten, vernichten' (zakoljak 'Ort, an dem geschlachtet wird' von zaklati 'schlachten, abstechen'); Die Bedeutungsnuancen der Bedeutung $R 2$ sind: $R 2 a$ 'verweilen, eine 
Stellung einnehmen' (zabavište 'Kindergarten' von zabaviti se 'verweilen').

\section{Material}

\section{A. Lexikalische Funktion}

AA. Nomina loci von Verben mit dem Präfix do- in lexikalischer Funktion

Die Ableitungsverfahren: I. Suffigierung, II. Konversion Die wortbildenden Typen nach ihren Formantien, ihrer Produktivität und den Bedeutungen der Präfixe der ableitenden Verben mit ihrer Häufigkeit:

Feminina: II. -HK-a (1), Bed.: L3 (1)

Neutra: I. -išt(e) (2), Bed.: II (2)

Die Ableitungsstämme und die Konjugationen:

Feminina: II. 5. Konjugation

Neutra: I. 1. Grundstamm der 3., 4. Konjugation

Der Aspekt der Ableitungsbasis:

Feminina: II. 1 pf. Verb

Neutra: I. 1 pf. und 1 ipf. Verb

Feminina

II. Konversion

Ableitungen auf $-\mathrm{HK}-\mathrm{a}$

Bed.: L3, a) vom pf. Aspekt, der 5. Konjugation dočka 'Ort, an dem der Jäger auf das Wild wartet'

Neutra

I. Suffigierung

Ableitungen mit dem Formans -išt(e)

Bed.: Il, a) vom pf. Aspekt, 1. vom Grundstamm, der 4. Konjugation doskočište 'Ort, auf dem man beim Sprung landet'

b) vom ipf. Aspekt, 1. vom Grundstamm, der 3. Konjugation doletište 'Anflugplatz'

AB. Nomina loci von Verben mit dem Präfix $\underline{\text { iz- }}$ in lexikalischer Funktion

Die Ableitungsverfahren: I. Suffigierung, II. Konversion Die wortbildenden Typen nach ihren Formantien, ihrer Produktivi- 
tät und den Bedeutungen der Präfixe der ableitenden Verben mit ihrer Häufigkeit:

Maskulina: I. -ak (1), Bed.: LI (1), -nik (2), Bed.: LI (2) II. $-\mathrm{HK}-\varnothing$ (4), Bed.: LI (4)

Feminina: I. $-b(a)$ (1), Bed.: LI (1), - in(a) (1), Bed.: LI (1) II. $-\mathrm{HK}-\mathrm{a}(1)$, Bed.: II (1)

Neutra: I. -išt(e) (9), Bed.: LI (9)

Die Ableitungsstämme und die Konjugationen:

Maskulina: I. 1. Grundstamm der 4., 5. Konjugation

II. 4. Konjugation

Feminina: I. 1. Grundstamm der 5., 4. Konjugation II. 1. Konjugation

Neutra: I. 1. Grundstamm der 4., 5., 6. Konjugation, 2. Stamm des Partizip Präteritum Aktiv der 5. Konjugation

Der Aspekt der Ableitungsbasis:

Maskulina: I. 1 pf. und 2 ipf. Verben, II. 1 pf. und 3 ipf. Verben Feminina: I. 1 pf. und 1 ipf. Verb, II. 1 pf. Verb

Neutra: I. 1 pf. und 8 ipf. Verben

Maskulina

I. Suffigierung

Ableitungen mit dem Formans -ak

Bed.: Ll, b) vom ipf. Aspekt, l. vom Grundstamm, der 4. Konjugation izlazak 'Ausgang; Hinausgehen'

Ableitungen mit dem Formans -nik

Bed.: LI, a) vom pf. Aspekt, 1. vom Grundstamm, der 4. Konjugation istočnik 'Ort, wo etwas herausfliesst, Quelle'

b) vom ipf. Aspekt, 1. vom Grundstamm, der 5. Konjugation izvornik 'Quelle'

II. Konversion

Ableitungen auf $-\mathrm{HK}-\varnothing$

Bed.: LI, a) vom pf. Aspekt, der 4. Konjugation

izlog 'Schaufenster, Auslage'

b) vom ipf. Aspekt, der 5. Konjugation

izliv 'Ort, an dem etwas herausläuft; Herauslaufen', izvor 'Quelle'

der 4. Konjugation

izlaz 'Ausgang; Hinausgehen' 
Feminina

I. Suffigierung

Ableitungen mit dem Formars - $b(a)$

Bed.: Il, a) vom pf. Aspekt, l. vom Grundstamm, der 4. Konjugation izložba 'Ausstellung'

Ableitungen mit dem Formans -in(a)

Bed.: Il, b) vom ipf. Aspekt, I. vom Grundstamm,

der 5. Konjugation

iskopina 'Ort, wo eine Ausgrabung durchgeführt wird; ausge-

grabene Grube, Vertiefung, 2. Gegenstand, der bei der Ausgrabung gefunden worden ist'

II. Konversion

Ableitungen auf $-\mathrm{HK}-\mathrm{a}$

Bed.: Il, a) vom pf. Aspekt, der 1. Konjugation

istoka 'Quelle, Ausgangsort'

Neutra

I. Suffigierung

Ableitungen mit dem Formans -išt(e)

Bed.: Il, a) vom pf. Aspekt, 1. vom Grundstamm, der 4. Konjugation izložište 'Ausstellungsgebäude'

b) vom ipf. Aspekt, 1. vom Grundstamm, der 4. Konjugation

izlazište 'Ausgangspunkt', ishodište 'Ausgangspunkt', istovarište 'Ausladeplatz'

der 5. Konjugation

izletište 'Ausflugsort', izvorište 'Quellgebiet',

istecište 'Ort, wo Wasser ausfliesst, Ableitungskanal'

2. vom Stamm des Partizip Präteritum Aktiv, der 5. Konjugation

iskrcalište 'Ausladeplatz', ispiralište 'Ort, an dem man etwas ausspült'

AC. Nomina loci von Verben mit dem Präfix na- in lexikalischer Funktion

Die Ableitungsverfahren: I. Suffigierung, II. Konversion

Die wortbildenden Typen nach ihren Formantien, ihrer Produktivität und den Bedeutungen der Präfixe der ableitenden Verben mit 
ihrer Häufigkeit:

Maskulina: I. -ak (1), Bed.: LI (1), II. - HK- $\varnothing$ (1), Bed.: Il (1)

Feminina: I. $-b(a)$ (1), Bed.: LI (1), $-i n(a)$ (1), Bed.: LI (1), $-\operatorname{nic}(a)(1)$, Bed.: II (1)

Neutra: I. -išt(e) (2), Bed.: LI (2), $-j(e)(1)$, Bed.: LI (1)

Die Ableitungsstämme und die Konjugationen:

Maskulina: I. 1. Grundstamm der 4. Konjugation, II. 4. Konjugation

Feminina: I. 1. Grundstamm der 4. Konjugation, 2. Stamm des Partizip Präteritum Aktiv der 5. Konjugation

Neutra: I. 1. Grundstamm der 4. Konjugation

Der Aspekt der Ableitungsbasis:

Maskulina: I. 1 pf. Verb, II. 1 ipf. Verb

Feminina: I. 2 pf. und 1 ipf. Verb

Neutra: I. 1 pf. und 2 ipf. Verben

Maskulina

I. Suffigierung

Ableitungen mit dem Formans -ak

Bed.: Il, a) vom pf. Aspekt, 1. vom Grundstamm, der 4. Konjugation naselak 'kleine Ansiedlung, Niederlassung'

II. Konversion

Ableitungen auf $-H K-\varnothing$

Bed.: Ll, b) vom ipf. Aspekt, der 4. Konjugation

navoz 'Ort, von dem man die Uberfahrt über den Fluss ausführt; Trockendock'

Feminina

I. Suffigierung

Ableitungen mit dem Formans $-b(a)$

Bed.: Il, a) vom pf. Aspekt, 1. vom Grundstamm, der 4. Konjugation naseoba 'Ansiedlung'

Ableitungen mit dem Formans -in(a)

Bed.: Il, a) vom pf. Aspekt, l. vom Grundstamm, der 4. Konjugation naselina (pokr.) 'Ansiedlung, Niederlassung'

Ableitungen mit dem Formans -nic(a)

Bed.: Il, b) vom ipf. Aspekt, 2. vom Stamm des Partizip Präteritum Aktiv, der 5. Konjugation 
namataonica 'Abteilung in der Fabrik, wo etwas aufgewickelt wird (Draht u.a.)'

Neutra

I. Suffigierung

Ableitungen mit dem Formans -išt(e)

Bed.: Ll, b) vom ipf. Aspekt, 1. vom Grundstamm, der 4. Konjugation

nahodište '1. Fundort, 2. Findelhaus', nalazište 'Fundort (gewöhnlich von Ausgrabungen)'

Ableitungen mit dem Formans $-j(e)$

Bed.: Il, a) vom pf. Aspekt, 1. vom Grundstamm, der 4. Konjugation naselje 'Ansiedlung'

AD. Nomina loci von Verben mit dem Präfix $\underline{\text { za- }}$ in lexikalischer Funktion

Die Ableitungsverfahren: I. Suffigierung, II. Konversion

Die wortbildenden Typen nach ihren Formantien, ihrer Produktivität und den Bedeutungen der Präfixe der ableitenden Verben mit ihrer Häufigkeit:

Maskulina: I. -ac (1), Bed.: Ll (1), -ak (2), Bed.: Il (1), L3

$$
\begin{aligned}
& \text { (1), -nik (1), Bed.: L3 (1), -ut(a)k (1), Bed.: } \\
& \text { LI (1), II. -HK- } \varnothing \text { (4), Bed.: LI (3), L2 (1) }
\end{aligned}
$$

Feminina: I. $-i c(a)$ (1), Bed.: LI (1), II. -HK-a (2), Bed.:L4 (2) Neutra: I. -išt(e) (3), Bed.: LI (3)

Die Ableitungsstämme und die Konjugationen:

Maskulina: I. 1. Grundstamm der 4., 5. Konjugation,

II. 5., 2., 4. Konjugation

Feminina: I. 1. Grundstamm der 4. Konjugation, II. 4., 5. Konjugation

Neutra: I. 1. Grundstamm der 1., 4., 5. Konjugation

Der Aspekt der Ableitungsbasis:

Maskulina: I. 4 pf. und 1 ipf. Verb, 11.2 pf. und 2 ipf. Verben Feminina: I. 1 pf. Verb, II. 1 pf. und 1 ipf. Verb Neutra: I. 2 pf. und 1 ipf Verb

Maskulina

I. Suffigierung 
Ableitungen mit dem Formans -ac

Bed.: Il, a) vom pf. Aspekt, 1. vom Grundstamm, der 4. Konjugation zaklonac 'Schirm, Schutz, Schlupfwinkel'

Ableitungen mit dem Formans - ak

Bed.: Ll, a) vom pf. Aspekt, 1. vom Grundstamm, der 4. Konjugation zaklonak 'geschützter Ort'

Bed.: L3, a) vom pf. Aspekt, 1. vom Grundstamm, der 4. Konjugation zasenak '1. beschatteter Raum, 2. Sonnenschirm'

Ableitungen mit dem Formans -nik

Bed.: L3, a) vom pf. Aspekt, 1. vom Grundstamm, der 4. Konjugation zamladnik (med. neol.) 'entzündete Stelle an kranker Zahnwurzel'

Ableitungen mit dem Formans -ut(a)k

Bed.: Ll, b) vom ipf. Aspekt, l. vom Grundstamm, der 5. Konjugation

zavijutak 'Einbiegung, Krümmung'

II. Konversion

Ableitungen auf $-\mathrm{HK}-\varnothing$

Bed.: Ll, a) vom pf. Aspekt, der 2. Konjugation

zamak 'Ort, wo etwas verschwindet'

der 4. Konjugation

zaklon 'Zufluchtsort; Schirm, Schild; Neigen des Kopfes und des Oberkörpers nach hinten'

b) vom ipf. Aspekt, der 5. Konjugation

zalet '1. Ort, zu dem Bienen gewöhnlich fliegen; Flugrichtung, 2. Anlauf'

Bed.: L2, b) vom ipf. Aspekt, der 5. Konjugation

zaliv (geogr.) 'Bucht, Bai, Meerbusen'

Feminina

1. Suffigierung

Ableitungen mit dem Formans -ic(a)

Bed.: Il, a) vom pf. Aspekt, l. vom Grundstamm, der 4. Konjugation zaklonica 'Schlupfwinkel, geschützter Ort' 
II. Konversion

Ableitungen auf $-\mathrm{HK}-\mathrm{a}$

Bed.: L4, a) vom pf. Aspekt, der 4. Konjugation

zastava (ist.) 'Hinterhalt beim Viehdiebstahl'

b) vom ipf. Aspekt, der 5. Konjugation

zaseda 'Hinterhalt'

Neutra

I. Suffigierung

Ableitungen mit dem Formans -išt(e)

Bed.: LI, a) vom pf. Aspekt, 1. vom Grundstamm, der 1. Konjugation zavojište 'Verbandsplatz'

der 4. Konjugation

zaklonište 'Schutzort, Zufluchtsort'

b) vom ipf. Aspekt, 1. vom Grundstamm, der 5. Konjugation

zaletište (sport.) 'Ort oder Raum, wo man Anlauf nimmt'

B. Modifizierende Funktion

BC. Nomina loci von Verben mit dem Präfix na- in modifizierender Funktion

Die Ableitungsverfahren: I. Suffigierung

Die wortbildenden Typen nach ihren Formantien, ihrer Produktivität und den Bedeutungen der Präfixe der ableitenden Verben mit ihrer Häufigkeit:

Maskulina: I. -nik (1), Bed.: MI (1)

Die Ableitungsstämme und die Konjugationen:

Maskulina: I. 3. Infinitivstamm der 5. Konjugation

Der Aspekt der Ableitungsbasis:

Maskulina: I. 1 pf. Verb

Maskulina

I. Suffigierung

Ableitungen mit dem Formans -nik

Bed.: MI, a) vom pf. Aspekt, 3. vom Infinitivstamm, der 5. Konjugation

nakopanik 'ausgespülter Weg, der mit Erde beschüttet wird, die von der Seite weggegraben wird' 
BD. Nomina loci von Verben mit dem Präfix za- in modifizierender Funktion

Die Ableitungsverfahren: I. Suffigierung, II. Konversion

Die wortbildenden Typen naoh ihren Formantien, ihrer Produktivität und den Bedeutungen der Präfixe der ableitenden Verben mit ihrer Häufigkeit:

Maskulina: II. $-\mathrm{HK}-\varnothing$ (1), Bed.: MI (1)

Feminina: I. - in(a) (1), Bed.: MI (1)

Die Ableitungsstämme und die Konjugationen:

Maskulina: II. 4. Konjugation

Feminina: I. 1. Grundstamm der 5. Konjugation

Der Aspekt der Ableitungsbasis:

Maskulina: II. 1 pf. Verb

Feminina: I. 1 pf. Verb

Maskulina

II. Konversion

Ableitungen auf $-H K-\varnothing$

Bed.: Ml, a) vom pf. Aspekt, der 4. Konjugation zakos '1. Ort, wo es Grass zum Mähen gibt, 2. Biegung'

Feminina

I. Suffigierung

Ableitungen mit dem Formans -in(a)

Bed.: Ml, a) vom pf. Aspekt, 1. vom Grundstamm, der 5. Konjugation zakopina ' 1 . Land, das einer zuerst anfing zu bearbeiten, 2. Grube, Loch'

C. Rein perfektivierende Funktion

CB. Nomina loci von Verben mit dem Präfix iz- in rein perfektivierender Funktion

a) $\underline{\text { iz- }}$ als reihendes Präfix

Die Ableitungsverfahren: I. Suffigierung, II. Konversion

Die wortbildenden Typen nach ihren Formantien, ihrer Produktivität und den Bedeutungen der Präfixe der ableitenden Verben mit ihrer Häufigkeit:

Maskulina: II. $-\mathrm{HK}-\varnothing$ (2), Bed.: Rlj (2)

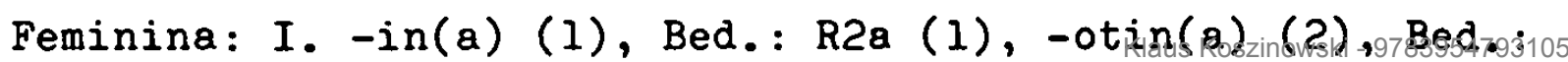


Rld (1), R2a (1)

Neutra: I. -išt(e) (2), Bed.: Rli (l), Rlj (1)

Die Ableitungsstämme und die Konjugationen:

Maskulina: II. 2., 4. Konjugation

Feminina: I. 1. Grundstamm der 5. Konjugation

Neutra: I. 1. Grundstamm der 1. Konjugation, 2. Stamm des Partizip Präteritum Aktiv der 1. Konjugation

Der Aspekt der Ableitungsbasis :

Maskulina: II. 2 pf. Verben

Feminina: I. 3 pf. Verben

Neutra: I. 2 pf. Verben

Maskulina

II. Konversion

Ableitungen auf $-\mathrm{HK}-\varnothing$

Bed.: Rlj, a) vom pf. Aspekt, der 2. Konjugation

izdig 'Ort im Gebirge, zu dem man über den Sommer die

Schafe treibt'

der 4. Konjugation

ispust 'Weidegrund'

Feminina

I. Suffigierung

Ableitungen mit dem Formans -in(a)

Bed.: R2a, a) vom pf. Aspekt, 1. vom Grundstamm, der 5. Konjugation

$$
\text { izderina 'Hohlweg' }
$$

Ableitungen mit dem Formans -otin(a)

Bed.: Rld, a) vom pf. Aspekt, 1. vom Grundstamm, der 5. Konjugation

izrezotina 'Ort, an dem etwas ausgeschnitten ist'

Bed.: R2a, a) vom pf. Aspekt, 1. vom Grundstamm, der 5. Konjugation

izderotina 'Ort, an dem etwas zerwühlt ist'

Neutra

I. Suffigierung

Ableitungen mit dem Formans -išt(e)

Bed.: Rli, a) vom pf. Aspekt, 1. vom Grundstamm, der 1. Konjugation 


\section{ispasište 'Weide, Trift'}

Bed.: Rlj, a) vom pf. Aspekt, 2. vom Stamm des Partizip Fräteritum Aktiv, der 1. Konjugation

izbeglište 'Ort, wo sich Flüchtlinge aufhalten'

CC. Nomina loci von Verben mit dem Präfix na- in rein perfektivierender Funktion

a) na- als reihendes Präfix

Die Ableitungsverfahren: I. Suffigierung, II. Konversion

Die wortbildenden Typen nach ihren Formantien, ihrer Produktivität und den Bedeutungen der Präfixe der ableitenden Verben mit ihrer Häufigkeit:

Maskulina: II. $-\mathrm{HK}-\varnothing$ (1), Bed.: Rld (1)

Feminina: I. $-\operatorname{nic}(a)$ (1), Bed.: Rld (1)

Neutra: I. -išt(e) (2), Bed.: R2b (2)

Die Ableitungsstämme und die Konjugationen:

Maskulina: II. 5. Konjugation

Feminina: I. 1. Grundstamm der 5. Konjugation

Neutra: I. 1. Grundstamm der 4. Konjugation, 2. Stamm des Partizip Präteritum Aktiv der 5. Konjugation

Der Aspekt der Ableitungsbasis:

Maskulina: II. 1 ipf. Verb

Feminina: I. 1 pf. Verb

Neutra: I. 1 pf. und 1 ipf. Verb

Maskulina

II. Konversion

Ableitungen auf $-\mathrm{HK}-\varnothing$

Bed.: Rld, b) vom ipf. Aspekt, der 5. Konjugation nagib 'Abhang, Böschung'

Feminina

I. Suffigierung

Ableitungen mit dem Formans -nic(a)

Bed.: Rld, a) vom pf. Aspekt, 1. vom Grundstamm, der 5. Konjugation nakapnica 'Zisterne'

Neutra

I. Suffigierung 
Ableitungen mit dem Formans -išt(e)

Bed.: R2b, a) vom pf. Aspekt, 1. vom Grundstamm, der 4. Konjugation

napojište 'Tränke'

b) vom ipf. Aspekt, 2. vom Stamm des Partizip Präteritum Aktiv, der 5. Konjugation

napajalište 'Tränke'

CD. Nomina loci von Verben mit dem Präfix za- in rein perfektivierender Funktion

a) za- als reihendes Präfix

Die Ableitungsverfahren: I. Suffigierung, II. Konversion

Die wortbildenden Typen nach ihren Formantien, ihrer Produktivität und den Bedeutungen der Präfixe der ableitenden Verben mit ihrer Häufigkeit:

Maskulina: I. -jak (1), Bed.: Rlh (1), II. -HK- $\varnothing$ (1), Bed.: Rla (1)

Feminina: II. $-\mathrm{HK}-\mathrm{a}$ ( 1 ), Bed.: RIb (1)

Neutra: I. -išt(e) (1), Bed.: R2a (I)

Die Ableitungsstämme und die Konjugationen:

Maskulina: I. 1. Grundstamm der 1. Konjugation, II. 5. Konjugation

Feminina: II. 4. Konjugation

Neutra: I. 1. Grundstamm der 4. Konjugation

Der Aspekt der Ableitungsbasis:

Maskulina: I. 1 pf. Verb, II. 1 ipf. Verb

Feminina: II. 1 pf. Verb

Neutra: I. 1 pf. Verb

Maskulina

I. Suffigierung

Ableitungen mit dem Formans -jak

Bed.: Rlj, a) vom pf. Aspekt, 1. vom Grundstamm, der 1. Konjugation zakoljak 'Ort, an dem geschlachtet wird'

II. Konversion

Ableitungen auf $-H K-\varnothing$

Bed.: Rla, b) vom ipf. Aspekt, der 5. Konjugation zaokret '1. Krümmung, Kurve, 2. Richtungsänderung' 
Feminina

II. Konversion

Ableitungen auf $-\mathrm{HK}-\mathrm{a}$

Bed.: Rlb, a) vom pf. Aspekt, der 4. Konjugation

zahvata 'Stück Land, das der Nachbar vom Nachbarn anackert'

Neutra

I. Suffigierung

Ableitungen mit dem Formans -išt(e)

Bed.: R2a, a) vom pf. Aspekt, l. vom Grundstamm, der 4. Konjugation

zabavište 'Kindergarten, Spielschule'

Schlussbemerkungen

la) Was die Präfixe in lexikalischer Funktion betrifft, so sind nomina loci von Verben mit den Präfixen do-, iz-, na-, zaausschliesslich in lokaler Bedeutung abgeleitet (s. Tabelle lb).

Es kann (s. Tabelle la) eine semantisch motivierte Affinität von Präfixen in lexikalischer Funktion und deren lokalen Bedeutungen zu nomina loci festgestellt werden, und zwar in der Reihenfolge: iz-, za-, na-, do-.

1b) Da nomina loci von Verben mit Präfixen in lexikalischer Funktion ausschliesslich von solchen mit lokaler Bedeutung abgeleitet sind, kann generell gesagt werden, dass eine semantisch motivierte Affinität von Verben mit Präfixen in dieser Funktion und Bedeutung zu nomina loci besteht.

2a) Nomina loci sind mit folgenden in quantitativer Reihenfolge aufgeführten Präfixen in lexikalischer Funktion gebildet: iz-, za-, na-, do-.

Nomina loci sind mit folgenden in quantitativer Reihenfolge aufgeführten Präfixen in modifizierender Funktion gebildet: za-, na-.

Nomina loci sind mit folgenden in quantitativer Reihenfolge aufgeführten reihenden Präfixen in rein perfektivierender Funktion gebildet: iz-, na-, za-.

Es kann (s. Tabelle la) in rein quantitativer Hinsicht eine starke Affinität von Verben mit iz-, za- in lexikalischer Funk- 
tion, eine weniger starke von solchen mit na- in lexikalischer und iz- in rein perfektivierender Funktion, eine schwache von solchen mit do- in lexikalischer und za-, na- in rein perfektivierender Funktion und eine sehr schwache von solchen mit na-, za- in modifizierender Funktion zu nomina loci festgestellt werden.

2b) Nomina loci sind mit Präfixen in folgenden in quantitativer Reihenfolge aufgeführten Funktionen gebildet: der lexikalischen, rein perfektivierenden und modifizierenden Funktion.

Es kann (s. Tabelle 2) in rein quantitativer Hinsicht eine sehr starke Affinität von Verben mit Präfixen in lexikalischer Funktion, eine schwache von solchen mit Präfixen in rein perfektivierender Funktion und eine sehr schwache von solchen mit Präfixen in modifizierender Funktion zu nomina loci konstatiert werden.

Tabelle 1a: Zahlenmässige Angabe über das Vorkommen der nomina loci nach den Funktionen und Präfixen sowie dem. Aspekt der ableitenden Verben

Lexikalische Funktion

Aspekt do- iz- na- za-

pf. $\quad 2 \quad 5 \quad 4 \quad 10$

ipf. $\quad 1 \quad 14 \quad 4 \quad 5$

$\begin{array}{lllll}\text { Summe } & 3 & 19 & 8 & 15\end{array}$

Modifizierende Funktion

Aspekt do- iz- na- za-

pf. - - 12

ipf. - - - -

Summe - -12

Rein perfektivierende Funktion

a) reihende Präfixe

Aspekt do-iz- na- za-

pf. $\quad-723$

ipf. - $\quad 2 \quad 1$

Summe $\quad-744$
Tabelle 1b: Angabe über das Vorkommen der nomina loci nach den Bedeutungen der Präfixe in Zahlen

$$
\begin{aligned}
& \text { do- L1 (2), L3 (1) } \\
& \text { iz- L1 (19) } \\
& \text { na- LI (8) } \\
& \text { za- L1 (10), L2 (1), L3 (2), } \\
& \text { L4 (2) }
\end{aligned}
$$

na- MI (1)

za- MI (2) 
Tabelle 2: Angabe über das Gesamtvorkommen der nomina loci nach den Funktionen der Präfixe in Zahlen und Prozenten

Lexikalische Funktion:

Modifizierende Funktion:

Rein perfektivierende Funktion:
a) reihende Präfixe
$15=23,80$

$$
\begin{aligned}
& \text { Summe Prozent } \\
& \begin{aligned}
45 & =71,42 \\
3 & =4,76
\end{aligned}
\end{aligned}
$$


NOMINA INSTRUMENTI

\section{Allgemeine Vorbemerkungen}

Unter nomina instrumenti werden allgemein Substantive verstanden, die als Mittel zu einer Handlung dienen, wobei sie sowohl Agens als auch in beschränktem Masse Patiens einer Handlung sein können (zasipač 'etwas, was zum Aufschütten dient, was aufschüttet' und nalepnica 'etwas, was zum Aufkleben dient, was aufgeklebt wird'). Bei den von präfigierten Verben abgeleiteten nomina instrumenti handelt es sich um Konkreta im engeren (izvojac 'Korkenzieher', izbijač 'Stosseisen') wie auch ganz vereinzelt um solche im weiteren Sinne (zadevalica 'Wörter und Sätze, mit denen man neckt', zaklinjalica 'Worte, mit denen man schwört).

Nomina instrumenti bezeichnen vor allem Gegenstände im weitesten Sinne des Wortes: nabadalo 'Pfrieme', nabijač 'Erdschlägel', zaglavak 'Keil', dozivalo 'Vorrichtung zum Rufen', ispirač 'Waschmaschine', ispražnjivač 'Entlader', navijača 'Winde', zahvatač 'Kuppelung';

darunter in geringem Masse auch Dokumente: dokazalo 'Beweisstück';

oder Materialien: dolevak 'Füllwein', nagrizalo 'Atzmittel', namaz 'Material zum Streichen', zalepa 'Leim'; oder Orte: 178 zagatac 'Damm', zagrad 'Einfriedung', zajaža 'Wehr'.

Vom onomasiologischen Standpunkt aus handelt es sich bei der wortbildenden Kategorie der nomina instrumenti um eine Modifikation der onomasiologischen Kategorie des Trägers der Handlungsbeziehung, deren eine die der Beziehung des Mittels zu einer Handlung ist, die in enger Wechselbeziehung zu der Modifikation der Beziehung des Agens einer Handlung steht 179 .

178 Orte werden in dem vorliegenden Material vor allem durch nomina instrumenti bezeichnet, deren Maskulina auf $\varnothing$ und Feminina auf -HK-a enden, und die vom onomasiologischen Gesichtspunkt erst sekundär als solche aufgefasst werden können. Näheres dazu Fussnote 181, S. 81.

179 M. Dokulil, Tvořeni slov I, S. 35. 
Auf der wortbildenden Ebene werden nomina instrumenti durch das wortbildende Verfahren der Suffigierung realisiert. Eine Reihe von maskulinen und femininen Substantiven, die vom heutigen Standpunkt eindeutig als nomina instrumenti aufgefasst werden, werden durch das wortbildende Verfahren der Konversion gebildet. Dieses Verfahren muss in diesem Rahmen $z u$ den uneigentlichen Mitteln gezählt werden, sofern man es überhaupt für ein Ableitungsmittel halten kann und nicht für ein semantisches Verfahren der Konkretisierung ursprünglicher nomina actionis im engeren Sinne ${ }^{180}$. Diese Substantive, deren Maskulina mit hartem bzw. weichem stammauslautendem Konsonanten und der Endung $\varnothing$ im Nominativ Singular enden, wie z.B. nakit 'Schmuck', zatak 'Stöpsel', zavoj 'Verband' und Feminina mit hartem stammauslautendem Konsonanten und der Endung -a im Nominativ Singular wie z.B. dopuna 'Ergänzung, Ersatz', namama 'Köder' und zamka 'Schlinge', werden nur bedingt für nomina instrumenti gehalten ${ }^{181}$.

Nomina instrumenti werden von Verben mit den Präfixen do-, iz-, na-, za- in lexikalischer Funktion, von Verben mit den Präfixen na-, do- in modifizierender Funktion und von Verben mit den reihenden Präfixen iz-, na-, za- und dem leeren na- in rein perfektivierender Funktion abgeleitet.

Folgende Formantien finden bei der Ableitung von nomina instrumenti Verwendung:

Maskulina: I. -ac, -ač, -aj, -ak, -anj, -nik, -njak, II. -HK-Ø und $-w K-\emptyset^{182}$

Feminina: I. $-\operatorname{ač}(a),-a l j k(a),-\operatorname{ancij}(a),-i c(a),-k(a),-n i c(a)$, II. $-\mathrm{HK}-\mathrm{a}$

Neutra: I. $-I(0)$.

Nach der Produktivität ergibt sich für die gesamte wortbildende Kategorie der nomina instrumenti folgendes Bild:

Maskulina: I. a) sehr produktiv: -ač, b) weniger produktiv: -ak,

180 J. Kuchař, in: Tvořeni slov II, S. 195.

181 Nomina instrumenti, die mit $-H K-\varnothing$ bzw. $-W K-\varnothing$ und $-H K-a$ enden, werden nur dann in diese wortbildende Kategorie aufgenommen, wenn sie vom heutigen Standpunkt eine primâre Bedeutung des Mittels zu einem Zweck aufweisen. Substantive dieses Typs, die neben der primären Handlungsbedeutung eine sekundäre Bedeutung des Mittels zu einer Handlung aufweisen, werden zur wortbildenden Kategorie der nomina actionis gezählt.

182 -WK- $\varnothing$ steht in verkürzter Ausdrucksweise für maskuline Substantive mit weichem stammauslautendem Konsonanten und der Endung $\varnothing$ im Nominativ Singular (Deklinationstyp "muž"). 
-anj, -ac, c) unproduktiv: -nik, -njak, d) ganz unproduktiv: $-a j$, II. a) sehr produktiv: $-H K-\varnothing$, d) ganz unproduktiv: $-W K-\varnothing$

Feminina: I. a) sehr produktiv: $-a c ̌(a)$, b) weniger produktiv: $-k(a),-\operatorname{nic}(a),-a l j k(a),-i c(a), d)$ ganz unproduktiv: -ancij(a), II. a) sehr produktiv: $-\mathrm{HK}-\mathrm{a}$

Neutra: I. b) weniger produktiv: $-1(0)$.

Nomina instrumenti werden generell ganz überwiegend von Verben mit Präfixen der lexikalischen Funktion abgeleitet, wobei die maskulinen Substantive überwiegen. In geringem Masse werden nomina instrumenti von Verben mit reihenden Präfixen der rein perfektivierenden und in ganz geringem Masse von Verben mit leeren Präfixen der rein perfektivierenden und von solchen mit Präfixen der modifizierenden Funktion gebildet.

Nomina instrumenti mit Präfixen der lexikalischen Funktion werden am häufigsten von Verben mit dem Präfix za- vor denen mit den Präfixen na-, iz-, do- abgeleitet.

Nomina instrumenti mit Präfixen der modifizierenden Funktion werden am häufigsten von Verben mit dem Präfix na- vor denen mit dem Präfix do- abgeleitet.

Nomina instrumenti mit reihenden Präfixen der rein perfektivierenden Funktion werden am häufigsten von Verben mit dem Präfix za- vor denen mit den Präfixen iz- und na- abgeleitet, während solche mit leeren Präfixen nur durch na- motiviert sind.

Der wortbildende Typ auf -ač bildet den Kern der maskulinen Substantive von Verben mit Präfixen der lexikalischen und von solchen von Verben mit reihenden Präfixen der rein perfektivierenden Funktion.

Die wortbildenden Typen auf $-\mathrm{HK}-\mathrm{a}$ und $-\mathrm{ač}(\mathrm{a})$ bilden den Kern der femininen Substantive von Verben mit Präfixen der lexikalischen Funktion und die auf $-\mathrm{HK}-\mathrm{a}$ den Kern der femininen Substantive von Verben mit Präfixen der rein perfektivierenden Funktion. Neutrale nomina instrumenti sind ausschliesslich durch den wortbildenden Typ auf $-1(0)$ vertreten.

Die Ableitungsbasis der nomina instrumenti bilden der Grundstamm, der Stamm des Partizip Präteritum Aktiv und der Infinitivstamm, wobei Ableitungen vom Grundstamm überwiegen.

Nomina instrumenti, die mit Hilfe der Suffigierung gebildet worden sind, sind durch Verben aller Konjugationen motiviert.

Den Kern der Ableitungsbasis der Ableitungen von Verben mit Präfixen der lexikalischen Funktion bildet der Grundstamm von 
Verben der 5. und 4. Konjugation, den der Ableitungen von Verben mit Präfixen der modifizierenden Funktion der Grundstamm von Verben der 5. Konjugation und den der Ableitungen von Verben mit Präfixen der rein perfektivierenden Funktion der Grundstamm von Verben der 4., 5. Konjugation.

Nomina instrumenti, die mit Hilfe der Konversion gebildet worden sind, sind durch Verben aller Konjugationen mit Ausnahme derer der 3. motiviert. Den Kern der Ableitungsbasis der Ableitungen von Verben mit Präfixen der lexikalischen und rein perfektivierenden Funktion bilden Verben der 4. Konjugation und den der Ableitungen von Verben mit Präfixen der modifizierenden Funktion Verben der 6. Konjugation.

Nomina instrumenti nach dem Ableitungsverfahren, dem Ableitungsstamm und der Konjugation:

A. Lexikalische Funktion

I. Suffigierung

1. Grundstamm

Maskulina: 5., 4., 6., 1., 2., 3. Konjugation

Feminina: 5., 4., 1.,2. Konjugation

2. Stamm des Partizip Präteritum Aktiv

Maskulina: 5. Konjugation

3. Infinitivstamm

Neutra: 5. Konjugation

II. Konversion

Maskulina: 5., 4., 1., 2. Konjugation

Feminina: 4., 2., 1. Konjugation.

B. Modifizierende Funktion

I. Suffigierung

1. Grundstamm

Maskulina: 6., 4. Konjugation

Ferinina: 5. Konjugation

3. Infinitivstamm

Neutra: 5., 6. Konjugation

II. Konversion

Maskulina: 6. Konjugation.

C. Rein perfektivierende Funktion

a) reihende Präfixe

I. Suffigierung

1. Grundstamm 
Maskulina: 5., 6., 4., 1., 2. Konjugation

Feminina: 5., 4., 2. Konjugation

2. Infinitivstamm

Neutra: 5. Konjugation

II. Konversion

Maskulina: 4., 5., 1. Konjugation

Feminina: 4. Konjugation

b) leere Präfixe

I. Suffigierung

1. Grundstamm

Maskulina: 4. Konjugation

Feminina: 1. Konjugation

4. Stamm des Partizip Präteritum Passiv

Maskulina: 1. Konjugation

II. Konversion

Maskulina: 1., 5. Konjugation

Feminina: 4. Konjugation.

Nomina instrumenti werden generell etwas häufiger von perfektiven als von imperfektiven Verben abgeleitet.

Nomina instrumenti mit Präfixen der lexikalischen Funktion werden häufiger von imperfektiven Verben abgeleitet, wenn die Ableitung mittels der Suffigierung geschieht, und häufiger von perfektiven Verben, wenn die Ableitung mittels der Konversion geschieht.

Nomina instrumenti mit Präfixen der modifizierenden und rein perfektivierenden Funktion werden häufiger von perfektiven Verben abgeleitet, sowohl wenn die Ableitung mittels der Suffigierung als auch wenn sie mittels der Konversion geschieht.

Die formale Aspektopposition hat sich, wie die Beispiele zakivak zu ipf. zakivati und zakovak zu pf. zakovati 'Niete' sowie navijača zu ipf. navijati und navitnjak (pokr.) zu pf. naviti 'Haspel, Winde' zeigen, bei den nomina instrumenti in ganz beschränktem Umfange bewahrt.

Die wortbilderde Kategorie der nomina instrumenti als die Realisierung einer der Modifikationen der onomasiologischen Kategorie des Trägers der Handlungsbeziehung lässt prinzipiell über das gemeinsame Merkmal der Handlung Berührungspunkte zu anderen wortbildenden Kategorien zu.

Unter dem Gesichtspunkt der Bedeutung der Präfixe der ableitenden Verben ergibt sich für das Vorkommen der nomina instrumenti folgendes Bild: 
In lexikalischer Funktion werden nomina instrumenti von Verben mit nachstehenden Präfixen und ihren Bedeutungen abgeleitet: do- L2 'zu (etwas) hinzu(fügen)' (dopuna 'Ergänzung' von dopuniti 'ergänzen');

L3 'bis zu (etwas gelangen)' (dočekač 'Klinkenhaken' von dočekati 'aufnehmen, empfangen');

iz- Il ' (etwas) von innen nach aussen (oder) von unten nach oben (bewegen)' (izvojač 'Korkenzieher' von izviti 'herauswinden'); na- Il '(einen Gegenstand) auf (einen anderen stellen)' (nabadač 'Pfrieme' von nabadati 'aufstecken, aufspiesser.');

za- LI '(etwas) hinter (etwas stellen)' (zabadača 'Nadel mit Kopf' von zabadati 'hineinstechen, feststecken');

I2 '(umfassen) von allen Seiten' (zakovica 'Niete' von zakovati 'nieten, verschmieden');

L3 '(umfassen) der äusseren Hülle' (zasena 'Lampenschirm' von zaseniti 'beschatten');

L4 'eine Stellung einnehmen' (zadržač 'Haltevorrichtung' von zadržati 'an-, aufhalten');

In modifizierender Funktion werden nomina instrumenti von Verben mit nechstehenden Präfixen und ihren Bedeutungen abgeleitet:

na- MI '(eine Handlung) in ausreichendem Masse (ausführen)' (nakovanj 'Amboss' von nakovati 'genug schmieden'); M2 '(eine Handlung) in geringem Masse (ausführen)' (nagrizalo 'Atzmittel' von nagrizati 'anbeissen');

In reihender Funktion werden nomina instrumenti von Verben mit nachstehenden Präfixen und ihren Bedeutungen abgeleitet: Das Präfix iz- kann in Zusammensetzung mit Verben in der Bedeutung (R1) 'von weg, heraus' und in der Bedeutung (R2) 'ausführen bis zum Erreichen des Ziels, bis zur Ausschöpfung der Möglichkeit' mit seinen jeweiligen Bedeutungsnuancen reihende Funktion ausüben. Die Bedeutungsnuancen der Bedeutung RI sind: RId 'ausschneiden' (isekač 'etwas, womit man schneidet'); RIh 'sichverlieren' (isparivač 'Apparat zum Verdunsten' von isparivati 'verdunsten'); Rlj 'Reștgruppe' (z.B. izdizač 'Hebevorrichtung' von izdizati 'auf-, emporheben');

Die Bedeutungsnuancen der Bedeutung R2 sind: R2a 'versehen mit einem neuen Gepräge' (ispražnjivač 'Entlader' von izpražnjivati 'entladen'); R2f 'erreichen des gewünschten Resultats durch geistige oder ähnliche Arbeit' (ispričnica 'Entschuldigungsschreiben' von ispričati 'entschuldigen'); 
Das Präfix na- kann in Zusammensetzung mit Verben in der Bedeutung (RI) 'stellen eines Gegenstandes auf einen anderen' und in ( $R 2$ ) der 'Augmentation' mit seinen jeweiligen Bedeutungsnuancen reihende Funktion ausüben. Die Bedeutungsnuancen der Bedeutung RI sind: Rla 'auftragen' (nakit 'Schmuck' von nakititi 'schmücken');

Die Bedeutungsnuancen der Bedeutung R2 sind: R2a 'anhäufen, etwas in Menge tun' (nadev (kuv.) 'Füllsel' von nadevati 'anmachen'); R2c 'anschwellen, zunehmen' (napinjač 'Gerät zum Spannen' von napinjati 'aufrichten, spannen');

Das Präfix za- kann in Zusammensetzung mitVerben in der Bedeutung (RI) 'hinter etwas gehen' und in (R2) 'einen neuen Zustand einnehmen' mit seinen jeweiligen Bedeutungsnuancen reihende Funktion ausüben. Die Bedeutungsnuancen der Bedeutung RI sind: Rla 'umdrehen' (zamotač 'Umschlag, Verpackung' von zamotati 'einwikkeln'); Rlb 'umfassen eines Teils oder des Ganzen' (zagrtač 'Mantel' von zagrtati 'überschlagen'); Rlf 'verschliessen und hindern' (zagatac 'Wehr, Damm' von zagatiti 'abdämmen'); Rlg 'schützen und nicht erlauben' (zaštitak 'Schild' von zaštititi 'schützen'); Rli 'Restgruppe (z.B. zamajac 'Schwungrad' von zamahati 'schwingen');

Die Bedeutungsnuancen der Bedeutung $R 2$ sind: $R 2 b$ 'versehen mit einer neuen Eigenschaft' (zašiljač 'Bleistiftanspitzer' von zašiljiti 'zuspitzen').

Material

A. Lexikalische Funktion

AA. Nomina instrumenti von Verben mit dem Präfix do- in lexikalischer Funktion

Die Ableitungsverfahren: I. Suffigierung, II. Konversion

Die wortbildenden Typen nach ihren Formantien, ihrer Produktivität und den Bedeutungen der Präfixe der ableitenden Verben mit ihrer Häufigkeit:

Maskulina: I. -ač (1), Bed.: L3 (1), -ak (2), Bed.: I2 (2)

Feminina: II. $-\mathrm{HK}-\mathrm{a}$ (2), Bed.: L2 (1), L4 (1)

Neutra: I. $-1(0)(2)$, Bed.: L3 (2)

Die Ableitungsstämme und die Konjugationen:

Maskulina: I. 1. Grundstamm der 5. Konjugation

Feminina: II. 4. Konjugation

Neutra: I. 3. Infinitivstamm der 5. Konjugation 
Der Aspekt der Ableitungsbasis:

Maskulina: I. 1 pf. und 2 ipf. Verben

Feminina: II. 2 pf. Verben

Neutra: I. 1 pf. und 1 ipf. Verb

Maskulina

I. Suffigierung

Ableitungen mit dem Formars - ač

Bed.: L3, a) vom pf. Aspekt, 1. vom Grundstamm, der 5. Konjugation dočekač 'Klinkenhaken'

Ableitungen mit dem Formans -ak

Bed.: L2, b) vom ipf. Aspekt, 1. vom Grundstamm, der 5. Konjugation

dolevak, dolivak 'Füllwein; Wein, mit dem das Fass gefüllt wird', dopunjak 'Ersatz; etwas, was zum Ergänzen dient'

Feminina

II. Konversion

Ableitungen auf $-\mathrm{HK}-\mathrm{a}$

Bed.: L2, a) vom pf. Aspekt, der 4. Konjugation

dopuna 'Ergänzung; Ersatz'

Bed.: L4, a) vom pf. Aspekt, der 4. Konjugation

dosuda 'Urteilsspruch'

Neutra

I. Suffigierung

Ableitungen mit dem Formans $-1(0)$

Bed.: L3, a) vom pf. Aspekt, 3. vom Infinitivstamm, der 5. Konjugation

dokazalo 'Beweismittel'

b) vom ipf. Aspekt, 3. vom Infinitivstamm, der 5. Konjugation dozivalo 'Sprachrohr, Vorrichtung zum Rufen'

AB. Nomina instrumenti von Verben mit dem Präfix $\underline{\text { iz- }}$ in lexikalischer Funktion

Die Ableitungsverfahren: I. Suffigierung, II. Konversion

Die wortbildenden Typen nach ihren Formantien, ihrer Produktivi-

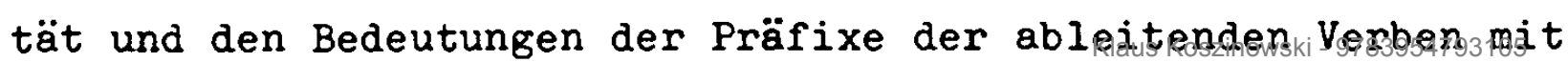


ihrer Häufigkeit:

Maskulina: I. -ac (1), Bed.: Ll (1), -ač (4), Bed.: Ll (4) II. $-W K-\varnothing(1)$, Bed.: Ll (1)

Feminina: I. -ač(a) (1), Bed.: Il (1), II. -HK-a (1), Bed.: Ll (1)

Neutra: I. -l(0) (1), Bed.: Il (1)

Die Ableitungsstämme und die Konjugationen:

Maskulina: I. 1. Grundstamm der 5., 6., 4., 1. Konjugation, II. 1. Konjugation

Feminina: I. 1. Grundstamm der 5. Konjugation, II. 1. Konjugation Neutra: I. 3. Infinitivstamm der 5. Konjugation

Der Aspekt der Ableitungsbasis:

Maskulina: I. 1 pf. und 4 ipf. Verben, II. 1 pf. Verb

Feminina: I. 1 ipf. Verb, II. I pf. Verb

Neutra: I. 1 ipf. Verb

Maskulina

I. Suffigierung

Ableitungen mit dem Formans -ac

Bed.: Ll, a) vom pf. Aspekt, 1. vom Grundstamm, der 1. Konjugation izvojac 'Korkenzieher'

Ableitungen mit dem Formans -ač

Bed.: Ll, b) vom ipf. Aspekt, 1. vom Grundstamm, der 5. Konjugation

izbijač 'Stosseisen', ispirač 'Apparat zum Waschen', isprašač, isprašivač 'Vorrichtung zum Abstauben'

der 4. Konjugation

izvlakač 'Vorrichtung zum Herausziehen der Hülse bei Feuerwaffen'

II. Konversion

Ableitungen auf $-W K-\varnothing$

Bed.: Ll, a) vom pf. Aspekt, der 1. Konjugation izboj 'Setzling'

Feminina

I. Suffigierung

Ableitungen mit dem Formans - ač(a)

Bed.: Ll, b) vom ipf. Aspekt, 1. vom Grundstamm, der 5. Konju- 
gation

\section{ispirača 'Waschlappen'}

II. Konversion

Ableitungen auf $-\mathrm{HK}-\mathrm{a}$

Bed.: LI, a) vom pf. Aspekt, der 1. Konjugation

izreka 'Satz oder Gruppe von Wörtern, mit denen etwas ausgesagt wird'

Neutra

I. Suffigierung

Ableitungen mit dem Formans - $1(0)$

Bed.: Ll, b) vom ipf. Aspekt, 3. vom Infinitivstamm, der 5. Konjugation

istezalo 'Gerät, mit dem man ein Boot ans Ufer zieht'

AC. Nomina instrumenti von Verben mit dem Präfix na- in lexikalischer Funktion

Die Ableitungsverfahren: I. Suffigierung, II. Konversion

Die wortbildenden Typen nach ihren Formantien, ihrer Produktivität und den Bedeutungen der Präfixe der ableitenden Verben mit ihrer Häufigkeit:

Maskulina: I. -ač (3), Bed.: Il (3), -ak (4), Bed.: Ll (4), -anj (1), Bed.: LI (1), -nik (1), Bed.: II (1), -njak (1), Bed.: II (1), II. -HK- $\varnothing$ (1), Bed.: II (1)

Feminina: I. -ač(a) (5), Bed.: LI (5), -aljk(a) (3), Bed.: LI (3), $-\mathrm{k}(a)$ (1), Bed.: Ll (1), $-\operatorname{nic}(a)$ (3), Bed.: Il (3), II. -HK-a (3), Bed.: LI (3)

Neutra: I. $-1(0)$ (2), Bed.: Ll (2)

Die Ableitungsstämme und die Konjugationen:

Maskulina: I. 1. Grundstamm der 5., 4., 1., 2. Konjugation, II. 5. Konjugation

Feminina: I. 1. Grundstamm der 4., 5., 1., 2. Konjugation, II. 4., 2. Konjugation

Neutra: I. 3. Infinitivstamm der 5. Konjugation Der Aspekt der Ableitungsbasis:

Maskulina: I. 3 pf. und 7 ipf. Verben, II. 1 ipf. Verb

Feminina: I. 4 pf. und 8 ipf. Verben, II. 2 pf. und 1 ipf. Verb Neutra: I. 2 ipf. Verben 
Maskulina

I. Suffigierung

Ableitungen mit dem Formans - ač

Bed.: Ll, a) vom pf. Aspekt, 1. vom Grundstamm, der 2. Konjugation nategač 'Reifenziehe'

b) vom ipf. Aspekt, 1. vom Grundstamm, der 5. Konjugation nabadač 'Pfrieme', nabijač 'Erdschlägel, Pflasterramme'

Ableitungen mit dem Formans -ak

Bed.: Ll, a) vom pf. Aspekt, 1. vom Grundstamm, der 4. Konjugation nastavak 'Fortsetzung'

b) vom ipf. Aspekt, 1. vom Grundstamm, der 5. Konjugation nadevak (neob.) 'Spitzname', navrtak 'Pfropfreis'

der 4. Konjugation

navlačak 'Gamasche'

Ableitungen mit dem Formans -anj

Bed.: II, b) vom ipf. Aspekt, 1. vom Grundstamm, der 5. Konjugation

navrtanj 'Schraubenmutter'

Ableitungen mit dem Formans -nik

Bed.: Il, b) vom ipf. Aspekt, 1. vom Grundstamm, der 4 . Konjugation

navodnici Pl. 'Anführungsstriche'

Ableitungen mit dem Formans -njak

Bed.: LI, a) vom pf. Aspekt, 1. vom Grundstamm, der 1. Konjugation navitnjak (pokr.) 'Winde, Haspel'

II. Konversion

Ableitungen auf $-H K-\varnothing$

Bed.: Il, b) vom ipf. Aspekt, der 5. Konjugation navrt 'Pfropfreis'

Feminina

I. Suffigierung 
Ableitungen mit dem Formans -ač(a)

Bed.: Ll, a) vom pf. Aspekt, 1. vom Grundstamm, der 1. Konjugation nabodača 'Nadel zum Anheften'

der 2. Konjugation

nategača ' 1 . Vorrichtung zum Umfüllen einer Flüssigkeit,

2. Reifziehe'

b) vom ipf. Aspekt, 1. vom Grundstamm, der 5. Konjugation nabijača 'Stockfischschlägel', navijača 'Winde, Haspel', der 4. Konjugation navlakača (pokr.) 'Sock; weiches Schuhzeug'

Ableitungen mit dem Formans -aljk(a)

Bed.: Il, b) vom ipf. Aspekt, 1. vom Grundstamm, der 5. Konjugation

nabadaljka 'Gabel', namataljka 'Aufwinder', navijaljka

'Hebewinde'

Ableitungen mit dem Formans - $k(a)$

Bed.: Ll, b) vom ipf. Aspekt, 1. vom Grundstamm, der 5. Konjugation

navrtka 'Schraubenmutter'

Ableitungen mit dem Formans -nic(a)

Bed.: Ll, a) vom pf. Aspekt, 1. vom Grundstamm, der 4. Konjugation nalepnica 'Aufkleber, Etikett', naselnica (pokr.) 'Balken auf der Mauer, an dessen Enden die Balken des Deckenbretts angelehnt werden'

b) vom ipf. Aspekt, 1. vom Grundstamm, der 4. Konjugation navodnica 'Webfaden'

1I. Konversion

Ableitungen auf $-\mathrm{HK}-\mathrm{a}$

Bed.: Il, a) vom pf. Aspekt, der 2. Konjugation natega 'Vorrichtung zum Umfüllen einer Flüssigkeit, 2. Reifziehe'

der 4. Konjugation nastava (neob.) 'Stück Stoff, das an ein Kleid angestückt wird'

b) vom ipf. Aspekt, der 4. Konjugation 
navlaka 'Uberzug'

Neutra

I. Suffigierung

Ableitungen mit dem Formans $-I(0)$

Bed.: LI, b) vom ipf. Aspekt, 3. vom Infinitivstamm, der 5. Konjugation

nabadalo 'Pfrieme', navijalo 'Hebewinde'

AD. Nomina instrumenti von Verben mit dem Präfix za- in lexikalischer Funktion

Die Ableitungsverfahren: I. Suffigierung, II. Konversion

Die wortbildenden Typen nach ihren Formantien, ihrer Produktivität und den Bedeutungen der Präfixe der ableitenden Verben mit ihrer Häufigkeit:

Maskulina: I. -ac (2), Bed.: LI (1), L2 (1), -ač (8), Bed.: Ll

(5), L2 (2), L4 (1), -ak (5), Bed.: L1 (2), L2 (3),

$-\operatorname{anj}(3)$, Bed.: Ll (2), L2 (1), -nik (1), Bed.: L2

(1), II. $-\mathrm{HK}-\varnothing$ (8), Bed.: LI (6), L2 (2), -WK- $\varnothing$ (1), Bed.: LI (1)

Feminina: I. -ač(a) (4), Bed.: Ll (3), L2 (1), -8ljk(a) (1), Bed.: LI (1), $-i c(a)$ (2), Bed.: LI (1), L2 (1), $-k(a)$ (3), Bed.: Ll (2), L2 (1), $-\operatorname{nic}(a)$ (1), Bed.:

L2 (1), II. -HK-a (5), Bed.: LI (3), L2 (1), L3 (1)

Die Ableitungsstämme und die Konjugationen:

Maskulina: I. 1. Grundstamm der 5., 4., 1., 3., 6. Konjugation,

2. Stamm des Partizip Präteritum Aktiv der

5. Konjugation

II. 5., 4., 1., 2. Konjugation

Feminina: I. 1. Grundstamm der 5., 4., 1. Konjugation, 1I. 4., 2., 1. Konjugation

Der Aspekt der Ableitungsbasis:

Maskulina: I. 8 pf. und 11 ipf. Verben, II. 7 pf. und 2 ipf. Verben

Feminina: I. 4 pf. und 7 ipf. Verben, II. 5 pf. Verben

Maskulina

I. Suffigierung 
Ableitungen mit dem Formans -ac

Bed.: Ll, a) vom pf. Aspekt, 1. vom Grundstamm, der 1. Konjugation zaponac 'Speiche, Gegenstand, der zum Halten dient'

Bed.: L2, a) vom pf. Aspekt, 1. vom Grundstamm, der 4. Konjugation zaklopac 'Deckel'

Ableitungen mit dem Formans -ač

Bed.: Ll, b) vom ipf. Aspekt, 1. vom Grundstamm, der 5. Konjugation

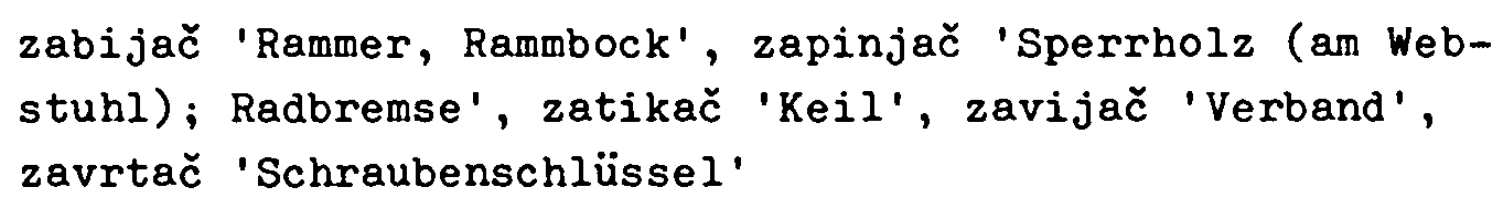

Bed.: L2, b) vom ipf. Aspekt, 1. vom Grundstamm, der 5. Konjugation

zakivač 'Vorrichtung zur Vereinigung von Blechen und ähnlichen metallischen Gegenständen', zasipač (zast.) 'Aufschütter'

Bed.: L4, a) vom pf. Aspekt, 1. vom Grundstamm, der 3. Konjugation zadržač 'Haltevorrichtung'

Ableitungen mit dem Formans -ak

Bed.: Ll, a) vom pf. Aspekt, 1. vom Grundstamm, der 1. Konjugation zaponak 'Manschette', zavojak 'Locke; Gewinde; Windung'

Bed.: L2, a) vom pf. Aspekt, 1. vom Grundstamm, der 4. Konjugation zaklopak 'Deckel, Stürze'

der 6. Konjugation

zakovak 'Niete'

b) vom ipf. Aspekt, 1. vom Grundstamm, der 5. Konjugation zakivak 'Niete'

Ableitungen mit dem Formans -anj

Bed.: Ll, b) vom ipf. Aspekt, 1. vom Grundstamm, der 5. Konjugation

zabadanj 'hölzerner oder eiserner Keil am Wagen', zavrtanj 'Schraubenbolzen'

Bed.: L2, a) vom pf. Aspekt, 1. vom Grundstamm, der 4. Konjugation zagažanj 'Zugnetz' 
Ableitungen mit dem Formans -nik

Bed.: L2, b) vom ipf. Aspekt, 2. vom Stamm des Partizip Präteritum Aktiv, der 5. Konjugation

zalevaonik 'Giesskanne'

II. Konversion

Ableitungen auf $-\mathrm{HK}-\varnothing$

Bed.: LI, a) vom pf. Aspekt, der 5. Konjugation zamot 'Umschlag, Verpackung', zavez 'Band'

der 1. Konjugation zatak 'Stöpsel'

der 2. Konjugation zasun 'Torriegel'

b) vom ipf. Aspekt, der 5. Konjugation zakret 'Verband; Spirale', zatik 'Stöpsel, Pfropfen'

Bed.: L2, a) vom pf. Aspekt, der 4. Konjugation zagrad 'Einfriedung, Zaun', zaklop 'Riegel'

Ableitungen auf $-W K-\varnothing$

Bed.: $L 1$, a) vom pf. Aspekt, der 1. Konjugation zavoj 'Verband; Umschlag'

Feminina

I. Suffigierung

Ableitungen mit dem Formans - ač (a)

Bed.: Ll, b) vom ipf. Aspekt, 1. vom Grundstamm, der 5. Konjugation

zabadača 'Nadel mit Kopf', zapinjača 'Sperrriegel', zavijača 'Strudel'

Bed.: L2, b) vom ipf. Aspekt, 1. vom Grundstamm, der 5. Konjugation

zalevača 'Giesskanne'

Ableitungen mit dem Formans -aljk(a)

Bed.: Ll, b) vom ipf. Aspekt, 1. vom Grundstamm, der 5. Konjugation

zavrtaljka 'Bezeichnung für verschiedene Geräte, mit denen etwas festgeschraubt wird' 
Ableitungen mit dem Formans -ic(a)

Red.: Ll, a) vom pf. Aspekt, 1. vom Grundstamm, der 5. Konjugation zavezice 'Handfessel'

Bed.: L2, a) vom pf. Aspekt, 1. vom Grundstamm, der 6. Konjugation zakovica 'Niete'

Ableitungen mit dem Formans - $k(a)$

Bed.: LI, a) vom pf. Aspekt, 1. vom Grundstamm, der 1. Konjugation zaponka 'Manschette'

b) vom ipf. Aspekt, 1. vom Grundstamm, der 5. Konjugation zavrtka 'Schraubenmutter'

Bed.: L2, b) vom ipf. Aspekt, 1. vom Grundstamm, der 5. Konjugation

zakivka 'Niete'

Ableitungen mit dem Formans -nic(a)

Bed.: I2, a) vom pf. Aspekt, 1. vom Grundstamm, der 4. Konjugation zaklopnica 'Deckel; Helm'

1I. Konversion

Ableitungen auf $-\mathrm{HK}-\mathrm{a}$

Bed.: Ll, a) vom pf. Aspekt, der 2. Konjugation zamka 'Schlinge', zatega 'Vorrichtung zum Spannen'

der 1. Konjugation zapona (pom.) 'Seil'

Bed.: L2, a) vom pf. Aspekt, der 4. Konjugation zalepa 'Leim'

Bed.: L3, a) vom pf. Aspekt, der 4. Konjugation zasena '1. Lampenschirm, 2. Schatten'

B. Modifizierende Funktion

BA. Nomina instrumenti von Verben mit dem Präfix do- in modifizierender Funktion

Die Ableitungsverfahren: I. Suffigierung

Die wortbildenden Typen nach ihren Formantien, ihrer Produktivi- 
tät und den Bedeutungen der Präfixe der ableitenden Verben mit inrer Häufigkeit:

Feminina: I. -k(a) (1), MI (1)

Die Ableitungsstämme und die Konjugationen:

Feminina: I. 1. Grundstamm der 5. Konjugation

Der Aspekt der Ableitungsbasis:

Feminina: I. 1 pr. Verb

Feminina

I. Suffigierung

Ableitungen mit dem Formans $-k(a)$

Bed.: MI, a) vom pf. Aspekt, 1. vom Grundstamm, der 5. Konjugation dopevka 'Ende, Abschluss des Liedes'

BC. Nomina instrumenti von Verben mit dem Präfix na- in modifizierender Funktion

Die Ableitungsverfahren: I. Suffigierung, II. Konversion

Die wortbildenden Typen nach ihren Formantien, ihrer Produktivität und den Bedeutungen der Präfixe der ableitenden Verben mit ihrer Häufigkeit:

Maskulina: I. -ač (1), Bed.: M2 (1), -anj (1), Bed.: MI (1), II. $-\mathrm{HK}-\varnothing$ (I), Bed.: MI (1)

Neutra: I. $-1(0)$ (2), Bed.: MI (1), M2 (1)

Die Ableitungsstämme und die Konjugationen:

Maskulina: I. 1. Grundstamm der 4., 6. Konjugation, II. 6. Konjugation

Neutra: I. 3. Infinitivstamm der 5., 6. Konjugation

Der Aspekt der Ableitungsbasis:

Maskulina: I. 2 pf. Verben, II. 1 pf. Verb

Neutra: I. I pf. und 1 ipf. Verb

Maskulina

I. Suffigierung

Ableitungen mit dem Formans -ač

Bed.: M2, a) vom pf. Aspekt, 1. vom Grundstamm, der 4. Konjugation napaljač 'Vorrichtung zum Anzünden' 
Bed.: MI, a) vom pf. Aspekt, 1. vom Grundstamm, der 6. Konjugation nakovanj 'Amboss'

II. Konversion

Ableitungen auf $-\mathrm{HK}-\varnothing$

Bed.: MI, a) vom pf. Aspekt, der 6. Konjugation nakov (pokr.) 'Amboss'

Neutra

I. Suffigierung

Ableitungen mit dem Formans $-1(0)$

Bed.: Ml, a) vom pf. Aspekt, 3. vom Infinitivstamm, der 6. Konjugation

\section{nakovalo 'Amboss'}

Bed.: M2, b) vom ipf. Aspekt, 3. vom Infinitivstamm, der 5. Konjugation

nagrizalo 'Atzmittel'

C. Rein perfektivierende Funktion

$\mathrm{CB}$. Nomina instrumenti von Verben mit dem Präfix $\underline{\text { iz- }}$ in rein perfektivierender Funktion

a) $\underline{i z}-$ als reihendes Präfix

Die Ableitungsverfahren: I. Suffigierung

Die wortbildenden Typen nach ihren Formantien, ihrer Produktivität und den Bedeutungen der Präfixe der ableitenden Verben mit ihrer Häufigkeit:

Maskulina: I. -ač (6), Bed.: Rld (1), Rlh (1), Rlj (2), R2a (2) Feminina: I. $-\operatorname{nic}(a)(1)$, Bed.: R2f (1)

Die Ableitungsstämme und die Konjugationen:

Maskulina: I. 1. Grundstamm der 6., 1., 5. Konjugation

Feminina: I. 1. Grundstamm der 5. Konjugation

Der Aspekt der Ableitungsbasis:

Maskulina: I. 1 pf. und 5 ipf. Verben

Feminina: I. 1 pf. Verb

Maskulina

I. Suffigierung 
Ableitungen mit dem Formans - ač

Bed.: Rld, a) vom pf. Aspekt, l. vom Grundstamm, der 1. Konjugation

isekač 'etwas, womit man schneidet'

Bed.: Rlh, b) vom ipf. Aspekt, l. vom Grundstamm, der 6. Konjugation

isparivač 'Apparat zum Verdampfen'

Bed.: RIj, b) vom ipf. Aspekt, l. vom Grundstamm, der 5. Konjugation

izdizač 'Hebevorrichtung', ispuštač 'Vorrichtung zum

Herauslassen'

Bed.: R2a, b) vom ipf. Aspekt, 1. vom Grundstamm, der 6. Konjugation

izmenjivač 'Vorrichtung, mit der man die Richtung oder

Stärke der Energie verändert', ispražnjivač 'Entlader'

Feminina

I. Suffigierung

Ableitungen mit dem Formans -nic(a)

Bed.: R2f, a) vom pf. Aspekt, 1. vom Grundstamm, der 5. Konjugation

ispričnica 'Entschuldigungsschreiben'

CC. Nomina instrumenti von Verben mit dem Präfix na- in rein perfektivierender Funktion

a) na- als reihendes Präfix

Die Ableitungsverfahren: I. Suffigierung, II. Konversion

Die wortbildenden Typen nach ihren Formantien, ihrer Produktivität und den Bedeutungen der Präfixe der ableitenden Verben mit ihrer Häufigkeit:

Maskulina: I. -ač (1), Bed.: R2c (1), II. -HK- $\varnothing$ (3), Bed.: Rla (2), $\mathrm{R} 2 \mathrm{a}(1)$

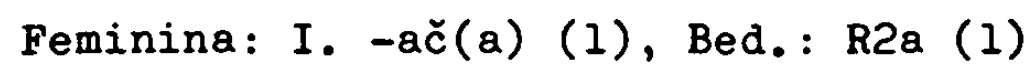

Die Ableitungsstämme und die Konjugationen:

Maskulina: I. 1. Grundstamm der 5. Konjugation,

II. 5., 4. Konjugation

Feminina: I. 1. Grundstamm der 5. Konjugation

Der Aspekt der Ableitungsbasis:

Maskulina: I. 1 ipf. Verb, II. 2 pf. und I ipfaus Kerfibski-9783954793105 
Feminina: I. 1 pf. Verb

Maskulina

I. Suffigierung

Ableitungen mit dem Formans -ač

Bed.: R2c, b) vom ipf. Aspekt, 1. vom Grundstamm, der 5. Konjugation

napinjač 'Gerät zum Spannen'

II. Konversion

Ableitungen auf $-H K-\varnothing$

Bed.: Rla, a) vom pf. Aspekt, der 4. Konjugation nakit 'Schmuck'

der 5. Konjugation

namaz 'Material zum Bestreichen'

Bed.: R2a, b) vom ipf. Aspekt, der 5. Konjugation nadev (kuv.) 'Füllsel, Spickmittel'

Feminina

I. Suffigierung

Ableitungen mit dem Formans -ač(a)

Bed.: R2a, a) vom pf. Aspekt, 1. vom Grundstamm, der 5. Konjugation

nasejača (pokr.) 'Sämaschine'

b) na- als leeres Präfix

Die Ableitungsverfahren: I. Suffigierung, II. Konversion Die wortbildenden Typen nach ihren Formantien sowie ihre Produktivität:

Maskulina: I. $-\operatorname{aj}(1),-a k(1), I I .-H K-\varnothing(1),-W K-\varnothing$ (I)

Feminina: I. $-i c(a)(1),-k(a)(1),-n i c(a)$ (2), II. - HK-a (2)

Die Ableitungsstämme und die Konjugationen:

Maskulina: I. 1. Grundstamm der 4. Konjugation, 4. Stamm des Partizip Präteritum Passiv der 1. Konjugation, II. 1., 5. Konjugation

Feminina: I. 1. Grundstamm der 4., 1. Konjugation, II. 4. Konjugation

Der Aspekt der Ableitungsbasis:

Maskulina: I. 2 pf. Verben, II. 1 pf. und 1 ipf. Verb

Feminina: I. 4 pf. Verben, II. 2 pf. Verben 
Maskulina

I. Suffigierung

Ableitungen mit dem Formans -aj

a) vom pf. Aspekt, 1. vom Grundstamm, der 4. Konjugation nameštaj 'Einrichtung, Möbel'

Ableitungen mit dem Formans -ak

a) vom pf. Aspekt, 4. vom Stamm des Partizip Präteritum Passiv, der 1. Konjugation napitak 'Getränk, Trank'

II. Konversion

Ableitungen auf $-\mathrm{HK}-\varnothing$

b) vom ipf. Aspekt, der 5. Konjugation naziv 'Benennung, Name'

Ableitungen auf $-W K-\varnothing$

a) vom pf. Aspekt, der 1. Konjugation napoj 'Getränk'

Feminina

I. Suffigierung

Ableitungen mit dem Formans -ic(a)

a) vom pf. Aspekt, 1. vom Grundstamm, der 4. Konjugation nazdravica 'Trinkspruch'

Ableitungen mit dem Formans - $k(a)$

a) vom pf. Aspekt, 1. vom Grundstamm, der 1. Konjugation napivka 'Trinkspruch'

Ableitungen mit dem Formans -nic(a)

a) vom pf. Aspekt, 1. vom Grundstamm, der 4. Konjugation namirnica 'Lebensmittel', naputnica (bank.) 'Anweisung'

II. Konversion

Ableitungen auf $-\mathrm{HK}-\mathrm{a}$ 
a) vom pf. Aspekt, der 4. Konjugation namama 'Köder', naprava 'Vorrichtung, Apparat'

CD. Nomina instrumenti von Verben mit dem Präfix za- in rein perfektivierender Funktion

a) za- als reihendes Präfix

Die Ableitungsverfahren: I. Suffigierung, II. Konversion

Die wortbildenden Typen nach ihren Formantien, ihrer Produktivität und den Bedeutungen der Präfixe der ableitenden Verben mit ihrer Häufigkeit:

Maskulina: I. -ac (2), Bed.: Rlf (1), Rli (1), -ač (8), Bed.: Rla (1), Rlb (4), R2b (3), -aj (1), Bed.: Rlb (1), -ak

(3), Bed.: Rlf (2), Rlg (1), -njak (1), Bed.: Rli

(1), II. $-\mathrm{HK}-\varnothing$ (1), Bed.: RIf (1), -WK- $\varnothing$ (1), Bed.: Rle (l)

Feminina: I. $-a c ̌ c(a)(1), \operatorname{Bed} .: \operatorname{Rlb}(1),-a l j k(a)(1), \operatorname{Bed} .:$ Rlb (1), $-\operatorname{ancij}(a)$ (1), Bed.: Rlf (1), -k(a) (3), Bed.: RIb (1), Rlf (2), II. -HK-a (6), Bed.: RIb (1), RIf (3), Rli (1), R2b (1)

Neutra: I. $-1(0)$ ( 1 , Bed.: Rlb (1)

Die Ableitungsstämme und die Konjugationen:

Maskulina: I. 1. Grundstamm der 5., 4., 2., 6. Konjugation, II. 4., 1. Konjugation

Feminina: I. 1. Grundstamm der 4., 2. Konjugation, II. 4. Konjugation

Neutra: I. 3. Infinitivstamm der 5. Konjugation

Der Aspekt der Ableitungsbasis:

Maskulina: I. $10 \mathrm{pf}$. und 5 ipf. Verben, II. 2 pf. Verben Feminina: I. 6 pf. Verben, II. 6 pf. Verben

Neutra: I. 1 ipf. Verb

Maskulina

I. Suffigierung

Ableitungen mit dem Formans -ac

Bed.: Rlf, a) vom pf. Aspekt, 1. vom Grundstamm, der 4. Konjugation

zagatac 'Wehr, Damm'

Bed.: Rli, a) vom pf. Aspekt, 1. vom Grundstamm, der 5. Konju- 
gation

$$
\text { zamajac 'Schwungrad' }
$$

Ableitungen mit dem Formans - ač

Bed.: Rla, a) vom pf. Aspekt, l. vom Grundstamm, der 5. Konjugation

$$
\text { zamotač 'Umschlag, Verpackung' }
$$

Bed.: RIb, a) vom pf. Aspekt, 1. vom Grundstamm, der 2. Konjugation

\section{zagrnjač 'Mantel, Uberwurf'}

b) vom ipf. Aspekt, 1. vom Grundstamm, der 5. Konjugation

zagrtač 'Mantel, Uberwurf', zahvatač 'Kuppelung'

der 6. Konjugation

zaprašivač 'Gerät zum Bestäuben'

Bed.: R2b, a) vom pf. Aspekt, 1. vom Grundstamm, der 4. Konjugation

zašiljač (kov.) 'Bleistiftanspitzer'

der 5. Konjugation

zagrejač 'Apparat zum Wärmen'

b) vom ipf. Aspekt, 1. vom Grundstamm, der 5. Konjugation zagrejavač 'Apparat zum Wärmen'

Ableitungen mit dem Formans - aj

Bed.: Rlb, a) vom pf. Aspekt, l. vom Grundstamm, der 5. Konjugation

$$
\text { zapašaj 'Gürtel' }
$$

Ableitungen mit dem Formans -ak

Bed.: Rlf, a) vom pf. Aspekt, l. vom Grundstamm, der 4. Konjugation

\section{zaglavak 'Keil'}

b) vom ipf. Aspekt, 1. vom Grundstamm, der 5. Konjugation zatisak (pokr.) 'Stöpsel'

Bed.: Rlg, a) vom pf. Aspekt, l. vom Grundstamm, der 4. Konjugation

\section{zaštitak 'Schild'}


Ableitungen mit dem Formans -njak

Bed.: Rli, b) vom ipf. Aspekt, 1. vom Grundstamm, der 5. Konjugation

zamašnjak 'Schwungrad'

II. Konversion

Ableitungen auf $-H K-\varnothing$

Bed.: RIf, a) vom pf. Aspekt, der 4. Konjugation zagat 'Damm'

Ableitungen auf $-W K-\varnothing$

Bed.: Rle, a) vom pf. Aspekt, der 1. Konjugation zapoj 'Trank'

Feminina

I. Suffigierung

Ableitungen mit dem Formans - ač (a)

Bed.: Rlb, a) vom pf. Aspekt, 1. vom Grundstamm, der 2. Konjugation

zapregača 'Schürze'

Ableitungen mit dem Formans -aljk(a)

Bed.: Rlb, a) vom pf. Aspekt, 1. vom Grundstamm, der 4. Konjugation

zakačaljka 'Haken, Wäscheklammer'

Ableitungen mit dem Formans -ancij(a)

Bed.: Rlf, a) vom pf. Aspekt, 1. vom Grundstamm, der 4. Konjugation

zaprekancija 'Hindernis'

Ableitungen mit dem Formans $-k(a)$

Bed.: RIb, a) vom pf. Aspekt, 1. vom Grundstamm, der 4. Konjugation

zakačka 'Gegenstand, mit dem verschiedene Sachen verbunden werden; Haken'

Bed.: RIf, a) vom pf. Aspekt, 1. vom Grundstamm, der 4. Konju- 
gation

zagatka 'Wehr, Damm', zaustavka 'Hindernis'

II. Konversion

Ableitungen auf $-\mathrm{HK}-\mathrm{a}$

Bed.: Rlb, a) vom pf. Aspekt, der 4. Konjugation zaprta 'Achselriemen'

Bed.: Rif, a) vom pf. Aspekt, der 4. Konjugation zaglava (arhit.) 'Schlussstein', zajaža 'Wehr', zapreka 'Hindernis'

Bed.: Rii, a) vom pf. Aspekt, der 4. Konjugation zamama 'Köder'

Bed.: R2b, a) vom pf. Aspekt, der 4. Konjugation zaslada 'Süssmittel, Naschwerk'

Neutra

I. Suffigierung

Ableitungen mit dem Formans -l(o)

Bed.: Rlb, b) vom ipf. Aspekt, 3. vom Infinitivstamm, der 5. Konjugation

zagrtalo 'Uberwurf, Mantel'

Schlussbemerkungen

2a) Nomina instrumenti sind mit folgenden in quantitativer Reihenfolge aufgeführten Präfixen in lexikalischer Funktion gebildet: za-, na-, iz-, do-.

Nomina instrumenti sind mit folgenden in quantitativer Reihenfolge aufgeführten Präfixen in modifizierender Funktion gebildet: na-, do-.

Nomina instrumenti sind mit folgenden in quantitativer Reihenfolge aufgeführten Präfixen in rein perfektivierender Funktion gebildet: a) mit reibenden Präfixen: za-, iz-, na- und b) leeren Präfixen: na-.

Es kann (s. Tabelle $3 a$ ) in rein quantitativer Hinsicht eine starke Affinität von Verben mit dem Präfix za- in lexikalischer Funktion, eine weniger starke von solchen mit na- in lexikalischer und dem reihenden $2 a-$ in rein perfektivierender Funktion, 
eine schwache von solchen mit iz-, do- in lexikalischer Funktion, den reihenden iz-, na- und dem leeren na- in rein perfektivierender Funktion und eine sehr schwache von solchen mit na-, do- in modifizierender Funktion zu nomina instrumenti festgestellt werden.

2b) Nomina instrumenti sind mit Präfixen in folgenden in quantitativer Reihenfolge aufgefürten Funktionen gebildet: der lexikalischen, rein perfektivierenden mit reihenden und leeren Präfixen und modifizierenden Funktion.

Es kann (s. Tabelle 4) in rein quantitativer Hinsicht eine starke Affinität von Verben mit Präfixen in lexikalischer Funktion, eine schwache von solchen mit reihenden Präfixen in rein perfektivierender Funktion und eine sehr schwache von solchen mit Präfixen in modifizierender und von solchen mit leeren Präfixen in rein perfektivierender Funktion konstatiert werden.

Tabelle 3a: Zahlenmässige Angabe über das Vorkommen der nomina instrumenti nach den Funktionen und Präfixen sowie dem Aspekt der ableitenden Verben

Lexikalische Funktion

$\begin{array}{lcccc}\text { Aspekt } & \text { do- } & \text { iz- } & \text { na- } & \text { za- } \\ \text { pf. } & 4 & 3 & 9 & 24 \\ \text { ipf. } & 3 & 6 & 19 & 20 \\ \text { Summe } & 7 & 9 & 28 & 44\end{array}$

Modifizierende Funktion Aspekt do- iz- na- zapf. $1-4$ ipf. - $\quad 1$ Summe $1-5$ -
Tabelle 3b: Angabe über das Vorkommen der nomina instrumenti nach den Bedeutungen der Präfixe in Zahlen

$$
\begin{aligned}
& \text { do- L2 (3), L3 (3), L4 (1) } \\
& \text { iz- L1 (9) } \\
& \text { na- L1 (28) } \\
& \text { za- Ll (27), L2 (15), L3 (1), } \\
& \quad \text { L4 (1) }
\end{aligned}
$$

do- MI (1)

na-M1 (3), M2 (2) 
Rein perfektivierende Funktion

a) reihende Präfixe

Aspekt do- iz- na- zaiz- RI (4), R2 (3)

pf. $\quad 2324$

na- RI (2), R2 (3)

ipf. $\quad-526$

za- Rl (26), R2 (4)

Summe - $\quad$ - 530

b) leere Präfixe

Aspekt do- iz- na- za-

pf. - - 9 -

ipf. - - 1 -

Summe - $\quad-10 \quad-$

Tabelle 4: Angabe über das Gesamtvorkommen der nomina instrumenti nach den Funktionen der Präfixe in Zahlen und Prozenten

Lexikalische Funktion:

Summe Prozent

Modifizierende Funktion:

$$
\begin{aligned}
88 & =60,20 \\
6 & =4,10
\end{aligned}
$$

Rein perfektivierende Funktion:
a) reihende Präfixe:
$42=28,76$
b) leere Präfixe:
$10=6,84$ 
NOMINA AGENTIS

\section{Allgemeine Vorbemerkungen}

Mit nomina agentis werden im allgemeinen Wesen, in der Regel Personen, seltener andere Lebewesen, nach der für sie charakteristischen Tätigkeit bezeichnet. $\mathrm{Zu}$ dieser Kategorie zählen wir nur Ableitungen von Verben ${ }^{183}$, so z.B. dovršilac 'einer, der etwas verrichtet, ausübt', dopunjavač 'einer, der hinzufügt',

183 Substantive vom Typ: dogovornik 'einer, der einen Vertrag aushandelt', dopisnik 'Berichterstatter', izletnik 'einer, der auf Ausflüge geht', izvozničar 'einer, der sich mit der Ausfuhr von Waren in andere Länder befasst', istupnik 'einer, der Vergehen begeht', nagoničar 'einer, der seine Schweine zur Mast treibt', nazdravičar 'einer, der Trinksprüche hält' und zadužbinar 'Begründer einer Stiftung', zakladatelj und zakladnik 'Stifter, Fundator', zakonar (kov.) und zakonik (arh.) 'einer, der das Gesetz kennt, Gesetzesgelehrter', zakovičar 'einer, der Nieten macht', zapisničar 'einer, der Protokoll führt', zastavnik 'einer, der die Fahne trägt' werden nicht in die wortbildende Kategorie der nomina agentis aufgenommen. Diese Substantive bezeichnen Lebewesen, die zumeist einer Tätigkeit nachgehen, einen Beruf ausüben, jedoch nicht direkt nach ihrer Tätigkeit, "...sondern nach dem Gegenstand im weiten Sinne des Wortes, auf den sich diese Tätigkeit bezieht..." (M. Dokulil, Tvořeni slov II, S. 125.) Dokulil nennt sie nomina actoris. Der onomasiologischen Struktur entsprechend werden diese Substantive in die onomasiologische Kategorie des Trägers der gegenständlichen Beziehung, in die Kategorie der Substanz also, die durch die Beziehung zu einem anderen Begriff derselben Kategorie bestimmt ist, eingeordnet. (M. Dokulil, Tvořeni slov I, S. 35; derselbe, Zur Theorie der Wortbildung..., a.a.0., S. 208.) Das onomasiologische Merkmal dieser Kategorie ist immer zusammengesetzt, und zwar aus dem bestimmenden Bestandteil, dem onomasiologischen Motiv, das einen Hinweis auf einen Begriff aus dem Bereich der Substanz gibt, und dem bestimmten Bestandteil, der einen Hinweis auf einen Begriff aus dem Bereich der Handlung gibt (onomasiologische Verbindung). In Substantiven des oben angeführten Typs ist jeweils nur der bestimmende Bestandteil des onomasiologischen Merkmals explizit ausgedrückt. Das Primäre der Substanz tritt hier deutlich hervor. "Die Substanz macht sich frei von ihrer Abhängigkeit von dem bestimmten Bestandteil urd tritt als eigentliches Motiv der Benennung in den Vordergrund." (M. Dokulil, Tvořeni slov I, S. 35.) Diese Substantive sind also nicht wie die nomina agentis durch das onomasiologische Merkmal der Handlung bestimmt, sondern primär durch das der Substanz, wobei jedoch die Substanz aufgrund ihres spezifischen Charakters 
donositelj 'Uberbringer', istraživalac 'Untersucher, Nachforscher', istovarač 'Aus-, Ablader', izmišljač 'einer, der etwas aussinnt, erdichtet', nagonitelj 'einer, der antreibt', naklapalo 'Plauderer', nadopunilac 'einer, der ergänzt', zaustavljač 'einer, der anhält', zanavljač 'einer, der etwas erneuert'.

Substantive zur Bezeichnung von Sachen, die der Ausführung einer Tätigkeit dienen, werden gesondert abgehandelt. Diese Benennungen haben in bezug auf ihre wortbildende struktur und die Verwendung der Formantien grosse Ahnlichkeit mit denen der Kategorie der nomina agentis. Häufig handelt es sich bei solchen Benennungen um nomina agentis, die eine Umwandlung erfahren haben, wie z.B. "Locher" in ein nomen instrumenti.

Vom onomasiologischen standpunkt stellt die wortbildende Kategorie der nomina agentis eine der wichtigsten Realisierungen "der onomasiologischen Kategorien des "Handlungsträgers" (die wiederum nur eine der grundlegenden Modifikationen der übergeordneten onomasiologischen Kategorie des Trägers der Handlungsbeziehung ist)" 184 dar.

Auf der wortbildenden Ebene werden nomina agentis durch das Wortbildungsverfahren der Suffigierung realisiert.

Nomina agentis werden von Verben mit den Präfixen do-, iz-, na-, za- in lexikalischer Funktion, von Verben mit den Präfixen do-, iz-, na-, za- in modifizierender Funktion und von Verben mit den Präfixen iz-, na-, za- in rein perfektivierender Funktion abgeleitet.

Folgende Formantien finden bei der Ableitung von nomina agentis Verwendung:

Maskulina: I. -ac, -ač, -ak, -ar, -adžij(a), -ić, -ič, -ic(a), $-\operatorname{nic}(a),-n i k,-\check{s}(a),-t e l j$

Sondergruppe: I. $-1(0)^{185}$.

nur immer eine indirekte Beziehung zur onomasiologischen Basis hat. Da in die vorliegende Arbeit nur Ableitungen aufgenommen werden, die primär durch Verben motiviert sind, müssen Substantive dieses Typs ausserhalb des abgesteckten Rahmens bleiben.

184 M. Dokulil, Trořeni slov II, S. 13.

185 Substantive mit dem Formans $-1(0)$ sind in den wörterbüchern als maskulin (z.B. V. S. Karadžić, Srpski rječnik. Wien 1818 und F. Iveković - I. Broz, Rečnik hrvatskoga jezika. Jagreb 1901), als maskulin, neutral oder maskulin und neutral gekennzeichnet (z.B. S. Ristić - J. Kangrga, Rečnik srpskohrvatskog i nemačkog jezika. Beograd 1928 und Rečnik srpskohrvatskoga književnog jezika. Novi Sad-Zagreb 1967). Heute 
Nach der Produktivität ergibt sich für die gesamte wortbildende Kategorie der nomina agentis folgendes Bild:

Maskulina: I. a) sehr produktiv: -ač, b) weniger produktiv: -ac, -telj, -nik, c) unproduktiv: -ic(a), d) ganz unproduktiv: $-\operatorname{adžij}(a),-a k,-a r,-i c ́,-i c ̌,-n i c(a)$, $-s(a)$

Sondergruppe: I. b) weniger produktiv: $-I(0)$.

Nomina agentis werden generell überwiegend von Verben mit Präfixen der lexikalischen Funktion abgeleitet. Etwa halb so viele nomina agentis werden von Verben mit reihenden Präfixen der rein perfektivierenden Funktion abgeleitet. In ganz geringem Masse werden nomina agentis von Verben mit leeren Präfixen der rein perfektivierenden und von solchen mit Präfixen der modifizierenden Funktion abgeleitet.

Innerhalb der Kategorie der nomina agentis, die von Verben mit Präfixen der lexikalischen Funktion abgeleitet werden, nehmen die Ableitungen von Verben mit dem Präfix iz- vor denen mit den Präfixen do-, na-, za- in bezug auf ihre Frequenz die erste Stelle ein.

Nomina agentis, die durch Verben mit Präfixen der modifizierenden Funktion motiviert sind, werden häufiger von Verben mit den Präfixen do-, iz- als von Verben mit den Präfixen na-, zaabgeleitet.

Nomina agentis, die durch Verben mit reihenden Präfixen der rein perfektivierenden Funktion motiviert sind, werden am häufigsten von Verben mit dem Präfix iz- vor denen mit den Präfixen za- und na- abgeleitet.

Nomina agentis, die durch Verben mit leeren Präfixen der rein perfektivierenden Funktion motiviert sind, werden etwas häufiger von Verben mit dem Präfix na- als von solchen mit den Präfixen iz-, za- abgeleitet, wobei letztere die gleiche Belegzahl aufweisen.

Die Ableitungsbasis der nomina agentis wird vom Grundstamm, vom Stamm des Partizip Präteritum Aktiv, vom Infinitivstamm und vom Stamm des Partizip Präteritum Passiv gebildet.

jedoch werden diese Substantive immer häufiger als Neutra bestimmt, obwohl sie in allen drei Genera kongruieren können. Der Grund dafür dürfte darin zu suchen sein, dass sie normalerweise als Neutra kongruieren. (Vgl. M. Stevanović, Savremeni srpskohrvatski jezik, a.a.0., S. 514 u. M. Babic, Nomina agentis izvedena sufiksom -lo. In: NJ XVI, $1967, \mathrm{~S} .88 \mathrm{u} .90$. ) Wegen der verschiedenen Bestimmung des Genus werden Substantive auf $-I(0)$ in einer Sondergruppe aufigefiühint gki-9783954793105 
Die Ableitungsbasis wird für alle Typen von nomina agentis, d.h. für die von Verben mit Präfixen der lexikalischen, modifizierenden und rein perfektivierenden Funktion, am häufigsten vom Grundstamm gebildet.

Die Ableitungsbasis, die vom Infinitivstamm gebildet wird, steht in der Häufigkeit der Verwendung zur Ableitung von nomina agentis von Verben mit Präfixen der lexikalischen und rein perfektivierenden Funktion an zweiter und von solchen mit Präfixen der modifizierenden Funktion an dritter Stelle.

Die Ableitungsbasis, die vom Stamm des Partizip Präteritum Aktiv gebildet wird, steht in der Häufigkeit der Verwendung zur Ableitung von nomina agentis von Verben mit Präfixen der modifizierenden Funktion an zweiter und von solchen mit Präfixen der lexikalischen und rein perfektivierenden Funktion an dritter Stelle.

Die Ableitungsbasis, die vom Stamm des Partizip Präteritum Passiv gebildet wird, wird nur in ganz seltenen Fällen zur Bildung von nomina agentis verwendet.

Nomina agentis erlauben, wenn sie vom Grundstamm abgeleitet sind, in Einzelfällen eine doppelte Motivationsbeziehung, und zwar primär zum Verb selbst und sekundär zum nomen actionis im engeren Sinne, so z.B. izvoznik zu izvoziti und izvoz 'einer, der ausführt und einer, der Ausfuhren macht', naletnik zu naletati und nalet 'einer, der überfällt und einer, der einen Uberfall macht', napadnik zu napadati und napad 'einer, der angreift und einer, der einen Angriff macht'.

Nomina agentis werden von Verben aller Konjugationen mit Ausnahme der zweiten und dritten abgeleitet. Am häufigsten sind Ableitungen von Verben der fünften Konjugation.

Die nomina agentis nach dem Ableitungsverfahren, dem Ableitungsstamm und der Konjugation:

A. Lexikalische Funktion

I. Suffigierung

1. Grundstamm

Maskulina: 5., 4., 6. Konjugation

2. Stamm des Partizip Präteritum Aktiv

Maskulina: 4., 5., 6., unregelmässige, 1. Konjugation

3. Infinitivstamm

Maskulina: 4., 5., 6., 1. Konjugation

Sondergruppe : 5., 6. Konjugation

4. Stamm des Partizip Präteritum Passiv 
Maskulina: 5. Konjugation.

B. Modifizierende Funktion

I. Suffigierung

1. Grundstamm

Maskulina: 6., 5., 4. Konjugation

2. Stamm des Partizip Präteritum Aktiv

Maskulina: 4., 1. Konjugation

3. Infinitivstamm

Maskulina: 4. Konjugation

Sondergruppe: 6 . Konjugation.

C. Rein perfektivierende Funktion

a) reihende Präfixe

I. Suffigierung

1. Grundstamm

Maskulina: 5., 6., 4. Konjugation

2. Stamm des Partizip Präteritum Aktiv

Maskulina: 4., 1., 5. Konjugation

3. Infinitivstamm

Maskulina: 4., 5., 1. Konjugation

Sondergruppe: 5 . Konjugation

b) leere Präfixe

I. Suffigierung

1. Grundstamm

Maskulina: 5., 6., 4. Konjugation

2. Stamm des Partizip Präteritum Aktiv

Maskulina: 4., 5. Konjugation

3. Infinitivstamm

Maskulina: 4. Konjugation

Sondergruppe: 5., 6. Konjugation.

Nomina agentis werden generell sowohl von perfektiven als auch von sekundär imperfektiven Verben abgeleitet.

Nomina agentis, die von Verben mit Präfixen der lexikalischen Funktion abgeleitet sind, basieren in überwiegendem Masse auf imperfektiven Verben.

Nomina agentis, die von Verben mit Präfixen der modifizierenden Funktion abgeleitet sind, basieren in etwa gleichem Masse auf perfektiven und imperfektiven Verben.

Nomina agentis, die von Verben mit Präfixen der rein perfektivierenden Funktion abgeleitet sind, basieren etwas, häufiger auf 
imperfektiven als auf perfektiven Verben ${ }^{186}$.

In einer ganz geringen Anzahl von Fällen sind nomina agentis Korrelate zweier Aspektformen, so z.B. izmiritelj zu pf. izmiriti und izmirivač zu ipf. izmirivati 'einer, der beschwichtigt', iskoristitelj zu pf. iskoristiti und iskorištavač zu ipf. iskorištavati (bzw. iskorišćivač zu ipf. iskorišćivati) 'einer, der ausnutzt'. Es kann angenommen werden, dass in diesen Fällen die Aspektopposition bei den nomina agentis erhalten geblieben ist.

Die wortbildende Kategorie der nomina agentis weist einen engen Berührungspunkt mit der Kategorie der Benennungen der Träger einer Eigenschaft auf, der einerseits auf der onomasiologischen Ebene gegeben ist, weil eine häufig wiederholte Handlung quasi den Charakter einer konstanten Eigenschaft annehmen und damit bestimmendes Element einer Substanz werden kann. So ist z.B. istražnik ein Mensch, der untersucht, nachforscht, dessen Untersuchen, Nachforschen aber auch seine besondere Eigenschaft ist. Andererseits wird der Berührungspunkt mit der Kategorie der Benennungen der Träger einer Eigenschaft auf der wortbildenden Ebene durch Benennungen hergestellt, die von adjektivierten Partizipien bzw. Handlungsadjektiven gebildet sind.

Eine besonders ausgeprägte adjektivische Nuance haben, wie Babic 187 nachweist, nomina agentis mit dem Formans -1(0) wie z.B. dolagivalo 'einer, der gerne lügt', izbiralo 'ein wählerischer Mensch'.

Unter dem Gesichtspunkt der Bedeutung der Präfixe der ableitenden Verben ergibt sich für das Vorkommen der nomina agentis folgendes Bild:

In lexikalischer Funktion werden nomina agentis von Verben mit nachstehenden Präfixen und ihren Bedeutungen abgeleitet: do- LI 'bis zu (einem bestimmten Ort gelangen)' oder '(einen Gegenstand) bis zu (einem bestimmten Ort bewegen)' (donosac 'Bringer, Uberbringer' von donositi 'bringen'); L2 'zu (etwas) hinzu(fügen)' (dodavač 'einer, der etwas zugibt' von dodavati 'hinzugeben'); I3 'bis zu (etwas gelangen)' (došaptač 'Zuflüsterer' von došaptati 'zuflüstern');

186 Ableitungen von Verben mit Präfixen in rein perfektivierender Funktion haben dann eine imperfektive Basis, wenn die ableitenden Verben mit reihenden und leeren Präfixen sekundär imperfektiviert sind.

187 M. Babić, Nomina agentis..., a.a.0., S. 90. 
I4 ' (etwas) zu jemandes Nutzen (tun)' (dostavljač 'Zusteller, Ubermittler' von dostavljati 'zustellen');

iz- Il '(etwas) von innen nach aussen (oder) von unten nach oben (bewegen)' (isterivalac 'Austreiber' von isterivati 'austreiben');

L2 '(jemanden oder etwas) aus einer Mitte heraus(bewegen)' (izbirač 'Wähler' von izbirati 'wählen');

na- Ll '(einen Gegenstand) auf (einen anderen stellen)' (nasledovač 'Nachfolger' von nasledovati 'nachfolgen');

za- Ll '(etwas) binter (etwas stellen)' (zabadač 'einer, der sticht' von zabadati 'hineinstechen');

L4 'eine Stellung einnehmen' (zasedač 'Nachsteller' von zasedati 'nachstellen';

In modifizierender Funktion werden nomina agentis von Verben mit nachstehenden Präfixen und ihren Bedeutungen abgeleitet:

do- MI '(eine früher nickt ausgeführte Handlung) bis zum Ende (ausführen)' (dovršilac 'einer, der etwas ausübt, verrichtet' von dovršiti 'ausüben, verrichten');

iz- MI 'erreichen, erlangen' (izradjivač 'einer, der etwas ausarbeitet, verfertigt' von izradjivati 'ausarbeiten, verfertigen');

na- MI '(eine Handlung) in ausreichendem Masse (ausführen)'

(nakupac 'einer, der Ware zum Weiterverkauf kauft' von nakupiti 'in Menge kaufen');

M2 '(eine Handlung) in geringem Masse (ausführen)' (nažigač 'einer, der anzündet' von nažigati 'anzünden');

za- MI ' (eine Handlung) beginnen' (zavojevač 'Eroberer' von zavojevati 'erobern');

In reihender Funktion werden nomina agentis von Verben mit nachstehenden Präfixen und ihren Bedeutungen abgeleitet:

Das Präfix iz- kann in Zusammensetzung mit Verben in der Bedeutung (RI) 'von weg, heraus' und in der Bedeutung (R2) 'ausführen bis zum Erreichen des Ziels, bis zur Ausschöpfung der Möglichkeit' mit seinen jeweiligen Bedeutungsnuancen reihende Funktion ausüben. Die Bedeutungsnuancen der Bedeutung RI sind: Rli 'verschwinden' (izješa 'einer, der viel isst' von izjesti 'essen'); Rlj 'Restgruppe' (z.B. ispomagač 'einer, der aushilft' von ispomagati 'aushelfen');

Die Bedeutungsnuancen der Bedeutung $\mathrm{R} 2$ sind: $\mathrm{R} 2 \mathrm{a}$ 'versehen mit einem neuen Gepräge' (ispunjavač 'einer, der ausfüllt' von ispunjavati 'ausfüllen'); R2c 'anwenden einer bestimmten Prozedur an 
einem Lebewesen zur Erlangung des erwünschten Zustands' (izučavalac 'einer, der lernt bzw. lehrt' von izučavati 'auslernen; auslehren'); R2e 'beseitigen des Unterschiedes' (izjednačilac 'einer, der ausgleicht' von izjednačiti 'ausgleichen'); R2f 'erreichen des gewünschten Resultats durch geistige oder ähnliche Arbeit' (izračunavač 'einer, der ausrechnet' von izračunavati 'ausrechnen'); $\mathrm{R} 2 \mathrm{~g}$ 'ausschöpfen der Brauchbarkeit' (izrabljivač 'einer, der jemanden ausnutzt' von izrabljivati 'ausnutzen');

Das Präfix na- kann in Zusammensetzung mit Verben in der Bedeutung (RI) 'stellen eines Gegenstandes auf einen anderen' und in (R2) der 'Augmentation' mit seinen jeweiligen Bedeutungsnuancen reihende Funktion ausüben. Die Bedeutungsnuancen der Bedeutung $R I$ sind: $R I b$ 'treten auf, veranlassen, auf etwas $z u$ treten' (naganjač 'einer, der jemanden zu etwas, auf etwas treibt' von naganjati 'an-, auftreiben'); Rlc 'schreiben' (napisatelj

'Schreiber' von napisati 'aufschreiben');

Die Bedeutungsnuancen der Bedeutung $R 2$ sind: $R 2 a$ 'anhäufen, etwas in Menge tun' (nadopunilac 'einer, der ergänzt' von nadopuniti 'ergänzen'); R2b 'Nahrung in ausreichender Menge geben' (napajalac 'einer, der tränkt' von napajati 'tränken';

Das Präfix za- kann in Zusammensetzung mit Verben in der Bedeutung (RI) 'hinter etwas gehen' und in (R2) 'einen neuen Zustand einnehmen' mit seinen jeweiligen Bedeutungsnuancen reihende Funktion ausüben. Die Bedeutungsnuancen der Bedeutung RI sind: Rla 'umdrehen' (zaokretač 'einer, der etwas umwendet' von zaokretati 'umwenden'); Rlb 'umfassen eines Teils oder des Ganzen' (zagledač 'einer, der das Mädchen vor dem Freien beschaut' von zagledati 'beschauen'); Rld 'an einem sicheren Ort aufbewahren (abstrakt)' (zapisivač 'einer, der etwas notiert' von zapisivati 'notieren'); Rlf 'verschliessen und hindern' (zaustavljač 'einer, der an-, zurückhält' von zaustavljati 'an-, zurückhalten'); Rlg 'schützen und nicht erlauben' (zaštitilac 'einer, der beschützt' von zaštititi 'beschützen'); Rli 'Restgruppe' (z.B. zamenik 'einer, der jemanden vertritt' von zameniti 'vertreten');

Die Bedeutungsnuancen der Bedeutung $\mathrm{R} 2$ sind: $\mathrm{R} 2 \mathrm{~b}$ 'versehen mit einer neuen Eigenschaft' (zanavljač 'einer, der etwas erneuert' von zanavljati 'erneuern'). 
Material

A. Lexikalische Funktion

AA. Nomina agentis von Verben mit dem Präfix do- in lexikalischer Funktion

Die Ableitungsverfahren: I. Suffigierung

Die wortbildenden Typen nach ihren Formantien, ihrer Produktivität und den Bedeutungen der Präfixe der ableitenden Verben mit ihrer Häufigkeit:

Maskulina: I. -ac (7), Bed.: LI (5), L3 (2), -ač (9), Bed.: II

(2), I2 (2), L3 (4), L4 (1), -ak (1), Bed.: Ll (1), $-\operatorname{ar}(1)$, Bed.: L3 (1), -ić (1), Bed.: Ll (1), $-i c(a)(1), \operatorname{Bed} .:$ Ll (1), $-\operatorname{nic}(a)(1), \operatorname{Bed} .:$ L3 (1), $\operatorname{nik}(1)$, Bed.: LI (1), -telj (2), Bed.: II (1), I2 (1)

Sondergruppe: I. $-1(0)$ (2), Bed.: L2 (1), L3 (1)

Die Ableitungsstämme und die Konjugationen:

Maskulina: I. 1. Grundstamm der 5., 4., 6. Konjugation, 2. Stamm des Partizip Präteritum Aktiv der unregelmässigen, 5., 6., 4. Konjugation, 3. Infinitivstamm der 4. Konjugation

Sondergruppe: I. 3. Infinitivstamm der 5. 6. Konjugation

Der Aspekt der Ableitungsbasis:

Maskulina: I. 5 pf. und 19 ipf. Verben

Sondergruppe: I. 2 ipf. Verben

Maskulina

I. Suffigierung

Ableitungen mit dem Formans -ac

Bed.: LI, a) vom pf. Aspekt, 2. vom Stamm des Partizip Präteritum Aktiv, der 1. Konjugation

dobegalac 'einer, der flieht'

der unregelmässigen Konjugation

došlac 'Ankömmling'

b) vom ipf. Aspekt, l. vom Grundstamm, der 4. Konjugation dohodac 'einer, der in das Haus der Frau geht, einheiratet', donosac 'Bringer, Uberbringer'

2. vom Stamm des Partizip Präteritum Aktiv, der 4. Konjugation donosilac 'tberbringer, Zubringer'

Bed.: I3, b) vom ipf. Aspekt, 2. vom Stamm des Partizip Präteritum Akiv, der 6. Konjugation 
dočekivalac 'einer, der erwartet', dokazivalac 'einer, der beweist'

Ableitungen mit dem Formans -ač

Bed.: Ll, b) vom ipf. Aspekt, 1. vom Grundstamm, der 6. Konjugation

dobacivač 'einer, der etwas zuwirft', doterivač 'An-, Herantreiber'

Bed.: L2, b) vom ipf. Aspekt, 1. vom Grundstamm, der 5. Konjugation

dodavač 'einer, der etwas zugibt', dopunjavač 'einer, der hinzurügt'

Bed.: L3, b) vom ipf. Aspekt, 1. vom Grundstamm, der 5. Konjugation

došaptač 'Zuflüsterer', dozivač 'Zu-, Herbeirufer'

der 6. Konjugation

dočekivač 'einer, der erwartet', dokazivač 'Beweisführer' Bed.: L4, b) vom ipf. Aspekt, 1. vom Grundstamm, der 5. Konjugation

dostavljač 'Zusteller, Ubermittler'

Ableitungen mit dem Formans -ak

Bed.: Ll, a) vom pf. Aspekt, 2. vom Stamm des Partizip Präteritum Aktiv, der unregelmässigen Konjugation

došljak 'Ankömmling'

Ableitungen mit dem Formans -ar

Bed.: L3, b) vom ipf. Aspekt, 1. vom Grundstamm, der 5. Konjugation

domišljar (pokr.) 'einer, der leicht nachsinnt, Witzbold'

Ableitungen mit dem Formans -ić

Bed.: Il, a) vom pf. Aspekt, 2. vom Stamm des Partizip Präteritum Aktiv, der unregelmässigen Konjugation

došlić (indiv.) 'Ankömmling' 
Ableitungen mit dem Formans -ic(a)

Bed.: Ll, a) vom pf. Aspekt, 2. vom Stamm des Partizip Präteritum Aktiv, der 1. Konjugation dobeglica 'Flüchtling'

Ableitungen mit dem Formans -nic(a)

Bed.: L3, b) vom ipf. Aspekt, 1. vom Grundstamm, der 5. Konjugation

dodvornica 'einer, der sich einschmeichelt'

Ableitungen mit dem Formans -nik

Bed.: LI, b) vom ipf. Aspekt, 1. vom Grundstamm, der 4. Konjugation

donosnik (zast.) 'einer, der herbeibringt'

Ableitungen mit dem Formans -telj

Bed.: Ll, b) vom ipf. Aspekt, 3. vom Infinitivstamm, der 4. Konjugation

donositelj 'Uberbringer, Zubringer'

Bed.: L2, a) vom pf. Aspekt, 3. vom Infinitivstamm, der 4. Konjugation

dopunitelj 'einer, der etwas ergänzt'

Sondergruppe

I. Suffigierung

Ableitungen mit dem Formans $-I(0)$

Bed.: L2, b) vom ipf. Aspekt, 3. vom Infinitivstamm, der 6. Konjugation

dolagivalo 'einer, der gern lügt'

Bed.: L3, b) vom ipf. Aspekt, 3. vom Infinitivstamm, der 5. Konjugation

došaptavalo 'Zuflüsterer, Einbläser'

$A B$. Nomina agentis von Verben mit dem Präfix $\underline{i z}-$ in lexikalischer Funktion

Die Ableitungsverfahren: I. Suffigierung 
Die wortbildenden Typen nach ihren Formantien, ihrer Produktivität und den Bedeutungen der Präfixe der ableitenden Verben mit ihrer Häufigkeit:

Maskulina: I. -ac (7), Bed.: Il (7), -ač (14), Bed.: LI (13), L2 (1), -nik (3), Bed.: Il (3), -telj (7), Bed.: Ll (7)

Sondergruppe: I. $-1(0)$ (1), Bed.: L2 (1)

Die Ableitungsstämme und die Konjugationen:

Maskulina: I. 1. Grundstamm der 5., 4., 6. Konjugation, 2. Stamm des Partizip Präteritum Aktiv der 4., 5., 6.

Konjugation, 3. Infinitivstamm der 4., 5. Konjugation, 4. Stamm des Partizip Präteritum Passiv der

5. Konjugation

Sondergruppe: I. 3. Infinitivstamm der 5. Konjugation

Der Aspekt der Ableitungsbasis:

Maskulina: I. $10 \mathrm{pf}$. und 21 ipf. Verben

Sondergruppe: I. I ipf. Verb

Maskulina

I. Suffigierung

Ableitungen mit dem Formans -ac

Bed.: Il, a) vom pf. Aspekt, 2. vom Stamm des Partizip Präteritum Aktiv, der 4. Konjugation

izgovorilac 'einer, der etwas ausspricht', izložilac 'Aussteller'

b) vom ipf. Aspekt, 2. vom Stamm des Partizip Präteritum Aktiv, der 4. Konjugation

izvodilac 'Ausführer'

der 5. Konjugation

izdavalac 'Herausgeber', izgovaralac 'einer, der etwas ausspricht'

der 6. Konjugation

isterivalac 'Austreiber', istraživalac 'Untersucher, Nachforscher'

Ableitungen mit dem Formans -ač

Bed.: Ll, a) vom pf. Aspekt, 1. vom Grundstamm, der 5. Konjugation izvikač 'einer, der schreiend ausruft'

b) vom ipf. Aspekt, 1. vom Grundstamm, der 5. Konjugation

izazivač 'Herausforderer; Erreger (Krankheit)', izdavač

'Aus- Herausgeber; Verleger', izgonjač 'einer, der austreibt', 
izlagač 'Aussteller', izvadjač, izvodjač 'einer, der aus-, wegführt', ispijač 'einer, der austrinkt', istovarač 'einer, der aus-, ablädt'

der 6. Konjugation

izvikivač 'einer, der etwas ausruft', isterivač 'Austreiber', istovarivač 'Aus-, Ablader', istraživač 'Forscher, Untersucher'

der 4. Konjugation

iznosač 'einer, der etwas hinausträgt'

Bed.: L2, b) vom ipf. Aspekt, 1. vom Grundstamm, der 5. Konjugation

izbirač 'Wähler, Auswähler'

Ableitungen mit dem Formans -nik

Bed.: Ll, a) vom pf. Aspekt, 1. vom Grundstamm, der 4. Konjugation istražnik 'einer, der untersucht, nachforscht'

4. vom Stamm des Partizip Präteritum Passiv, der 5. Konjugation

izdatnik 'einer, der etwas ausstellt (Urkunde)'

b) vom ipf. Aspekt, 1. vom Grundstamm, der 4. Konjugation

izvoznik 'einer, der sich mit der Ausfuhr von Waren

beschäftigt'

Ableitungen mit dem Formans -tel $j$

Bed.: LI, a) vom pf. Aspekt, 3. vom Infinitivstamm, der 4. Konjugation

izgovoritelj 'einer, der etwas ausspricht', izložitelj 'Aussteller', iskupitelj 'einer, der jemandes sünde, Schuld

kauft oder gekauft hat, Retter', istražitelj 'l. Untersuchungsrichter, 2. Forscher'

b) vom ipf. Aspekt, 3. vom Infinitivstamm, der 4. Konjugation izgonitelj 'einer, der hinaustreibt', izvoditelj 'einer, der ausführt'

der 5. Konjugation

izdavatelj 'Verleger'

Sondergruppe

I. Suffigierung

Ableitungen mit dem Formans $-1(0)$

Bed.: L2, b) vom ipf. Aspekt, 3. vom Infinitivstamm, der 5. Kon- 
jugation

izbiralo 'wählerischer Mensch, einer, der sich nicht leicht zufrieden gibt'

AC. Nomina agentis von Verben mit dem Präfix na- in lexikalischer Funktion

Die Ableitungsverfahren: 1. Suffigierung

Die wortbildenden Typen nach ihren Formantien, ihrer Produktivität und den Bedeutungen der Präfixe der ableitenden Verben mit ihrer Häufigkeit:

Maskulina: I. -ac (1), Bed.: Ll (1), -ač (6), Bed.: Ll (6), $-\operatorname{adžij(a)~(l),~Bed.:~Ll~(1),~-ic(a)~(2),~Bed.:~LI~}$

(2), -nik (6), Bed.: Ll (6),-telj (3), Bed.: Ll (3)

Sondergruppe: I. $-1(0)$ (1), Bed.: Ll (1)

Die Ableitungsstämme und die Konjugationen:

Maskulina: I. 1. Grundstamm der 5., 4., 6. Konjugation, 2. Stamm des Partizip Präteritum Aktiv der 6. Konjugation, 3. Infinitivstamm der 4., 6., 1. Konjugation

Sondergruppe: I. 3. Infinitivstamm der 5. Konjugation

Der Aspekt der Ableitungsbasis:

Maskulina: I. 4 pf. und 15 ipf. Verben

Sondergruppe: I. 1 ipf. Verb

Maskulina

1. Suffigierung

Ableitungen mit dem Formans -ac

Bed.: Ll, b) vom ipf. Aspekt, 2. vom Stamm des Partizip Präteritum Aktiv, der 6. Konjugation

nasledovalac 'Nachfolger'

Ableitungen mit dem Formans -ač

Bed.: Ll, b) vom ipf. Aspekt, l. vom Grundstamm, der 5. Konjugation

nadevač 'einer, der einem Namen zulegt', napadač 'Angreifer', nasrtač 'Angreifer', nastavljač 'Fortsetzer'

der 4. Konjugation

navodjač (kov.) 'einer, der einen anderen $z u$ etwas verleitet' der 6. Konjugation 
nasledovač, nasledjivač 'Nachfolger'

Ableitungen mit dem Formans -adžij(a)

Bed.: Ll, b) vom ipf. Aspekt, l. vom Grundstamm, der 4. Konjugation

navodadžija 'Heiratsvermittler'

Ableitungen mit dem Formans -ic(a)

Bed.: Ll, b) vom ipf. Aspekt, l. vom Grundstamm, der 5. Konjugation

naletica 'Angreifer; Stänker'

der 6. Konjugation

natrkušica 'Angreifer; Stänker'

Ableitungen mit dem Formans -nik

Bed.: Ll, a) vom pf. Aspekt, 1. vom Grundstamm, der 4. Konjugation najeznik 'Angreifer', navalnik 'einer, der einen Zusammenstoss hervorruft, Angreifer'

b) vom ipf. Aspekt, 1. vom Grundstamm, der 5. Konjugation naletnik 'Angreifer', nametnik 'Aufdringling, Eindringling', napadnik (neob.) 'Angreifer', nasrtnik 'Angriffslustiger, Angreifer'

Ableitungen mit dem Formans - telj

Bed.: Il, a) vom pf. Aspekt, 3. vom lnfinitivstamm, der I. Konjugation

navezitelj 'einer, der anstickt'

der 4. Konjugation

nahrupitelj 'einer, der überrumpelt, anfällt'

b) vom ipf. Aspekt, 3. vom Infinitivstamm, der 6. Konjugation nasledovatel $j$ 'Fortsetzer'

Sondergruppe

I. Suffigierung

Ableitungen mit dem Formans $-1(0)$

Bed.: Ll, b) vom ipf. Aspekt, 3. vom Infinitivstamm, der 5. Konjugation 
nasrtalo 'Angreifer'

AD. Nomina agentis von Verben mit dem Präfix za- in lexikalischer Funktion

Die Ableitungsverfahren: I. Suffigierung

Die wortbildenden Typen nach ihren Formantien, ihrer Produktivität und den Bedeutungen der Präfixe der ableitenden Verben mit ihrer Häufigkeit:

Maskulina: I. -ač (4), Bed.: II (3), L4 (1), -nik (2), Bed.: L4 (2)

Sondergruppe: I. $-I(0)$ (I), Bed.: LI (1)

Die Ableitungsstämme und die Konjugationen:

Maskulina: I. 1. Grundstamm der 5. Konjugation

Sondergruppe: I. 3. Infinitivstamm der 5. Konjugation

Der Aspekt der Ableitungsbasis:

Maskulina: I. 6 ipf Verben

Sondergruppe: I. 1 ipf. Verb

Maskulina

I. Suffigierung

Ableitungen mit dem Formans -ač

Bed.: Ll, b) vom ipf. Aspekt, 1. vom Grundstamm, der 5. Konjugation

zabadač 'einer, der sticht', zaklanjač 'Beschützer', zaletač 'einer, der Anlauf nimmt'

Bed.: L4, b) vom ipf. Aspekt, 1. vom Grundstamm, der 5. Konjugation

zasedač 'Nachsteller; einer, der im Hinterhalt wartet'

Ableitungen mit dem Formans -nik

Bed.: L4, b) vom ipf. Aspekt, 1. vom Grundstamm, der 5. Konjugation

zasednik (pesn.) 'einer, der im Hinterhalt wartet', zastupnik 'einer, der die Interessen eines anderen vertritt; einer, der eine Arbeit anstelle eines anderen verrichtet'

Sondergruppe

I. Suffigierung 
Ableitungen mit dem Formans $-1(0)$

Bed.: Ll, b) vom ipf. Aspekt, 3. vom Infinitivstamm, der 5. Konjugation

zabadalo 'einer, der stichelt'

\section{B. Modifizierende Funktion}

EA. Nomina agentis von Verben mit dem Präfix do- in modifizierender Funktion

Die Ableitungsverfahren: I. Suffigierung

Die wortbildenden Typen nach ihren Formantien, ihrer Produktivität und den Bedeutungen der Präfixe der ableitenden Verben mit ihrer Häufigkeit:

Maskulina: I. -ac (1), Bed.: MI (1), -ic(a) (1), Bed.: MI (I), -telj (l), Bed.: MI (l)

Die Ableitungsstämme und die Konjugationen:

Maskulina: I. 2. Stamm des Partizip Präteritum Aktiv der 1., 4. Konjugation, 3. Infinitivstamm der 4. Konjugation

Der Aspekt der Ableitungsbasis:

Maskulina: I. $3 \mathrm{pf}$. Verben

Maskulina

\section{Suffigierung}

Ableitungen mit dem Formans -ac

Bed.: Ml, b) vom pf. Aspekt, 2. vom Stamm des Partizip Präteritum Aktiv, der 4. Konjugation

dovršilac 'einer, der etwas ausübt, verrichtet'

Ableitungen mit dem Formans -ic(a)

Bed.: Ml, a) vom pf. Aspekt, 2. vom Stamm des Partizip Präteritum Aktiv, der 1. Konjugation

doraslica 'Heranwachsender'

Ableitungen mit dem Formans -tel $j$

Bed.: Ml, a) vom pf. Aspekt, 3. vom Infinitivstamm, der 4. Konjugation

dovršitelj 'einer, der etwas verrichtet, Klausjübtúw'ski-9783954793105 
BB. Nomina agentis von Verben mit dem Präfix iz- in modifizierender Funktion

Die Ableitungsverfahren: I. Suffigierung

Die wortbildenden Typen nach ihren Formantien, ihrer Produktivität und den Bedeutungen der Präfixe der ableitenden Verben mit ihrer Häufigkeit:

Maskulina: I. -ac (1), Bed.: MI (1), -ač (2), Bed.: MI (2) Die Ableitungsstämme und die Konjugationen:

Maskulina: I. 1. Grundstamm der 6. Konjugation, 2. Stamm des Partizip Präteritum Aktiv der 4. Konjugation

Der Aspekt der Ableitungsbasis:

Maskulina: I. 1 pf. und 2 ipf. Verben

Maskulina

I. Suffigierung

Ableitungen mit dem Formans -ac

Bed.: Ml, a) vom pf. Aspekt, 2. vom Stamm des Partizip Präteritum Aktiv, der 4. Konjugation

izgradilac 'Erbauer'

Ableitungen mit dem Formans - ač

Bed.: Ml, b) vom ipf. Aspekt, 1. vom Grundstamm, der 6. Konjugation

izgradjivač 'einer, der ausbaut', izradjivač 'einer, der etwas ausarbeitet, verfertigt'

BC. Nomina agentis von Verben mit dem Präfix na- in modifizierender Funktion

Die Ableitungsverfahren: I. Suffigierung

Die wortbildenden Typen nach ihren Formantien, ihrer Produktivität und den Bedeutungen der Präfixe der ableitenden Verben mit inrer Häufigkeit:

Maskulina: I. -ac (1), Bed.: Ml (1), -ač (l), Bed.: M2 (1)

Die Ableitungsstämme und die Konjugationen:

Maskulina: I. 1. Grundstamm der 5., 4. Konjugation

Der Aspekt der Ableitungsbasis:

Maskulina: I. 1 pf. und 1 ipf. Verb 
Maskulina

I. Suffigierung

Ableitungen mit dem Formans -ac

Bed.: MI, a) vom pf. Aspekt, 1. vom Grundstamm, der 4. Konjugation nakupac 'einer, der Ware zum Weiterverkauf kauft'

Ableitungen mit dem Formans -ač

Bed.: M2, b) vom ipf. Aspekt, 1. vom Grundstamm, der 5. Konjugation

nažigač 'einer, der anzündet'

BD. Nomina agentis von Verben mit dem Präfix za- in modifizierender Funktion

Die Ableitungsverfahren: I. Suffigierung

Die wortbildenden Typen nach ihren Formantien, ihrer Produktivität und den Bedeutungen der Präfixe der ableitenden Verben mit ihrer Häufigkeit:

Maskulina: I. -ač (1), Bed.: MI (1)

Sondergruppe: I. $-1(0)$ (1), Bed.: MI (1)

Die Ableitungsstämme und die Konjugationen:

Maskulina: I. 1. Grundstamm der 6. Konjugation

Sondergruppe: I. 3. Infinitivstamm der 6. Konjugation

Der Aspekt der Ableitungsbasis:

Maskulina: I. 1 pf. Verb

Sondergruppe: I. 1 ipf. Verb

Maskulina

I. Suffigierung

Ableitungen mit dem Formans - ač

Bed.: Ml, a) vom pf. Aspekt, 1. vom Grundstamm, der 6. Konjugation zavojevač 'Eroberer'

Sondergruppe

I. Suffigierung

Ableitungen mit dem Formans - $1(0)$

Bed.: MI, b) vom ipf. Aspekt, 3. vom Infinitivstamm, der 6. Konjugation 
C. Rein perfektivierende Funktion

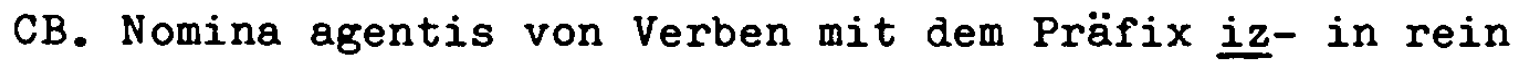
perfektivierender Funktion

a) $\underline{\text { iz- }}$ als reihendes Präfix

Die Ableitungsverfahren: I. Suffigierung

Die wortbildenden Typen nach ihren Formantien, ihrer Produktivität und den Bedeutungen der Präfixe der ableitenden Verben mit ihrer Häufigkeit:

Maskulina: I. -ac (4), Bed.: R2a (1), R2c (1), R2e (1), R2f (1), -ač (10), Bed.: Rlj (1), R2a (2), R2e (1), R2f (3), R2g (3), $-i c(a)$ (2), Bed.: Rli (1), Rlj (1), -š(a) (1), Bed.: Rli (1), -telj (7), Bed.: Rlj (1), R2c (3), R2e (1), R2f (1), R2g (1)

Sondergruppe: I. $-1(0)$ (1), Bed.: R2f (1)

Die Ableitungsstämme und die Konjugationen:

Maskulina: I. 1. Grundstamm der 5., 6., 4. Konjugation, 2. Stamm des Partizip Präteritum Aktiv der 4., 1., 5. Konjugation, 3. Infinitivstamm der 4., 5., 1. Konjugation

Sondergruppe: I. 3. Infinitivstamm der 5. Konjugation

Der Aspekt der Ableitungsbasis:

Maskulina: I. 12 pf. und 12 ipf. Verben

Sondergruppe: I. 1 ipf. Verb

Maskulina

I. Suffigierung

Ableitungen mit dem Formans -ac

Bed.: R2a, a) vom pf. Aspekt, 2. vom Stamm des Partizip Präteritum Aktiv, der 4. Konjugation

izjavilac 'einer, der etwas zur Kenntnis bringt'

Bed.: R2c, b) vom ipf. Aspekt, 2. vom Stamm des Partizip Präteritum Aktiv, der 5. Konjugation

izučavalac ${ }^{188}$ 'einer, der lernt bzw. lehrt'

Bed.: R2e, a) vom pf. Aspekt, 2. vom Stamm des Partizip

188 Pomianowska weist darauf hin, dass die Verbindung zwischen dem ableitenden Verb und der Ableitung vom heutigen Sprachgefühl aus nicht in dem gleichen Masse durchsichtig ist. Unter 'izučavalac' wird heute einer verstanden, der lernt bzw. lehrt und nicht einer, der gelernt bzw. gelehrt hat. W. Pomianowska, Klasyfikacja rzeczowników odrzeczownikowych. Wrocław-Warszawa-Krakow 1963, S. 16. 
Präteritum Aktiv der 4. Konjugation

izjednačilac 'einer, der ausgleicht'

Bed.: R2f, a) vom pf. Aspekt, 2. vom Stamm des Partizip Präteritum Aktiv, der 1. Konjugation

izumelac 'einer, der durch Forschen etwas findet'

Ableitungen mit dem Formans -ač

Bed.: Rlj, b) vom ipf. Aspekt, 1. vom Grundstamm, der 5. Konjugation

ispomagač 'einer, der aushilft'

Bed.: R2a, b) vom ipf. Aspekt, 1. vom Grundstamm, der 5. Konjugation

ispunjavač 'einer, der ausfüllt'

der 6. Konjugation

ispunjivač 'einer, der ausfüllt'

Bed.: R2e, b) vom ipf. Aspekt, 1. vom Grundstamm, der 6. Konjugation

izmirivač 'Beschwichtiger'

Bed.: R2f, b) vom ipf. Aspekt, 1. vom Grundstamm, der 5. Konjugation

izmišljač 'einer, der etwas aussinnt', izračunavač 'einer, der ausrechnet', izumevač 'Erfinder'

Bed.: R2g, b) vom ipf. Aspekt, 1. vom Grundstamm, der 6. Konjugation

izrabljivač 'einer, der jemanden ausnutzt', iskorišćivač

'einer, der ausnutzt'

der 5. Konjugation

iskorištavač 'einer, der ausnutzt'

Ableitungen mit dem Formans -ic(a)

Bed.: Rli, a) vom pf. Aspekt, 2. vom Stamm des Partizip

Präteritum Aktiv, der 1. Konjugation

izelica 'einer, der viel isst'

Bed.: Rlj, a) vom pf. Aspekt, 2. vom Stamm des Partizip

Präteritum Aktiv, der 1. Konjugation

izbeglica 'Flüchtling'

Ableitungen mit dem Formans -š(a) 
Bed.: Rli, a) vom pf. Aspekt, 3. vom Infinitivstamm, der 1. Konjugation

izješa 'einer, der viel isst'

Ableitungen mit dem Formans -telj

Bed.: Rlj, a) vom pf. Aspekt, 3. vom Infinitivstamm, der 5. Konjugation

ispisatelj 'einer, der abschreibt, Abschriften anfertigt' Bed.: R2c, a) vom pf. Aspekt, 3. vom Infinitivstamm, der 4. Konjugation

izlečitelj 'einer, der heilt', iscelitelj 'einer, der heilt' b) vom ipf. Aspekt, 3. vom Infinitivstamm, der 5. Konjugation

izučavatelj 'einer, der lernt bzw. lehrt'

Bed.: R2e, a) vom pf. Aspekt, 3. vom Infinitivstamm, der 4. Konjugation

izmiritelj 'einer, der beschwichtigt'

Bed.: R2f, a) vom pf. Aspekt, 3. vom Infinitivstamm, der 4. Konjugation

izumitelj 'Erfinder'

Bed.: R2g, a) vom pf. Aspekt, 3. vom Infinitivstamm, der 4. Konjugation

iskoristitelj 'einer, der ausnutzt'

Sondergruppe

I. Suffigierung

Ableitungen mit dem Formans $-l(0)$

Bed.: R2f, b) vom ipf. Aspekt, 3. vom Infinitivstamm, der 5. Konjugation

izmišljalo 'einer, der erdichtet, phantasiert'

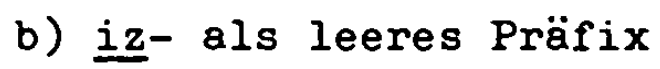

Die Ableitungsverfahren: I. Suffigierung

Die wortbildenden Typen nach ihren Formantien sowie ihre Produktivität:

Maskulina: I. -ac (1), -ač (1), -nik (1), -telj (2)

Die Ableitungsstämme und die Konjugationen:

Maskulina: I. 1. Grundstamm der 4., 6. Konjugation, 2. Stamm des Partizip Präteritum Aktiv der 4. Konjugation,

3. Infinitivstamm der 4. Konjugation 
Der Aspekt der Ableitungsbasis:

Maskulina: I. 4 pf. und 1 ipf. Verb

Maskulina

I. Suffigierung

Ableitungen mit dem Formans -ac

a) vom pf. Aspekt, 2. vom Stamm des Partizip Präteritum Aktiv, der 4. Konjugation

izvršilac 'einer, der etwas ausführt, verrichtet'

Ableitungen mit dem Formans -ač

b) vom ipf. Aspekt, 1. vom Grundstamm, der 6. Konjugation iznajmljivač 'einer, der etwas vermietet'

Ableitungen mit dem Formans -nik

a) vom pf. Aspekt, 1. vom Grundstamm, der 4. Konjugation izvršnik 'einer, der vollführt, ausführt'

Ableitungen mit dem Formans - telj

a) vom pf. Aspekt, 3. vom Infinitivstamm, der 4. Konjugation izvršitelj 'einer, der vollführt, ausführt', istumačitelj 'einer, der auslegt, ausdeutet'

CC. Nomina agentis von Verben mit dem Präfix na- in rein perfektivierender Funktion

a) na- als reihendes Präfix

Die Ableitungsverfahren: I. Suffigierung

Die wortbildenden Typen nach ihren Formantien, ihrer Produktivität und den Bedeutungen der Präfixe der ableitenden Verben mit ihrer Häufigkeit:

Maskulina: I. -ac (2), Bed.: R2a (1), R2b (1), -ač (2), Bed.: Rlb (1), R2a (1), -ič (1), Bed.: Rlb (1), -telj (2), Bed.: Rlb (1), Rlc (l)

Sondergruppe: I. $-1(0)$ (1), Bed.: R2a (1)

Die Ableitungsstämme und die Konjugationen: 
Maskulina: I. 1. Gruncstamm der 5., 4. Konjugation, 2. Stamm des Partizip Präteritum Aktiv der 4., 5. Konjugation,

3. Infinitivstamm der 5., 4. Konjugation

Sondergruppe: I. 3. Infinitivstamm der 5. Konjugation

Der Aspekt der Ableitungsbasis:

Maskulina: I. 2 pf. und 5 ipf. Verben

Sondergruppe: I. 1 ipf. Verb

Maskulina

I. Suffigierung

Ableitungen mit dem Formans -ac

Bed.: R2a, a) vom pf. Aspekt, 2. vom Stamm des Partizip Präteritum Aktiv, der 4. Konjugation nadopunilac 'einer, der ergänzt'

Bed.: R2b, b) vom ipf. Aspekt, 2. vom Stamm des Partizip Präteritum Aktiv, der 5. Konjugation

napajalac (neob.) 'einer, der tränkt'

Ableitungen mit dem Formans -ač

Bed.: Rlb, b) vom ipf. Aspekt, 1. vom Grundstamm, der 5. Konjugation

naganjač 'einer, der jemanden zu etwas, auf etwas treibt' Bed.: R2a, b) vom ipf. Aspekt, 1. vom Grundstamm, der 5. Konjugation

nakupljač 'einer, der ansammelt'

Ableitungen mit dem Formans -ič

Bed.: Rlb, b) vom ipf. Aspekt, l. vom Grundstamm, der 4. Konjugation

nagonič (lov.) 'Treiber'

Ableitungen mit dem Formans -telj

Bed.: Rlb, b) vom ipf. Aspekt, 3. vom Infinitivstamm, der 4. Konjugation

nagonitelj 'einer, der antreibt'

Bed.: Rlc, a) vom pf. Aspekt, 3. vom Infinitivstamm, der 5. Konjugation

napisatelj (arh.) 'Schreiber' 
Sondergruppe

I. Suffigierung

Ableitungen mit dem Formans $-1(0)$

Bed.: R2a, b) vom ipf. Aspekt, 3. vom Infinitivstamm, der 5. Konjugation

naklapalo 'Plauderer'

\section{b) na- als leeres Präfix}

Die Ableitungsverfahren: I. Suffigierung

Die wortbildenden Typen nach ihren Formantien sowie ihre Produktivität:

Maskulina: I. -ac (1), -ač (5), -telj (1)

Sondergruppe: I. $-1(0)$ (2)

Die Ableitungsstämme und die Konjugationen:

Maskulina: I. 1. Grundstamm der 5., 6. Konjugation, 2. Stamm des Partizip Präteritum Aktiv der 4. Konjugation,

3. Infinitivstamm der 4. Konjugation

Sondergruppe: I. 3. Infinitivstamm der 5., 6. Konjugation

Der Aspekt der Ableitungsbasis:

Maskulina: I. 2 pf. und 5 ipf. Verben

Sondergruppe: I. 2 ipf. Verben

Maskulina

I. Suffigierung

Ableitungen mit dem Formans -ac

a) vom pf. Aspekt, 2. vom Stamm des Partizip Präteritum Aktiv, der 4. Konjugation narušilac 'einer, der zerstört'

Ableitungen mit dem Formans -ač

b) vom ipf. Aspekt, 1. vom Grundstamm, der 5. Konjugation nabavljač 'Anschaffer, Lieferant', napijač 'Zutrinker', narikač 'einer, der jammert, klagt', nazdravljač 'Zutrinker' der 6. Konjugation najavljivač 'einer, der bekannt macht'

Ableitungen mit dem Formans -telj

a) vom pf. Aspekt, 3. vom Infinitivstamm, denaut 


\section{naučitelj (zast.) 'Lehrer'}

Sondergruppe

I. Suffigierung

Ableitungen mit dem Formans $-1(0)$

b) vom ipf. Aspekt, 3. vom Infinitivstamm, der 5. Konjugation nameštalo 'einer, der seine Worte zusammenstellt, viel nachdenkt, bevor er redet'

der 6. Konjugation namigivalo 'einer, der zublinzelt, kokettiert'

CD. Nomina agentis von Verben mit dem Präfix za- in rein perfektivierender Funktion

a) za- als reihendes Präfix

Die Ableitungsverfahren: I. Suffigierung

Die wortbildenden Typen nach ihren Formantien, ihrer Produktivität und den Bedeutungen der Präfixe der ableitenden Verben mit ihrer Häufigkeit:

Maskulina: I. -ac (1), Bed.: Rlg (1), -ač (7), Bed.: Rla (1), Rlb (1), Rld (1), Rlf (2), R2b (2), -nik (2), Bed.: Rlg (1), Rli (1)

Die Ableitungsstämme und die Konjugationen:

Maskulina: I. I. Grundstamm der 5., 6., 4. Konjugation, 2. Stamm des Partizip Präteritum Aktiv der 4., 5. Konjugation

Der Aspekt der Ableitungsbasis:

Maskulina: I. $4 \mathrm{pf}$. und 6 ipf. Verben

Maskulina

I. Suffigierung

Ableitungen mit dem Formans -ac

Bed.: Rlg, a) vom pf. Aspekt, 2. vom Stamm des Partizip Präteritum Aktiv, der 4. Konjugation

zaštitilac 'einer, der beschützt'

Ableitungen mit dem Formans -ač

Bed.: Rla, b) vom ipf. Aspekt, 1. vom Grundstamm, der 5. Konjugation

zaokretač (indiv.) 'einer, der etwas umwendet' 
Bed.: Rlb, a) vom pf. Aspekt, 1. vom Grundstamm, der 5. Konjugation

zagledač (etn.) 'einer, der das Mädchen vor dem Freien beschaut'

Bed.: Rld, b) vom ipf. Aspekt, 1. vom Grundstamm, der 6. Konjugation

zapisivač 'einer, der etwas notiert'

Bed.: Rlf, b) vom ipf. Aspekt, 1. vom Grundstamm, der 5. Konjugation

zaustavljač 'einer, der an-, zurückhält'

der 6. Konjugation

zavarivač 'einer, der lötet'

Bed.: R2b, b) vom ipf. Aspekt, 1. vom Grundstamm, der 5. Konjugation

zanavljač 'einer, der erneuert'

der 6. Konjugation

zaslepljivač 'einer, der blind macht'

Ableitungen mit dem Formans -nik

Bed.: Rlg, a) vom pf. Aspekt, 1. vom Grundstamm, der 4. Konjugation

$$
\text { zaštitnik 'einer, der schützt' }
$$

Bed.: Rli, a) vom pf. Aspekt, 1. vom Grundstamm, der 4. Konjugation

zamenik 'einer, der jemanden vertritt'

b) za- als leeres Präfix

Die Ableitungsverfahren: I. Suffigierung

Die wortbildenden Typen nach ihren Formantien sowie ihre Produktivität:

Maskulina: I. -ac (1), -ač (3)

Sondergruppe: I. $-1(0)$ (1)

Die Ableitungsstämme und die Konjugationen:

Maskulina: I. 1. Grundstamm der 5., 6. Konjugation, 2. Stamm des Partizip Präteritum Aktiv der 5. Konjugation

Sondergruppe: I. 3. Infinitivstamm der 5. Konjugation

Der Aspekt der Ableitungsbasis:

Maskulina: I. 4 ipf. Verben

Sondergruppe: I. 1 ipf. Verb 
Maskulina

I. Suffigierung

Ableitungen mit dem Formans -ac

b) vom ipf. Aspekt, 2. vom Stamm des Partizip Präteritum Aktiv, der 5. Konjugation

zanovetalac 'einer, der faselt'

Ableitungen mit dem Formans -ač

b) vom ipf. Aspekt, 1. vom Grundstamm, der 5. Konjugation zanovetač 'einer, der faselt', započinjač 'einer, der anfängt'

der 6. Konjugation

zakašnjivač 'einer, der häufig oder gern zu spät kommt'

Sondergruppe

I. Suffigierung

Ableitungen mit dem Formans $-1(0)$

b) vom ipf. Aspekt, 3. vom Infinitivstamm, der 5. Konjugation zanovetalo 'einer, der faselt'

Schlussbemerkungen

2a) Nomina agentis sind mit folgenden in quantitativer Reihenfolge aufgeführten Präfixen in lexikalischer Funktion gebildet: iz-, do-, na-, za-.

Nomina agentis sind mit folgenden in quantitativer Reihenfolge aufgeführten Präfixen in modifizierender Funktion gebildet: do-, iz- und na-, za- (mit jeweils gleich grosser Belegzahl). Nomina agentis sind mit folgenden in quantitativer Reihenfolge aufgeführten Präfixen in rein perfektivierender Funktion gebildet: a) mit reihenden Präfixen: iz-, za-, na- und b) leeren Präfixen: na-, iz-, za- (letztere mit gleich grosser Belegzahl).

Es kann ( $s$. Tabelle $5 a$ ) in rein quantitativer Hinsicht eine starke Affinität von Verben mit iz- in lexikalischer Funktion, eine weniger starke von solchen mit do-, na- in lexikalischer und dem reihenden Präfix iz- in rein perfektivierender Funktion, eine schwache von solchen mit den reihenden za-, na- und dem leeren 
Präfix na- in rein perfektivierender und za- in lexikalischer Funktion und eine sehr schwache von solchen mit do-, iz-, na-, za- in modifizierender und den leeren Präfixen iz-, za- in rein perfektivierender Funktion zu nomina agentis festgestellt werden.

2b) Nomina agentis sind mit Präfixen in folgenden in quantitativer Reihenfolge aufgeführten Funktionen gebildet: der lexikalischen, rein perfektivierenden mit reihenden und leeren Präfixen und modifizierenden Funktion.

Es kann (s. Tabelle 6) in rein quantitativer Hinsicht eine starke Affinität von Verben mit Präfixen in lexikalischer Funktion, eine schwache von solchen mit reihenden und leeren Präfixen in rein perfektivierender Funktion und eine sehr schwache von solchen mit Präfixen in modifizierender Funktion zu nomina agentis konstatiert werden.

Tabelle 5a: Zahlenmässige Angabe über das Vorkommen der nomina agentis nach den Funktionen und Präfixen sowie dem Aspekt der ableitenden Verben

Lexikalische Funktion

Aspekt do-iz- na- za-

pf. $\quad 5 \quad 10 \quad 4 \quad-$

ipf. $\quad 21 \quad 22 \quad 16 \quad 7$

Summe $\quad \begin{array}{llll}26 & 32 & 20 & 7\end{array}$

Modifizierende Funktion

Aspekt do-iz- na- za-

pf. $\quad 3 \quad 1 \quad 111$

ipf. $\quad 2 \quad 1 \quad 1$

Summe $\quad \begin{array}{llll}3 & 3 & 2 & 2\end{array}$

Rein perfektivierende Funktion

a) reihende Präfixe

\begin{tabular}{|c|c|c|c|c|}
\hline $\begin{array}{l}\text { Aspekt } \\
\text { pf. }\end{array}$ & do- & $\begin{array}{l}\text { iz- } \\
12\end{array}$ & $\begin{array}{c}\text { na- } \\
2\end{array}$ & $\begin{array}{c}28- \\
4\end{array}$ \\
\hline f & - & 13 & 6 & 6 \\
\hline $\mathrm{mm}$ & & 25 & 8 & 10 \\
\hline
\end{tabular}

Tabelle 5b: Angabe über das Vorkommen der nomina agentis nach den Bedeutungen der Präfixe in Zahlen

$$
\begin{aligned}
& \text { do- LI (12), L2 (4), L3 (9), } \\
& \text { L4 (1) } \\
& \text { iz- L1 (30), L2 (2) } \\
& \text { na- L1 (20) } \\
& \text { za- L1 (4), L4 (3) }
\end{aligned}
$$

do- MI (3)

iz- $M I$ (3)

na- MI (1), M2 (1)

za- MI (2)

$$
\begin{aligned}
& i z-R I(5), R 2(20) \\
& n a-R 1(4), R 2(4) \\
& z a-R I(8), R 2(2)
\end{aligned}
$$


b) leere Präfixe

Aspekt do- iz- na-za-

pf. $\quad-42$ -

ipf. $\quad-175$

Summe $\quad-595$

Tabelle 6: Angabe über das Gesamtvorkommen der nomina agentis nach den Funktionen der Präfixe in Zahlen und Prozenten

Lexikalische Funktion:

Modifizierende Funktion:

Rein perfektivierende Funktion:
a) reihende Präfixe:
b) leere Präfixe:
$43=27,38$
$19=12,10$

Summe Prozent

$85=54,14$

$10=6,36$ 
NOMINA RESULTATIVA

\section{Allgemeine Vorbemerkungen}

Unter nomina resultativa verstehen wir von Verben abgeleitete Substantive, die das Resultat der Handlung ausdrücken.

Unter den Begriff nomina resultativa werden Substantive subsumiert, die das Resultat einer Handlung und das Resultat eines Vorgangs ausdrücken. Substantive, die das Resultat einer Handlung ausdrücken, werden von transitiven Verben abgeleitet. Substantive, die das Resultat eines Vorgangs ausdrücken, werden von intransitiven Verben abgeleitet.

Zur ersten Gruppe werden Substantive gerechnet wie z.B. domišljaj 'Resultat des Denkens, Gedanke' zu domišljati, izrezak 'Ausschnitt' zu izrezati, izričaj 'Ausgesprochenes, Ausspruch' $z u$ izricati, istisak 'Ausgedrücktes' $z u$ istiskati oder istisnuti, izlučak 'Abgesondertes' $z u$ izlučiti, naduvak 'Aufgeblasenes' $z u$ naduvati, namotak 'Knäuel' $z u$ namotati, zalomak 'Stummel' $z u$ zalomiti, zavitak 'Bündel, Paket' zu zaviti.

Zur zweiten Gruppe werden Substantive gerechnet wie z.B. izrastak 'Auswuchs' $z u$ izrasti, iznikao 'Spross, Trieb' zu iznići, zaostanak 'Rückstand' zu zaostati, zaparotina 'Narbe vom Verbrühen' zu zapariti, napuklina 'Spalt, Riss' zu napući.

Nomina resultativa werden in der überwiegenden Mehrzahl der Fälle von transitiven Verben abgeleitet.

$\mathrm{Zu}$ den nomina resultativa werden keine Substantive gezählt, die neben ihrer primären Bedeutung die Bedeutung des Resultats einer Handlung sekundär erhalten. Das ist sehr häufig bei nomina actionis der Fall, besonders bei nomina actionis im engeren Sinne. Diese Substantive werden nach ihrer primären Bedeutung eingeordnet. $\mathrm{Zu}$ diesen Substantiven gehören z.B. dograda 'Anbauen; Anbau', nametak 'Aufsetzen; Aufsatz', nasad 'Anpflanzen; Anpflanzung', izdanje 'Herausgeben; Ausgabe', zarašćanje 'Zuwachsen; Narbe' .

In die Untersuchung hineingenommen werden jedoch Substantive, die durch Bedeutungsübertragung aus nomina actionis im engeren Sinne entstanden sind und vom heutigen Standpunkt eine primär 
resultative Bedeutung aufweisen, wie z.B. nagaz 'Spur', nalep 'Aufgeklebtes', nasada 'Anlage von Bäumen'.

Vom onomasiologischen Standpunkt handelt es sich bei den nomina resultativa um die onomasiologische Kategorie des Trägers einer Handlungsbeziehung, von welcher eine der abgeleiteten Modifikationen die Beziehung einer Handlung zu ihrem Resultat ist $^{189}$. (namotak = eine Sache, die dadurch bestimmt ist, dass sie das Resultat des Aufwickelns ist, dass sie aufgewickelt ist.)

Auf der wortbilderden Ebene werden nomina resultativa in erster Linie durch das wortbildende Verfahren der Suffigierung, in zweiter durch das der Konversion realisiert. Das wortbildende Verfahren der Suffigierung stellt das Hauptableitungsverfahren der nomina resultativa dar.

Das wortbildende Verfahren der Konversion, das bei der Ableitung von nomina resultativa eine nicht unerhebliche Rolle spielt, ist vor allem ein Ableitungsverfahren der nomina actionis im engeren Sinne. Bei der Ableitung von nomina resultativa gilt die Konversion nur als uneigentliches 190 Verfahren. Mit diesem Verfahren werden maskuline Substantive mit hartem stammauslautendem Konsonanten und der Endung $-\varnothing$ im Nominativ Singular (Deklinationsmuster "rad") bzw. mit weichem stammauslautendem Konsonanten und der Endung $\varnothing$ im Nominativ Singular (Deklinationstyp "muž") sowie feminine Substantive mit hartem oder weichem stammauslautendem Konsonanten und der Endung -a im Nominativ Singular (Deklinationstypen "žena" und "učiteljica") abgeleitet.

Nomina resultativa werden von Verben mit den Präfixen do-, iz-, na-, za- in lexikalischer Funktion, von Verben mit den Präfixen do-, iz-, na-, za- in modifizierender Funktion und von Verben mit den Präfixen iz-, na-, za- in rein perfektivierender Funktion abgeleitet.

Folgende Formantien finden bei der Bildung von nomina resultativa Verwendung:

Maskulina: I. $-a c,-a j,-a k,-a n j,-u l j(a) k, I I .-H K-\varnothing,-W K-\varnothing$ Feminina: I. $-a c ̌(a),-a \operatorname{ljk}(a),-a o,-d b(a),-\operatorname{etin}(a),-i c(a)$, Neutra: I. $-1(0)$.

$$
-n j(a),-i n(a),-k(a),-\operatorname{otin}(a), I I .-H K-a,-W K-a 19 I
$$

189 M. Dokulil, Tvořeni slov I, S. 35.

190 Mit uneigentlichem Verfahren bzw. Mittel werden nomina resultativa abgeleitet, die durch Bedeutungsübertragung sekundär aus nomina actionis im engeren Sinne entstanden sind. Mit eigentlichem Verfahren bzw. Mittel werden primär gebildete 
Nach der Produktivität ergibt sich für die gesamte wortbildende Kategorie der nomina resultativa folgendes Bild:

Maskulina: I. a) sehr produktiv: -ak, b) weniger produktiv: -aj,

d) ganz unproduktiv: $-a c,-a n j,-u l j(a) k$

II. a) sehr produktiv: $-\mathrm{HK}-\varnothing, \mathrm{c})$ unproduktiv: $-W K-\varnothing$

Feminina: I. b) weniger produktiv: $-i n(a),-i c(a),-\operatorname{otin}(a)$,

c) unproduktiv: $-a o,-\operatorname{etin}(a),-k(a)$, d) ganz unproduktiv: $-a c ̌(a),-a l j k(a),-d b(a),-n j(a)$

II. b) weniger produktiv: $-H K-a, d)$ ganz unproduktiv: $-W K-a$

Neutra: I. d) ganz unproduktiv: $-1(0)$.

Die wortbildenden Typen auf -ak,-HK- $\varnothing$ und $-a j$ bilden den Kern der maskulinen Substantive mit Präfixen sowohl der lexikalischen als auch der modifizierenden und mit reihenden Präfixen in rein perfektivierender Funktion, wobei der Typ mit dem Formans -ak eine dominierende Stellung bei den Substantiven mit den Präfixen aller drei Funktionen einnimmt. Maskuline Substantive mit leeren Präfixen in rein perfektivierender Funktion sind nur durch die wortbildenden Typen auf -ak und -HK- $\varnothing$ vertreten.

Die wortbildenden Typen auf -in(a), -ic(a), -HK-a bilden den Kern der femininen Substantive mit Präfixen in lexikalischer und modifizierender und mit reihenden Präfixen in rein perfektivierender Funktion. Feminine Substantive mit leeren Präfixen in rein perfektivierender Funktion sind lediglich durch den wortbildenden Typ auf -HK-a vertreten.

Nomina resultativa werden in überwiegendem Masse von Verben mit Präfixen in rein perfektivierender Funktion reihenden Charakters, in geringerem Masse von Verben mit Präfixen in lexikalischer und modifizierender Funktion und in einem sehr geringen Masse von Verben mit leeren Präfixen in rein perfektivierender Funktion abgeleitet.

In bezug auf das Genus der Substantive werden maskuline und feminine nomina resultativa am häufigsten von Verben mit reihenden Präfixen in rein perfektivierender Funktion abgeleitet.

Die Ableitungsbasis der nomina resultativa wird in erster Linie vom Grundstamm und vereinzelt vom Stamm des Partizip Präteritum Passiv, vom Stamm des Partizip Präteritum Aktiv und vom Infinitivstamm gebildet.

nomina resultativa abgeleitet.

191 -WK-a steht für feminine Substantive mit weichem stammauslau-

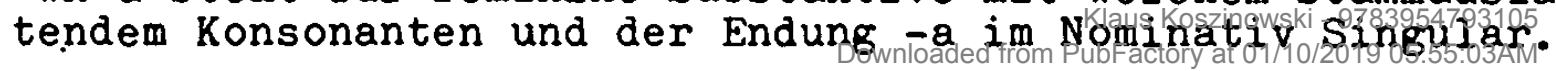


Nomina resultativa, die mit Hilfe der Suffigierung gebildet sind, sind durch Verben aller Konjugationen mit Ausnahme derer der 6. motiviert. Der Kern der Ableitungsbasis der Ableitungen von Verben mit Präfixen in lexikalischer und modifizierender Funktion wird vom Grundstamm von Verben der 5., 4. Konjugation, der der Ableitungen von Verben mit reihenden Präfixen in rein perfektivierender Funktion vom Grundstamm von Verben der 4., 5. Konjugation und der der Ableitungen von Verben mit leeren Präfixen in rein perfektivierender Funktion vom Stamm des Partizip Präteritum Passiv von Verben der 4., 1. Konjugation gebildet.

Nomina resultativa, die mit Hilfe der Konversion gebildet sind, sind durch Verben aller Konjugationen mit Ausnahme derer der 6. motiviert. Den Kern der Ableitungsbasis der Ableitungen von Verben mit Präfixen der lexikalischen, modifizierenden und rein perfektivierenden Funktion bilden Verben der 4. Konjugation.

Die nomina resultativa nach dem Ableitungsverfahren, dem Ableitungsstamm und der Konjugation:

A. Lexikalische Funktion

I. Suffigierung

1. Grundstamm

Maskulina: 5., 4., 1., 2., 3., Konjugation

Feminina: 4., 5., 2., 1. Konjugation

2. Stamm des Partizip Präteritum Aktiv

Feminina: 1. Konjugation

4. Stamm des Partizip Präteritum Passiv

Maskulina: 5., 1. Konjugation

II. Konversion

Maskulina: 5., 4., 1., 2. Konjugation

Feminina: 4. Konjugation

B. Modifizierende Funktion

I. Suffigierung

1. Grundstamm

Maskulina: 5., 4., 1., 3. Konjugation

Feminina: 4., 5., 1., 3. Konjugation

2. Stamm des Partizip Präteritum Aktiv

Feminina: 1., 2., 3. Konjugation

II. Konversion

Maskulina: 5., 4., 1. Konjugation

Feminina: 4., 5., Konjugation 
C. Rein perfektivierende Funktion

a) reihende Präfixe

I. Suffigierung

1. Grundstamm

Maskulina: 5., 4., 1., 3., 2. Konjugation

Feminina: 4., 1., 5., 3., 2. Konjugation

2. Stamm des Partizip Präteritum Aktiv

Feminina: 1., 3. Konjugation

3. Infinitivstamm

Feminina: 5. Konjugation

4. Stamm des Partizip Präteritum Passiv

Maskulina: 1. Konjugation

Feminina: 5. Konjugation

Neutra: 5. Konjugation

\section{Konversion}

Maskulina: 4., 5., 1.,2., 3. Konjugation

Feminina: 4. Konjugation

b) leere Präfixe

I. Suffigierung

4. Stamm des Partizip Präteritum Passiv

Maskulina: 4., 1. Konjugation

II. Konversion

Maskulina: 4. Konjugation

Feminina: 4. Konjugation

Nomina resultativa werden vorwiegend von perfektiven Verben abgeleitet. Eine Disposition zur Ableitung der nomina resultativa in erster Linie von perfektiven Verben ist zweifellos durch die Tatsache gegeben, dass das Resultat konstituierendes Element des perfektiven Aspekts ist.

Ableitungen von imperfektiven Verben treten am relativ häufigsten von Verben mit Präfixen der lexikalischen Funktion auf.

Nomina resultativa von imperfektiven Verben mit Präfixen der lexikalischen Funktion sind 2.B. izbirak 'Uberbleibsel' zu izbirati, izričaj 'Ausgesprochenes, Ausspruch' zu izricati, nahodjaj 'Fund' zu nahoditi und zavijača 'Strudel' zu zavijati.

Nomina resultativa von imperfektiven Verben mit Präfixen der modifizierenden Funktion sind z.B. zasecaj (indiv.) 'Anschnitt, Falte' zu zasecati, dogarak 'Zigarettenstummel' zu dogarati.

Nomina resultativa von imperfektiven Verben mit Präfixen der rein perfektivierenden Funktion sind $z . B$. istmiganica- (quokras) 5 
'Stück geschorener Wolle' $z u$ istrizati, naduv 'Odem' zu naduvati.

In semantischer Hinsicht weisen die von imperfektiven Verben abgeleiteten nomina resultativa generell eine Beziehung zu perfektiven Verben auf. Es besteht eine Diskrepanz zwischen der Semantik der Derivate, die mit einem perfektiven Verb korreliert, und der formalen Ableitungsbeziehung zu einem imperfektiven Verb. Roudnýl ${ }^{192}$ erklärt die formale Ableitung der nomina resultativa von imperfektiven Verben mit der Schwierigkeit, in solchen Fällen perfektive Verben $z u$ verwenden.

Nomina resultativa sind generell überwiegend konkrete und weitgehend lexikalisierte Substantive wie z.B. izgorak 'Kerzenstumpf', izvarak 'Schlacke', zamotak 'Bündel'. Während Substantive, die von Verben mit Präfixen der lexikalischen und modifizierenden Funktion und von solchen mit reihenden Präfixen der rein perfektivierenden Funktion abgeleitet sind, fast ausschliesslich Konkreta sind, überwiegen bei Substantiven, die von Verben mit leeren Präfixen in rein perfektivierender Funktion abgeleitet sind, die abstrakten Substantive wie z.B. izgubitak 'Verlust', zadobitak 'Errungenschaft' .

Das unterschiedliche Vorkommen von abstrakten und konkreten Substantiven scheint meiner Ansicht nach tendenziell mit der Bedeutung der Präfixe in Zusammenhang gebracht werden zu können. Lexikalische und modifizierende Präfixe besitzen eine eigene konkrete Bedeutung und übertragen diese über die mit ihrer Hilfe abgeleiteten Verben auf die Substantive. Diese Präfixe liegen den nomina resultativa zugrunde, die von Verben mit Präfixen der lexikalischen und modifizierenden Funktion abgeleitet sind.

Die überwiegend grosse Zahl von konkreten Substantiven bei nomina resultativa, die von Verben mit reihenden Präfixen in rein perfektivierender Funktion abgeleitet sind, scheint im Zusammenhang mit deren semantischen Gehalt gesehen werden zu können. Der konkrete Inhalt der reihenden Präfixe wird über die mit ihrer Hilfe abgeleiteten Substantive übertragen. Das völlige Fehlen der konkreten Substantive bei nomina resultativa, die von Verben mit leeren Präfixen in rein perfektivierender Funktion abgeleitet sind, kann durch ihren semantisch "leeren" Charakter erklärt werden. Diese Präfixe fügen dem Verb und dem von ihm abgeleiteten Substantiv keine neue Bedeutung hinzu, sondern ändern lediglich den Aspekt.

192 M. Roudný, in: Tvořeni slov II, S. 267. 
Einige wenige Substantive, die noch für nomina resultativa gehalten werden können, weisen eine Verbindung zu anderen Modifikationen der Beziehung des Trägers einer Handlung auf, und zwar zu der der Beziehung des Mittels zu einer Handlung und zu der der Beziehung der Tätigkeit zum Ort. Eine Verbindung besteht vor allem auch 2 wischen der Bedeutung der nomina resultativa und der Bedeutung der Handlung selbst. So bezeichnen z.B. izmera 'Ergebnis des Messens; Messen', ispupčina 'Ausbuchtung, Erhebung; Ausbauchung' neben dem Resultat der Handlung die Handlung selbst.

Das Substantiv završetak 'Schluss, Abschluss; eine Sache, mit der etwas beendet wird' bezeichnet neben dem Resultat der Handlung das Mittel zu einer Handlung.

Das Substantiv izrezak 'Ausschnitt; Ort, Stelle, wo etwas ausgeschnitten ist' bezeichnet neben dem Resultat der Handlung den Ort, an dem eine Handlung geschieht.

Einige nomina resultativa mit den Formantien -in(a) und -ic(a), die vom Grundstamm bzw. Stamm des Partizip Präteritum Aktiv abgeleitet sind, bilden einen Ubergang von der onomasiologischen Kategorie des Trägers einer Handlungsbeziehung zu der des Trägers einer Eigenschaft. Diese Substantive erlauben in formaler Hinsicht ausser der direkten Motivation durch den Grundstamm oder den Stamm des Partizip Präteritum Aktiv eine sekundäre Motivation durch das Adjektiv, das sich aus dem Partizip des entsprechenden Verbs gebildet hat. So ist ispupčina, das vom Grundstamm abgeleitet ist, primär 'das, was ausgebaucht ist' und sekundär 'etwas, dessen Eigenschaft es ist, ausgebaucht zu sein'. Auch in formaler Hinsicht völlig identisch mit nomina attributiva sind izgorelina 'Brandwunde', naraslica 'Auswuchs' und zaraslica 'Narbe', die vom Stamm des Partizip Präteritum Aktiv abgeleitet sind, da dieser auch zur Bildung von Adjektiven verwendet wird, von denen nomina attributiva abgeleitet werden (z.B. zagorelica 'gebrannter Schnaps').

Unter dem Gesichtspunkt der Bedeutung der Präfixe der ableitenden Verben ergibt sich für das Vorkommen der nomina resultativa folgendes Bild:

In lexikalischer Funktion werden nomina resultativa von Verben mit nachstehenden Präfixen und ihren Bedeutungen abgeleitet: do- Ll 'bis $z u$ (einem bestimmten Ort gelangen)' oder (einen Gegenstand) bis zu (einem bestimmten Ort bewegen)' (dohodak 'Einkommen' von dohoditi 'kommen, heran-');

L2 'zu (etwas) hinzu(fügen)' (dodatak 'Zugabe Zusatz' von 
dodati 'zugeben');

L3 'bis zu (etwas gelangen)' (dosetka 'Einfall, Witz' von dosetiti se 'einfallen');

L4 '(etwas) zu jemandes Nutzer (tun)' (dosuda 'Urteilsspruch' von dosuditi 'zuerkennen, zusprechen');

iz- Il '(etwas) von innen nach aussen (oder) von unten nach oben (bewegen)' (izmetak 'Auswurf' von izmetati 'auswerfen'); L2 '(jemanden oder etwas) aus einer Mitte heraus(bewegen)' (izostanak 'Ausbleiben, Fehlen' von izostati 'ausbleiben'); na- Il '(einen Gegenstand) auf (einen anderen stellen)' (nahodjaj 'gefundener Gegenstand, Fund' von nahoditi 'finden');

za- II '(etwas) hinter (etwas stellen)' (zavitak 'Eingewickeltes' von zaviti 'einwickeln');

L2 '(umfassen) von allen Seiten' (zapletaj 'Verwicklung, Verflechtung' von zaplesti 'verwickeln');

L3 '(umfassen) der äusseren Hülle' (zarastica 'Narbe, Vernarbung' von zarasti 'vernarben');

In modifizierender Funktion werden nomina resultativa von Verben mit nachstehenden Präfixen und ihren Bedeutungen abgeleitet: do- MI '(eine früher nicht ausgeführte Handlung) bis zum Ende (ausführen)' (dogarak 'Zigarettenstummel' von dogarati 'abbrennen');

iz- Ml 'erreichen, erlangen' (izradak 'Produkt einer Arbeit' von izraditi 'ausarbeiten, verfertigen');

na- Ml '(eine Handlung) in ausreichendem Masse (ausführen)' (naslagaj 'Aufschichtung' von naslagati 'aufschichten'); M2 '(eine Handlung) in geringem Masse (ausführen)' (narez 'Kerbe, Einschnitt' von narezati 'einschneiden'); za- Ml '(eine Handlung) beginnen' (zalizak 'ein vom Vieh angelecktes Stück Salz' von zalizati 'anlecken');

In reihender Funktion werden nomina resultativa von Verben mit nachstehenden Präfixen und ihren Bedeutungen abgeleitet: Das Präfix iz- kann in Zusammensetzung mit Verben in der Bedeutung (RI) 'von weg, heraus' und in (R2) 'ausführen bis zum Erreichen des Ziels, bis zur Ausschöpfung der Möglichkeit' mit seinen jeweiligen Bedeutungsnuancen reihende Funktion ausüben. Die Bedeutungsnuancen der Bedeutung RI sind: Rla 'ausdrücken' (istisak 'Ausgedrücktes' von istiskati 'ausdrücken'); Rlb 'wachsen' (iznikao 'Aufgesprossenes' von iznići 'aufspriessen'); Rlc 'umwerfen' (izvala 'umgewehter Baum' von izvaliti 'umwehen'); Rld 'ausschneiden' (isečak 'Ausgeschnittenes' von iseći 'ausschneiden') 
Rle 'aushöhlen' (izdubak 'Aushöhlung, Nische' von izdubiti 'aushöhlen'); Rlf 'absondern' (izlučak 'Ab-, Ausgesondertes' von izlučiti 'ab-, aussondern'); Rlh 'sichverlieren' (ishlapina 'Dampf' von ishlapiti 'verdampfen'); RIi 'verschwinden' (izgorak 'Kerzenstummel' von izgoreti 'niederbrennen'); Rlj 'Restgruppe' (z.B. iscrpak 'Ausgeschöpftes' von iscrpsti 'ausschöpfen'); Die Bedeutungsnuancen der Bedeutung R2 sind: $R 2 a$ 'versehen mit einem neuen Gepräge' (izjava 'Erklärung' von izjaviti 'erklären'); $\mathrm{R} 2 \mathrm{~b}$ 'bei Anwendung eines chemischen oder physischen Verfahrens in den gewünschten Zustand bringen' (izvarak 'Schlacke' von izvariti 'auskochen'); R2c 'anwenden einer bestimmten Prozedur an einem Lebewesen zur Erlangung des erwünschten Zustands' (ishrana 'Ernährung' von ishraniti 'ernähren'); R2f 'erreichen des gewünschten Resultats durch geistige oder ähnliche Arbeit' (izum 'Erfindung' von izumeti 'erfinden');

Das Präfix na- kann in Zusammensetzung mit Verben in der Bedeutung ( $R I$ ) 'stellen eines Gegenstandes auf einen anderen' und in (R2) der 'Augmentation' mit seinen jeweiligen Bedeutungsnuancen reihende Funktion ausüben. Die Bedeutungsnuancen der Bedeutung $R I$ sind: $R I b$ 'treten auf, veranlassen, auf etwas zu treten' (nastupak 'Auftritt' von nastupati 'auftreten'); Rlc 'schreiben' (nacrtaj 'Skizze' von nacrtati 'zeichnen, auf-'); Die Bedeutungsnuancen der Bedeutung R2 sind: R2a 'anhäufen, etwas in Menge tun' (nadometak 'Zusatz' von nadometnuti 'zusetzen'); R2c 'anschwellen, zunehmen' (napetak 'Geschwür' von napeti 'anspannen, straffen');

Das Präfix za- kann in Zusammensetzung mit Verben in der Bedeutung ( $R I$ ) 'hinter etwas gehen' und in (R2) 'einen neuen Zustand einnehmen' mit seinen jeweiligen Bedeutungsnuancen reihende Funktion ausüben. Die Bedeutungsnuancen der Bedeutung RI sind: Rla 'umdrehen' (zamotljaj 'Umschlag, Bündel' von zamotati 'einwickeln'); Rlb 'umfassen eines Teils oder des Ganzen' (zagrabljaj 'Ansichgerafftes' von zagrabiti 'an sich raffen'); Rld 'an einem sicheren Ort aufbewahren' (zapisak 'Aufzeichnung, Notiz' von zapisati 'notieren'); Rle 'Nahrung aufnehmen' (zapoj 'Trank' von zapiti 'trinken'); Rlf 'verschliessen und hindern' (zapret 'Zugedecktes, mit Asche zugedeckte Glut' von zapretati 'mit Asche zudecken'); Rlh 'töten, vernichten' (zalomak 'Stummel' von zalomiti 'abbrechen');

Die Bedeutungsnuancen der Bedeutung R2 sind: R2a 'verweilen, eine Stellung einnehmen' (zaostatak 'Rückstand' von zaostati 'zurück- 
bleiben'); R2b 'versehen mit einer neuen Eigenschaft' (zamor

'Erschöpftheit' von zamoriti 'ermüden').

\section{Material}

A. Lexikalische Funktion

AA. Nomina resultativa von Verben mit dem Präfix do- in lexikalischer Funktion

Die Ableitungsverfahren: I. Suffigierung, II. Konversion Die wortbildenden Typen nach ihren Formantien, ihrer Produktivität und den Bedeutungen der Präfixe der ableitenden Verben mit ihrer Häufigkeit:

Maskulina: I. -aj (2), Bed.: Ll (1), L3 (1), -ak (7), Bed.: LI (1), L2 (6)

Feminina: I. -80 (1), Bed.: L3 (1), -ic(a) (1), Bed.: Ll (1), $-k(a)(1)$, Bed.: L3 (1)

II. $-\mathrm{HK}-\mathrm{a}$ (1), Bed.: L2 (1)

Die Ableitungsstämme und die Konjugationen:

Maskulina: I. 1. Grundstamm der 4., 5., 3. Konjugation

Feminina: I. 1. Grundstamm der 4. Konjugation, II. 4. Konjugation

Der Aspekt der Ableitungsbasis:

Maskulina: I. 8 pf. und 1 ipf. Verb

Feminina: I. 3 pf. Verben, II. I pf. Verb

Maskulina

I. Suffigierung

Ableitungen mit dem Formans - aj

Bed.: LI, a) vom pf. Aspekt, 1. vom Grundstamm, der 3. Konjugation doživljaj 193 'Erlebnis'

Bed.: L3, a) vom pf. Aspekt, 1. vom Grundstamm, der 4. Konjugation domišljaj 'Erdachtes'

Ableitungen mit dem Formars -ak

Bed.: Ll, b) vom ipf. Aspekt, 1. vom Grundstamm, der 4. Konjugation

193 Der Konsonant $-1 j$ - bei Wörtern vom Typ 'doživljaj' muss als eine Analogieerscheinung zu Wörtern wie 'zagrljaj' und 'predomišljaj' erklärt werden, bei denen man -lj- durch Jotierung des Konsonanten -1-erhält. Vgl. M. Stevanović, Savremeni srpskohrvatski jezik..., a.a.0., S. 484. 
dohodak 'Einkommen'

Bed.: L2, a) vom pf. Aspekt, 1. vom Grundstamm, der 4. Konjugation domerak 'Zuwage', doplatak 'Zulage', dopunak 'Ergänzung'

der 5. Konjugation

dodatak 'Zugabe, Zusatz', dometak 'Zusatz', dozidak 'Ange-

bautes; Haus, das an ein anderes angebaut ist.

Feminina

I. Suffigierung

Ableitungen mit dem Formans -ao

Bed.: I3, a) vom pf. Aspekt, 1. vom Grundstamm, der 4. Konjugation domisao 'Einfall'

Ableitungen mit dem Formans -ic(a)

Bed.: LI, a) vom pf. Aspekt, 1. vom Grundstamm, der 4. Konjugation doskočica 'geistreiche Bemerkung, Einfall'

Ableitungen mit dem Formans $-k(a)$

Bed.: L3, a) vom pf. Aspekt, 1. vom Grundstamm, der 4. Konjugation dosetka 'Einfall, Witz'

II. Konversion

Ableitungen auf $-\mathrm{HK}-\mathrm{a}$

Bed.: L2, a) vom pf. Aspekt, der 4. Konjugation doplata 'Nachzahlung'

$A B$. Nomina resultativa von Verben mit dem Präfix $\underline{\text { iz- }}$ in lexikalischer Funktion

Die Ableitungsverfahren: I. Suffigierung, II. Konversion

Die wortbildenden Typen nach ihren Formantien, ihrer Produktivität und den Bedeutungen der Präfixe der ableitenden Verben mit ihrer Häufigkeit:

Maskulina: I. -aj (4), Bed.: II (4), -ak (10), Bed.: II (6), L2 (4), II. $-\mathrm{HK}-\varnothing(5)$, Bed.: II (5)

Feminina: I. $-\operatorname{in}(a)$ (1), Bed.: LI (1), $-k(a)$ (1), Bed.: Il (1) II. $-\mathrm{HK}-\mathrm{a}$ (1), Bed.: LI (1) 
Die Ableitungsstämme und die Konjugationen:

Maskulina: I. 1. Grundstamm der 5., 4., 1. Konjugation, 4. Stamm des Partizip Präteritum Passiv der 5., 1. Konjugation

II. 5., 1., 4., 2. Konjugation

Feminina: I. 1. Grundstamm der 2., 5. Konjugation

II. 4. Konjugation

Der Aspekt der Ableitungsbasis:

Maskulina: I. 8 pf. und 6 ipf. Verben, II. 2 pf. und 3 ipf. Verben Feminina: I. 1 pf. und 1 ipf. Verb, II. 1 pf. Verb

Maskulina

I. Suffigierung

Ableitungen mit dem Formans -aj

Bed.: LI, a) vom pf. Aspekt, 1. vom Grundstamm, der 4. Konjugation izbacaj 'Herausgeworfenes'

der 5. Konjugation

iskašljaj 'Auswurf'

b) vom ipf. Aspekt, 1. vom Grundstamm, der 5. Konjugation

izdisaj '1. das, was der Mensch auf einmal ausatmet, 2. Sterben', izričaj 'Ausgesprochenes'

Ableitungen mit dem Formans -ak

Bed.: Ll, a) vom pf. Aspekt, 1. vom Grundstamm, der 1. Konjugation izbojak 'Trieb, Schössling'

der 5. Konjugation

izlizak 'Abgelecktes'

4. vom Stamm des Partizip Präteritum Passiv, der 5. Konjugation

izdatak 'Ausgabe'

b) vom ipf. Aspekt, 1. vom Grundstamm, der 5. Konjugation

izlivak 'Ausgegossenes', izmetak 'Auswurf, Ausschuss'

der 4. Konjugation

iznosak 'Aus-, Hinausgetragenes'

Bed.: L2, a) vom pf. Aspekt, 4. vom Stamm des Partizip Präteritum Passiv, der 5. Konjugation

izostanak 'Ausbleiben, Fehlen', izostatak'194 'Ausgebliebenes'

194 Ableitungen vom Typ 'izostatak', deren ableitende Verben intransitiv sind und daher keine Bildung eines Partizip Präteritum Passiv zulassen, müssen als Analogiebildungen zu Ableitungen gewertet werden, deren zugrunde liegende Verben transitiv sind und die Bildung eines Partizi lauprateritura 954793105 
der 1. Konjugation

izuzetak 'Ausnahme'

b) vom ipf. Aspekt, 1. vom Grundstamm, der 5. Konjugation izbirak 'Uberbleibsel, Ausschuss, Rest'

II. Konversion

Ableitungen auf $-H K-\varnothing$

Bed.: LI, a) vom pf. Aspekt, der 1. Konjugation izrek 'Ausgesprochenes'

der 2. Konjugation

izmak 'Neige'

b) vom ipf. Aspekt, der 5. Konjugation

izgrt 'angehäufelte Erde im Weinberg', izmet 'Absonderung, Auswurf'

der 4. Konjugation

izvod 'Auszug, Exzerpt'

Feminina

I. Suffigierung

Ableitungen mit dem Formans -in(a)

Bed.: Ll, a) vom pf. Aspekt, 1. vom Grundstamm, der 2. Konjugation izmetina 'Auswurf, Ausschuss'

Ableitungen mit dem Formans $-k(a)$

Bed.: Il, b) vom ipf. Aspekt, l. vom Grundstamm, der 5. Konjugation

izlivka 'Blut, das aus dem Blutgefäss gelaufen ist und sich

im Körper gehalten hat, extravasatum'

II. Konversion

Ableitungen auf $-\mathrm{HK}-\mathrm{a}$

Bed.: Ll, a) vom pf. Aspekt, der 4. Konjugation

ispara 'Schwüle, Dampf'

AC. Nomina resultativa von Verben mit dem Präfix na- in lexikalischer Funktion 
Die Ableitungsverfahren: I. Suffigierung, II. Konversion

Die wortbildenden Typen nach ihren Formantien, ihrer Produktivität und den Bedeutungen der Präfixe der ableitenden Verben mit ihrer Häufigkeit:

Maskulina: 1. -aj (3), Bed.: Ll (3), -ak (6), Bed.: II (6), II. $-H K-\varnothing$ (5), Bed.: II (5), -WK- $\varnothing$ (2), Bed.: II (2)

Feminina: I. $-\operatorname{aljk(a)~(1),~Bed.:~Ll~(1),~}-i n(a)$ (1), Bed.: LI (1) Die Ableitungsstämme und die Konjugationen:

Maskulina: I. 1. Grundstamm der 5., 4., 2., 1. Konjugation II. 4., 5., 1. Konjugation

Feminina: I. 1. Grundstamm der 4., 5. Konjugation

Der Aspekt der Ableitungsbasis:

Maskulina: I. 7 pf. und 2 ipf. Verben, II. 5 pf. und 2 ipf. Verben Feminina: I. 2 pf. Verben

Maskulina

I. Suffigierung

Ableitungen mit dem Formans - aj

Bed.: Il, a) vom pf. Aspekt, 1. vom Grundstamm, der 5. Konjugation namotaj 'ein Kreis aufgewickelten Materials'

b) vom ipf. Aspekt, 1. vom Grundstamm, der 4. Konjugation nahodjaj 'gefundener Gegenstand, Fund'

der 5. Konjugation nakretaj 'Schlagseite (Schiff)'

Ableitungen mit dem Formans -ak

Bed.: LI, a) vom pf. Aspekt, 1. vom Grundstamm, der 4. Konjugation nalepak 'Aufgeklebtes'

der 5. Konjugation

namotak 'Knäuel', navezak 'Faden, der an einen anderen gebunden ist'

der 1. Konjugation navojak 'Spule'

der 2. Konjugation nametak 'Aufgesetztes, Aufgelegtes'

4. vom Stamm des Partizip Präteritum Passiv, der 1. Konjugation navitak (navijutak) 'aufgewickeltes Garn am Garnbaum; Aufzug (Weberei)'

II. Konversion 
Ableitungen auf $-H K-\varnothing$

Bed.: LI, a) vom pf. Aspekt, der 4. Konjugation nalep 'Aufgeklebtes'

der 5. Konjugation

namet 'Anhäufung zusammengewehten Schnees', navez 'Stickerei'

b) vom ipf. Aspekt, der 4. Konjugation

nahod 'Findelkind', navod 'Zitat; Anführen'

Ableitungen auf $-W K-\varnothing$

Bed.: Ll, a) vom pf. Aspekt, der 1. Konjugation

naboj '1. gestampfte Erde, 2. Gegenstand zum Stampfen', navoj 'Schraubenwindung; Spule'

Feminina

I. Suffigierung

Ableitungen mit dem Formans -aljk(a)

Bed.: Ll, a) vom pf. Aspekt, 1. vom Grundstamm, der 5. Konjugation navezaljka 'Angeknüpftes; angehefteter Schmuck'

Ableitungen mit dem Formans -in(a)

Bed.: Ll, a) vom pf. Aspekt, 1. vom Grundstamm, der 4. Konjugation naselina 'Schicht'

AD. Nomina resultativa von Verben mit dem Präfix za- in lexikalischer Funktion

Die Ableitungsverfahren: 1. Suffigierung, II. Konversion Die wortbildenden Typen nach ihren Formantien, ihrer Produktivität und den Bedeutungen der Präfixe der ableitenden Verben mit ihrer Häufigkeit:

Maskulina: I. -ac (1), Bed.: L3 (1), -aj (2), Bed.: II (2), -ak (2), Bed.: Ll (2), $-u l j(a) k$ (1), Bed.: Il (1)

$$
\text { II. }-\mathrm{HK}-\varnothing \text { (3), Bed.: LI (1), L2 (1), L3 (1) }
$$

Feminina: I. -ač(a) (1), Bed.: Il (1), -ic(a) (3), Bed.: L3 (3) Die Ableitungsstämme und die Konjugationen:

Maskulina: I. 1. Grundstamm der 5., 4., 1. Konjugation, 4. Stamm des Partizip Präteritum Passiv der 1. Konjugation, II. 2., I., 5. Konjugation 
Feminina: I. 1. Grundstamm der 1., 4. Konjugation, 2. Stamm des Partizip Präteritum Aktiv der 1. Konjugation

Der Aspekt der Ableitungsbasis:

Maskulina: I. 5 pf. und 1 ipf Verb, II. 3 pf. Verben

Feminina: I. 3 pf. und 1 ipf. Verb

Maskulina

I. Suffigierung

Ableitungen mit dem Formans -ac

Bed.: L3, a) vom pf. Aspekt, 1. vom Grundstamm, der 4. Konjugation zasenac 'Schatten

Ableitungen mit dem Formans - aj

Bed.: Ll, a) vom pf. Aspekt, 1. vom Grundstamm, der 5. Konjugation zalogaj 'Bissen'

b) vom ipf. Aspekt, 1. vom Grundstamm, der 5. Konjugation zalagaj 'Bissen'

Ableitungen mit dem Formans -ak

Bed.: LI, a) vom pf. Aspekt, 1. vom Grundstamm, der 1. Konjugation zabodak (pokr.) 'Stich (bei der Naht)'

4. vom Stamm des Partizip Präteritum Passiv, der 1. Konjugation zavitak 'Eingewickeltes'

Ableitungen mit dem Formans $-u l j(a) k$

Bed.: Ll, b) vom ipf. Aspekt, 1. vom Grundstamm, der 5. Konjugation

$$
\text { zavrtuljak 'Eingedrehtes' }
$$

II. Konversion

Ableitungen auf $-\mathrm{HK}-\varnothing$

Bed.: Ll, a) vom pf. Aspekt, der 2. Konjugation zamet 'an einer Stelle zusammengewehter Schnee'

Bed.: L2, a) vom pf. Aspekt, der 5. Konjugation zasip 'Aufgeschüttetes'

Bed.: L3, a) vom pf. Aspekt, der 1. Konjugation

zarast 'Narbe; Vernarbung' 
Feminina

I. Suffigierung

Ableitungen mit dem Formans -ač(a)

Bed.: Ll, b) vom ipf. Aspekt, 1. vom Grundstamm, der 5. Konjugation

zavijača 'Strudel, Eingewickeltes'

Ableitungen mit dem Formans -ic(a)

Bed.: L3, a) vom pf. Aspekt, 1. vom Grundstamm, der 1. Konjugation zarastica 'Narbe, Vernarbung'

der 4. Konjugation

zasenica 'Schatten'

2. vom Stamm des Partizip Präteritum Aktiv, der 1. Konjugation zaraslica 'Zugewachsenes, Narbe'

B. Modifizierende Funktion

BA. Nomina resultativa von Verben mit dem Präfix do- in modifizierender Funktion

Die Ableitungsverfahren: I. Suffigierung, II. Konversion

Die wortbildenden Typen nach ihren Formantien, ihrer Produktivität und den Bedeutungen der Präfixe der ableitenden Verben mit ihrer Häufigkeit:

Maskulina: I. -aj (1), Bed.: MI (1), -ak (1), Bed.: MI (I)

$$
\text { II. }-\mathrm{HK}-\varnothing(1) \text {, Bed.: MI (1) }
$$

Die Ableitungsstämme und die Konjugationen:

Maskulina: I. 1. Grundstamm der 1., 5. Konjugation

II. 5. Konjugation

Der Aspekt der Ableitungsbasis:

Maskulina: I. I pf. und I ipf. Verb, II. I pf. Verb

Maskulina

I. Suffigierung

Ableitungen mit dem Formans - aj

Bed.: Ml, a) vom pf. Aspekt, 1. vom Grundstamm, der 1. Konjugation doraštaj (zast.) 'der höchste erreichbare Wuchs' 
Ableitungen mit dem Formans -ak

Bed.: Ml, b) vom ipf. Aspekt, 1. vom Grundstamm, der 5. Konjugation

dogarak 'Zigarettenstummel'

II. Konversion

Ableitungen auf $-H K-\varnothing$

Bed.: MI, a) vom pf. Aspekt, der 5. Konjugation dopis 'Bericht'

BB. Nomina resultativa von Verben mit dem Präfix iz- in modifizierender Funktion

Die Ableitungsverfahren: I. Suffigierung, II. Konversion

Die wortbildenden Typen nach ihren Formantien, ihrer Produktivität und den Bedeutungen der Präfixe der ableitenden Verben mit ihrer Häufigkeit:

Maskulina: I. -ak ( 1 ), Bed.: MI (1)

Feminina: I. - in(a) (1), Bed.: MI (1), II. -HK-a (1), Bed.: MI (1)

Die Ableitungsstämme und die Konjugationen:

Maskulina: I. 1. Grundstamm der 4. Konjugation

Feminina: I. 1. Grundstamm der 4. Konjugation

II. 4. Konjugation

Der Aspekt der Ableitungsbasis:

Maskulina: I. 1 pf. Verb

Feminina: I. 1 pf. Verb, II. 1 pf. Verb

Maskulina

I. Suffigierung

Ableitungen mit dem Formans -ak

Bed.: $M I$, a) vom pf. Aspekt, l. vom Grundstamm, der 4. Konjugation izradak 'Produkt einer Arbeit'

Feminina

I. Suffigierung

Ableitungen mit dem Formans -in(a)

Bed.: Ml, a) vom pf. Aspekt, l. vom Grundstamm, der 4. Konjugation izradjevina $195^{\circ}$ 'Fabrikat, Erzeugnis'

195 Ableitungen vom Typ 'izradjevina' (vgl. auch prošcevina 'Braut- 
II. Konversion

Ableitungen auf -HK-a

Bed.: MI, a) vom pf. Aspekt, der 4. Konjugation izgrada 'Bauwerk'

BC. Nomina resultativa von Verben mit dem Präfix na- in modifizierender Funktion

Die Ableitungsverfahren: I. Suffigierung, II. Konversion

Die wortbildenden Typen nach ihren Formantien, ihrer Produktivität und den Bedeutungen der Präfixe der ableitenden Verben mit ihrer Häufigkeit:

Maskulina: I. -aj (1), Bed.: MI (1), -ak (4), Bed.: MI (2), M2 (2), II. $-\mathrm{HK}-\varnothing$ (8), Bed.: MI (7), M2 (1)

Feminina: I. $-\operatorname{in}(a)$ (3), Bed.: M2 (3), II. - HK-a (4), Bed.: MI (4) Die Ableitungsstämme und die Konjugationen:

Maskulina: I. 1. Grundstamm der 5., 4. Konjugation

II. 5., 4., 1. Konjugation

Feminina: I. 1. Grundstamm der 4. Konjugation, 2. Stamm des Partizip Präteritum Aktiv der 1., 2. Konjugation II. 4., 5. Konjugation

Der Aspekt der Ableitungsbasis:

Maskulina: I. 4 pf. und 1 ipf. Verb, II. 5 pf. und 3 ipf. Verben Feminina: I. 3 pf. Verben, II. 4 pf. Verben

Maskulina

I. Suffigierung

Ableitungen mit dem Formans -aj

Bed.: $M 1$, a) vom pf. Aspekt, 1. vom Grundstamm, der 5. Konjugation naslagaj 'Aufschichtung, Ablagerung'

werbung' zu prositi 'freien') sehen wir als Bildungen vom Grundstamm an, analog zu Ableitungen wie z.B. trgovina zu trgovati 'Handel', kraljevina zu kraljevati 'Königreich', carevina zu carevati 'Kaiserreich'. Vgl. M. Stevanović, Savremeni srpskohrvatski jezik, a.a.0., S. 526ff. Eine Ableitung dieses Substantivs vom Stamm des Partizip Präteritum Passiv oder vom Stamm des präteritalen Adverbialpartizips scheint ausgeschlossen $z u$ werden können, da dies 'izradjenina' $z u$ 'izradjen' bzw. izradivina' $z u$ 'izradiv' lauten müsste. 
Ableitungen mit dem Formans -ak

Bed.: Ml, a) vom pf. Aspekt, 1. vom Grundstamm, der 4. Konjugation naplavak 'Anschwemmung'

b) vom ipf. Aspekt, 1. vom Grundstamm, der 5. Konjugation naborak 'Falte (Gewebe); Runzel'

Bed.: M2, a) vom pf. Aspekt, 1. vom Grundstamm, der 5. Konjugation narezak 'abgeschnittenes Stück Fleisch'

der 4. Konjugation

nabušak 'Angebohrtes; beutelartige offnung an faltenreicher Kleidung '

II. Konversion

Ableitungen auf $-\mathrm{HK}-\varnothing$

Bed.: $M 1$, a) vom pf. Aspekt, der 4. Konjugation nakos (pokr.) 'Gemähtes', nakot 'Wurf', naplav 'Anschwemmung' der 1. Konjugation

naplet 'Angeflochtenes'

b) vom ipf. Aspekt, der 5. Konjugation

nabir 'Falte; Ansammlung', nabor 'Angesammeltes; Runzel; Faltenwurf'

der 4. Konjugation nanos 'Anschwemmung, Schlamm'

Bed.: M2, a) vom pf. Aspekt, der 5. Konjugation narez 'Kerbe, Einschnitt'

Feminina

I. Suffigierung

Ableitungen mit dem Formans -in(a)

Bed.: M2, a) vom pf. Aspekt, 1. vom Grundstamm, der 4. Konjugation nagnječina 'Quetschwunde'

2. vom Stamm des Partizip Präteritum Aktiv, der 1. Konjugation napuklina 'Spalt, Sprung'

der 2. Konjugation naprslina 'Spalt, Sprung, Riss'

II. Konversion

Ableitungen auf $-\mathrm{HK}-\mathrm{a}$

Bed.: M1, a) vom pf. Aspekt, der 4. Konjugation nagrada 'Aufgebautes', naplava 'Anschwemmung', natruna

'Angeschwemmtes' 
der 5. Konjugation

naslaga 'Aufschichtung, Ablagerung'

BD. Nomina resultativa von Verben mit dem Präfix za- in modifizierender Funktion

Die Ableitungsverfahren: I. Suffigierung, II. Konversion

Die wortbildenden Typen nach ihren Formantien, ihrer Produktivität und den Bedeutungen der Präfixe der ableitenden Verben mit ihrer Häufigkeit:

Maskulina: I. -aj (3), Bed.: MI (3), -ak (5), Bed.: MI (5), -anj (2), Bed.: MI (2), II. -HK- $\varnothing$ (3), Bed.: MI (3)

Feminina: I. $-\operatorname{etin}(a)$ (1), Bed.: MI (1), $-i c(a)$ (1), Bed.: MI (1), $-\operatorname{in}(a)(3), \operatorname{Bed} .:$ MI (3), $\operatorname{-otin}(a)$ (3), Bed.: MI (3)

Die Ableitungsstämme und die Konjugationen:

Maskulina: I. 1. Grundstamm der 5., 1., 3., 4. Konjugation II. 1., 5. Konjugation

Feminina: I. 1. Grundstamm der 5., 1., 3. Konjugation, 2. Stamm des Partizip Präteritum Aktiv der 1., 3. Konjugation

Der Aspekt der Ableitungsbasis:

Maskulina: I. 9 pf. und I ipf. Verb, II. 3 pf. Verben

Feminina: I. 7 pf. und 1 ipf. Verb

Maskulina

I. Suffigierung

Ableitungen mit dem Formans - $a j$

Bed.: $M 1$, a) vom pf. Aspekt, 1. vom Grundstamm, der 5. Konjugation zagucaj (pokr.) 'Schluck', zavitljaj 'Herumgeschlungenes'

b) vom ipf. Aspekt, 1. vom Grundstamm, der 5. Konjugation zasecaj (indiv.) 'Anschnitt, Falte'

Ableitungen mit dem Formans -ak

Bed.: Ml, a) vom pf. Aspekt, 1. vom Grundstamm, der 5. Konjugation zalizak 'ein vom Vieh angelecktes Stïck Salz'

der 1. Konjugation

zapredak 'Eingesponnenes; Kapsel der Seidenraupe' zagrizak 'kleines Stück, kleiner Bissen'

der 3. Konjugation

zarudak 'etwas, was rot geworden ist, Beginn der Reife' 
der 4. Konjugation

zaljuštak 'Abgeschältes'

Ableitungen mit dem Formans -anj

Bed.: M1, a) vom pf. Aspekt, 1. vom Grundstamm, der 1. Konjugation zažanj 'Schnittweite (beim Ernten)'

der 5. Konjugation

zarežanj 'Kerbe, Einschnitt'

II. Konversion

Ableitungen auf $-\mathrm{HK}-\varnothing$

Bed.: Ml, a) vom pf. Aspekt, der 5. Konjugation

zarez 'Einschnitt, Kerbe'

der 1. Konjugation

zagriz 'Angebissenes', zasek 'Anschnitt'

Feminina

I. Suffigierung

Ableitungen mit dem Formans -etin(a)

Bed.: MI, a) vom pf. Aspekt, 1. vom Grundstamm, der 3. Konjugation zagoretina 'Angebranntes'

Ableitungen mit dem Formans -ic(a)

Bed.: MI, b) vom ipf. Aspekt, 1. vom Grundstamm, der 5. Konjugation zapuhica 'Zusammengeblasenes (Schnee)'

Ableitungen mit dem Formans -in(a)

Bed.: Ml, a) vom pf. Aspekt, 1. vom Grundstamm, der 3. Konjugation zagorina (pokr.) 'Angebranntes'

2. vom Stamm des Partizip Präteritum Aktiv, der 1. Konjugation zaseklina 'Anschnitt, Schnitt'

der 3. Konjugation

zagorelina 'Angebranntes'

Ableitungen mit dem Formans -otin(a)

Bed.: Ml, a) vom pf. Aspekt, 1. vom Grundstamm, der 1. Konjugation zagre botina 'Kratzer, Riss', zasekotina 'Alusschnitt' 
der 5. Konjugation

zarezotina 'Kerbe, Einschnitt'

C. Rein perfektivierende Funktion

CB. Nomina resultativa von Verben mit dem Präfix iz- in rein perfektivierender Funktion

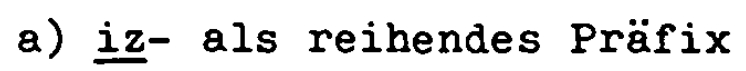

Die Ableitungsverfahren: I. Suffigierung, II. Konversion

Die wortbildenden Typen nach ihren Formantien, ihrer Produktivität und den Bedeutungen der Präfixe der ableitenden Verben mit ihrer Häufigkeit:

Maskulina: I. -aj (1), Bed.: Rlb (1), -ak (2l), Bed.: Ria (3),

Rlb (1), Rld (3), Rie (2), Rlf (1), Rlb (1), Rli (2), RIj (4), R2b (3), R2f (1)

II. $-H K-\varnothing$ (5), Bed.: RIb (1), RIj (1), RId (2), R2f (1)

Feminina: I. -ao (3), Bed.: RIb (2), R2f (1), -etin(a) (1), Bed.:

Rii (1), -ic(a) (1), Bed.: Rld (1), -in(a) (10),

Bed.: Rla (1), Rlb (1), Rle (3), Rlf (1), Rlh (1),

Rli (2), Rlj (1), $-\operatorname{otin}(a)$ (4), Bed.: Rle (2),

R2b (1), R2f (1)

II. $-H K-a$ (3), Bed.: Rlc (1), R2f (2)

Die Ableitungsstämme und die Konjugationen:

Maskulina: I. 1. Grundstamm der 4., 1., 5., 3. Konjugation

4. Stamm des Partizip Präteritum Passiv der 1., 4.

Konjugation, II. 1., 4., 5. Konjugation

Feminina: I. 1. Grundstamm der 4., 1., 2., 3., 5. Konjugation,

2. Stamm des Partizip Präteritum Aktiv der 1., 3.

Konjugation, 4. Stamm des Partizip Präteritum

Passiv der 5. Konjugation, II. 4. Konjugation

Der Aspekt der Ableitungsbasis:

Maskulina: I. $21 \mathrm{pf}$. und 1 ipf. Verb, II. 5 pf. Verben

Feminina: I. 18 pf. und 1 ipf. Verb, II. 3 pf. Verben

Maskulina

I. Suffigierung

Ableitungen mit dem Formans $-a j$

Bed.: RIb, a) vom pf. Aspekt, 1. vom Grundstamm, der 1. Konju- 
gation

izraštaj 'Geschwulst'

Ableitungen mit dem Formans -ak

Bed.: Rla, a) vom pf. Aspekt, 1. vom Grundstamm, der 4. Konjugation

izvadak 'Auszug, Extrakt', iscedak 'Extrakt'

der 5. Konjugation

istisak 'Ausgedrücktes, Ausgepresstes'

Bed.: Rlb, a) vom pf. Aspekt, 4. vom Stamm des Partizip Präteritum Passiv, der 1. Konjugation

izrastak 'Auswuchs'

Bed.: Rld, a) vom pf. Aspekt, 1. vom Grundstamm, der 5. Konjugation

izrezak 'Ausschnitt, Abgeschnittenes'

der 4. Konjugation

iskrojak 'Zugeschnittenes'

der 1. Konjugation

isečak 'Abgeschnittenes'

Bed.: Rle, a) vom pf. Aspekt, 1. vom Grundstamm, der 4. Konjugation

izdubak 'Aushöhlung, Nische', ispupak 'Ausbauchung'

Bed.: RIf, a) vom pf. Aspekt, 1. vom Grundstamm, der 4. Konjugation

izlučak 'Ab-, Ausgesondertes'

Bed.: RIh, a) vom pf. Aspekt, 1. vom Grundstamm, der 3. Konjugation

isprdak (vulg.) 'Ausfurzung'

Bed.: Rli, a) vom pf. Aspekt, 1. vom Grundstamm, der 3. Konjugation

izgorak 'Kerzenstummel'

der 4. Konjugation

ispušak 'Stummel einer Zigarette oder einer Zigarre'

Bed.: RIj, a) vom pf. Aspekt, 1. vom Grundstamm, der 1. Konjugation

iscrpak 'Ausgeschöpftes', istresak 'Uberbleibsel'

der 5. Konjugation

izbljuvak 'Gekotze', ispljuvak 'Auswurf'

Bed.: R2b, a) vom pf. Aspekt, 1. vom Grundstamm, der 4. Konjugation 
izbrusak (min.) 'dünnes geschliffenes Plättchen eines Minerals zur mikroskopischen Untersuchung', izvarak 'Schlacke' b) vom ipf. Aspekt, 1. vom Grundstamm, der 5. Konjugation

izdirak 'abgerissenes Stück'

Bed.: R2f, a) vom pf. Aspekt, 4. vom Stamm des Partizip Präteritum Passiv, der 1. Konjugation

izumetak 'Erfindung'

II. Konversion

Ableitungen auf $-\mathrm{HK}-\varnothing$

Bed.: Rlb, a) vom pf. Aspekt, der 1. Konjugation izrast 'Auswuchs'

Bed.: RIj, a) vom pf. Aspekt, der 5. Konjugation ispis 'Aus-, Abgeschriebenes'

Bed.: Rld, a) vom pf. Aspekt, der 1. Konjugation isek 'Ausschnitt'

der 5. Konjugation

izrez 'Ausschnitt'

Bed.: R2f, a) vom pf. Aspekt, der 4. Konjugation izum 'Erfindung'

Feminina

I. Suffigierung

Ableitungen mit dem Formans -ao

Bed.: RIb, a) vom pf. Aspekt, 1. vom Grundstamm, der 1. Konjugation

iznikao 'Aufgesprossenes', izrastao 'Aufgesprossenes' Bed.: R2f, a) vom pf. Aspekt, 1. vom Grundstamm, der 4. Konjugation

izumisao 'Erdichtetes'

Ableitungen mit dem Formans -etin(a)

Bed.: Rli, a) vom pf. Aspekt, 1. vom Grundstamm, der 3. Konjugation

izgoretina 'Verbranntes, Brandwunde'

Ableitungen mit dem Formans -ic(a)

Bed.: Rld, b) vom ipf. Aspekt, 4. vom Stamm des Partizip Präteritum Passiv, der 5. Konjugation 
istrizanica (pokr.) 'Stück geschorener Wolle'

Ableitungen mit dem Formans -in(a)

Bed.: Rla, a) vom pf. Aspekt, 1. vom Grundstamm, der 2. Konjugation

istisnina 'Verdrängung (Wasser)'

Bed.: Rlb, a) vom pf. Aspekt, 2. vom Stamm des Partizip Präteritum Aktiv, der 1. Konjugation

izraslina 'Auswuchs'

Bed.: Rle, a) vom pf. Aspekt, 1. vom Grundstamm, der 4. Konjugation

izdubina 'Aushöhlung, Vertiefung', ižlebina 'vom Wasser ausgehöhlte Stelle', ispupčina 'Ausbauchung, Hervorwölbung' Bed.: Rlf, a) vom pf. Aspekt, l. vom Grundstamm, der 4. Konjugation

izlučina 'Absonderungsstoff, Abgesondertes'

Bed.: Rlh, a) vom pf. Aspekt, 1. vom Grundstamm, der 4. Konjugation

ishlapina 'Dampf'

Bed.: Rli, a) vom pf. Aspekt, 1. vom Grundstamm, der 1. Konjugation

izjedina 'angenagte, zernagte Stelle'

2. vom Stamm des Partizip Präteritum Aktiv, der 3. Konjugation

izgorelina 'Verbranntes, Brandwunde'

Bed.: Rlj, a) vom pf. Aspekt, 1. vom Grundstamm, der 1. Konjugation

istresine 'Uberbleibsel'

Ableitungen mit dem Formans -otin(a)

Bed.: Rle, a) vom pf. Aspekt, l. vom Grundstamm, der 1. Konjugation

izgrizotina 'zerfressene, zernagte Stelle'

der 4. Konjugation

izdubotina 'Aushöhlung, Vertiefung'

Bed.: R2b, a) vom pf. Aspekt, 1. vom Grundstamm, der 1. Konjugation

ispekotina 'Brandwunde'

Bed.: R2f, a) vom pf. Aspekt, 1. vom Grundstamm, der 4. Konjugation 
izmišljotina 'Erdichtung'

II. Konversion

Ableitungen auf $-\mathrm{HK}-\mathrm{a}$

Bed.: Rlc, a) vom pf. Aspekt, der 4. Konjugation izvala 'umgewehter Baum'

Bed.: R2f, a) vom pf. Aspekt, der 4. Konjugation izmera 'Ergebnis des Messens; Messen', izuka 'Erlerntes'

b) $\underline{\text { iz- }}$ als leeres Präfix

Die Ableitungsverfahren: I. Suffigierung, II. Konversion Die wortbildenden Typen nach ihren Formantien sowie ihre Produktivität:

Maskulina: I. -ak (1), II. $-\mathrm{HK}-\varnothing$ (2)

Die Ableitungsstämme und die Konjugationen:

Maskulina: I. 4. Stamm des Partizip Präteritum Passiv der 4. Konjugation, II. 4. Konjugation

Der Aspekt der Ableitungsbasis:

Maskulina: I. 1 pf. Verb, II. 2 pf. Verben

Maskulina

I. Suffigierung

Ableitungen mit dem Formans -ak

a) vom pf. Aspekt, 4. vom Stamm des Partizip Präteritum Passiv, der 4. Konjugation

izgubitak 196 'Verlust'

II. Konversion

Ableitungen auf $-\mathrm{HK}-\varnothing$

a) vom pf. Aspekt, der 4. Konjugation

izgub 'Verlust', iskup 'Versammlung'

CC. Nomina resultativa von Verben mit dem Präfix na- in rein perfektivierender Funktion

a) na- als reihendes Präfix

Die Ableitungsverfahren: I. Suffigierung, II. Konversion

196 s. Anmerkungen unter Fussnote 194, S. 148/daus Koszinowski-9783954793105 
Die wortbildenden Typen nach ihren Formantien, ihrer Produktivität und den Bedeutungen der Präfixe der ableitenden Verben mit ihrer Häufigkeit:

Maskulina: I. $-a j(2)$, Bed.: Rlc (1), R2c (1), -ak (5), Bed.: $\mathrm{R} 2 \mathrm{a}$ (3), $\mathrm{R} 2 \mathrm{c}(2)$

$$
\text { II. }-\mathrm{HK}-\varnothing \text { (9), Bed.: RIb (1), Rlc (2), R2a (6) }
$$

Feminina: I. -ao (1), Bed.: R2c (1), $-\mathrm{db}(\mathrm{a})$ (1), Bed.: R2a (1), $-i c(a)(1), \operatorname{Bed} .: \operatorname{R2c}(1),-i n(a)(4), B e d .: R 2 a$

(3), R2c (1), II. -HK-a (3), Bed.: R2a (2), R2c (1)

Die Ableitungsstämme und die Konjugationen:

Maskulina: I. 1. Grundstamm der 4., 5., 1., 2. Konjugation,

4. Stamm des Partizip Präteritum Passiv der 1.

Konjugation, II. 4., 5. Konjugation

Feminina: I. 1. Grundstamm der 4., 5., 1. Konjugation,

3. Infinitivstamm der 5. Konjugation

II. 4. Konjugation

Der Aspekt der Ableitungsbasis:

Maskulina: I. 6 pf. und 1 ipf. Verb, II. 8 pf. und 1 ipf. Verb Feminina: I. $5 \mathrm{pf}$. und 2 ipf. Verben, II. 3 pf. Verben

Maskulina

I. Suffigierung

Ableitungen mit dem Formans -aj

Bed.: Rlc, a) vom pf. Aspekt, 1. vom Grundstamm, der 5. Konjugation

nacrtaj 'Skizze, Abriss'

Bed.: R2c, a) vom pf. Aspekt, 1. vom Grundstamm, der 1. Konjugation

naraštaj '1. Anwuchs, 2. Generation'

Ableitungen mit dem Formans -ak

Bed.: R2a, a) vom pf. Aspekt, l. vom Grundstamm, der 4. Konjugation

nadopunjak 'Ergänzung'

der 5. Konjugation

naduvak 'Aufgeblasenes'

der 2. Konjugation

nadometak 'Zusatz, Anhang'

Bed.: R2c, a) vom pf. Aspekt, 4. vom Stamm des Partizip Präteritum Passiv, der 1. Konjugation 
napetak 'Geschwür'

b) vom ipf. Aspekt, 1. vom Grundstamm, der 5. Konjugation nabujak (kuv.) 'Speise aus Reis u.a.'

II. Konversion

Ableitungen auf $-\mathrm{HK}-\varnothing$

Bed.: RIb, a) vom pf. Aspekt, der 4. Konjugation nagaz 'Spur'

Bed.: Rlc, a) vom pf. Aspekt, der 5. Konjugation nacrt 'Skizze, Abriss', napis 'Anschrift'

Bed.: R2a, a) vom pf. Aspekt, der 4. Konjugation nakup 'Anhäufung', nasad 'Angepflanztes; Anpflanzen', natop 'Durchtränktes'

der 5. Konjugation

naniz 'Kette', naduv 'Odem'

b) vom ipf. Aspekt, der 5. Konjugation nasip 'Anschüttung, Aufschüttung'

Feminina

I. Suffigierung

Ableitungen mit dem Formans -ao

Bed.: R2c, a) vom pf. Aspekt, 1. vom Grundstamm, der 1. Konjugation

natekao 'Geschwulst'

Ableitungen mit dem Formans - $d b(a)$

Bed.: R2a, a) vom pf. Aspekt, 3. vom Infinitivstamm,

der 5. Konjugation

nadodadba (pokr.) 'Zugabe, Zusatz'

Ableitungen mit dem Formans -ic(a)

Bed.: R2c, a) vom pf. Aspekt, 1. vom Grundstamm, der 4. Konjugation nagnojica (med.) 'vereiterte Wunde'

Ableitungen mit dem Formans -in(a)

Bed.: R2a, a) vom pf. Aspekt, 1. vom Grundstamm, der 4. Konjugation 
nakupina 'Zusammengesammeltes', natopina 'Durchtränktes'

b) vom ipf. Aspekt, 1. vom Grundstamm, der 5. Konjugation nasipina (neob.) 'Schlamm'

Bed.: R2c, a) vom pf. Aspekt, 2. vom Stamm des Partizip Präteritum Aktiv, der 1. Konjugation

nateklina 'Geschwulst'

\section{Konversion}

Ableitungen auf $-\mathrm{HK}-\mathrm{a}$

Bed.: R2a, a) vom pf. Aspekt, der 4. Konjugation nadoplata 'Nachzahlung', nasada 'gepflanzte Bäume, Anlage von Bäumen'

Bed.: R2c, a) vom pf. Aspekt, der 4. Konjugation naoblaka (met.) 'Bewölkungsgrad'

b) na- als leeres Präfix

Die Ableitungsstämme: II. Konversion

Die wortbildenden Typen nach ihren Formantien sowie ihre Produktivität:

Feminina: II. - HK-a (2)

Die Ableitungsstämme und die Konjugationen:

Feminina: II. 4. Konjugation

Der Aspekt der Ableitungsbasis:

Feminina: II. 1 pf. und 1 ipf. Verb

Feminina

II. Konversion

Ableitungen auf $-\mathrm{HK}-\mathrm{a}$

a) vom pf. Aspekt, der 4. Konjugation nadoknada 'Ersatz'

b) vom ipf. Aspekt, der 4. Konjugation nazloba 'Bossheit, Missgunst'

CD. Nomina resultativa von Verben mit dem Präfix za- in rein perfektivierender Funktion

a) za- als reihendes Präfix

Die Ableitungsverfahren: I. Suffigierung, II. Konversion

Die wortbildenden Typen nach ihren Formantien, ihrer Produktivi- 
tät und den Bedeutungen der Präfixe der ableitenden Verben mit ihrer Häufigkeit:

Maskulina: I. -aj (4), Bed.: Rla (2), Rlb (1), R2b (1), -ak (8), Bed.: Rla (4), Rld (1), Rlh (1), R2a (1), R2b (1), $-\operatorname{anj}(1)$, Bed.: Ria (1), - ulj (a)k (1), Bed.: Rla (1) II. $-H K-\varnothing$ (1I), Bed.: RIb (3), RIf (3), RIh (1), R2b (4)

Feminina: I. $-i c(a)$ (2), Bed.: R2b (2), -in(a) (2), Bed.: RIf (1), R2a (1), $-k(a)$ (2), Bed.: RId (2), $-n j(a)$ (1), Bed.: RIf (1), $\operatorname{-otin}(a)(1)$, Bed.: RIb (1)

II. $-\mathrm{HK}-\mathrm{a}$ (4), Bed.: RIb (1), RId (1), RIf (1), R2b

Neutra: I. $-1(0)$ (1), Bed.: Rla (1)

Die Ableitungsstämme und die Konjugationen:

Maskulina: I. 1. Grundstamm der 5., 4. Konjugation, 4. Stamm des Partizip Präteritum Passiv der 5. Konjugation II. 4., 5., 2. Konjugation

Feminina: I. 1. Grundstamm der 4., 5., 3. Konjugation II. 4., 3. Konjugation

Neutra: I. 3. Infinitivstamm der 5. Konjugation Der Aspekt der Ableitungsbasis:

Maskulina: I. 14 pf. Verben, II. 11 pf. Verben

Feminina: I. 8 pf. Verben, II. 4 pf. Verben

Neutra: I. 1 pr. Verb

Maskulina

I. Suffigierung

Ableitungen mit dem Formans $-a j$

Bed.: Rla, a) vom pr. Aspekt, l. vom Grundstamm, der 5. Konjugation

zamotljaj 'Umschlag, Bündel', zavežljaj 'Eingebundenes, Bündel'

Bed.: RIb, a) vom pf. Aspekt, l. vom Grundstamm, der 4. Konjugation

zagrabljaj 'Ansichgerafftes'

Bed.: R2b, a) vom pf. Aspekt, 1. vom Grundstamm, der 4. Konjugation

zamršaj 'Verwirrtes, Verwicklung'

Ableitungen mit dem Formans -ak

Bed.: Rla, a) vom pf. Aspekt, 1. vom Grundstamm, der 5. Konju- 
gation

zamotak 'Bündel, Paket', zasučak 'Wickel', zavezak 'Eingebundenes, Knoten'

der 4. Konjugation

zavratak 'zurückgezogener Teil des Armels'

Bed.: Rld, a) vom pf. Aspekt, 1. vom Grundstamm, der 5. Konjugation

zapisak 'Aufzeichnung, Notiz'

Bed.: RIh, a) vom pf. Aspekt, l. vom Grundstamm, der 4. Konjugation

zalomak 'Stummel'

Bed.: R2a, a) vom pf. Aspekt, 4. vom Stamm des Partizip Präteritum Passiv, der 5. Konjugation

zaostatak 'Rückstand'

Bed.: R2b, a) vom pf. Aspekt, 1. vom Grundstamm, der 5. Konjugation

zakržnjak 'Rudiment'

Ableitungen mit dem Formans -anj

Bed.: Ria, a) vom pf. Aspekt, 1. vom Grundstamm, der 5. Konjugation

zavežanj (pokr.) 'Eingebundenes, Knoten, Bündel'

Ableitungen mit dem Formans $-u l j(a) k$

Bed.: Rla, a) vom pf. Aspekt, 1. vom Grundstamm, der 5. Konjugation

zamotuljak 'kleines Paket, Bündel, Rolle'

II. Konversion

Ableitungen auf $-H K-\varnothing$

Bed.: Rlb, a) vom pf. Aspekt, der 4. Konjugation

zarub 'Saum'

der 5. Konjugation

zapas 'Fang (Fische)'

der 2. Konjugation

zapreg 'Bespannung am Wagen'

Bed.: Rlf, a) vom pf. Aspekt, der 4. Konjugation

zamrež 'Star (Auge)', zasad 'Anpflanzung; Setzling' 
der 5. Konjugation

zapret 'Zugedecktes, mit Asche zugedeckte Glut'

Bed.: RIh, a) vom pf. Aspekt, der 4. Konjugation

zalom 'Anbruch, Knick'

Bed.: R2b, a) vom pf. Aspekt, der 4. Konjugation

zabel 'Grenzstein', zagojat (pokr.) 'Unsauberkeit; Abfälle', zamor 'Erschöpftheit'

der 2. Konjugation

zagluh (neob.) 'Betäubung'

Feminina

I. Suffigierung

Ableitungen mit dem Formans -ic(a)

Bed.: R2b, a) vom pf. Aspekt, 1. vom Grundstamm, der 4. Konjugation

zahladica 'Schatten; Kühle, Frische', zamrsica 'wirres Zeug'

Ableitungen mit dem Formans -in(a)

Bed.: Rlf, a) vom pf. Aspekt, 1. vom Grundstamm, der 3. Konjugation

$$
\text { zaštedjevina197 'Ersparnis' }
$$

Bed.: R2a, a) vom pf. Aspekt, 1. vom Grundstamm, der 5. Konjugation

zaostavina, zaostavština 'Hinterlassenschaft, Nachlass'

Ableitungen mit dem Formans $-k(a)$

Bed.: Rld, a) vom pf. Aspekt, 1. vom Grundstamm, der 4. Konjugation

$$
\text { zabeleška 'Notiz' }
$$

der 5. Konjugation

zapiska 'Aufzeichnung, Notiz'

Ableitungen mit dem Formans $-n j(a)$

Bed.: Rlf, a) vom pf. Aspekt, 1. vom Grundstamm, der 3. Konjugation

$$
\text { zaštednja 'Ersparnis' }
$$

$197 \mathrm{Vgl}$. Fussnote 195, S. 154. 
Ableitungen mit dem Formans -otin(a)

Bed.: Rlb, a) vom pf. Aspekt, 1. vom Grundstamm, der 4. Konjugation

zaparotina 'Verbrühung; Narbe'

II. Konversion

Ableitungen auf $-\mathrm{HK}-\mathrm{a}$

Bed.: Rlb, a) vom pf. Aspekt, der 4. Konjugation

zažara 'flammende Röte am Himmel beim Auf- und Untergang der Sonne'

Bed.: Rld, a) vom pf. Aspekt, der 4. Konjugation zataja '1. Geheimnis, 2. Unterschlagung'

Bed.: Rlf, a) vom pf. Aspekt, der 3. Konjugation zašteda 'Ersparnis'

Bed.: R2b, a) vom pf. Aspekt, der 4. Konjugation zamrsa 'Verwirrtes, wirres Zeug'

Neutra

I. Suffigierung

Ableitungen mit dem Formans $-1(0)$

Bed.: Rla, a) vom pf. Aspekt, 3. vom Infinitivstamm,

der 5. Konjugation

zasukalo (indiv.) 'Eingewickeltes'

b) za- als leeres Präfix

Die Ableitungsverfahren: I. Suffigierung, II. Konversion Die wortbildenden Typen nach ihren Formantien sowie ihre Produktivität:

Maskulina: I. -ak (3)

Feminina: II. $-\mathrm{HK}-\mathrm{a}$ ( 1 )

Die Ableitungsstämme und die Konjugationen:

Maskulina: I. 4. vom Stamm des Partizip Präteritum Passiv der 1., 4. Konjugation

Feminina: II. 4. Konjugation

Der Aspekt der Ableitungsbasis:

Maskulina: I. 3 pf. Verben

Feminina: II. I pf. Verb

Maskulina

I. Suffigierung 
Ableitungen mit dem Formans -ak

a) vom pf. Aspekt, 4. vom Stamm des Partizip Präteritum Passiv, der 1. Konjugation zadobitak 'Errungenschaft', započetak 'Anfang'

der 4. Konjugation

završetak 'Schluss, Vollendung; eine Sache, mit der etwas beendet wird'

Feminina

II. Konversion

Ableitungen auf $-\mathrm{HK}-\mathrm{a}$

a) vom pf. Aspekt, der 4. Konjugation

zamuka 'das mit Mühe Erreichte, Verdienst'

Schlussbemerkungen

2a) Nomina resultativa sind mit folgenden in quantitativer Reihenfolge aufgeführten Präfixen in lexikalischer Funktion gebildet: iz-, na-, za-, do-.

Nomina resultativa sind mit folgenden in quantitativer Reihenfolge aufgeführten Präfixen in modifizierender Funktion gebildet: za-, na-, do- und iz- (letztere mit gleich grosser Belegzahl).

Nomina resultativa sind mit folgenden in quantitativer Reihenfolge aufgeführten Präfixen in rein perfektivierender Funktion gebildet: a) mit reihenden Präfixen: iz-, za-, na- und b) leeren Präfixen: za-, iz-, na-.

Es kann (s. Tabelle $7 a$ ) in rein quantitativer Hinsicht eine starke Affinität von Verben mit den reihenden Präfixen iz-, zain rein perfektivierender Funktion, eine weniger starke von solchen mit dem reihenden na- in rein perfektivierender, na-, zain modifizierender und iz- in lexikalischer Funktion, eine schwache von solchen mit na-, za-, do- in lexikalischer Funktion und eine sehr schwache von solchen mit do-, iz- in modifizierender und den leeren Präfixen za-, iz-, na- in rein perfektivierender Funktion zu nomina resultativa festgestellt werden.

2b) Nomina resultativa sind mit Präfixen in folgenden in quantitativer Reihenfolge aufgeführten Funktionen gebildet: 
der rein perfektivierenden mit reihenden Präfixen, lexikaiischen, modifizierenden und rein perfektivierenden Funktion mit leeren Präfixen.

Es kann (s. Tabelle 8 ) in rein quantitativer Hinsicht eine weniger starke Affinität von Verben mit reihenden Präfixen in rein perfektivierender Funktion, eine schwache von solchen mit Präfixen in lexikalischer und modifizierender Funktion und eine sehr schwache von solchen mit leeren Präfixen in rein perfektivierender Funktion zu nomina resultativa konstatiert werden.

Tabelle 7a: Zahlenmässige Angabe über das Vorkommen der nomina resultativa nach den Funktionen und Präfixen sowie dem Aspekt der ableitenden Verben

Lexikalische Funktion

Aspekt do- iz- na- za-

$\begin{array}{lllll}\text { pf. } & 12 & 10 & 14 & 11\end{array}$

ipf. $\quad 1 \quad 12 \quad 4 \quad 2$

Summe $\quad \begin{array}{llll}13 & 22 & 18 & 13\end{array}$

Modifizierende Funktion

Aspekt do- iz- na- za-

$\begin{array}{lllll}\text { pf. } & 2 & 3 & 16 & 19\end{array}$

ipf. $1-42$

Summe $\quad \begin{array}{llll}3 & 3 & 20 & 21\end{array}$

Rein perfektivierende Funktion

a) reihende Präfixe

Aspekt do- iz- na- za-

pf. $\quad-4722 \quad 38$

ipf. - 24 -

Summe - $49 \quad 26 \quad 38$

b) leere Präfixe

Aspekt do- iz- na- za-

pf. $\quad-\quad 3 \quad 1 \quad 4$

ipf. - - 1 -

Summe $\quad-\quad 324$
Tabelle 7b: Angabe über das Vorkommen der nomina resultativa nach den Bedeutungen der Präfixe in Zahlen

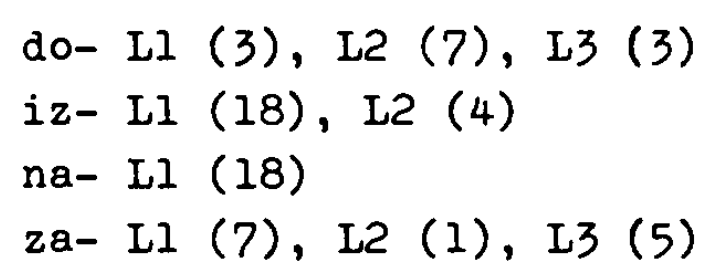


Tabelle 8: Angabe über das Gesamtvorkommen der nomina resultativa nach den Funktionen der Präfixe in Zahlen und Prozenten

Lexikalische Funktion:

Modifizierende Funktion:

Rein perfektivierende Funktion:

a) reihende Präfixe:

b) leere Präfixe:

\section{Summe Prozent}

$$
\begin{aligned}
& 66=28,08 \\
& 47=20,00
\end{aligned}
$$

$$
113=48,08
$$$$
9=3,82
$$ 
NOMINA ACTIONIS 198

\section{Allgemeine Vorbemerkungen}

Unter nomina actionis werden Substantive mit abstrakter Bedeutung verstanden, die als Resultat des Prozesses der Nominalisierung des Verbs entstehen, d.h. der Uberführung der Wortart des Verbs in die des Substantivs. Bei diesem Vorgang handelt es sich darum, dass der Begriff der Handlung von seinen charakteristischen Merkmalen, die die Handlung in der Form von Person, Tempus, Numerus, Genus und Modus ausdrücken, abstrahiert und als eine gegenständliche und selbständig existierende Erscheinung aufgefasst wird. Die Kategorie des Aspekts dagegen, die ebenfalls zu den charakteristischen Merkmalen des Begriffs der Handlung gehört, wird von diesem Abstrahierungsprozess ausgenommen. Der Aspekt ist mit verschieden grosser Intensität in den nomina actionis enthalten.

Bei dem Vorgang der Nominalisierung des Verbs wird das Verb unter Verlust der Kategorien von Person, Tempus, Numerus, Genus und Modus in ein Substantiv übergeführt wie z.B. dohoditi/ dohadjati 'herankommen' zu dohodjenje/ dohadjanje/ dohod 'An-, Herankommen', izmiriti/ izmirivati 'aussöhnen' zu izmirenje/ izmirivanje/ izmir 'Aussöhnung', zabosti/ zabadati 'hineinstechen' zu zabadanje/ zabod 'Hineinstechen, Stich'.

Die Substantivierung des Verbs wird als wortbildender 199

198 Unter den Begriff nomina actionis subsumieren wir Verbalsubstantive und nomina actionis im engeren Sinne, worunter alle Bildungen fallen, die keine Verbalsubstantive sind. Die gemeinsamen Merkmale von nomina actionis im engeren Sinne und Verbalsubstantiven werden zusammen abgehandelt. Die speziellen Merkmale werden zunächst für die Verbalsubstantive und danach für die nomina actionis im engeren Sinne dargelegt.

199 Mit der Frage, inwieweit es sich bei nomina actionis um Substantive mit allen ihren grammatischen Eigenschaften handelt, befassen sich für das Russische, Tschechische und Slovakische Baláž und für das Deutsche Schippan. G. Baláž, Abstraktné deverbatíva $v$ ruštine, slovenčine a češtine. In: Sovětská jazykovèda IV, 1954, S. 12 - 21. Th. Schippan, Die Verbalsubstantive der deutschen Sprache der Gegenwart. Habil.Schrift. Leipzig 1967, S. 42ff. zit. nach W. Fleischer, Wort- 
Prozess und nicht als formbildender aufgefasst.

Die Nominalisierung des Verbs wird nach der Wortbildungstheorie von Dokulil zum Transpositionstyp 200 gezählt, der neben den Typen der Mutation und Modifikation steht. Bei diesem handelt es sich nicht um die Benennung einer Erscheinung, sondern lediglich um die Umwertung einer schon benannten Erscheinung. Das Verb wird in die Klasse der Substantive überführt, wobei seine Bedeutung keinerlei Modifizierung erfährt. Der Transpositionstyp kann also streng genommen nur bedingt für eine onomasiologische Kategorie gehalten werden, da es sich bei dem Vorgang der Transposition nicht um die Bezeichnung eines neuen Begriffs handelt, sondern lediglich um die Umwertung eines schon bekannten, vorhandenen.

Auf der wortbildenden Ebene werden nomina actionis durch zwei verschiedene Verfahren realisiert, und zwar durch das wortbildende Verfahren der Suffigierung und das der Konversion.

1. Nomina actionis im engeren Sinne

Nomina actionis im engeren Sinne werden auf der wortbildenden Ebene durch die wortbildenden Verfahren der Suffigierung und der Konversion realisiert. Die wortbildenden Verfahren der Suffigierung und der Konversion dienen in etwa gleichem Umfange der Ableitung von nomina actionis im engeren Sinne, die durch Verben mit Präfixen der modifizierenden und rein perfektivierenden Funktion motiviert sind. Das wortbildende Verfahren der Konversion stellt das Hauptableitungsverfahren der nomina actionis im engeren Sinne dar, die durch Verben mit Präfixen der lexikalischen Funktion motiviert sind.

Nomina actionis im engeren Sinne werden von Verben mit den Präfixen do-, iz-, na-, za- in lexikalischer und modifizierender Funktion und von Verben mit den Präfixen iz-, na-, za- in rein perfektivierender Funktion abgeleitet.

Folgende Formantien finden bei der Bildung von nomina actionis im engeren Sinne Verwendung:

Maskulina: I. $-a j,-a k$, II. $-\mathrm{HK}-\varnothing,-W K-\varnothing$

Feminina: I. $-a c ̌ i n(a),-a l j k(a),-b(a),-b i n(a),-i c(a),-i j(a)$, $-k(a),-n i c(a),-n j(a)$

bildung der deutschen Gegenwartssprache. Leipzig 1969, S. 70. 200 M. Dokulil, Tvořeni slov I, S. $43 \mathrm{ff}$. 


$$
\text { II. }-W K-\phi^{201},-H K-a,-W K-a \text {. }
$$

Nach der Produktivität ergibt sich für die Gesamtheit der nomina actionis im engeren Sinne dieses Bild:

Maskulina: I. b) weniger produktiv: -aj, -ak, II. a) sehr produktiv: $-H K-\varnothing, c)$ unproduktiv: $-W K-\varnothing$

Feminina: I. b) weniger produktiv: $-i c(a),-b(a),-k(a), c)$ unproduktiv: $-n j(a), d)$ ganz unproduktiv: -ačin(a), -aljk(a), $-b i n(a),-i j(a),-n i c(a)$, II. b) weniger produktiv: $-H K-a, d)$ ganz unproduktiv: $-W K-\varnothing,-W K-a$.

Der wortbildende Typ auf $-H K-\varnothing$ bildet den Kern der maskulinen Substantive von Verben mit Präfixen der lexikalischen Funktion, die wortbildenden Typen auf $-H K-\varnothing$ und - aj bilden den Kern der maskulinen Substantive von Verben mit Präfixen der modifizierenden Funktion und die auf $-H K-\varnothing$ und $-a j$ bilden den Kern der maskulinen Substantive von Verben mit Präfixen der rein perfektivierenden Funktion.

Nomina actionis im engeren Sinne werden generell in überwiegendem Masse von Verben mit Präfixen der lexikalischen Funktion abgeleitet. In der Häufigkeit der Bildung folgen Substantive, die von Verben mit reihenden und leeren Präfixen der rein perfektivierenden und von solchen mit Präfixen der modifizierenden Funktion abgeleitet sind.

Die Ableitungsbasis der nomina actionis im engeren Sinne bilden der Grundstamm und bei einem Substantiv der Stamm des Partizip Präteritum Aktiv.

Nomina actionis im engeren Sinne, die mit Hilfe der Suffigierung gebildet worden sind, sind durch Verben der 3., 4., 5., 2. Konjugation motiviert. Den Kern der Ableitungsbasis der Ableitungen von Verben mit Präfixen der lexikalischen Funktion bildet der Grundstamm von Verben der 5., 4. Konjugation, den der Ableitungen von Verben mit Präfixen der modifizierenden Funktion der Grundstamm von Verben der 5. Konjugation und den der Ableitungen von Verben mit Präfixen der rein perfektivierenden Funktion der Grundstamm von Verben der 4. Konjugation.

Nomina actionis im engeren Sinne, die mit Hilfe der Konversion gebildet worden sind, sind durch Verben aller Konjugationen mit Ausnahme derer der 6. motiviert. Den Kern der Ableitungsbasis der Ableitungen von Verben mit Präfixen der lexikalischen und

201 -WK- $\varnothing$ steht für feminine Substantive mit weichem stammauslautendem Konsonanten und der Endung - $\varnothing$ im Nominativ Singular (Deklinationstyp "noć"). 
rein perfektivierenden Funktion bilden Verben der 4. Konjugation und den der Ableitungen von Verben mit Präfixen der modifizierenden Funktion Verben der 5. Konjugation.

Nomina actionis im engeren Sinne nach dem Ableitungsverfahren, dem Ableitungsstamm und der Konjugation:

A. Lexikalische Funktion

I. Suffigierung

1. Grundstamm

Maskulina: 5., 4., 3. Konjugation

Feminina: 4., 5., 3. Konjugation

II. Konversion

Maskulina: 4., 5., 2., 1., 3. Konjugation

Feminina: 4. Konjugation

B. Modifizierende Funktion

I. Suffigierung

1. Grundstamm

Maskulina: 5., 4. Konjugation

Feminina: 4. Konjugation

II. Konversion

Maskulina: 5., 4., 2. Konjugation

Feminina: 4. Konjugation

C. Rein perfektivierende Funktion

a) reihende Präfixe

I. Suffigierung

1. Grundstamm

Maskulina: 4., 5., 2. Konjugation

Feminina: 4., 5., 2. Konjugation

2. Stamm des Partizip Präteritum Aktiv

Feminina: 5. Konjugation

II. Konversion

Maskulina: 4., 1., 5., 2. Konjugation

Feminina: 4., 1.,2. Konjugation

b) leere Präfixe

I. Suffigierung

1. Grundstamm

Maskulina: 4., 5., 2. Konjugation

Feminina: 5., 4. Konjugation

II. Konversion 
Maskulina: 4., 2., 5. Konjugation

Feminina: 4., 2. Konjugation.

Präfigierte nomina actionis im engeren Sinne werden von perfektiven und imperfektiven Verben abgeleitet. Ableitungen von perfektiven Verben sind: dostig 'Erreichen', izbačaj 'Zuwurf', nalet 'Entgegenfliegen', zaustava 'Anhalten' u.a.; Ableitungen von imperfektiven Verben sind: dogar 'Abbrennen', dovod 'Zuleitung', izvoz 'Ausfuhr', nalivak 'Anguss, Aufguss', zavrt 'Drehung' u. a.

Nomina actionis im engeren Sinne werden vorwiegend von perfektiven Verben abgeleitet, wobei jedoch zwischen den einzelnen Gruppen mit den Präfixen und deren Funktionen deutliche Unterschiede festgestellt werden können. Fast durchweg von perfektiven Verben sind nomina actionis abgeleitet, die durch Verben mit Präfixen der modifizierenden Funktion motiviert sind, und zwar unabhängig davon, ob sie mittels der Suffigierung oder Konversion realisiert worden sind. Ebenfalls sehr häufig von perfektiven Verben sind nomina actionis abgeleitet, die durch Verben mit Präfixen der rein perfektivierenden Funktion motiviert sind, wobei Ableitungen von perfektiven Verben noch überwiegen, wenn sie durch das Verfahren der Konversion realisiert worden sind.

Am relativ seltensten werden nomina actionis im engeren Sinne von perfektiven Verben abgeleitet, wenn sie durch Verben mit Präfixen der lexikalischen Funktion motiviert sind. Während nomina actionis, die mittels der Suffigierung realisiert sind, fast jeweils zur Hälfte von perfektiven und imperfektiven Verben abgeleitet sind, überwiegen bei denen, die mittels der Konversion realisiert sind, die Ableitungen von perfektiven Verben.

Eine Aspektopposition scheint bei den nomina actionis im engeren Sinne, wie etwa teilweise bei den Verbalsubstantiven, nicht gegeben zu sein. Es kann lediglich das Beispiel zastajak (indiv.) 'Stehenbleiben, Halten' - zastanak 'Anhalten, Stehenbleiben; Ruheort' angeführt werden, dem möglicherweise eine Aspektopposition nicht ganz abgesprochen werden kann. Als motivierende Verben könnte man ipf. zastajati - pf. zastati voraussetzen. Ob eine Aspektopposition bei diesem oder ähnlichen Beispielen tatsächlich besteht, kann ohne eine Untersuchung an umfangreichem Material nicht festgestellt werden.

Nomina actionis im engeren Sinne werden in der Regel entweder von perfektiven oder imperfektiven Verben abgeleitet. Es wäre interessant, in einer gesonderten studie zu untersuchen, inwieweit 
nomina actionis im engeren Sinne die Funktionen des nichtvorhandenen Substantivs des anderen Aspekts übernehmen 202 .

Nomina actionis im engeren Sinne weisen neben der ursprünglichen Handlungsbedeutung häufig auch andere Bedeutungen auf, und zwar eine resultative, instrumentale und lokale, die infolge von metonymischen Umwertungen der ursprünglichen Handlungsbedeutung entstehen. Die Bedeutung solcher Wörter muss dann jeweils aus dem Kontext erschlossen werden. Ob z.B. mit izvoz 'Ausfuhr' der Akt des Ausführens oder das Resultat der Handlung in Gestalt eines Produktes gemeint ist, muss aus dem Kontext erschlossen werden.

Die Möglichkeit, neben dem Vorgang der Handlung auch das Resultat $z u$ bezeichnen, ist potentiell in allen nomina actionis enthalten, wird aber nicht immer realisiert. Diese Tatsache erklärt auch, dass infolge der metonymischen Umwertung die resultative Bedeutung am häufigsten auftritt. Den Begriff des Handlungsakts und den des Handlungsresultats intendieren z.B. izvoz, izbor 'Auswahl', izgradnja 'Bauen, Bau'.

Weniger häufig ist die instrumentale Bedeutung neben der Handlung anzutreffen wie z.B. nateg 'Anziehen (Schiff an das Ufer); Heber'.

Schliesslich benennen nomina actionis im engeren Sinne in sekundärer Bedeutung Orte, an denen eine Handlung verlaufen kann, wie z.B. ispaša 'Weiden; Weideort', zagon 'Anlauf; Ort, wo Vieh eingesperrt wird', zahod 'Unter-, Niedergang; Abort'.

Unter dem Gesichtspunkt der Bedeutung der Präfixe der ableitenden Verben ergibt sich für das Vorkommen der nomina actionis im engeren Sinne folgendes Bild:

In lexikalischer Funktion werden nomina actionis im engeren Sinne von Verben mit nachstehenden Präfixen und ihren Bedeutungen abgeleitet:

do- LI 'bis zu (einem bestimmten Ort gelangen)' (doskok 'Ansprung, der letzte Teil des Sprungs' von doskočiti 'herbeispringen') oder '(einen Gegenstand) bis zu (einem bestimmten Ort bewegen)' (dovod 'Zuleitung' von dovoditi 'zuleiten');

L2 'zu (etwas) hinzu(fügen)' (doliv 'Zugiessen' von dolivati

202 Für das Polnische hat Puzynina nachgewiesen, dass nomina actionis im engeren Sinne in bezug auf den Inhalt beide Aspekte ausdrücken können, die formalen Exponenten zum Ausdrücken der Aspektopposition jedoch fehlen. J. Puzynina, Kategoria aspektu $w$ polskich nazwach czynności. In: Prace filologiczne XIX, 1969, S. 107. 
'zugiessen');

L3 'bis zu (etwas gelangen)' (domašaj 'Reichweite' von domašati 'erlangen, erreichen');

L4 '(etwas) zu jemandes Nutzen (tun)' (dodela 'Zuteilen' von dodeliti 'zuteilen');

iz- Ll ' (etwas) von innen nach aussen (oder) von unten nach oben (bewegen)' (iskrcaj 'Ausladen' von iskrcati 'ausladen');

L2 '(jemanden oder etwas) aus einer Mitte heraus(bewegen)' (izbor 'Auswählen, Wahl' von izbrati 'auswählen');

na- Ll '(einen Gegenstand) auf (einen anderen stellen)' (nametak 'Aufsetzen, Aufsatz' von nametati 'auflegen');

za- Ll '(etwas) hinter (etwas stellen)' (zabod 'Stich' von zabosti 'stechen');

L2 '(umfassen) von allen Seiten' (zapletavica 'Verwicklung, Verflechtung' von zapletati 'verflechten');

L3 ' (umfassen) der äusseren Hülle' (zamlad 'Vernarben' von zamladiti 'vernarben, zuheilen');

I4 'eine Stellung einnehmen' (zastanak 'Anhalten, Stehenbleiben' von zastati 'anhalten');

In modifizierender Funktion werden nomina actionis im engeren Sinne von Verben mit nachstehenden Präfixen und ihren Bedeutungen abgeleitet:

do- MI '(eine früher nicht ausgeführte Handlung) bis zum Ende (ausführen)' (doradak 'Aufarbeiten' von doraditi 'aufarbeiten');

iz- Ml 'erreichen, erlangen' (izradba 'Aus-, Erarbeiten' von izraditi 'aus-, erarbeiten');

na- $M I$ ' (eine Handlung) in ausreichendem Masse (ausführen)' (natisak 'Vollstopfen' von natiskati 'vollstopfen');

za- Ml ' (eine Handlung) beginnen' (zadrhtaj 'Erbeben' von zadrhtati 'erbeben');

In reihender Funktion werden nomina actionis im engeren Sinne von Verben mit nachstehenden Präfixen und ihren Bedeutungen

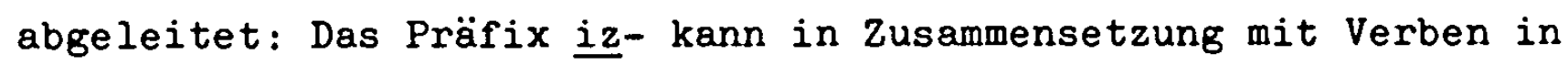
der Bedeutung (RI) 'von weg, heraus' und in der Bedeutung (R2) 'ausführen bis zum Erreichen des Ziels, bis zur Ausschöpfung der Möglichkeit' mit seinen jeweiligen Bedeutungsnuancen reihende Funktion ausüben. Die Bedeutungsnuancen der Bedeutung RI sind: Rlf 'absondern' (izludžba 'Ab-, Aussonderung' von izlučiti 'absondern'); Rli 'verschwinden' (ispaša 'Weiden' von ispasti 'abweiden'); Rlj 'Restgruppe' z.B. (izbeg 'Fliehen' von izbeći 
'fliehen');

Die Bedeutungsnuancen der Bedeutung R2 sind: R2a 'versehen mit einem neuen Gepräge' (ispunjaj 'Ausfüllen' von ispuniti 'ausfüllen'); R2b 'bei Anwendung eines chemischen oder physischen Verfahrens in den gewünschten Zustand bringen' (izgradnja 'Erbauen' von izgraditi 'erbauen'); R2d 'ausführen einer Prozedur an einem Lebewesen' (iskušaj 'Versuchen, Erproben' von iskušati 'versuchen, erproben'); R2e 'beseitigen des Unterschiedes' (izmir 'Aussöhnung' von izmiriti 'aussöhnen');

Das Präfix na- kann in Zusammensetzung mit Verben in der Bedeutung (RI) 'stellen eines Gegenstands auf einen anderen' und in (R2) der 'Augmentation' mit seinen jeweiligen Bedeutungsnuancen reihende Funktion ausüben. Die Bedeutungsnuancen der Bedeutung $R l$ sind: $R l b$ 'treten auf, veranlassen, auf etwas zu treten' (nagon 'Zutrieb; Antrieb' von nagoniti 'an-, auftreiben'); Rld 'Restgruppe' z.B. (namigaj 'Zublinzeln' von namigati 'zublinzeln'); Die Bedeutungsnuancen der Bedeutung $R 2$ sind: $R 2 a$ 'anhäufen, etwas in Menge tun' (nasad 'Anpflanzen' von nasaditi 'anpflanzen'); R2c 'anschwellen, zunehmen' (nadolazak 'Steigen' von nadolaziti 'steigen');

Das Präfix za- kann in Zusammensetzung mit Verben in der Bedeutung (RI) 'hinter etwas gehen' mit seinen Bedeutungsnuancen und in der Bedeutung $R 3$ 'eine Handlung beginnen' (zapažaj 'Bemerken' von zapaziti 'bemerken') reihende Funktion ausüben. Die Bedeutungsnuancen der Bedeutung Rl sind: Rla 'umdrehen' (zasuk 'Drehen auf die eine oder andere Seite' von zasukati 'aufdrehen'); Rlb 'umfassen eines Teils oder des Ganzen' (zahvat 'Ergreifen' vcn zahvatiti 'ergreifen'); RIf 'verschliessen und hindern' (zaustava 'An-, Zurückhalten' von zaustaviti 'an-, zurückhalten'); $R l_{g}$ 'schützen und nicht erlauben' (zaštita 'Schützen, Schutz' von zaštiti 'schützen'); Rlh 'töten, vernichten' (zadava 'Erwürgen' von zadaviti 'erwürgen'); Rli 'Restgruppe' z.B. (zamah 'kräftige Bewegung, Schwung' von zamahnuti 'ausholen, schwingen').

\section{Verbalsubstantive}

Verbalsubstantive werden auf der wortbildenden Ebene ausschliesslich durch das wortbildende Verfahren der suffigierung realisiert.

Formantien der Verbalsubstantive sind: $-n j(e)$ und $-\dot{c}(e)$. 
Verbalsubstantive werden generell von Verben mit den Präfixen do-, iz-, na-, za- in lexikalischer Funktion, von Verben mit den Präfixen do-, iz-, na-, za- in modifizierender Funktion und von Verben mit den Präfixen iz-, na-, za- in rein perfektivierender Funktion ${ }^{203}$ abgeleitet.

In Hinsicht auf das Ableitungssuffix, den Aspekt des ableitenden Verbs sowie die Funktion des Präfixes des ableitenden Verbs ergibt sich für das Vorkommen der Verbalsubstantive folgendes Bild:

Ableitungen mit dem Formans $-n j(e)$ von Verben mit Präfixen in lexikalischer Funktion und perfektivem Aspekt sind mit den Präfixen do-, iz-, za- und imperfektivem Aspekt mit den Präfixen do-, iz-, na-, za- vorhanden.

Ableitungen mit dem Formans $-n j(e)$ von Verben mit Präfixen in modifizierender Funktion und perfektivem sowie imperfektivem Aspekt sind mit den Fräfixen do-, iz-, na-, za- vorhanden.

Ableitungen mit dem Formans $-n j(e)$ von Verben ait Präfixen in rein perfektivierender Funktion und perfektivem sowie imperfektivem Aspekt sind mit den Präfixen iz-, na-, za- vorhanden.

Ableitungen mit dem Formans - $c(e)$ von Verben mit Präfixen in lexikalischer Funktion und perfektivem Aspekt sind mit den Fräfixen do-, iz-, na- vorhanden.

Ableitungen mit dem Formans -ćc(e) vcn Verben mit reihenden Präfixen in rein perfektivierender Funktion und perfektivem Aspekt sind lediglich mit dem Präfix iz- vorhanden. Ableitungen dieses Typs von Verben mit leeren Präfixen in rein perfektivierender Funktion und perfektivem Aspekt sind mit iz-, na- vertreten.

Verbalsubstantive werden nicht grundsätzlich van jedem Verb abgeleitet. Nach den von uns vorgenommenen Untersuchungen werden Verbalsubstantive weniger häufig gebildet von Verben mit Präfixen der modifizierenden und lexikalischen als von Verben mit Präfixen der rein perfektivierenden Funktion.

Der Ableitungsstamm der Verbalsubstantive ist der Stamm des Partizip Präteritum Passiv auf $-n-b z w$. auf - $t-$.

Bei dem Ableitungsstamm auf -t- tritt eine lautliche Veränderung auf, so z.B. nagnut-je > nagnuće, nadahnut-je / nadahnuće. Als eine Ableitung vom Stamm des Partizip Präteritum Passiv

203 Der Begriff 'Präfixe in rein perfektivierender Funktion' beinhaltet stets reihende unà leere Präfixe, sofern keine Spezifizierung vorgenommen wird. 
lassen sich jedoch nur Verbalsubstantive erklären, die von einem transitiven Verb abgeleitet worden sind, da nur von transitiven Verben solche Partizipien gebildet werden können. Daneben gibt es aber noch eine grosse Anzahl von Verbalsubstantiven, die von intransitiven Verben abgeleitet worden sind, wie z.B. doletanje 'Herbeifliegen', izbijanje 'Keimen', naviranje 'Aufsieden', zakašnjavanje 'Verspäten' sowie Ableitungen von reflexiven Verben wie z.B. domašanje zu domašati se 'Greifen', iznojavanje zu iznojavati se 'Ausschwitzen', naoblačenje zu naoblačiti se 'Bewölkung', zastidjivanje zu zastidjivati se 'Beschämen'. Die reflexive Partikel wird von den Verbalsubstantiven im Serbokroatischen nicht übernommen wie etwa im Slovakischen 204 oder mit einigen Einschränkungen auch im Tschechischen ${ }^{205}$. Die Ableitungsbasis dieser Substantive kann keinesfalls ein Partizip sein. Diese Substantive stellen eine Analogiebildung ${ }^{206} \mathrm{zu}$ den Bildungen dar, deren Ableitungsstamm ein Partizip Präteritum Passiv ist, wenn angenommen wird, dass diese die primären sind 207 .

Präfigierte Verbalsubstantive mit dem Suffix $-n j(e)$ werden in der modernen serbokroatischen Literatursprache in überwiegender Mehrzahl von imperfektiven präfigierten Verben abgeleitet ${ }^{208}$.

204 G. Baláž, Abstraktné deverbativa..., a.a.0., s. 16.

205 Ebenda, S. 17; M. Jelínek, Podstatná jména slovesná se zvratným zájmenem. In: NR 46, 1963, S. 229 - 236. (zit. nach M. Dokulil, Tvoření slov II, S. 574.)

206 M. Stevanović, Savremeni srpskohrvatski jezik..., a.a.0., S. 491; Szymanski spricht in dieser Beziehung von einer allgemein slavischen Erscheinung. Vgl. T. Szymański, Słowotwórstwo rzeczownika w bułgarskich tekstach XVII-XVIII wieku, Wrocław-Warszawa-Kraków 1968, S. 72.

207 Die bisherige Erklärung der Entstehung der Verbalsubstantive auf $-n j(e)$ und -ć(e) ist vor allem in Hinblick auf die Ableitungen von intransitiven Verben nicht befriedigend. Neue Versuche, die Entstehung der Verbalsubstantive zu erkiären, sehen nicht mehr im Stamm des Partizip Präteritum Passiv die Ableitungsbasis, sondern im Infinitivstamm, an den die Formantien $-n j(e)$ bzw. -ć(e) angefügt werden. Ebenso schliesst man von der Stellung des Akzents der Verbalsubstantive, dass diese direkt vom Infinitivstamm abgeleitet worden sein müssen, da hier die Stellung des Akzents übereinstimmt, und nicht vom Stamm des Partizip Präteritum Passiv. Vgl. M. Stevanović, Savremeni srpskohrvatski jezik..., a.a.0., S. 49 lff.

Im Tschechischen wird die Entstehung der Verbalsubstantive des gleichen Typs genetisch in Zusammenhang mit dem Stamm des Partizip Präteritum Passiv gebracht. Vom synchronischen Standpunkt muss die Entstehung als direkte Ableitung vom Verbalstamm betrachtet werden. Vgl. M. Jelínek, in: Tvoření slov II, S. 576.

208 Die serbokroatische Sprache schliesst sichladamitodemengein 
(So z.B. dočaravanje von dočaravati 'Herbeizaubern', izvlačenje von izvlačiti 'Herausziehen', nabadanje von nabadati 'Aufstecken, Aufspiessen', zabeležavanje von zabeležavati 'Aufzeichnen, Notieren'.)

Präfigierte Verbalsubstantive mit dem Formans -nj(e) werden in der modernen serbokroatischen Sprache in einem relativ geringen Umfange von perfektiven Verben abgeleitet. Man kann Ableitungen von perfektiven Verben unterscheiden, die das Korrelat zur imperfektiven Aspektform bilden, wie z.B. dovršenje - ipf. dovršivanje 'Verrichten, Beendigen', pf. izjednačenje - ipf. izjednačavanje 'Ausgleichen', pf. izlučenje - ipf. izlučivanje 'Absondern', pf. nadraženje - ipf. nadraživanje 'Reizen', pf. naoružanje - ipf. naoružavanje 'Bewaffnen', pf. zamirenje - ipf. zamirivanje 'Beschwichtigen' und Ableitungen, die keine entsprechende Form von imperfektiven Verben aufweisen, die lediglich vom perfektiven Aspekt abgeleitet sind, wie z.B. doturanje 'Herbeischieben', isplovljenje 'Hinausfahren', zajamčenje 'Verbürgen', zaklanje 'Schlachten'.

Verbalsubstantive, die von imperfektiven Verben abgeleitet sind und neben sich keine entsprechenden Formen aufweisen, die von dem perfektiven Aspekt derselben Verben abgeleitet sind, übernehmen die Bedeutungsfunktion der nicht gebildeten oder im Laufe der Zeit verschwundenen Ableitungen von perfektiven Verben, sie werden zweiaspektisch ${ }^{209}$, d.h. sie können hinsichtlich des Aspekts in jedem beliebigen Kontext verwendet werden.

Verbalsubstantive, die von perfektiven Verben abgeleitet

südslavischen Tendenz zur Beseitigung der Ableitungen der Verbalsubstantive von perfektiven Verben an. $\mathrm{Vgl}_{\mathrm{gl}}$. H. Orzechowska, Orzeczeniowe formacje odsłowne w jezykach południowosłowiańskich, Wrocław-Warszawa-Kraków 1966, S. $23 \mathrm{ff}$. Auf die Tatsache, dass Ableitungen von Verbalsubstantiven auf $-n j(e)$ und -ć(e) von perfektiven Verben begrenzt sind, weist schon Belic hin. Er wendet sich damit gegen die allgemein vorherrschende und von Daničić (Osnove, 1876, S. 81) geäusserte Feststellung, dass Verbalsubstantive, die von perfektiven Verben abgeleitet werden, in gleicher Weise produktiv seien, wie die, die von imperfektiven Verben abgeleitet werden. A. Belić, O gradjenju glagolskih imenica na -nje $i$-ce. In: NJ I, 1933, S. 263.

209 Nach den Untersuchungen von Orzechowska setzt die verstärkte Bildung von Verbalsubstantiven, die von imperfektiven Verben abgeleitet sind, und die gleichzeitige teilweise Verdrängung der $\ddot{a}$ teren von perfektiven Verben abgeleiteten Verbalsubstantive um das 17 . Jahrhundert ein. Vgl. H. Orzechowska, Orzeczeniowe formacje odsłowne..., a.a.0., s. 77 . 
sind, haben nach der Auffassung von Belić immer die Bedeutung der Resultativität der Handlung ${ }^{210}$, die Resultativität der Handlung nähert die Verbalsubstantive der konkreten Bedeutung. Der Begriff der "Resultativität", der seiner Meinung nach über die Möglichkeit der Bildung von Verbalsubstantiven auf $-n j(e)$ und -ć(e) entscheidet, ist in dem der Ableitung zugrunde liegenden perfektiven Verb enthalten. Belić führt zur Verdeutlichung seiner Darlegungen Beispiele an, aus denen man Schlüsse ziehen kann, die seinen Darlegungen entgegengesetzt sind, da sie teilweise eine perfektive Handlung und nicht das Resultat der Handlung bzw. eine Konkretheit ausdrücken. Er führt u.a. an: pokajanje 'Reue, Busse', raskinuće dogovora 'Lösen eines Vertrages', svrgnuće sa položaja 'Amtsenthebung', dovršenje zgrade 'Beendigung des Gebäudes'211.

Zweifellos kann allgemein bestätigt werden, dass Verbalsubstantive, die von perfektiven Verben abgeleitet sind, häufiger eine konkrete Bedeutung aufweisen - meiner Meinung nach in der Mehrzahl der Fälle jedoch erst in der sekundären Bedeutung - als Verbalsubstantive, die von imperfektiven Verben abgeleitet sind. Diese Erscheinung ist jedoch nicht bei allen Verbalsubstantiven in gleichem Masse zu beobachten. Ableitungen von Verben mit Präfixen der lexikalischen und modifizierenden Funktion weisen in weit geringerem Masse neben der primären Handlungsbedeutung eine konkrete auf als etwa solche von Verben mit Präfixen der rein perfektivierenden Funktion 212 .

Orzechowska kann sich mit den Darlegungen von Belić nicht einverstanden erklären. Für sie ist die Konkretheit einiger Verbaisubstantive, die von perfektiven Verben abgeleitet sind, eine lexikalische Erscheinung und hängt nicht von der Aspektbedeutung des zugrunde liegenden perfektiven Verbs ab. Nach ihr nehmen diese Substantive die konkrete Bedeutung erst im Laufe der Zeit an. Aus der Tatsache, dass Ableitungen von perfektiven Verben relativ häufig eine konkrete Bedeutung aufweisen, schliesst die Autorin auf das hohe Alter vieler Ableitungen von perfektiven Verben. Dieselbe Erscheinung wird, so führt die Autorin aus, auch bei Verbalsubstantiven von imperfektiven Verben festgestellt, jedoch in einem sehr geringen Umfange, was darauf schliessen lässt, dass

210 A. Belić, 0 gradjenju glagolskih imenica..., a.a.0., S. 265. 211 Ebenda, S. 265 u. 264.

212 Ausführliches Material weiter unten. 
es sich bei den Verbalsubstantiven von imperfektiven Verben um relativ junge Bildungen handelt 213 .

Einige Jahre später kommt Vukovic $\dot{c}^{214}$ in einer Arbeit über die Verbalsubstantive im Serbokroatischen anhand der von Belić übernommenen Kriterien $z u$ denselben Schlussfolgerungen wie dieser hinsichtlich der Bedeutung und der Produktivität der von perfektiven Verben abgeleiteten Verbalsubstantive. Vuković versucht ausserdem, in seiner Arbeit das Problem der Abhängigkeit des Aspekts der Verbalsubstantive auf $-n j(e)$ und $-c(e)$ vom Aspekt der ihnen zugrunde liegenden Verben zu untersuchen. Der Autor kommt dabei zu Ergebnissen, die denen von Orzechowska genau entgegengesetzt sind. Auf Grund meiner Untersuchungen kann den Ergebnissen von Vuković in dieser Beziehung ebenfalls nicht zugestimmt werden. Vuković behauptet, dass die Ableitungen von imperfektiven Verben den Aspekt der Ableitungsbasis völlig übernehmen, während die Ableitungen von perfektiven Verben in Hinsicht auf den Aspekt schwankend seien (d.h. perfektiv oder imperfektiv sein können). Diesen Zustand führt er auf russische Einflüsse zurück (wo die Ableitungen von perfektiven Verben tatsächlich zweiaspektisch sind). In den zweiaspektischen Ableitungen von perfektiven Verben sieht Vuković eine Bedrohung des Anwendungsbereichs der Substantive von imperfektiven Verben. Er meint, dass es dazu kommen könnte, dass letztere von den Ableitungen perfektiver Verben verdrängt werden könnten ${ }^{215}$. Seine Befürchtungen illustriert er mit einigen Beispielen aus der Zeitungssprache, wo Substantive von perfektiven Verben zur Bezeichnung einer dauernden Handlung verwendet werden (z.B. neprekinjeno povišenje životnog standarda 'ununterbrochene Erhöhung des Lebensstandardes', u toku izvršenja 'im Laufe der Ausführung') 216 .

Orzechowska stellt dagegen fest, dass im Serbokroatischen die Verbalsubstantive von imperfektiven Verben zweiaspektisch sind und dass diese die Funktionen der nicht vorhandenen oder bereits verdrängten Substantive von perfektiven Verben übernehmen bzw. übernommen haben.

213 H. Orzechowska, Orzeczeniowe formacje odsłowne..., a.a.0., S. $79 \mathrm{ff} \mathrm{u.} 93$.

$214 \mathrm{~J}$. Vuković, Glagolske imenice na -nje i -íe. In: Pitanja savremenog knjizevnog jezika I u. II, 1949 u. 1950, S. 40 53 u. S. $149-171$.

215 Ebenda, I, S. 50.

216 Ebenda. 
In Fällen jedoch, in denen lediglich Ableitungen von perfektiven Verben vorhanden sind, kann den Ausführungen von Vukovićc zugestimmt werden. Dann nämlich sind diese Substantive zweiaspektisch und übernehmen die Funktion der Ableitungen von imperfektiven Verben. Es handelt sich in diesen Fällen um eine analoge Erscheinung $z u$ den Substantiven von imperfektiven Verben. Der Unterschied besteht lediglich darin, dass Ableitungen von perfektiven Verben in relativ geringer Zahl auftreten und dass sie keineswegs den Verwendungsbereich der Ableitungen von imperfektiven Verben bedrohen, wie Vuković behauptet.

In einer Reihe von Fällen, wie oben gezeigt wurde, können Verbalsubstantive also Korrelate zweier Aspektformen sein. Es kann angenommen werden, dass in diesen Fällen die Aspektopposition bei den Verbalsubstantiven erhalten geblieben ist ${ }^{217}$. Vor einer endgültigen Wertung bedarf es jedoch einer genauen Analyse dieser Fälle, die im Rahmen dieser Arbeit nicht geleistet werden kann.

In der Regel bilden Verbalsubstantive mit dem Formans $-n j(e)$ Aspektkorrelationen, also pf. izlučenje - ipf. izlučivanje 'Absondern'. En Einzelfällen bilden Aspektkorrelationen die perfektive Ableitung auf $-\dot{c}(e)$ und die imperfektive auf $-n j(e)$ wie z.B. pf. izmetnuće - ipf. izmetanje 'Aus-, Hinauswerfen'.

Verbalsubstantive als Korrelate zweier Aspektformen treten bei den einzelnen Funktionen der Präfixe quantitativ verschieden auf. Am zahlreichsten sind sie, wenn sie von Verben mit Präfixen der rein perfektivierenden Funktion abgeleitet sind und am seltensten, wenn sie von Verben mit Präfixen der modifizierenden Funktion abgeleitet sind. Relativ gering sind sie, wenn sie von Verben mit Präfixen der lexikalischen Funktion abgeleitet sind, mit Ausnahme derer mit dem Präfix iz- 218 .

Die Tatsache, dass Verbalsubstantive als Korrelate zweier Aspektformen überwiegend Ableitungen von Verben mit Präfixen der rein perfektivierenden Funktion sind, scheint sich einerseits aus dem teilweisen Nichtfunktionieren bzw. der noch nicht völligen Generalisierung des Prozesses der Ubernahme der perfektiven Funk-

217 Im Polnischen ist dieser Zustand weitgehend erhalten geblieben. Das Verbalsubstantiv drückt die Aspektopposition im Bereich seiner primären Bedeutung aus. Vgl. J. Puzynina, Kategoria aspektu..., a.a.0., S. 104.

218 Eine ausführliche Aufstellung der Aspektkorrelationen für jedes Präfix mit seinen Funktionen wird im Materialteil gegeben. 
tion durch die sekundäre imperfektive Form - Orzechowska stellt für die Verbalsubstantive generell fest, dass dieser Prozess weitgehend generalisiert ist - gerade bei Ableitungen von Verben mit Präfixen der rein perfektivierenden Funktion und daher der Notwendigkeit, beide Aspektformen zu bilden, erklären zu lassen, und andererseits aus dem Fehlen mit ihnen korrelierender entsprechender perfektiver Aspektformen der nomina actionis im engeren Sinne, wie sie bei den Ableitungen von Verben mit Präfixen der lexikalischen Funktion in zunehmendem Masse und in einem etwas weniger ausgeprägten Masse auch bei Ableitungen von Verben mit Präfixen der modifizierenden Funktion vorhanden sind.

Zusammenfassend kann gesagt werden, dass in der modernen serbokroatischen Sprache in Fällen, in denen Verbalsubstantive auf $-n j(e)$ lediglich von imperfektiven Verben vorhanden sind, diese zweiaspektisch sind, d.h. die Funktionen des nicht vorhandenen Substantivs vom perfektiven Aspekt übernehmen. In Fällen, in denen das Verbalsubstantiv auf $-n j(e)$ nur vom perfektiven Verb vorhanden ist, übernimmt dieses die Funktionen des nicht vorhandenen Substantivs vom imperfektiven Verb. In Fällen schliesslich, in denen Verbalsubstantive von beiden Aspekten desselben Verbs vorhanden sind, scheint die Aspektopposition erhalten geblieben zu sein. Ein abschliessendes Urteil kann aber vor einer eingehenden Untersuchung nicht gegeben werden.

Verbalsubstantive mit dem Formans -ćc(e) werden in der modernen serbokroatischen Sprache ausschliesslich von Verben des perfektiven Aspekts gebildet, und zwar in ganz geringer Anzahl von Verben der 1. Konjugation wie z.B. izuzeće von izuzeti 'Ausschliessen; Vorwegnehmen' und in grösserer Anzahl von Verben der 2. Konjugation wie z.B, dosegnuće von dosegnuti 'Erreichen, Erlangen', iskliznuće von iskliznuti 'Ausgleiten, Ausrutschen', nategnuce von nategnuti 'Anspannen'.

$\mathrm{Zu}$ den von perfektiven Verben abgeleiteten Verbalsubstantiven auf -ćc(e) werden in der überwiegenden Mehrzahl der Fälle Substantive vom imperfektiven Aspekt desselben Verbs gebildet. Ohne eine Spezialuntersuchung kann allerdings nicht gesagt werden, ob die Aspektopposition, wie sie formal gegeben ist, in der modernen serbokroatischen Sprache auch von der Funktion her noch intakt ist, oder ob eine der beiden Verbalsubstantive die Funktion des anderen übernommen hat.

Wie bereits ausgeführt wurde, werden Verbalsubstantive mit dem Formans $-n j(e)$ überwiegend von imperfektiven Verben und 
nomina actionis im engeren Sinne in der Mehrzahl der Fälle von perfektiven Verben abgeleitet. In zahlreichen Fällen stehen sich Verbalsubstantive, die von imperfektiven Verben abgeleitet sind, und nomina actionis im engeren Sinne, die von perfektiven Verben abgeleitet sind, gegenüber ${ }^{219}$, so z.B. dogradjivanje - dograda 'Aus-, Zuendebauen', doradjivanje - dorada 'Zuendearbeiten', dočekivanje - dočèk 'Empfangen, Empfang', izgradjivanje - izgradnja 'Erbauen; Bau', istovaravanje - istovar 'Aus-, Abladen', iskopavanje - iskop 'Ausgraben; Ausgrabungsort', nabavljanje nabava 'Beschaffen, Beschaffung', najavljivanje - najava 'Benachrichtigen, Bekanntmachen', zabadanje - zabod 'Hineinstechen, Stich', zamenjivanje - zamena 'Eintauschen', zadržavanje - zadrška 'Auf-, Anhalten'. Verbalsubstantive wie auch nomina actionis im engeren Sinne haben eine Handlungsbedeutung. Den Unterschied in der Handlungsbedeutung bei Verbalsubstantiven und nomina actionis im engeren Sinne versucht Jelinek im Tschechischen zu erklären. Nach ihm hat "...das Verbalsubstantiv in der Regel einen grösseren Bedeutungsumfang als das nomen actionis mit gleicher wurzel, denn das wortbildende Formans der nomina actionis im engeren Sinne pflegt für eine speziellere Bedeutung im Rahmen der allgemeinen Handlungsbedeutung reserviert zu sein" 220 .

Es taucht nun die Frage auf, inwieweit imperfektive Verbalsubstantive und perfektive nomina actionis im engeren Sinne in einer Aspektkorrelation stehen können. Orzechowska ${ }^{221}$ bringt den höheren Anteil von nomina actionis im engeren Sinne, die von perfektiven Verben abgeleitet sind, in Zusammenhang mit dem Verfall der Aspektopposition bei den Verbalsubstantiven, bei der die Verbalsubstantive, die von imperfektiven Verben abgeleitet sind, die

219 Auf das Vorhandensein einer Aspektkorrelation zwischen Verbalsubstantiven und nomina actionis im engeren Sinne kann in gewissem Sinne bei einem Vergleich der Verhältnisse im Polabischen und Serbokroatischen geschlossen werden. Nach Untersuchungen von Djordjić stehen anstelle von Verbalsubstantiven im Polabischen, die von perfektiven Verben abgeleitet sind, im Serbokroatischen von perfektiven Verben abgeleitete nomina actionis im engeren Sinne, so z.B. pol. nalysene - skr. navika 'Gewöhnung', pol. wassemarciôn - skr. sumrak 'Abenddämmerung', pol. ka warsikonye - skr. napast 'Versuchung'. Vgl. P. Djordjić, Połabskie rzeczowniki odsłowne. In: SO XII, 1933, S. 168 .

220 M. Jelinek, in: Tvořeni slov II, S. 566.

221 H. Orzechowska, Orzeczeniowe formacje odsłowne..., a.a.0., S. 94 u. 218. 
Funktion der nichtvorhandenen Bildungen von perfektiven Verben übernehmen. Da nun, so schliesst die Autorin, eine grammatische Kategorie nur vorübergehend ohne formalen Exponenten auskommt, muss ein Ausgleich geschaffen werden, der in einer neuen Form seinen Ausdruck finden kann. Diesen Ausgleich sieht sie in der erhöhten Produktivität einiger Formantien zur Bildung der nomina actionis im engeren Sinne.

Auf Grund der vorliegenden Untersuchungen wurde festgestellt, dass nomina actionis im engeren Sinne nicht überall gleich häufig vorkommen. Es scheint, als ob die erhöhte Produktivität von nomina actionis im engeren Sinne - nach Ansicht von Orzechowska eine Folge des Verfalls der Aspektopposition bei den Verbalsubstantiven - in sich jedoch wiederum differenziert, vom Charakter des Präfixes des ableitenden Verbs abhängig ist. Sehr häufig werden nomina actionis im engeren Sinne von Verben mit Präfixen der lexikalischen Funktion abgeleitet. Relativ selten werden nomina actionis im engeren Sinne von Verben mit Präfixen der modifizierenden und von Verben mit leeren Präfixen der rein perfektivierenden Funktion abgeleitet, während solche von Verben mit reihenden Präfixen der rein perfektivierenden Funktion in der Häufigkeit der Ableitung eine mittlere stellung einnehmen. Unterschiede in der Häufigkeit können jedoch von Präfix zu Präfix auftreten.

Um Wechselbeziehungen in aspektaler Hinsicht zwischen Verbalsubstantiven, die von imperfektiven Verben abgeleitet sind, und nomina actionis im engeren Sinne, die von perfektiven Verben abgeleitet sind, festzustellen, bedarf es aber nicht nur der Auffindung dieser "Paare", sondern auch ihrer genauen Analyse im kontextuellen Zusammenhang, die im Rahmen dieser Arbeit nicht durchgeführt werden kann.

Verbalsubstantive mit dem Formans $-n j(e)$, die von Verben mit Präfixen der lexikalischen, modifizierenden und rein perfektivierenden Funktion abgeleitet sind, sind durch imperfektive Verben der 5., 6., 4. und durch perfektive Verben der 4., 5. und ganz vereinzelt der 1 . und 3. Konjugation motiviert.

Verbalsubstantive mit dem Formans - $\dot{c}(e)$, die von Verben mit Präfixen der lexikalischen und rein perfektivierenden Funktion abgeleitet sind, sind durch perfektive Verben der 2. und ganz vereinzelt der 1. und der unregelmässigen Konjugation motiviert.

Die Möglichkeit, neben dem Vorgang der Handlung auch das Resultat der Handlung $z u$ bezeichnen, ist prinzipiell bei den Verbalsubstantiven gegeben, so z.B. bei zadebljenje 'Verdickung; 
Wulst', zadubljivanje 'Vertiefen; Vertiefung', zamršivanje 'Verwirren; Verwickeltheit'.

Unter dem Gesichtspunkt der Bedeutung der Präfixe der ableitenden Verben ergibt sich für das Vorkommen der Verbalsubstantive auf $-n j(e)$ und $-\dot{c}(e)$ folgendes Bild:

In lexikalischer Funktion werden Verbalsubstantive von Verben mit nachstehenden Präfixen und ihren Bedeutungen abgeleitet: do- Ll 'bis zu (einem bestimmten Ort gelangen)' (dohadjanje 'Herankommen' von dohadjati 'herankommen') oder '(einen Gegenstand) bis zu (einem bestimmten Ort bewegen)' (dovlačenje 'Heran-, Herbeischleppen' von dovlačiti 'heran-, herbeischleppen');

L2 'zu (etwas) hinzu(fügen)' (dodavanje 'Hinzugeben, Hinzufügen' von dodavati 'hinzugeben, hinzufügen');

L3 'bis zu (etwas gelangen)' (dosegnuce 'Erreichen, Erlangen' von dosegnuti 'erreichen, erlangen');

L4 '(etwas) zu jemandes Nutzen (tun)' (dodeljenje 'Zuteilen' von dodeliti 'zuteilen');

iz- Ll ' (etwas) von innen nach aussen (oder) von unten nach oben (bewegen)' (iznašanje 'Hinaustragen' von iznašati 'hinaustragen');

L2 ' (jemanden oder etwas) aus einer Mitte heraus(bewegen)' (izopćenje 'Exkommunizierung; Acht' von izopštiti 'exkommunizieren');

na- Ll '(einen Gegenstand) auf (einen anderen stellen)' (navlačenje 'An-, Uberziehen' von navlačiti 'überziehen');

za- Ll '(etwas) hinter (etwas stellen)' (zabacivanje 'Hinterwerfen' von zabacivati 'hinterwerfen');

L2 '(umfassen) von allen Seiten' (zašivanje 'Zunähen' von zašivati 'zunähen');

L3 ' (umfassen) der äusseren Hülle' (zarašćenje 'Zuwachsen, Verheilen' von zarasti 'zuwachsen, verheilen');

L4 'eine Stellung einnehmen' (zadržavanje 'Auf-, Anhalten' von zadržavati 'auf-, anhalten');

In modifizierender Funktion werden Verbalsubstantive von Verten mit nachstehenden Präfixen und ihren Bedeutungen abgeleitet:

do- MI '(eine früher nicht ausgeführte Handlung) bis zum Ende (ausführen)' (dogorevanje 'Abbrennen' von dogorevati 'abbrennen');

iz- MI 'erreichen, erlangen' (izradjivanje 'Erarbeiten' von iz- 
radjivati 'erarbeiten');

na- MI '(eine Handlung) in ausreichendem Masse (ausführen)' (nabiranje 'Ansammeln' von nabirati 'ansammeln');

M2 '(eine Handlung) in geringem Masse (ausführen)' (nadizanje 'Anheben' von nadizati 'anheben');

za- MI '(eine Handlung) beginnen' (zahukavanje 'Anhauchen' von zahukavati 'anhauchen');

In reihender Funktion werden Verbalsubstantive von Verben mit nachstehenden Präfixen und ihren Bedeutungen abgeleitet: Das Präfix iz- kann in Zusammensetzung mit Verben in der Bedeutung (RI) 'von wo weg, heraus' und in (R2) 'ausführen bis zum Erreichen des Ziels, bis zur Ausschöpfung der Möglichkeit' mit seinen jeweiligen Bedeutungsnuancen reihende Funktion ausüben. Die Bedeutungsnuancen der Bedeutung RI sind: Rla 'ausdrücken' (izažimanje 'Ausdrücken, Auspressen' von izažimati 'ausdrücken'); Rlb 'wachsen' (iznicanje 'Aufkeimen' von iznicati 'aufkeimen'); Rlc 'umwerfen' (izvraćanje 'Umstülpen' von izvraćati 'umstülpen'); Rld 'ausschneiden' (isecanje 'Ausschneiden' von isecati 'ausschneiden'); Rle 'aushöhlen' (izbočenje 'Ausbauchen' von izbočiti 'ausbauchen'); Rlf 'absondern' (izlučenje 'Absondern, Ausscheiden' von izlučiti 'absondern, ausscheiden'); Rlg 'versperren' (isprečavanje 'Versperren' von isprečavati 'versperren'); Rlh 'sichverlieren' (ishlapljenje 'Auslüften' von ishlapiti 'auslüften'); Rli 'verschwinden' (izgaranje 'Abbrennen' von izgarati 'abbrennen'); Rlj 'Restgruppe' z.B. (iscrpljenje 'Ausschöpfen' von iscrpsti 'ausschöpfen');

Die Bedeutungsnuancen der Bedeutung R2 sind: R2a 'versehen mit einem neuen Gepräge' (ispunjenje 'Ausfüllen' von ispuniti 'ausfüllen'); R2b 'bei Anwendung eines chemischen oder physischen Verfahrens in den gewünschten Zustand bringen' (izmilanje 'Ausmahlen' von izmilati 'ausmahlen'); R2c 'anwenden einer bestimmten Prozedur an einem Lebewesen zur Erlangung des erwünschten Zustands' (izlečenje 'Ausheilen' von izlečiti 'ausheilen'); R2d 'ausführen einer Prozedur an einem Lebewesen' (iskaranje 'Ausschelten' von iskarati 'ausschelten'); R2e 'beseitigen des Unterschiedes' (izjednačenje 'Ausgleichen' von izjednačiti 'ausgleichen'); R2f 'erreichen des gewünschten Resultats durch geistige oder ähnliche Arbeit' (izračunavanje 'Ausrechnen' von izračunavati 'ausrechnen'); R2g 'ausschöpfen der Brauchbarkeit' (iskorištenje 'Ausnutzen' von iskoristiti 'ausnutzen');

Das Präfix na- kann in Zusammensetzung mit Verben in der 
Bedeutung (RI) 'stellen eines Gegenstandes auf einen anderen' und in (R2) der 'Augmentation' mit seinen jeweiligen Bedeutungsnuancen reihende Funktion ausüben. Die Bedeutungsnuancen der Bedeutung Rl sind: Rla 'auftragen' (namirisivanje 'Parfümieren' von namirisivati 'parfümieren'); Rlb 'treten auf, veranlassen, auf etwas zu treten' (naganjanje 'Antreiben' von naganjati 'an-, auftreiben'); Rld 'Restgruppe' z.B. (natočenje 'Eingiessen' von natočiti 'eingiessen');

Die Bedeutungsnuancen der Bedeutung $R 2$ sind: $R 2 a$ 'anhäufen, etwas in Menge tun' (nadodavanje 'Zufügen' von nadodavati 'zufügen'); $\mathrm{R} 2 \mathrm{~b}$ 'Nahrung in ausreichender Menge geben' (napajanje 'Tränken' von napajati 'tränken'); R2c 'anschwellen, zunehmen' (naticanje 'Anschwellen' von naticati 'anschwellen');

Das Präfix za- kann in Zusammensetzung mit Verben in der Bedeutung (RI) 'hinter etwas gehen' und in (R2) 'einen neuen Zustand einnehmen' mit seinen jeweiligen Bedeutungsnuancen sowie in der Bedeutung (R3) 'eine Handlung beginnen' (z.B. zastrašavanje 'Abschrecken' von zastrašavati 'abschrecken') reihende Funktion ausüben. Die Bedeutungsnuancen der Bedeutung Rl sind: Rla 'umdrehen' (zasukivanje 'Aufkrempeln' von zasukivati 'aufkrempeln'); RIb 'umfassen eines Teils oder des Ganzen' (zagrtanje 'Umhängen' von zagrtati 'umhängen'); Rlc 'unter die Oberfläche, hinter die Grenze der Sichtbarkeit gehen' (zaranjanje 'Eintauchen' von zaranjati 'eintauchen'); Rld 'an einem sicheren Ort aufbewahren (abstrakt)' (zapamćenje 'Erinnern' von zapamtiti 'erinnern'); Rle 'Nahrung aufnehmen' (zadajanje 'Säugen, Stillen' von zadajati 'säugen, stillen'); Rlf 'verschliessen und hindern' (zalemljavanje 'Verlöten' von zalemljavati 'verlöten'); Rlg 'schützen und nicht erlauben' (zabranjivanje 'Verbieten' von zabranjivati 'verbieten') Rlh 'töten, vernichten' (zagušavanje 'Erwürgen' von zagušavati 'erwürgen'); Rli 'Restgruppe' z.B. (zamahivanje 'Aushohlen' von zamahivati 'aushohlen');

Die Bedeutungsnuancen der Bedeutung $R 2$ sind: $R 2 a$ 'verweilen, eine Stellung einnehmen' (zanoćavanje 'Ubernachten' von zanoćavati 'übernachten'); $R 2 b$ 'versehen mit einer neuen Eigenschaft' (zamršavanje 'Verwirren' von zamršavati 'verwirren'); R2c 'überführen des Objekts in einen neuen Zustand' (zapopljenje 'Ordinieren' von zapopiti 'ordinieren'). 


\section{Material}

1. Nomina actionis im engeren Sinne

A. Lexikalische Funktion

AA. Nomina actionis im engeren Sinne von Verben mit dem Präfix. do- in lexikalischer Funktion

Die Ableitungsverfahren: I. Suffigierung, II. Konversion

Die wortbildenden Typen nach ihren Formantien, ihrer Produktirität und den Bedeutungen der Präfixe der ableitenden Verben mit ihrer Häufigkeit:

Maskulina: I. -aj (2), Bed.: L3 (2), II. -HK-Ø (2l), Bed.: LI (7), L2 (1), L3 (13)

Feminina: I. - bin(a) (1), Bed.: LI (1), II. -HK-a (3), Bed.:

$$
\text { L3 (1), L4 (2) }
$$

Die Ableitungsstämme und die Konjugationen:

Maskulina: I. 1. Grundstamm der 5. Konjugation

II. 4., 5., 2., 3. Konjugation

Feminina: I. 1. Grundstamm der 4. Konjugation, II. 4. Konjugation Der Aspekt der Ableitungsbasis:

Maskulina: I. 2 ipf. Verben, II. 12 pf. und 9 ipf. Verben

Feminina: I. 1 pf. Verb, II. 3 pf. Verben

Maskulina

I. Suffigierung

Ableitungen mit dem Formans - aj

Bed.: L3, b) vom ipf. Aspekt, 1. vom Grundstamm, der 5. Konjugation

domašaj 'Reichweite', doticaj 'Berühren'

\section{Konversion}

Ableitungen auf $-\mathrm{HK}-\varnothing$

Bed.: LI, a) vom pf. Aspekt, der 4. Konjugation doskok 'Ansprung, der letzte Teil des Sprungs'

b) vom ipf. Aspekt, der 4. Konjugation

dogon 'Zutrieb', dohod 'Ankommen, Ankunft; Ertrag, Einkonmen', donos 'Herbeibringung', dovod 'Zuleitung', dovoz 'Zufuhr, Anfuhr'

der 5. Konjugation

dolet 'An-, Zuflug'

Bed.: L2, b) vom ipf. Aspekt, der 5. Konjugation 
doliv 'Zugiessen; Zugegossenes'

Bed.: L3, a) vom pf. Aspekt, der 4. Konjugation

doum 'Sinnen, Grübeln', dohvat 'Reichweite'

der 5. Konjugation

doček 'Empfang, Aufnahme', dogled 'Sehweite; Fernglas',

dokaz 'Beweisen, Beweis', dovik 'Rufweite'

der 2: Konjugation

domah 'Reichweite', domet 'Schussweite', doseg 'Tragweite', dostig 'Erreichen'

der 3. Konjugation

dovid 'Sehweite'

b) vom ipf. Aspekt, der 5. Konjugation

dodir 'Berürren, Berührung', doziv 'Zurufen, Zuruf'

Feminina

I. Suffigierung

Ableitungen mit dem Formans -bin(a)

Bed.: LI, a) vom pf. Aspekt, 1. vom Grundstamm, der 4. Konjugation doseobina (veralt.) 'Ansiedlung, Einwanderung'

II. Konversion

Ableitungen auf $-\mathrm{HK}-\mathrm{a}$

Bed.: L3, a) vom pf. Aspekt, der 4. Konjugation

dojava 'Benachrichtigen; Benachrichtigung'

Bed.: L4, a) vom pf. Aspekt, der 4. Konjugation dodela 'Zuteilen', dostava 'Ubermitteln, Zustellung'

AB. Nomina actionis im engeren Sinne von Verben mit dem Präfix iz- in lexikalischer Funktion

Die Ableitungsverfahren: I. Suffigierung, II. Konversion

Die wortbildenden Typen nach ihren Formantien, ihrer Produktivität und den Bedeutungen der Präfixe der ableitenden Verben mit ihrer Häufigkeit:

Maskulina: 1. $-a j$ (3), Bed.: Ll (3)

$$
\text { II. }- \text { HK- } \varnothing \text { (18), Bed.: LI (17), L2 (1) }
$$

Feminina: I. $-b(a)(1)$, Bed.: Ll (l), $-n_{j}(a)$ (l), Bed.: Il (l)

$$
\text { II. }-H K-a(1) \text {, Bed.: Ll (1) }
$$

Die Ableitungsstämme und die Konjugationen:

Maskulina: I. 1. Grundstamm der 4., 5. Konjugationowski-9783954793105 
II. 4., 1., 5., 2., 3. Konjugation

Feminina: I. 1. Grundstamm der 4. Konjugation

II. 4. Konjugation

Der Aspekt der Ableitungsbasis:

Maskulina: I. 3 pf. Verben, II. 14 pf. und 4 ipf. Verben Feminina: I. 2 pf. Verben, II. 1 pf. Verb

Maskulina

I. Suffigierung

Ableitungen mit dem Formans - aj

Bed.: LI, a) vom pf. Aspekt, 1. vom Grundstamm, der 5. Konjugation iskrcaj 'Ausladen'

der 4. Konjugation

izbačaj 'Zuwurf', ispraćaj 'Abschiedsbegleitung'

II. Konversion

Ableitungen auf $-\mathrm{HK}-\varnothing$

Bed.: LI, a) vom pf. Aspekt, der 4. Konjugation

izgovor 'Aussprache', iskok 'Sprung (Sprung auf der Stelle aus dem wasser in die Höhe)', iskup 'Zurückkaufen; Geld mit dem etwas zurückgekauft wird', istovar 'Ausladung', istup 'Vorgehen'

der 1. Konjugation

ispad 'Ausfall', istek 'Ablauf', istok 'Herausfliessen'

der 5. Konjugation

iskaz 'Aussage', iskop 'Ausgraben; Ausgrabungsort'

der 2. Konjugation

izdah 'Herauslassen der Luft; Aushauchen des Geistes, Verscheiden', izmah 'der letzte Teil des Schwunges'

der 3. Konjugation

izlet 'Herausfliegen; Ausflug'

b) vom ipf. Aspekt, der 4. Konjugation

izgon 'Vertreibung', iznos 'Hinaustragen; Betrag', izvoz

'Ausfuhr, Export', ishod 'Aufgang (Sonne); Ende, Ergebnis'

Bed.: L2, a) vom pf. Aspekt, der 5. Konjugation

izbor 'Auswählen, Wahl'

Feminina

I. Suffigierung

Ableitungen mit dem Formans $-b(a)$

Bed.: Ll, a) vom pf. Aspekt, l. vom Grundstamm, der 4. Konjugation 
iselidba (zast.) 'Aussiedlung, Auswanderung'

Ableitungen mit dem Formans $-n j(a)$

Bed.: Ll, a) vom pf. Aspekt, l. vom Grundstamm, der 4. Konjugation ispratnja 'Abschiedsbegleitung'

II. Konversion

Ableitungen auf $-\mathrm{HK}-\mathrm{a}$

Bed.: Ll, a) vom pf. Aspekt, der 4. Konjugation istraga 'Untersuchung'

AC. Nomina actionis im engeren Sinne von Verben mit dem Präfix na- in lexikalischer Funktion

Die Ableitungsverfahren: I. Suffigierung, II. Konversion

Die wortbildenden Typen nach ihren Formantien, ihrer Produktivität und den Bedeutungen der Präfixe der ableitenden Verben mit ihrer Häufigkeit:

Maskulina: I. -aj (3), Bed.: LI (3), -ak (3), Bed.: LI (3)

$$
\text { II. }-\mathrm{HK}-\varnothing(7), \text { Bed. : LI (7) }
$$

Feminina: I. $-i c(a)$ (1), Bed.: LI (1)

$$
\text { II. }-H K-a \text { (3), Bed.: LI (3), -WK-a (1), Bed.: II (1) }
$$

Die Ableitungsstämme und die Konjugationen:

Maskulina: I. 1. Grundstamm der 5., 4., 2. Konjugation

II. 1., 4., 2., 3., 5. Konjugation

Feminina: I. 1. Grundstamm der 4. Konjugation

II. 4., 2. Konjugation

Der Aspekt der Ableitungsbasis:

Maskulina: I. 1 pf. und 5 ipf. Verben, II. 5 pf. und 2 ipf. Verben Feminina: I. 1 pf. Verb, II. 4 pf. Verben

Maskulina

I. Suffigierung

Ableitungen mit dem Formans -aj

Bed.: Ll, a) vom pf. Aspekt, 1. vom Grundstamm, der 2. Konjugation nategljaj (neob.) 'Schluck'

b) vom ipf. Aspekt, 1. vom Grundstamm, der 5. Konjugation nasrtaj 'Angriff', navrtaj 'Drehung, Wendung' 
Ableitungen mit dem Formans -ak

Bed.: Il, b) vom ipf. Aspekt, 1. vom Grundstamm, der 5. Konjugation

nalivak 'An-, Aufguss', nametak 'Aufsetzen; Aufsatz, Auflage' der 4. Konjugation nailazak 'Treffen, Antreffen'

1I. Konversion

Ableitungen auf $-\mathrm{HK}-\varnothing$

Bed.: Ll, a) vom pf. Aspekt, der 4. Konjugation naskok 'Anfall'

der 1. Konjugation naliv 'An-, Aufguss', napad 'Angriff'

der 2. Konjugation nateg 'Schleppen eines Bootes bis zum Anker; Heber'

der 3. Konjugation nalet 'Entgegenfliegen, Finden im Flug'

b) vom ipf. Aspekt, der 5. Konjugation nasrt 'Angriff', nalev 'An-, Aufguss'

Feminina

1. Suffigierung

Ableitungen mit dem Formans -ic(a)

Bed.: Ll, a) vom pf. Aspekt, 1. vom Grundstamm, der 4. Konjugation navalica 'Zulauf'

\section{I. Konversion}

Ableitungen auf $-\mathrm{HK}-\mathrm{a}$

Bed.: Ll, a) vom pf. Aspekt, der 4. Konjugation najezda 'Anfallen', navala 'Angriff'

der 2. Konjugation nameta (nar. med.) 'Wundinfektion'

Ableitungen auf $-W K-a$

Bed.: Il, a) vom pf. Aspekt, der 4. Konjugation nabača (prazn.) 'was jemandem durch Zauberei bestimmt ist' 
AD. Nomina actionis im engeren Sinne von Verben mit dem Präfix za- in lexikalischer Funktion

Die Ableitungsverfahren: I. Suffigierung, II. Konversion

Die wortbildenden Typen nach ihren Formantien, ihrer Produktivität und den Bedeutungen der Präfixe der ableitenden Verben mit ihrer Häufigkeit:

Maskulina: I. -aj (3), Bed.: Ll (2), L2 (1), -ak (3), Bed.: Ll

$$
\begin{aligned}
& \text { (1), L4 (2), II. -HK- } \varnothing \text { (9), Bed.: Ll (7), L2 (1), } \\
& \text { L3 (1), -WK- } \varnothing \text { (1), Bed.: L4 (1) }
\end{aligned}
$$

Feminina: I. $-b(a)$ (1), Bed.: II (1), -ic(a) (1), Bed.: L2 (1),

$$
-k(a)(1), \text { Bed.: L4 (1) }
$$

Die Ableitungsstämme und die Konjugationen:

Maskulina: I. 1. Grundstamm der 5., 3., 4. Konjugation

$$
\text { II. 4., 5., 1., 2. Konjugation }
$$

Feminina: I. 1. Grundstamm der 5., 4., 3. Konjugation

Der Aspekt der Ableitungsbasis:

Maskulina: I. 2 pf. und 4 ipf. Verben, II. 5 pf. und 5 ipf. Verben Feminina: I. 1 pf. und 2 ipf. Verben

Maskulina

I. Suffigierung

Ableitungen mit dem Formans - aj

Bed.: Ll, b) vom ipf. Aspekt, 1. vom Grundstamm, der 5. Konjugation zakretaj 'Umdrehen'

der 3. Konjugation

zavrtaj 'Drehung'

Bed.: L2, a) vom pf. Aspekt, 1. vom Grundstamm, der 1. Konjugation zapletaj 'Verwicklung, Verflechtung'

Ableitungen mit dem Formans -ak

Bed.: LI, b) vom ipf. Aspekt, 1. vom Grundstamm, der 4. Konjugation

zalazak 'Untergang (Sonne); Umweg, Irrweg'

Bed.: L4, a) vom pf. Aspekt, 1. vom Grundstamm, der 5. Konjugation zastanak 'Anhalten, Stehenbleiben; Ruheort'

b) vom ipf. Aspekt, 1. vom Grundstamm, der 5. Konjugation zastajak (indiv.) 'Stehenbleiben, Halten'

II. Konversion 
Ableitungen auf $-\mathrm{HK}-\varnothing$

Bed.: Ll, a) vom pf. Aspekt, der 1. Konjugation zabod 'Stich', zapad 'Untergang der Sonne; Westen'

der 2. Konjugation

zateg 'Spannung'

b) vom ipf. Aspekt, der 4. Konjugation

zagon 'Anlauf, 2. (pokr.) Gerüst zum Bändigen einer Kuh', zahod 'Untergang; Westen; Abort', zalaz 'Untergang (Sonne); Umweg, Irrweg'

der 5. Konjugation zavrt 'Drehung'

Bed.: L2, a) vom pf. Aspekt, der 1. Konjugation zaplet 'Verwicklung, Verflechtung'

Bed.: L3, a) vom pf. Aspekt, der 4. Konjugation zamlad 'Vernarben'

Ableitungen auf $-W K-\varnothing$

Bed.: L4, b) vom ipf. Aspekt, der 5. Konjugation zastoj 'Stocken; Stauung'

Feminina

I. Suffigierung

Ableitungen mit dem Formans $-b(a)$

Bed.: Il, b) vom ipf. Aspekt, 1. vom Grundstamm, der 4. Konjugation

zahodba (nar. pesn.) 'Untergang (Sonne, Mond)'

Ableitungen mit dem Formans -ic(a)

Bed.: L2, b) vom ipf. Aspekt, 1. vom Grundstamm, der 5. Konjugation

zapletavica 'Verwicklung, Verflechtung'

Ableitungen mit dem Formans $-k(a)$

Bed.: L4, a) vom pf. Aspekt, 1. vom Grundstamm, der 3. Konjugation zadrška 'Ab-, Auf-, Zurückhalten' 
B. Modifizierende Funktion

BA. Nomina actionis im engeren Sinne von Verben mit dem Präfix do- in modifizierender Funktion

Die Ableitungsverfahren: I. Suffigierung, II. Konversion

Die wortbildenden Typen nach ihren Formantien, ihrer Produktivität und den Bedeutungen der Präfixe der ableitenden Verben mit ihrer Häufigkeit:

Maskulina: I. -ak (1), Bed.: MI (1), II. -HK- $\varnothing$ (2), Bed.: MI (2)

Feminina: I. $-k(a)$ (1), Bed.: MI (1), $-n j(a)(1)$, Bed.: Ml (1)

$$
\text { II. }-\mathrm{HK}-\mathrm{a} \text { (3), Bed.: MI (3) }
$$

Die Ableitungsstämme und die Konjugationen:

Maskulina: I. 1. Grundstamm der 4. Konjugation

II. 4., 5. Konjugation

Feminina: I. 1. Grundstamm der 4. Konjugation, II. 4. Konjugation

Der Aspekt der Ableitungsbasis:

Maskulina: I. 1 pf. Verb, II. 2 ipf. Verben

Feminina: I. 2 pf. Verben, II. 3 pf. Verben

Maskulina

I. Suffigierung

Ableitungen mit dem Formans -ak

Bed.: MI, a) vom pf. Aspekt, 1. vom Grundstamm, der 4. Konjugation doradak 'Aufarbeiten; Aufgearbeitetes'

II. Konversion

Ableitungen auf $-\mathrm{HK}-\varnothing$

Bed.: Ml, b) vom ipf. Aspekt, der 5. Konjugation dogar 'Abbrennen'

der 4. Konjugation doprinos 'Beitrag'

Feminina

I. Suffigierung

Ableitungen mit dem Formans $-k(a)$

Bed.: M1, a) vom pf. Aspekt, 1. vom Grundstamm, der 4. Konjugation dopravka 'Vollführung'

Ableitungen mit dem Formans $-n j(a)$

Bed.: MI, a) vom pf. Aspekt, 1. vom Grundstamm, der 4. Konjugation dogradnja 'Aus-, Zuendearbeiten' 
II. Konversion

Ableitungen auf $-\mathrm{HK}-\mathrm{a}$

Bed.: $M I$, a) vom pf. Aspekt, der 4. Konjugation

dograda 'Zuendebauen; Ausbau', dohrana 'Ernähren; Nahrung', dorada 'Ausarbeiten'

BB. Nomina actionis im engeren Sinne von Verben mit dem Präfix iz- in modifizierender Funktion

Die Ableitungsverfahren: I. Suffigierung, II. Konversion

Die wortbildenden Typen nach ihren Formantien, ihrer Produktivität und den Bedeutungen der Präfixe der ableitenden Verben mit ihrer Häufigkeit:

Maskulina: I. -ak (1), Bed.: MI (1), II. - HK- $\varnothing$ (1), Bed.: MI (1)

Feminina: I. $-b(a)(1)$, Bed.: MI (1), $-n j(a)$ (1), Bed.: MI (1)

II. $-\mathrm{HK}-\mathrm{a}$ (1), Bed.: MI (1)

Die Ableitungsstämme und die Konjugationen:

Maskulina: I. 1. Grundstamm der 4. Konjugation

II. 4. Konjugation

Feminina: I. 1. Grundstamm der 4. Konjugation

II. 4. Konjugation

Der Aspekt der Ableitungsbasis:

Maskulina: I. 1 ipf. Verb, II. I pf. Verb

Feminina: I. 2 pf. Verben, II. 1 pf. Verb

Maskulina

I. Suffigierung

Ableitungen mit dem Formans -ak

Bed.: MI, b) vom ipf. Aspekt, 1. vom Grundstamm, der 4. Konjugation

\section{iznalazak 'Erfinden'}

II. Konversion

Ableitungen auf $-\mathrm{HK}-\varnothing$

Bed.: MI, a) vom pf. Aspekt, der 4. Konjugation ispros 'Freien, Erbitten'

Feminina

I. Suffigierung 
Ableitungen mit dem Formans $-b(a)$

Bed.: MI, a) vom pf. Aspekt, 1. vom Grundstamm, der 4. Konjugation izradba 'Erarbeiten'

Ableitungen mit dem Formans - $n j(a)$

Bed.: M1, a) vom pf. Aspekt, 1. vom Grundstamm, der 4. Konjugation izgradnja 'Erbauen; Bau'

II. Konversion

Ableitungen auf $-\mathrm{HK}-\mathrm{a}$

Bed.: MI, a) vom pf. Aspekt, der 4. Konjugation

izrada 'Ausarbeiten, Erarbeiten'

BC. Nomina actionis im engeren Sinne von Verben mit dem Präfix na- in modifizierender Funktion

Die Ableitungsverfahren: I. Suffigierung

Die wortbildenden Typen nach ihren Formantien, ihrer Produktivität und den Bedeutungen der Präfixe der ableitenden Verben mit ihrer Häufigkeit:

Maskulina: I. -ak (1), Bed.: MI (1)

Die Ableitungsstämme und die Konjugationen:

Maskulina: I. 1. Grundstamm der 5. Konjugation

Der Aspekt der Ableitungsbasis:

Maskulina: I. 1 pf. Verb

Maskulina

I. Suffigierung

Ableitungen mit dem Formans -ak

Bed.: MI, a) vom pf. Aspekt, 1. vom Grundstamm, der 5. Konjugation natisak 'Vollstopfen'

BD. Nomina actionis im engeren Sinne von Verben mit dem Präfix za- in modifizierender Funktion

Die Ableitungsverfahren: I. Suffigierung, II. Konversion

Die wortbildenden Typen nach ihren Formantien, ihrer Produktivi- 
tät und den Bedeutungen der Präfixe der ableitenden Verben mit ihrer Häufigkeit:

Maskulina: I. -aj (5), Bed.: MI (5), -ak (1), Bed.: MI (1)

$$
\text { II. }-\mathrm{HK}-\varnothing(5), \text { Bed.: MI (5) }
$$

Feminina: I. $-i j(a)$ (1), Bed.: MI (1)

Die Ableitungsstämme und die Konjugationen:

Maskulina: I. 1. Grundstamm der 5. Konjugation

$$
\text { II. 2., 5. Konjugation }
$$

Feminina: I. 1. Grundstamm der 4. Konjugation

Der Aspekt der Ableitungsbasis:

Maskulina: I. 5 pf. und 1 ipf. Verb, II. 4 pf. und 1 ipf. Verb

Feminina: I. 1 pf. Verb

Maskulina

I. Suffigierung

Ableitungen mit dem Formans - aj

Bed.: Ml, a) vom pf. Aspekt, 1. vom Grundstamm, der 5. Konjugation zadrhtaj 'Erbeben', zakašljaj 'Husten', zaljuljaj 'Anschaukeln', zaveslaj 'Schwung mit dem Ruder bei der Fahrt'

b) vom ipf. Aspekt, 1. vom Grundstamm, der 5. Konjugation zapuhaj 'Windstoss'

Ableitungen mit dem Formans -ak

Bed.: $M 1$, a) vom pf. Aspekt, l. vom Grundstamm, der 5. Konjugation zamucak (indiv.) 'Stotternanfangen'

\section{Konversion}

Ableitungen auf $-H K-\varnothing$

Bed.: MI, a) vom pf. Aspekt, der 2. Konjugation zažeg (pokr.) 'Anzünden'

der 5. Konjugation

zahuk 'Anhauchen', zakop (pokr.) 'ein Griff beim Graben mit dem Spaten oder der Hacke; Beerdigung; Loch', zapev (muz.)

'Ausruf am Anfang des Textes, den man singt'

b) vom ipf. Aspekt, der 5. Konjugation

zapuh 'Windstoss; Schneewehe'

Feminina

I. Suffigierung

Ableitungen mit dem Formans - $i j(a)$

Bed.: MI, a) vom pf. Aspekt, 1. vom Grundstamm, der 4. Konjugation zaorija (indiv.) 'Anblasen (Horn)' 
C. Rein perfektivierende Funktion

CB. Nomina actionis im engeren Sinne von Verben mit dem Präfix iz- in rein perfektivierender Funktion

a) $\underline{i z}-$ als reihendes Präfix

Die Ableitungsverfahren: I. Suffigierung, II. Konversion

Die wortbildenden Typen nach ihren Formantien, ihrer Produktivität und den Bedeutungen der Präfixe der ableitenden Verben mit ihrer Häufigkeit:

Maskulina: I. -aj (2), Bed.: R2a (1), R2d (1)

$$
\text { II. }-\mathrm{HK}-\varnothing(4), \operatorname{Bed} .: \operatorname{Rlj}(2), \mathrm{R} 2 \mathrm{a} \text { (1), R2e (1) }
$$

Feminina: I. $-b(a)$ (2), Bed.: Rif (1), R2e (1)

II. $-W K-\varnothing$ (1), Bed.: RIj (1), $-\mathrm{HK}-\mathrm{a}(6), \operatorname{Bed} .: \mathrm{RIj}$ (1), R2a (3), R2c (1), R2e (1)

Die Ableitungsstämme und die Konjugationen:

Maskulina: I. 1. Grundstamm der 4., 5. Konjugation

II. 1., 4. Konjugation

Feminina: I. 1. Grundstamm der 4. Konjugation

II. 4., 1. Konjugation

Der Aspekt der Ableitungsbasis:

Maskulina: I. 2 pf. Verben, II. 4 pf. Verben

Feminina: I. 2 pf. Verben, II. 7 pf. Verben

Maskulina

I. Suffigierung

Ableitungen mit dem Formans - $a j$

Bed.: R2a, a) vom pf. Aspekt, 1. vom Grundstamm, der 4. Konjugation

\section{ispunjaj 'Ausfüllen'}

Bed.: R2d, a) vom pf. Aspekt, 1. vom Grundstamm, der 5. Konjugation

iskušaj 'Versuchen, Erproben'

II. Konversion

Ableitungen auf $-\mathrm{HK}-\varnothing$

Bed.: Rlj, a) vom pf. Aspekt, der 1. Konjugation izbeg 'Fliehen', ispon 'Hervorwölbung'

Bed.: R2a, a) vom pf. Aspekt, der 4. Konjugation izmor 'Ermüden, Ermatten'

Bed.: R2e, a) vom pf. Aspekt, der 4. Konjugation izmir 'Aussöhnung' 
Feminina

I. Suffigierung

Ableitungen mit dem Formans - $b(a)$

Bed.: Rlf, a) vom pf. Aspekt, 1. vom Grundstamm, der 4. Konjugation

izludžba 'Ab-, Aussonderung'

Bed.: R2e, a) vom pf. Aspekt, 1. vom Grundstamm, der 4. Konjugation

izmirba 'Aussöhnung'

II. Konversion

Ableitungen auf $-W K-\varnothing$

Bed.: Rlj, a) vom pf. Aspekt, der I. Konjugation ispomoć 'Aushelfen'

Ableitungen auf $-\mathrm{HK}-\mathrm{a}$

Bed.: Rlj, a) vom pf. Aspekt, der l. Konjugation ispaša 'Weiden; Weideort'

Bed.: R2a, a) vom pf. Aspekt, der 4. Konjugation izjava 'Erklärung, Deklaration', izmena 'Abändern', ispuna 'Ausfüllen'

Bed.: R2c, a) vom pf. Aspekt, der 4. Konjugation ishrana 'Ernährung'

Bed.: R2e, a) vom pf. Aspekt, der 4. Konjugation izmira 'Aussöhnung'

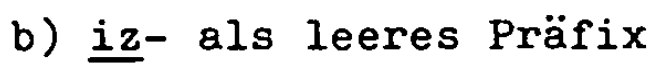

Die Ableitungsverfahren: I. Suffigierung, II. Konversion Die wortbildenden Typen nach ihren Formantien sowie ihre Produktivität:

Maskulina: I. -ak (1), II. $-H K-\varnothing$ (I)

Feminina: I. -b(a) (2), II. - HK-a (1)

Die Ableitungsstämme und die Konjugationen:

Maskulina: I. 1. Grundstamm der 4. Konjugation

II. 4. Konjugation

Feminina: I. 1. Grundstamm der 4. Konjugation

II. 4. Konjugation

Der Aspekt der Ableitungsbasis: 
Maskulina: I. 1 pf. Verb, II. I pf. Verb

Feminina: I. 2 pf. Verben, II. 1 pf. Verb

Maskulina

I. Suffigierung

Ableitungen mit dem Formans -ak

a) vom pf. Aspekt, 1. vom Grundstamm, der 4. Konjugation izvršetak 'Aus-, Vollführung'

II. Konversion

Ableitungen auf $-\mathrm{HK}-\varnothing$

a) vom pf. Aspekt, der 4. Konjugation iskup 'Versammlung'

Feminina

I. Suffigierung

Ableitungen mit dem Formans $-b(a)$

a) vom pf. Aspekt, 1. vom Grundstamm, der 4. Konjugation

izvržba 'Ausführung, Vollstreckung', isporedba 'Vergleichen'

II. Konversion

Ableitungen auf $-\mathrm{HK}-\mathrm{a}$

a) vom pf. Aspekt, der 4. Konjugation

isplata 'Auszahlung'

CC. Nomina actionis im engeren Sinne von Verben mit dem Präfix na- in rein perfektivierender Funktion

a) na- als reihendes Präfix

Die Ableitungsverfahren: I. Suffigierung, II. Konversion

Die wortbildenden Typen nach ihren Formantien, ihrer Produktivität und den Bedeutungen der Präfixe der ableitenden Verben mit ihrer Häufigkeit:

Maskulina: I. -ak (2), Bed.: Rlb (1), R2c (1)

$$
\begin{aligned}
& \text { II. }-\mathrm{HK}-\varnothing \text { (8), Bed.: RIb (2), RId (1), R2a (1), R2c } \\
& \text { (4), -WK- } \varnothing \text { (2), Bed.: R2a (1), R2c (1) }
\end{aligned}
$$

Feminina: I. $-i c(a)$ (3), Bed.: Rlb (1), R2a (1), R2c (1), -nj(a)

$$
\text { (1), Bed.: R2a (1), II. -HK-a (1), Bed.: R2a (1) }
$$

Die Ableitungsstämme und die Konjugationen: 
Maskulina: I. 1. Grundstamm der 4. Konjugation II. 4., 1., 5. Konjugation

Feminina: I. 1. Grundstamm der 4. Konjugation, 2. Stamm des Partizip Präteritum Aktiv der 5. Konjugation II. 4. Konjugation

Der Aspekt der Ableitungsbasis:

Maskulina: I. 1 pf. und 1 ipf. Verb, II. 7 pf. und 3 ipf. Verben Feminina: I. 2 pf. und 2 ipf. Verben, II. 1 pf. Verb

Maskulina

I. Suffigierung

Ableitungen mit dem Formans -ak

Bed.: Rlb, a) vom pf. Aspekt, 1. vom Grundstamm, der 4. Konjugation

$$
\text { nastupak 'Auftritt' }
$$

Bed.: R2c, b) vom ipf. Aspekt, 1. vom Grundstamm, der 4. Konjugation

$$
\text { nadolazak 'Steigen (Wasser)' }
$$

\section{Konversion}

Ableitungen auf $-\mathrm{HK}-\varnothing$

Bed.: Rlb, a) vom pf. Aspekt, der 4. Konjugation nastup 'Auftritt'

b) vom ipf. Aspekt, der 4. Konjugation nagon 'Zutrieb (Schweine zur Mast); Antrieb'

Bed.: Rld, a) vom pf. Aspekt, der 4. Konjugation naklon 'Neigen'

Bed.: R2a, a) vom pf. Aspekt, der 4. Konjugation nasad 'Anpflanzen, Anpflanzung'

Bed.: R2c, a) vom pf. Aspekt, der 1. Konjugation nadam 'Blähung', narast (pokr.) 'Anwachsen, Zunehmen'

b) vom ipf. Aspekt, der 5. Konjugation nadim (indiv.) 'Blähung, Luftansammlung', navir (knjiž.) 'Aufwallen, Aufsieden'

Ableitungen auf $-W K-\varnothing$

Bed.: R2a, a) vom pf. Aspekt, der 1. Konjugation nažanj 'Einschnitt, Ernte'

Bed.: R2c, a) vom pf. Aspekt, der 4. Konjugation nagnoj 'Eitern' 
Feminina

\section{Suffigierung}

Ableitungen mit dem Formans -ic(a)

Bed.: Rlb, b) vom ipf. Aspekt, 1. vom Grundstamm, der 4. Konjugation

\section{nagonica 'Antrieb zur Mast'}

Bed.: R2a, b) vom ipf. Aspekt, 2. vom Stamm des Partizip Präteritum Aktiv, der 5. Konjugation

naklapalica 'Plaudern'

Bed.: R2c, a) vom pf. Aspekt, 1. vom Grundstamm, der 4. Konjugation

$$
\text { naježica 'Schaudern' }
$$

Ableitungen mit dem Formans - $n j(a)$

Bed.: R2a, a) vom pf. Aspekt, 1. vom Grundstamm, der 4. Konjugation

$$
\text { nadogradnja 'Zubauen; Zugebautes' }
$$

\section{Konversion}

Ableitungen auf $-\mathrm{HK}-\mathrm{a}$

Bed. R2a, a) vom pf. Aspekt, der 4. Konjugation nadopuna 'Ergänzung'

b) na- als leeres Präfix

Die Ableitungsverfahren: I. Suffigierung, II. Konversion Die wortbildenden Typen nach ihren Formantien sowie ihre Produktivität:

Maskulina: I. $-a j(5),-a k$ (2), II. $-H K-\varnothing$ (3)

Feminina: I. -ao (1), -ic(a) (3), -k(a) (1), II. $-\mathrm{HK}-\mathrm{a}$ (8)

Die Ableitungsstämme und die Konjugationen:

Maskulina: I. 1. Grundstamm der 4., 5., 2. Konjugation

$$
\text { II. 2. Konjugation }
$$

Feminina: I. 1. Grundstamm der 4., 5. Konjugation II. 4., 2. Konjugation

Der Aspekt der Ableitungsbasis:

Maskulina: I. 6 pf. und 1 ipf. Verben, II. 3 pf. Verben Feminina: I. 4 pr. und 1 ipf. Verb, II. 8 pf. Verben 
Maskulina

I. Suffigierung

Ableitungen mit dem Formans - aj

a) vom pf. Aspekt, 1. vom Grundstamm, der 4. Konjugation nadražaj 'Reiz', namišljaj 'Vorhaben, Absicht', naslućaj (neob.) 'Erahnen'

der 2. Konjugation namigaj 'Zublinzeln'

b) vom ipf. Aspekt, 1. vom Grundstamm, der 5. Konjugation naprezaj (neob.) 'Anspannung'

Ableitungen mit dem Formans -ak

a) vom pr. Aspekt, 1. vom Grundstamm, der 4. Konjugation naputak 'Hinweis', navršetak 'Verrichten, Ausüben'

II. Konversion

Ableitungen auf $-\mathrm{HK}-\varnothing$

a) vom pf. Aspekt, der 2. Konjugation

namig 'Augenwink', napomen 'Erwähnung, Anmerkung', napreg 'Anspannung'

Feminina

I. Suffigierung

Ableitungen mit dem Formans -ao

a) vom pf. Aspekt, l. vom Grundstamm, der 4. Konjugation namisao 'Vorhaben, Absicht'

Ableitungen mit dem Formans -ic(a)

a) vom pf. Aspekt, 1. vom Grundstamm, der 4. Konjugation nakanica 'Vornehmen', nasilica (pokr.) 'Gewalttat'

b) vom ipf. Aspekt, 1. vom Grundstamm, der 5. Konjugation natezavica 'angestrengter Stuhlgang'

Ableitungen mit dem Formans - $k(a)$

a) vom pf. Aspekt, I. vom Grundstamm, der 4. Konjugation nabavka 'Anschaffung' 
Ableitungen auf $-\mathrm{HK}-\mathrm{a}$

a) vom pf. Aspekt, der 4. Konjugation nabava 'Beschaffung', najava 'Bekanntmachen', nakana 'Vorhaben, Absicht', namira 'Befriedigung', nauka 'Lehre', naplata 'Bezahlen', naznaka 'Bezeichnen'

der 2. Konjugation napomena 'Erwähnung',

CD. Nomina actionis im engeren Sinne von Verben mit dem Präfix za- in rein perfektivierender Funktion

a) za- als reihendes Präfix

Die Ableitungsverfahren: I. Suffigierung, II. Konversion Die wortbildenden Typen nach ihren Formantien, ihrer Produktivität und den Bedeutungen der Präfixe der ableitenden Verben mit ihrer Häufigkeit:

Maskulina: I. $-a j$ (5), Bed.: Rlb (3), Rli (1), R3 (1), -ak (1), Bed.: Rla (1)

II. $-\mathrm{HK}-\varnothing$ (9), Bed.: Rla (2), RIb (3), Rld (1), RIh (1), RIi (1), R2b (1), -WK- Ø (1), Bed.: RIh (1)

Feminina: I. -ačin(a) (1), Bed.: Rlb (1), $-b(a)$ (1), Bed.: Rld

$$
\begin{aligned}
& \text { (1), }-i c(a)(1), \text { Bed.: Rlb (1), }-k(a)(1), \text { Bed.: } \\
& \text { RIb (1), }-\operatorname{nic}(a)(1), \operatorname{Bed}: \text { Rli (1) } \\
& \text { II. -HK-a (8), Bed.: Rlb (1), Rlf (1), Rlg (1), RIh } \\
& \text { (2), Rli (1), R2b (2) }
\end{aligned}
$$

Die Ableitungsstämme und die Konjugationen:

Maskulina: I. 1. Grundstamm der 4., 5., 2. Konjugation

II. 4., 5., 1., 2. Konjugation

Feminina: I. 1. Grundstamm der 5., 4., 2. Konjugation

II. 4., 5. Konjugation

Der Aspekt der Ableitungsbasis:

Maskulina: I. 5 pf. und 1 ipf. Verb, II. 10 pf. Verben Feminina: I. 3 pf. und 2 ipf. Verben, II. 8 pf. Verben Maskulina

I. Suffigierung

Ableitungen mit dem Formans -aj

Bed.: Rlb, a) vom pf. Aspekt, 1. vom Grundstamm, der 4. Konjugation 
der 5. Konjugation

začešljaj 'ein Griff mit dem Kamm durch das Haar', zapljuskaj 'Vollschlagen (von Wellen)'

Bed.: Rli, a) vom pr. Aspekt, 1. vom Grundstamm, der 2. Konjugation

zamahaj (pokr.) und zamašaj 'Schwung, schnelle Bewegung' Bed.: R3, a) vom pf. Aspekt, 1. vom Grundstamm, der 4. Konjugation

zastrašaj 'Abschrecken'

Ableitungen mit dem Formans -ak

Bed.: Rla, b) vom ipf. Aspekt, l. vom Grundstamm, der 4. Konjugation

zaobilazak 'Umgehen, einen Umweg machen'

II. Konversion

Ableitungen auf $-\mathrm{HK}-\varnothing$

Bed.: Rla, a) vom pf. Aspekt, der 4. Konjugation zavrat (pokr.) 'Rückkehr'

der 5. Konjugation

zasuk (fisk.) 'Drehen auf die eine oder andere Seite'

Bed.: Rlb, a) vom pf. Aspekt, der 4. Konjugation

zahvat 'Ergreifen'

der 5. Konjugation

zagled (etn.) 'Beschauen des Mädchens vor dem Freien',

zapljus 'Flüssigkeit, die einmal anspült'

Bed.: RId, a) vom pf. Aspekt, der 5. Konjugation

zapis 'Notiz'

Bed.: RIh, a) vom pf. Aspekt, der 4. Konjugation

zaguš (pokr.) 'Erwürgen'

Bed.: Rli, a) vom pf. Aspekt, der 2. Konjugation

zamah 'kräftige Bewegung, Schwung'

Bed.: R2b, a) vom pf. Aspekt, der 4. Konjugation

zabun 'Verlegenheit, Verwirrung'

Ableitungen auf $-W K-\varnothing$

Bed.: RIh, a) vom pf. Aspekt, der 1. Konjugation zakolj 'Schlachten' 


\section{Feminina}

I. Suffigierung

Ableitungen mit dem Formans -ačin(a)

Bed.: RIb, a) vom pf. Aspekt, 1. vom Grundstamm, der 5. Konjugation

$$
\text { zagledačina 'Mädchenschau, Beschauen' }
$$

Ableitungen mit dem Formans $-b(a)$

Bed.: Rld, a) vom pf. Aspekt, 1. vom Grundstamm, der 4. Konjugation

zabeležba 'Art der Aufzeichnung in Grundbücher'

Ableitungen mit dem Formans -ic(a)

Bed.: Rlb, b) vom ipf. Aspekt, 1. vom Grundstamm, der 5. Konjugation

$$
\text { zadjevica 'Streit' }
$$

Ableitungen mit dem Formans - $k(a)$

Bed.: Rlb, b) vom ipf. Aspekt, 1. vom Grundstamm, der 5. Konjugation

$$
\text { zadevka 'Streit, Zank' }
$$

Ableitungen mit dem Formans -nic(a)

Bed.: Rli, a) vom pf. Aspekt, 1. vom Grundstamm, der 2. Konjugation

zamajnica (indiv.) 'Schwung, schnelle Bewegung'

II. Konversion

Ableitungen auf $-\mathrm{HK}-\mathrm{a}$

Bed.: RIb, a) vom pf. Aspekt, der 4. Konjugation zaplena 'Plündern, Plünderung'

Bed.: Rlf, a) vom pf. Aspekt, der 4. Konjugation zaustava 'An-, Zurückhalten'

Bed.: RIg, a) vom pf. Aspekt, der 4. Konjugation zaštita 'Schützen, Schutz'

Bed.: RIh, a) vom pf. Aspekt, der 4. Konjugation 
zadava (nar.) 'Erwürgen'

dèr 5. Konjugation

zaduha 'Atemnot'

Bed.: Rli, a) vom pf. Aspekt, der 4. Konjugation zamena 'Eintauschen'

Bed.: R2b, a) vom pf. Aspekt, der 4. Konjugation zabuna 'Verlegenheit; Verwirrung'

der 5. Konjugation zastara 'Verjährung'

b) za- als leeres Präfix

Die Ableitungsverfahren: I. Suffigierung Die wortbildenden Typen nach ihren Formantien sowie ihre Produktivität:

Maskulina: I. $-a j$ ( 1 ), II. $-\mathrm{HK}-\varnothing$ (1)

Feminina: I. $-a l j k(a)(1),-k(a)$ (1), II. $-H K-a$ (I)

Die Ableitungsstämme und die Konjugationen:

Maskulina: I. 1. Grundstamm der 4. Konjugation

II. 5. Konjugation

Feminina: I. 1. Grundstamm der 5. Konjugation II. 4. Konjugation

Der Aspekt der Ableitungsbasis:

Maskulina: I. 1 pf. Verb, II. 1 ipf. Verb

Feminina: I. 2 ipf. Verben, II. 1 pf. Verb

Maskulina

I. Suffigierung

Ableitungen mit dem Formans - aj

a) vom pf. Aspekt, 1. vom Grundstamm, der 4. Konjugation zapažaj 'Bemerken'

II. Konversion

Ableitungen auf $-\mathrm{HK}-\varnothing$

b) vom ipf. Aspekt, der 5. Konjugation

zanovet 'Belästigung, Störung'

Feminina

I. Suffigierung

Ableitungen mit dem Formans -aljk(a)

b) vom ipf. Aspekt, 1. vom Grundstamm, der 5. Konjugation 
zavijaljka 'Heulen, Wimmern'

Ableitungen mit dem Formans $-k(a)$

b) vom ipf. Aspekt, 1. vom Grundstamm, der 5. Konjugation zanovetka 'Belästigung, Störung'

II. Konversion

Ableitungen auf $-\mathrm{HK}-\mathrm{a}$

a) vom pf. Aspekt, der 4. Konjugation zahvala 'Dank'

2. Verbalsubstantive

A. Lexikalische Funktion

AA. Verbalsubstantive von Verben mit dem Präfix do- in lexikalischer Funktion

Die Ableitungsverfahren: I. Suffigierung

Die wortbildenden Typen nach ihren Formantien, ihrer Produktivität und den Bedeutungen der Präfixe der ableitenden Verben mit ihrer Häufigkeit:

Neutra: I. $-n j(e)$ (65), Bed.: LI (26), L2 (12), L3 (23), L4 (4), -ćc(e) (3), Bed.: Ll (1), L3 (2)

Die Ableitungsstämme und die Konjugationen:

Neutra: I. 4. Stamm des Partizip Präteritum Passiv der 5., 6., 4., 2., 3., unregelmässigen Konjugation

Der Aspekt der Ableitungsbasis:

Neutra: I. 8 pf. und 60 ipf. Verben

Verbalsubstantive mit dem Formans $-n j(e)$, die durch den pf. und ipf. Aspekt des ableitenden Verbs motiviert sind: pf. dodeljenje - ipf. dodeljivanje 'Zuteilen', pf. dokučenje - ipf. dokučivar.je 'Dahinterkommen, Ergründen', pf. domišljenje - ipf. domišljanje 'Daraufkommen, Gelangen', pf. doseljenje - ipf. doseljavanje 'Ansiedeln', pf. doživljenje - ipf. doživljavanje 'Erleben'.

Keine Verbalsubstantive sind von folgenden Verben abgeleitet, von denen Substantive anderer wortbildender Kategorien 
abgeleitet sind: dobežati, dogledati, doterati, dovideti.

Verbalsubstantive mit dem Präfix do- haben ihre ursprüngliche Bedeutung weitgehend bewahrt. Lediglich das Substantiv dobacivanje 'Zuwerfen; Bemerkungen, Hohnruf' hat neben der ursprünglichen Bedeutung eine sekundäre abstrakte.

Ableitungen mit dem Formans $-n j(e)$

Bed.: Ll, a) vom pf. Aspekt, 4. vom Stamm des Partizip Präteritum Passiv, der 4. Konjugation

doseljenje 'Ansiedlung; Einwanderung'

der 3. Konjugation

doživljenje 'Erleben'

b) vom ipf. Aspekt, 4. vom Stamm des Partizip Präteritum Passiv, der 5. Konjugation

dohadjanje 'Herankommen', dokradanje 'Heranschleichen', doletanje 'Zu-, Heran-, Herbeifliegen', donašanje 'Zu-, Heran-, Herbeibringen', dopadanje 'Herbeieilen, Anstürzen', doperjavanje 'Dahergeflattertkommen', doseljavanje 'Ansiedeln, Einwanderung', doskakanje 'Herangesprungenkommen', dotjecanje 'Herbeifliessen', doturanje 'Herbeischieben', doživljavanje 'Erleben, Erfahren'

der 6. Konjugation

dobacivanje 'Zuwerfen; Bemerkungen, Hohnruf', dojahivanje 'Herbeireiten', doježdjivanje 'Herbeireiten', dokasivanje 'Heran-, Herbeitraben', dokaskivanje 'Herbeitrippeln', doplakivanje 'Weinendherbeikommen', doseljivanje

'Ansiedeln'

der 4. Konjugation

dogonjenje 'Herbeitreiben', dohodjenje 'Heran-, Daherkommen', donošenje 'Bringen, Herbeitragen', dovlačenje 'Heranziehen, Herbeischleppen', dovodjenje 'Herbei-, Zuführen', dovoženje 'Herbeifahren, Zufuhr'

Bed.: L2, b) vom ipf. Aspekt, 4. vom Stamm des Partizip Präteritum Passiv, der 5. Konjugation

dodavanje 'Hinzugeben, Hinzufügen', dogrtanje 'Hinzuschaufeln, Hinzuscharren', dolevanje 'Zu-, Vollgiessen', domeravanje 'Zuwiegen, Zumessen', donalevanje und donalivanje 'Zu-, Vollgiessen', dopunjavanje 'Ergänzen, Auffüllen', dosipanje 'Hinzuschütten', dotakanje 'Hinzugiessen' 
der 6. Konjugation

dokupljivanje 'Zukaufen', dolagivanje 'Zulügen', doplaćivanje 'Zuzahlen, Nachzahlen', dozidjivanje 'An-, Zubauen'

Bed.: L3, a) vom pf. Aspekt, 4. vom Stamm des Partizip Präteritum Passiv, der 4. Konjugation

dokučenje 'Dahinterkommen, Ergründen', domišljenje 'Daraufkommen, Gelangen'

b) vom ipf. Aspekt, 4. vom Stamm des Partizip Präteritum Passiv, der 5. Konjugation

dohvatanje 'Ergreifen', domašanje 'Erreichen, Erlangen', dometanje 'Erreichen, Erlangen (werfend, schiessend)', domišljanje 'Daraufkommen', dosećanje 'Sichentsinnen', dosezanje 'Erreichen', dosizanje 'Erreichen', dostizanje 'Erreichen, Einholen', došaptavanje 'Zu-, Einflüstern', doticanje 'Antasten, Berühren', dozivanje 'Herbeirufen' der 6. Konjugation

dočekivanje 'Erwarten, Empfangen', dodirivanje 'Berühren', dojavljivanje 'Benachrichtigen', dojekivanje 'Erlangen, Erreichen (vom Klang)', dokazivanje 'Beweisen, Beweis', dokučivanje 'Dahinterkommen, Ergründen', domahivanje 'Herbei-, Heranwinken', domamljivanje 'Herbeilocken', doslućivanje 'Erahnen', dovikivanje 'Herbeirufen; Zurufen'

Bed.: L4, a) vom pf. Aspekt, 4. vom Stamm des Partizip Präteritum Passiv, der 4. Konjugation

dodeljenje 'Zuteilen'

b) vom ipf. Aspekt, 4. vom Stamm des Partizip Präteritum Passiv, der 5. Konjugation

dostavljanje 'Ubermitteln, Mitteilen, Anzeigen'

der 6. Konjugation

dodeljivanje 'Zuteilen', dosudjivanje 'Zuerkennen, Zusprechen (Gericht)'

Ableitungen mit dem Formans - $\dot{c}(e)$

Bed.: Il, a) vom pf. Aspekt, 4. vom Stamm des Partizip Präteritum Passiv, der unregelmässigen Konjugation došašce 'Ankunft'

Bed.: L3, a) vom pf. Aspekt, 4. vom Stamm des Partizip Präteritum Passiv, der 2. Konjugation

dosegnuce 'Erreichen, Erlangen', dostignuće 'Erreichen' 
$A B$. Verbalsubstantive von Verben mit dem Präfix $\underline{\text { iz }}$ - in lexikalischer Funktion

Die Ableitungsverfahren: I. Suffigierung

Die wortbildenden Typen nach ihren Formantien, ihrer Produktivität und den Bedeutungen der Präfixe der ableitenden Verben mit ihrer Häufigkeit:

Neutra: I. $-n j(e)(80)$, Bed.: LI (75), L2 (5),

$$
\text { -ć(e) (7), Bed.: Il (6), I2 (1) }
$$

Die Ableitungsstämme und die Konjugationen:

Neutra: I. 4. Stamm des Partizip Präteritum Passiv der 5., 6., 4., 2., 1., unregelmässigen Konjugation

Der Aspekt der Ableitungsbasis:

Neutra: I. $15 \mathrm{pf}$. und 72 ipf. Verben

Lediglich durch ein pf. Verb motiviert ist: isplovljenje 'Hinausfahren'.

Verbalsubstantive mit dem Formans $-n j(e)$, die durch den pf. und ipf. Aspekt des ableitenden Verbs motiviert sind: pf. izdanje - ipf. izdavanje 'Herausgeben', pf. izopćenje - ipf. izopštivanje 'Exkommunizieren, Áchten', pf. iseljenje - ipf. iseljivanje 'Aussiedeln', pf. isparenje - ipf. isparavanje 'Verdunsten; Dampf', pf. istupljenje - ipf. istupanje 'Hervortreten; Auftreten'.

Verbalsubstantive, die durch den pf. und ipf. Aspekt des ableitenden Verbs motiviert sind, wobei das pf. Verbalsubstantiv auf -ćc(e) und das ipf. auf $-n j(e)$ endet: pf. izašašće - ipf. izilaženje und izlaženje 'Hinausgehen', pf. izmetnuće - ipf. izmetanje 'Aus-, Hinauswerfen', pf. izrinuce - ipf. izrivanje 'Auswühlen', pf. izuzeće - ipf. izuzimanje 'Aus-, Vorwegnehmen'.

Keine Verbalsubstantive sind von folgenden Verben abgeleitet, von denen Substantive anderer wortbildender Kategorien abgeleitet sind: isprašiti, isprositi, izveriti.

Zahlreiche Verbalsubstantive von Verben mit dem Präfix izweisen neben der ursprünglichen Bedeutung eine konkrete bzw. abstrakte auf, und zwar von pf. Verben: izdanje 'Herausgeben; Ausgabe', izgnanje 'Vertreiben; Verbannung', izopćenje 'Exkommunizierung; Acht', izašašće 'Ausgehen; Ausgang, Ergebnis', izuzéce 'Ausschliessung; Vorwegnahme, Befangenheit (Gericht)' und von ipf. Verben: izdisanje 'Ausatmen; Veratmen, Sterben', iskazivanje 'Aussagen; Aussage'. 
Ableitungen mit dem Formans $-n j(e)$

Bed.: Ll, a) vom pf. Aspekt, 4. vom Stamm des Partizip Präteritum Passiv, der 4. Konjugation

iseljenje 'Ausziehen, Aussiedeln', iskupljenje 'Loskaufen', isparenje 'Verdunsten; Dampf', isplovljenje 'Hinausfahren (mit Schiff, Boot)', istupljenje 'Hervor-, Raustreten; Auftreten'

der 5. Konjugation

izdanje 'Herausgeben; Ausgabe', izgnanje 'Hinausjagen, Vertreiben; Verbannung'

b) vom ipf. Aspekt, 4. vom Stamm des Partizip Präteritum Passiv, der 5. Konjugation

izazivanje 'Heraus-, Hervorrufen', izbijanje 'Herausschlagen', izbrijavanje 'Ab-, Ausrasieren', izdavanje 'Herausgeben; Verlegen', izdisanje 'Ausatmen; Veratmen, Sterben', izgrtanje 'Herausscharren', izgovaranje 'Aussprechen; Ausrede', izlaganje 'Ausstellung', izletanje 'Hinaus-, Herausfliegen', izlevanje 'Ausgiessen', izmetanje 'Aus-, Hinauswerfen', izmicanje 'Wegrücken', izmotavanje 'Abwikkeln', iznašanje 'Hinaustragen', izoravanje 'Aus-, Herausackern', izricanje 'Aussprechen', izrivanje 'Auswühlen', izronjavanje 'Hervortauchen', izvijanje 'Herauswinden', izviranje 'Quellen, Entspringen', izvrgavanje 'Auswerfen', isejavanje 'Aussäen', isipavanje 'Ausschütten', isisavanje 'Heraussaugen', iskakanje 'Herausspringen', iskapanje 'Herauströpfeln', iskašljavanje 'Heraushusten', iskopavanje 'Ausgraben', iskrcavanje 'Ausladen', ispadanje 'Herausfallen', ispijanje 'Austrinken', ispiranje 'Ausspülen, Auswaschen', ispraćanje 'Hinausbegleiten', isprezanje 'Ausspannen (Pferd)', istakanje 'Auslaufenlassen', istavIjanje 'Aus-, Herausstellen', isteravanje 'Austreiben, Ausweisen', istezanje 'Ausdehnen', isticanje 'Herausfliessen', istovaravanje 'Aus-, Abladen', istrčavanje 'Hinauslaufen', ištrcavanje 'Herausspritzen', istupanje 'Hervortreten', isturanje 'Herausschieben, Herausstossen'

der 6. Konjugation

izbacivanje 'Hinauswerfen', izjahivanje 'Aus-, Hinausreiten', izlepljivanje 'Be-, Auskleben', izmahivanje 'Herausziehen mit Schwung', izmamljivanje 'Heraus-, Entlocken', izvikivanje 'Aussprechen (schreiend)', izvirivanje 'Herauslugen', iseljivanje 'Aussiedeln', ishrakivanje 'Heraushusten', 
iskakivanje 'Hinausspringen', iskapljivanje 'Austropfen', iskašljivanje 'Heraushusten', iskazivanje 'Aussagen; Aussage', iskupljivanje 'Zurückkaufen', isparivanje 'Verdunsten', isterivanje 'Austreiben', istovarivanje 'Aus-, Abladen', istraživanje 'Untersuchung, Nachforschung'

der 4. Konjugation

izgonjenje 'Aus-, Hinaustreiben', izilaženje und izlaženje

'Aus-, Hinausgehen', izvlačenje 'Aus-, Herausziehen', izvodjenje 'Aus-, Hinausführen', izvoženje 'Ausführen, Hinaustransportieren', ishodjenje 'Aus-, Hinausgehen'

Bed.: I2, a) vom pf. Aspekt, 4. vom Stamm des Partizip Präteritum Passiv, der 4. Konjugation

izopćenje 'Exkommunizierung; Acht'

b) vom ipf. Aspekt, 4. vom Stamm des Partizip Präteritum Passiv, der 5. Konjugation

izabiranje 'Auswählen', izostajanje 'Aus-, Wegbleiben',

izostavljanje 'Aus-, Weglassen'

der 6. Konjugation

izopćivanje und izopštivanje 'Exkommunizieren'

Ableitungen mit dem Formans -ć(e)

Bed.: Il, a) vom pf. Aspekt, 4. vom Stamm des Partizip Präteritum Passiv, der 2. Konjugation

izdahnuće 'Ausatmen; Sterben', izmaknuce 'Wegrücken', izmetnuće 'Hinauswerfen', izrinuće 'Hinauswerfen, Hinausstossen', istrgnuće 'Herausreissen'

der unregelmässigen Konjugation

izašašće 'Ausgehen; Ausgang, Ergebnis'

Bed.: L2, a) vom pf. Aspekt, 4. vom Stamm des Partizip Präteritum Passiv, der 1. Konjugation

izuzeće 'Ausschliessung; Vorwegnahme; Befangenheit (Gericht)'

AC. Verbalsubstantive von Verben mit dem Präfix na- in lexikalischer Funktion

Die Ableitungsverfahren: I. Suffigierung

Die wortbildenden Typen nach ihren Formantien, ihrer Produktivität und den Bedeutungen der Präfixe der ableitenden Verben mit 
ihrer Häufigkeit:

Neutra: I. -nj(e) (29), Bed.: LI (29), -ć(e) (1), Bed.: II (1) Die Ableitungsstämme und die Konjugationen:

Neutra: I. 4. Stamm des Partizip Präteritum Passiv der 5.,6., 4., 2. Konjugation

Der Aspekt der Ableitungsbasis:

Neutra: I. 2 pf. und 28 ipf. Verben

Verbalsubstantive mit dem Formans $-n j(e)$, die durch den pf. und ipf. Aspekt des ableitenden Verbs motiviert sind: pf. naseljenje - ipf. naseljavanje 'Ansiedlung; Bevölkerung'.

Verbalsubstantive, die durch den pf. und ipf. Aspekt des ableitenden Verbs motiviert sind, wobei das pf. Verbalsubstantiv auf - $\dot{c}(e)$ und das ipf. auf $-n j(e)$ endet: pf. napregnuce - ipf. naprezanje 'Anstrengung, Anspannung', pf. nategnuce - ipf. natezanje 'Bringen in eine angespannte Lage; Glattziehen'.

Keine Verbalsubstantive sind von folgenden Verben abgeleitet, von denen Substantive anderer wortbildender Kategorien abgeleitet sind: nagaziti, nakapati, nalepiti.

Einige Verbalsubstantive von Verben mit dem Präfix naweisen neben der ursprünglichen Bedeutung eine konkrete auf, und zwar von pf. Verben: nategnuce 'Bringen in eine angespannte Lage; Verletzung des Gewebes durch Anspannung' und von ipf. Verben: naleganje 'Anlegen, Aufsetzen; Uberlagerung'.

Ableitungen mit dem Formans $-n j(e)$

Bed.: LI, a) vom pf. Aspekt, 4. vom Stamm des Partizip Präteritum Passiv, der 4. Konjugation

naseljenje 'Ansiedeln; Bevölkerung'

b) vom ipf. Aspekt, 4. vom Stamm des Partizip Präteritum Passiv, der 5. Konjugation

nabadanje 'Aufstecken, Aufgabeln', nabijanje 'Schlagen (auf etwas), Rammen', nadevanje 'Anmachen, Anstecken; Füllen', nakretanje 'Kippen, Seitwärtsneigen', naleganje 'Anlegen, Aufsetzen (zum Brüten); Uberlagerung', naletanje 'Anprallen (fliegend)', namatanje 'Aufwickeln, Aufwinden', nametanje 'Anwerfen, Auflegen', namicanje 'Uberziehen', napadanje 'Anfallen, Angreifen', naseljavanje 'Ansiedeln', nasrtanje 'Anrennen, Angreifen', nastavljanje 'Fortsetzen', natezanje 'Glattziehen', natrčavanje 'Anrennen, Anlaufen', navijanje

'Aufhaspeln, Aufwinden', navrtanje 'Auf-, Anschrauben' 
najahivanje 'Anreiten, Anfallen', naskakivanje 'Anfallen', nasledovanje 'Fortsetzen', natrkivanje 'Anlaufen, Anfallen', navaljivanje 'Anwälzen, Daraufwälzen', navezivanje 'Daranbinden'

der 4. Konjugation

nahodjenje 'Finden', nailaženje 'Treffen', navlačenje 'An-, Uberziehen', navodjenje 'Anführen, An-, Hinleiten', navoženje 'Herbeitransportieren'

Ableitungen mit dem Formans -ć(e)

Bed.: Il, a) vom pf. Aspekt, 4. vom Stamm des Partizip Präteritum Passiv, der 2. Konjugation

nategnuće 'Bringen in eine angespannte Lage, Verletzung des Gewebes durch Anspannung'

AD. Verbalsubstantive von Verben mit dem Präfix za- in lexikalischer Funktion

Die Ableitungsverfahren: I. Suffigierung

Die wortbildenden Typen nach ihren Formantien, ihrer Produktivität und den Bedeutungen der Präfixe der ableitenden Verben mit ihrer Häufigkeit:

Neutra: I. $-n j(e)(43)$, Bed.: II (21), L2 (10), L3 (6), L4 (6) Die Ableitungsstämme und die Konjugationen:

Neutra: I. 4. Stamm des Partizip Präteritum Passiv der 5., 6., 4., 1. Konjugation

Der Aspekt der Ableitungsbasis:

Neutra: I. 2 pf. und 41 ipf. Verben

Verbalsubstantive mit dem Formans $-n j(e)$, die durch den pf. und ipf. Aspekt des ableitenden Verbs motiviert sind: pf. zarašćenje - ipf. zarastanje 'Zuwachsen, Verheilen', pf. zasenjenje - ipf. zasenjavanje 'Beschatten'.

Keine Verbalsubstantive sind von folgenden Verben abgeleitet, von denen Substantive anderer wortbildender Kategorien abgeleitet sind: zagaziti, zagoniti - zagnati, zakrckati, zaprtiti, zavaliti.

Einige Verbalsubstantive von Verben mit dem Präfix zaweisen neben der ursprünglichen Bedeutung eine konkrete bzw. 
abstrakte auf, und zwar von pf. Verben: zarašćenje 'Zuwachsen, Verheilen; Narbe', zasenjenje 'Beschatten; Schatten' und von ipf. Verben: zasedavanje 'Vorsitzen; Vorsitz'.

Ableitungen mit dem Formans $-n j(e)$

Bed.: Ll, b) vom ipf. Aspekt, 4. vom Stamm des Partizip Präteritum Passiv, der 5. Konjugation

zabadanje 'Hineinstechen, Hineinstossen', zabijanje 'Hineinschlagen', zaklanjanje 'Schützen, Schirmen', zakretanje 'Ab-, Umdrehen', zalaganje 'Hinterlegen', zaletanje und zaletavanje 'Hinteretwasfliegen, Verfliegen', zametanje 'Anbinden', zamicanje 'Hinteretwasrücken, Entrücken', zapadanje 'Dahinterfallen', zapinjanje 'Anspannen, Aufziehen', zaskakanje 'Umzingeln', zatezanje 'Spannen, Anspannen', zavijanje 'Verbinden, Einwickeln', zavrtanje 'Um-, Eindrehen, Anschrauben'

der 6. Konjugation

zabacivanje 'Dahinter-, Zurückwerfen', zaletivanje 'Verfliegen', zaskakivanje 'Umzingeln'

der 4. Konjugation

zahodjenje 'Untergehen', zailaženje und zalaženje 'Hinteretwasgehen, Untergehen', zanošenje 'Hinter-, Dahintertragen', zavlačenje 'Hineinstecken, Hineinziehen'

Bed.: L2, b) vom ipf. Aspekt, 4. vom Stamm des Partizip Präteritum Passiv, der 5. Konjugation

zakivanje 'Anschmieden', zaklapanje 'Zudecken, Verschliessen', zalevanje 'An-, Begiessen', zapletanje 'Ein-, Zu-, Zusammenflechten', zasipanje und zasipavanje 'Uber-, Hineinschütten', zašivanje 'Zunähen'

der 6. Konjugation

zagradjivanje 'Einzäunen', zalepljivanje 'Ver-, Zukleben', zatiskivanje 'Verstopfen, Verstopfung', zazidjivanje

'Ver-, Zumauern'

Bed.: L3, a) vom pf. Aspekt, 4. vom Stamm des Partizip Präteritum Passiv, der 4. Konjugation zasenjenje 'Beschatten; Schatten'

der 1. Konjugation

zarašćenje 'Zuwachsen, Verheilen; Narbe'

b) vom ipf. Aspekt, 4. vom Stamm des Partizip Präteritum Passiv, 
der 5. Konjugation

zarastanje 'Zuwachsen', zasenjavanje 'Beschatten' der 6. Konjugation

zamladjivanje 'Vernarben, Zuheilen', zarašćivanje 'Ver-, Zuwachsen'

Bed.: L4, b) vom ipf. Aspekt, 4. vom Stamm des Partizip Präteritum Passiv, der 5. Konjugation

zadržavanje 'Auf-, Anhalten', zasedanje 'Sichindenhinterhaltlegen; Tagen, Tagung', zasedavanje 'Vorsitzen, Vorsitz; Sitzung', zastajanje 'Antreffen; Stehenbleiben, Halten', zastavljanje 'Anhalten', zastupanje 'Vertreten (die Stelle eines anderen)'

B. Modifizierende Funktion

BA. Verbalsubstantive von Verben mit dem Präfix do- in modifizierender Funktion

Die Ableitungsverfahren: I. Suffigierung

Die wortbildenden Typen nach ihren Formantien, ihrer Produktivität und den Bedeutungen der Präfixe der ableitenden Verben mit ihrer Häufigkeit:

Neutra: I. $-n j(e)$ (30), Bed.: MI (30)

Die Ableitungsstämme und die Konjugationen:

Neutra: I. 4. Stamm des Partizip Präteritum Passiv der 5., 6., 4. Konjugation

Der Aspekt der Ableitungsbasis:

Neutra: I. 3 pf. und 27 ipf. Verben

Verbalsubstantive, die durch den pf. und ipf. Aspekt des ableitenden Verbs motiviert sind: pf. docepljenje - ipf. docepljivanje 'Zuendespalten', pf. dokončanje - ipf. dokončavanje 'Beenden, Vollenden', pf. dovršenje - ipf. dovršavanje und dovršivanje 'Verrichten, Ausüben, Vollenden'.

Keine Verbalsubstantive sind von folgenden Verben abgeleitet, von denen Substantive anderer wortbildender Kategorien abgeleitet sind: dopevati, doprinositi, dorasti, doumiti se.

Ableitungen mit dem Formans $-n j(e)$

Bed.: MI, a) vom pf. Aspekt, 4. vom Stamm des Partizip Präteri- 
tum Passiv, der 4. Konjugation

docepljenje 'Zuendespalten', dovršenje 'Beenden, Vollenden'

der 5. Konjugation

dokončanje 'Beenden, Zuendebringen'

b) vom ipf. Aspekt, 4. vom Stamm des Partizip Präteritum Passiv,

der 5. Konjugation

dobiranje 'Auspflücken, Der=Beendigung=des=Pflückens=Näherkommen', docvetavanje 'Ab-, Verblühen', dočitavanje 'Zuendelesen', dodelavanje 'Vollbringen', dogaranje 'Ab-, Niederbrennen', dogorevanje 'Abbrennen', dogotavljanje und dogotovljavanje 'Fertigmachen', doigravanje 'Abspielen', dokivanje 'Zuendeschmieden', dokončavanje 'Be-, Vollenden', dokuhavanje 'Zuende-, Garkochen', dopletanje 'Zuendeflechten', dopravljanje 'Aus-, Zuendebauen', došivanje 'Fertig-, Zuendenähen', dotkivanje 'Zuendeweben', dovršavanje 'Beenden, Abschliessen', dozrevanje 'Ausreifen', dožinjanje und dožnjevanje 'Zuendeernten'

der 6. Konjugation

docepljivanje 'Zuendespalten', dogotovljivanje 'Zuendebereiten', dogradjivanje 'Aus-, Zuendebauen', dohranjivanje 'Aus-, Ernähren', dokresivanje 'Zuendestutzen', dopisivanje 'Zuendeschreiben', doradjivanje 'Zuendearbeiten', dosluživanje 'Zuendedienen', dovršivanje 'Beenden, Abschliessen'

BB. Verbalsubstantive von Verben mit dem Präfix $\underline{i z}-$ in modifizierender Funktion

Die Ableitungsverfahren: I. Suffigierung

Die wortbildenden Typen nach ihren Formantien, ihrer Produktivität und den Bedeutungen der Präfixe der ableitenden Verben mit ihrer Häufigkeit:

Neutra: I. $-n j(e)(6)$, Bed.: MI (6)

Die Ableitungsstämme und die Konjugationen:

Neutra: I. 4. Stamm des Partizip Präteritum Passiv der 5., 4., 6. Konjugation

Der Aspekt der Ableitungsbasis:

Neutra: I. 6 ipf. Verben

Ableitungen mit dem Formans - $n j(e)$

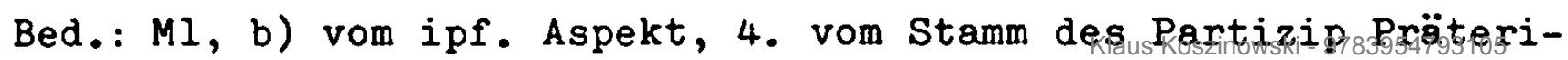


tum Passiv, der 4. Konjugation

$$
\text { iznalaženje 'Erfindung' }
$$

der 5. Konjugation

iskivanje 'Erschmieden', iskucavanje 'Herausklopfen', iskuhavanje 'Auskochen'

der 6. Konjugation

izradjivanje 'Ausarbeiten, Erarbeiten', izgradjivanje

'Bauen, Verfertigen'

BC. Verbalsubstantive von Verben mit dem Präfix na- in modifizierender Funktion

Die Ableitungsverfahren: I. Suffigierung

Die wortbildenden Typen nach ihren Formantien, ihrer Produktivität und den Bedeutungen der Präfixe der ableitenden Verben mit ihrer Häufigkeit:

Neutra: I. $-n j(e)$ (3l), Bed.: MI (20), M2 (11)

Die Ableitungsstämme und die Konjugationen:

Neutra: I. 4. Stamm des Partizip Präteritum Passiv der 5., 4., 6., 1. Konjugation

Der Aspekt der Ableitungsbasis:

Neutra: I. 3 pf. und 28 ipf. Verben

Lediglich durch pf. Verben sind folgende Verbalsubstantive motiviert: nagnječenje 'Anquetschen', narodjenje 'Gebären'.

Ein Verbalsubstantiv ist durch den pf. und ipf. Aspekt des ableitenden Verbs motiviert: pf. nažeženje - ipf. nažizanje und nažganje 'Anzünden'.

Keine Verbalsubstantive sind von folgenden Verben abgeleitet, von denen Substantive anderer wortbildender Kategorien abgeleitet sind: nabušiti, nakositi, nakotiti, nakovati, nakupiti, naplaviti, naprsnuti, napući.

Ableitungen mit dem Formans - $n j(e)$

Bed.: Ml, a) vom pf. Aspekt, 4. vom Stamm des Partizip Präteritum Passiv, der 4. Konjugation

narodjenje 'Gebären; Geburt'

b) vom ipf. Aspekt, 4. vom Stamm des Partizip Präteritum Passiv, der 5. Konjugation

nabiranje 'Ansammeln', nabrajanje 'Aufzählen', nadavanje

'Geben (in Menge)', nagomilavanje 'Anhäufen', nagrtanje

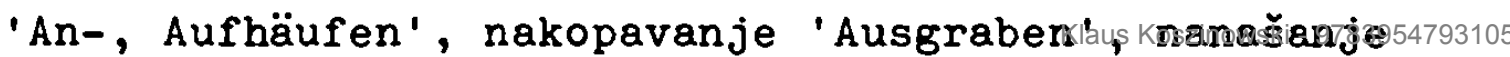


'Herantragen, Anhäufen', napletanje 'Anflechten', napredanje

'Anspinnen', natiskavanje 'Vollstopfen, Vollpfropfen',

natresanje 'Ausschütteln', naturanje 'Vollstopfen'

der 6. Konjugation

nabacivanje 'Werfen (in Menge)', nagradjivanje 'Auf-, Ausbauen (in Menge)', natiskivanje 'Vollstopfen', natresivanje

'Ausschütteln', naturivanje 'Vollstopfen', nazidjivanje

'Fertigbauen (in bestimmter Menge)'

der 4. Konjugation

nanošenje 'Zusammentragen, Anschwemmen'

Bed.: M2, a) vom pf. Aspekt, 4. vom Stamm des Partizip Präteritum Passiv, der 1. Konjugation

nažeženje 'Anzünden'

der 4. Konjugation

nagnječenje 'Anquetschen'

b) vom ipf. Aspekt, 4. vom Stamm des Partizip Präteritum Passiv, der 5. Konjugation

nadizanje 'Anheben', nagrizanje 'Anbeissen', nakašljavanje 'Räuspern', narezivanje 'Anschneiden', naziranje 'Sehen

(einen undeutlichen Schimmer)', nažganje 'Anzünden', nažizanje 'Anzünden'

der 6. Konjugation

nakašljivanje 'Räuspern', napaljivanje 'Anbrennen'

BD. Verbalsubstantive von Verben mit dem Präfix za- in modifizierender Funktion

Die Ableitungsverfahren: I. Suffigierung

Die wortbildenden Typen nach ihren Formantien, ihrer Produktivität und den Bedeutungen der Präfixe der ableitenden Verben mit ihrer Häufigkeit:

Neutra: I. $-n j(e)(26)$, Bed.: MI (26)

Die Ableitungsstämme und die Konjugationen:

Neutra: I. 4. Stamm des Partizip Präteritum Passiv der 5., 6. Konjugation

Der Aspekt der Ableitungsbasis:

Neutra: I. 1 pf. und 25 ipf. Verben

Lediglich durch ein pf. Verb motiviert ist: zavojevanje

'Kriegbeginnen'. 
Keine Verbalsubstantive sind von folgenden Verben abgeleitet, von denen Substantive anderer wortbildender Kategorien abgeleitet sind: zadrhtati, zaduvati, zagrepsti, zagucati, zakašljati se, zaljuljati, zaljuštiti, zapevati, zapuhati, zaveslati.

Das Verbalsubstantiv zavojevanje 'Kriegbeginnen; Eroberung; erobertes Territorium' weist neben der ursprünglichen Bedeutung eine konkrete auf.

Ableitungen mit dem Formans $-n j(e)$

Bed.: MI, a) vom pf. Aspekt, 4. vom Stamm des Partizip Präteritum Passiv, der 6. Konjugation

zavojevanje 'Kriegbeginnen; Eroberung; erobertes Territorium' b) vom ipf. Aspekt, 4. vom Stamm des Partizip Präteritum Passiv, der 5. Konjugation

zagorevanje 'Anbrennen', zagrizanje 'Anbeissen', zahukavanje

'Anhauchen', zaigravanje 'Zutanzenanfangen', zakopavanje

'Angraben', zakukavanje 'Zuklagenanfangen', zamucavanje

'Stotternanfangen', zamučanje 'Verstummen', zaoravanje

'Anackern', zasecanje 'An-, Einschneiden', zatrčavanje

'Ansetzen (zu laufen)', zavitlavanje 'Aufwirbeln', zazjavanje 'Gähnenanfangen', zažinjanje 'Zuerntenanfangen', zažizanje 'Anzünden'

der 6. Konjugation

zagrizivanje 'An-, Einbeissen', zahukivanje 'Anhauchen', zalizivanje 'Anlecken', zamuckivanje 'Stotternanfangen', zapiskivanje 'Pfeifen, Zischen', zapljeskivanje 'Klatschen', zaprdivanje 'Furzen', zarezivanje 'An-, Einschneiden', zarudjivanje 'Erröten', zatrkivanje 'Ansetzen (zu laufen)'

C. Rein perfektivierende Funktion

$C B$. Verbalsubstantive von Verben mit dem Präfix $\underline{\text { iz }-}$ in rein perfektivierender Funktion

a) iz- als reihendes Präfix

Die Ableitungsverfahren: I. Suffigierung

Die wortbildenden Typen nach ihren Formantien, ihrer Produktivität und den Bedeutungen der Präfixe der ableitenden Verben mit ihrer Häufigkeit: 
Neutra: I. $-n j(e)(90)$, Bed.: Rla (3), Rlb (3), Rlc (3), Rld (2), Rle (3), Rlf (4), Rlg (1), Rlb (3), Rli (3), Rlj (12), R2a (16), R2b (7), R2c (10), R2d (5), R2e (5), R2f (4), R2g (4), R2h (2), -ć(e) (3), Bed.: Rla (1), Rli (1), $R I j(1)$

Die Ableitungsstämme und die Konjugationen:

Neutra: I. 4. Stamm des Partizip Präteritum Passiv der 5., 6., 4., 1., 2. Konjugation

Der Aspekt der Ableitungsbasis:

Neutra: I. $20 \mathrm{pf}$. und 73 ipf. Verben

Lediglich durch pf. Verben sind folgende Verbalsubstantive mit dem Formans -nj(e) motiviert: izbočenje 'Ausbauchen; Ausbuchtung', izdubljenje 'Einbauchen; Aushöhlung', izlečenje 'Ausheilen', izravnanje 'Ebenen; Ausgleichung, Beilegung', ishlapljenje 'Auslüften', iskaranje 'Ausschelten', ispupčenje 'Ausbauchung; Erhebung', istrežnjenje 'Ausnüchtern'.

Verbalsubstantive mit dem Formans $-n j(e)$, die durch den pf. und ipf. Aspekt des ableitenden Verbs motiviert sind: pf. izjednačenje - ipf. izjednačavanje 'Ausgleichen, Gleichmachen', pf. izlučenje - ipf. izlučivanje 'Absondern', pf. izmirenje - ipf. izmiravanje 'Aussöhnen; Abfinden', pf. izopačenje - ipf. izopačavanje 'Verdrehen, Verkehren; Entarten', pf. isceljenje - ipf. isceljivanje 'Ausheilen', pf. iskorištenje - ipf. iskorištavanje 'Ausnutzen', pf. ispunjenje - ipf. ispunjivanje 'Ausfüllen'.

Verbalsubstantive, die durch den pf. und ipf. Aspekt des ableitenden Verbs motiviert sind, wobei das pf. Verbalsubstantiv auf $-\dot{c}(e)$ und das ipf. auf $-n j(e)$ endet: pf. iskliznuce - ipf. isklizavanje 'Ausgleiten', pf. istisnuće - ipf. istiskivanje 'Ausdrücken; Verdrängung' .

Keine Verbalsubstantive sind von folgenden Verben abgeleitet, von denen Substantive anderer wortbildender Kategorien abgeleitet sind: izbljuvati, izbrusiti, izderati, izgristi, izgubiti, izlizati, izmeriti, izvaditi, ižlebiti, iskrojiti, ispàsti 'weiden', ispeći, ispomagati, isprdeti (-se), ispušiti.

Zahlreiche Verbalsubstantive von Verben mit dem Präfix izweisen neben der ursprünglichen Bedeutung eine konkrete bzw. abstrakte auf, und zwar von pf. Verben: izbočenje 'Ausbauchen; Ausbuchtung', izdubljenje 'Einbauchen; Aushöhlung', izmirenje 'Aussöhnen; Aussöhnung; Abfindung, Auszahlung', izravnanje 'Ebenen; Ausgleichung, Beilegung', ispupčenje 'Ausbauchung; Erhebung' . 
Ableitungen mit dem Formans $-n j(e)$

Bed.: Rla, b) vom ipf. Aspekt, 4. vom Stamm des Partizip Präteritum Passiv, der 5. Konjugation

izažimanje 'Ausdrücken, Auspressen'

der 6. Konjugation

iscedjivanje 'Auspressen, Ausdrücken', istiskivanje

'Ausdrücken, Auspressen'

Bed.: Rlb, b) vom ipf. Aspekt, 4. vom Stamm des Partizip Präteritum Passiv, der 5. Konjugation

iznicanje 'Aufkeimen, Entspriessen', izrastanje

'Auswachsen', isklasavanje 'Ahrentreiben'

Bed.: Rlc, b) vom ipf. Aspekt, 4. vom Stamm des Partizip Präteritum Passiv, der 5. Konjugation

izvraćanje 'Umstülpen, Umwenden', izvrtanje 'Umdrehen'

der 6. Konjugation

izvaljivanje 'Umwerfen, Umwehen'

Bed.: Rld, b) vom ipf. Aspekt, 4. vom Stamm des Partizip Präteritum Passiv, der 5. Konjugation

isecanje 'Aus-, Herausschneiden'

der 6. Konjugation

izrezivanje 'Ausschneiden, Ausschnitzen'

Bed.: Rle, a) vom pf. Aspekt, 4. vom Stamm des Partizip Präteritum Passiv, der 4. Konjugation

izbočenje 'Ausbauchen; Ausbuchtung', izdubljenje

'Einbauchen; Aushöhlung', ispupčenje 'Ausbauchung;

Erhebung'

Bed.: Rlf, a) vom pf. Aspekt, 4. vom Stamm des Partizip Präteritum Passiv, der 4. Konjugation

izlučenje 'Absondern, Ausscheiden'

b) vom ipf. Aspekt, 4. vom Stamm des Partizip Präteritum Passiv, der 5. Konjugation

izdvajanje 'Aussondern; Ausscheiden', iznojavanje

'Ausschwitzen'

der 6. Konjugation

izlučivanje 'Absondern, Ausscheiden'

Bed.: Rlg, b) vom ipf. Aspekt, 4. vom Stamm des Partizip Präteritum Passiv, der 5. Konjugation 
isprečavanje 'Versperren'

Bed.: Rlh, a) vom pf. Aspekt, 4. vom Stamm des Partizip Präteritum Passiv, der 4. Konjugation

ishlapljenje 'Auslüften'

b) vom ipf. Aspekt, 4. vom Stamm des Partizip Präteritum Passiv, der 5. Konjugation

izvetravanje 'Auslüften', isparavanje 'Verdunsten'

Bed.: Rli, b) vom ipf. Aspekt, 4. vom Stamm des Partizip Präteritum Passiv, der 5. Konjugation

izgaranje 'Ab-, Niederbrennen', izjedanje 'Aufessen', iscvetavanje 'Verblühen'

Bed.: Rlj, a) vom pf. Aspekt, 4. vom Stamm des Partizip Präteritum Passiv, der 1. Konjugation

iscrpljenje 'Ausschöpfen'

b) vom ipf. Aspekt, 4. vom Stamm des Partizip Präteritum Passiv, der 5. Konjugation

izašiljanje 'Aus-, Absenden', izbegavanje 'Meiden, Vermeiden, Fliehen', izdizanje 'Auf-, Emporheben', izvrdavanje 'Ausweichen', isklizavanje 'Ausrutschen', ispinjanje 'Emporheben', ispljuvavanje 'Ausspucken', ispružanje 'Ausstrecken', ispuštanje 'Aus-, Herauslassen', istresanje 'Ausbeuteln, Ausschütten'

der 6. Konjugation

ispisivanje 'Ausschreiben'

Bed.: R2a, a) vom pf. Aspekt, 4. vom Stamm des Partizip Präteritum Passiv, der 4. Konjugation

izopačenje 'Verdrehen', ispunjenje 'Ausfüllen'

b) vom ipf. Aspekt, 4. vom Stamm des Partizip Präteritum Passiv, der 5. Konjugation

izopačavanje 'Verdrehen', izoštravanje 'Schleifen, Schärfen', izvitoperavanje 'Sichverwerfen, Verbiegen', iskrivljavanje 'Krummmachen', ispunjavanje 'Ausfüllen'

der 6. Konjugation

izjavljivanje 'Erklären, Bekanntmachen', izlepljivanje 'Be-, Auskleben', izmenjivanje 'Abändern', izopačivanje 'Verdrehen', iskrivljivanje 'Krümmen, Krummbiegen', ispražnjivanje 'Ent-, Ausleeren', ispunjivanje 'Ausfüllen', istanjivanje 'Dünnmachen, Verdünnen', isušivanje 


\section{'Austrocknen'}

Bed.: R2b, b) vom ipf. Aspekt, 4. vom Stamm des Partizip Präteritum Passiv, der 5. Konjugation

izmilanje 'Ausmahlen', izmržnjavanje 'Zueiswerdenlassen',

iskašanje 'Abmähen', ispredanje 'Ausspinnen',

iščešljavanje 'Auskämmen'

der 6. Konjugation

izluživanje 'Auslaugen',

iskaljivanje 'Stählen'

Bed.: R2c, a) vom pf. Aspekt, 4. vom Stamm des Partizip Präteritum Passiv, der 4. Konjugation

izlečenje 'Ausheilen', isceljenje 'Ausheilen',

istrežnjenje 'Ausnüchtern'

b) vom ipf. Aspekt, 4. vom Stamm des Partizip Präteritum Passiv, der 5. Konjugation

izgladnjavanje 'Hungrigmachen', izučavanje 'Lehren', izvežbavanje 'Ausbilden'

der 6. Konjugation

izgladnjivanje 'Hungrigmachen', izludjivanje 'Verrücktmachen', isceljivanje 'Ausheilen',

ishranjivanje 'Ernähren'

Bed.: R2d, a) vom pf. Aspekt, 4. vom Stamm des Partizip Präteritum Passiv, der 4. Konjugation

izopačenje 'Entarten; Verdrehen'

der 5. Konjugation

iskaranje 'Ausschelten'

b) vom ipf. Aspekt, 4. vom Stamm des Partizip Präteritum Passiv, der 5. Konjugation

izrugavanje 'Verspotten', iskušavanje 'Erproben', isprobavanje 'Ausprobieren'

Bed.: R2e, a) vom pf. Aspekt, 4. vom Stamm des Partizip Präteritum Passiv, der 4. Konjugation

izjednačenje 'Ausgleichen, Gleichmachen',

izmirenje 'Aussöhnen; Abfindung'

der 5. Konjugation

izravnanje 'Ebenen; Ausgleichung, Beilegung'

b) vom ipf. Aspekt, 4. vom Stamm des Partizip Präteritum

Passiv, der 5. Konjugation 
izjednačavanje 'Ausgleichen', izmiravanje 'Friedenerneuern'

Bed.: R2f, b) vom ipf. Aspekt, 4. vom Stamm des Partizip Präteritum Passiv, der 5. Konjugation

izmišljanje, izmišljavanje 'Aussinnen, Erdenken', izračunavanje 'Ausrechnen', izumevanje 'Erfinden, Ausdenken, Ersinnen', ispričavanje 'Entschuldigen'

Bed.: R2g, a) vom pf. Aspekt, 4. vom Stamm des Partizip Präteritum Passiv, der 4. Konjugation

iskorištenje 'Ausnutzen'

b) vom ipf. Aspekt, 4. vom Stamm des Partizip Präteritum Passiv, der 5. Konjugation

iskorištavanje 'Ausnutzen'

der 6. Konjugation

izrabljivanje 'Gebrauchen', iskorišćivanje 'Ausnutzen'

Bed.: R2h, b) vom ipf. Aspekt, 4. vom Stamm des Partizip Präteritum Passiv, der 5. Konjugation

izdržavanje 'Aushalten', izduravanje 'Aushalten,

Uberstehen'

Ableitungen mit dem Formans -íc(e)

Bed.: Rla, a) vom pf. Aspekt, 4. vom Stamm des Partizip

Präteritum Passiv, der 2. Konjugation

istisnuće 'Verdrängung'

Bed.: Rli, a) vom pf. Aspekt, 4. vom Stamm des Partizip Präteritum Passiv, der 1. Konjugation

izumrće 'Aussterben'

Bed.: Rlj, a) vom pf. Aspekt, 4. vom Stamm des Partizip Präteritum Passiv, der 2. Konjugation

iskliznuce 'Ausgleiten, Ausrutschen'

b) $\underline{\text { iz- }}$ als leeres Präfix

Die Ableitungsverfahren: I. Suffigierung

Die wortbildenden Typen nach ihren Formantien sowie ihre Produktivität: 
Neutra: I. $-n j(e)(15),-c(e)$ (2)

Die Ableitungsstämme und die Konjugationen:

Neutra: I. 4. Stamm des Partizip Präteritum Passiv der 5., 6.. 4., 2. Konjugation

Der Aspekt der Ableitungsbasis:

Neutra: I. 5 pf. und 12 ipf. Verben

Lediglich durch pf. Verben sind folgende Verbalsubstantire mit dem Formans -nj(e) motiviert: isluženje 'Ausdienen', ištećenje 'Beschädigen'.

Verbalsubstantive mit dem Formans $-n j(e)$, die durch den pf. und ipf. Aspekt des ableitenden Verbs motiviert sind: pf. izvršenje - ipf. izvršavanje 'Ausführen, Verrichten', pf. isporedjenje - ipf. isporedjivanje 'Vergleichen'.

Keine Verbalsubstantive sind von folgenden Verben abgele:tet, von denen Substantive anderer wortbildender Kategorien abgeleitet sind: izmoriti, istumačiti.

Das Verbalsubstantiv izminuće 'Vergehen; Ende' weist neben der ursprünglichen Bedeutung eine abstrakte auf.

Ableitungen mit dem Formans $-n j(e)$

a) vom pf. Aspekt, 4. vom Stamm des Partizip Präteritum Passiv, der 4. Konjugation

izvršenje 'Ausführen, Verrichten', isporedjenje

'Vergleichen', ištećenje 'Beschädigen'

b) vom ipf. Aspekt, 4. vom Stamm des Partizip Präteritum Passiv, der 5. Konjugation

izigravanje 'Zuendespielen, Aus-', izvršavanje 'Ausführen, Vollziehen', iskupljanje 'Sammeln, Versammeln', islikavanje 'Malen', išćuškavanje 'Ohrfeigen', iščekavanje 'Abwarten'

der 6. Konjugation

iziskivanje 'Verlangen', iznajmljivanje 'Mieten',

izvršivanje 'Verrichten, Ausüben', isplaćivanje

'Auszahlen', isporedjivanje 'Vergleichen',

iščekivanje 'Ab-, Erwarten'

Ableitungen mit dem Formans -ćc(e)

a) vom pf. Aspekt, 4. vom Stamm des Partizip Präteritum Passiv, der 2. Konjugation

izginuće 'Umkommen', izminuće 'Vergehen; Endee' 
CC. Verbalsubstantive von Verben mit dem Präfix na- in rein perfektivierender Funktion

a) na- als reihendes Präfix

Die Ableitungsverfahren: I. Suffigierung

Die wortbildenden Typen nach ihren Formantien, ihrer Produktivität und den Bedeutungen der Präfixe der ableitenden Verben mit ihrer Häufigkeit:

Neutra: I. $-n j(e)$ (37), Bed.: Rla (2), Rlb (5), Rld (3), R2a

$$
\text { (18), R2b (2), R2c (7) }
$$

Die Ableitungsstämme und die Konjugationen:

Neutra: I. 4. Stamm des Partizip Präteritum Passiv der 5., 6., 4. Konjugation

Der Aspekt der Ableitungsbasis:

Neutra: I. 4 pf. und 33 ipf. Verben

Lediglich durch ein pf. Verb motiviert ist: naoblačenje

'Bewölken' .

Verbalsubstantive mit dem Formans $-n j(e)$, die durch den pf. und ipf. Aspekt des ableitenden Verbs motiviert sind: pf. naduvanje - ipf. naduvavanje 'Aufblasen', pf. naoružanje - ipf. naoružavanje 'Bewaffnen; Rüstung'.

Keine Verbalsubstantive sind von folgenden Verben abgeleitet, von denen Substantive anderer wortbildender Kategorien abgeleitet sind: nabujati, nacrtati, nadograditi, nadometati, nadoplatiti, nagnojiti, nakititi, namazati, napisati, napušiti, nasejati, nateći, nažeti.

Das Verbalsubstantiv naoružanje 'Bewaffnen; Rüstung' weist neben der ursprünglichen Bedeutung eine konkrete auf.

Ableitungen mit dem Formans $-n j(e)$

Bed.: Rla, b) vom ipf. Aspekt, 4. vom Stamm des Partizip

Präteritum Passiv, der 5. Konjugation

namirisivanje 'Parfümieren'

der 6. Konjugation

navranjivanje 'Schwärzen'

Bed.: Rlb, b) vom ipf. Aspekt, 4. vom Stamm des Partizip Präteritum Passiv, der 5. Konjugation

naganjanje 'Antreiben', nastupanje 'An-, Auftreten', nateravanje 'Treiben, An-, Zu-'

der 4. Konjugation

nagonjenje 'Antreiben' 
der 6. Konjugation

naterivanje 'An-, Zutreiben'

Bed.: Rld, a) vom pf. Aspekt, 4. vom Stamm des Partizip Präteritum Passiv, der 4. Konjugation

natočenje 'Eingiessen, Einschenken'

b) vom ipf. Aspekt, 4. vom Stamm des Partizip Präteritum Passiv, der 5. Konjugation

nagibanje 'Neigen, Hin-', natakanje 'Einschenken'

Bed.: R2a, a) vom pf. Aspekt, 4. vom Stamm des Partizip Präteritum Passiv, der 5. Konjugation

naduvanje 'Aufblasen', naoružanje 'Bewaffnen;

Rüstung'

b) vom ipf. Aspekt, 4. vom Stamm des Partizip Präteritum Passiv, der 5. Konjugation

nadodavanje 'Zufügen', nadomeravanje 'Zuwiegen', nadopunjavanje 'Zufüllen, Ergänzen', naduvavanje

'Aufblasen', naklapanje 'Plaudern, Faseln', namakanje 'Nassmachen, Weichen', namnožavanje 'Vermehren', nanizavanje 'Auffädeln', naoružavanje

'Bewaffnen; Rüstung', nasipanje 'Aufschütten', natapanje 'Durchtränken', natrpavanje 'Auftürmen, Anhäufen'

der 6. Konjugation

nabedjivanje 'Beschuldigen (ungerecht)', nabrecivanje

'Anschnauzen, Anfahren', nagrdjivanje 'Beschimpfen', nasadjivanje 'Anpflanzen'

Bed.: R2b, b) vom ipf. Aspekt, 4. vom Stamm des Partizip Präteritum Passiv, der 5. Konjugation napajanje 'Tränken', napasanje 'Weiden'

Bed.: R2c, a) vom pf. Aspekt, 4. vom Stamm des Partizip Präteritum Passiv, der 4. Konjugation

naoblačenje 'Bewölken'

b) vom ipf. Aspekt, 4. vom Stamm des Partizip Präteritum Passiv, der 5. Konjugation

nadimanje 'Aufblähen, Vergrössern', napinjanje

'Aufrichten, Spannen', narastanje 'Anwachsen', naviranje 'Aufsieden'

der 4. Konjugation 
nadolaženje 'Steigen (Wasser)'

der 6. Konjugation

naticanje 'Anschwellen'

b) na- als leeres Präfix

Die Ableitungsverfahren: I. Suffigierung

Die wortbildenden Typen nach ihren Formantien sowie ihre Produktivität :

Neutra: I. $-n j(e)(38),-c(e)$ (1)

Die Ableitungsstämme und die Konjugationen:

Neutra: I. 4. Stamm des Partizip Präteritum Passiv der 5., 6., 4., 2. Konjugation

Der Aspekt der Ableitungsbasis:

Neutra: I. 10 pf. und 29 ipf. Verben

Verbalsubstantive mit dem Formans $-n j(e)$, die durch den pf. und ipf. Aspekt des ableitenden Verbs motiviert sind: pf. nadoknadjenje - ipf. nadoknadjivanje 'Ersetzen, Entschädigen', pf. nadraženje - ipf. nadraživanje 'Reizen, Anreiz', pf. naslućenje - ipf. naslućivanje 'Erahnen', pf. nameštenje - ipf. nameštanje 'Zurechtstellen', pf. namirenje - ipf. namirivanje 'Befriedigen, Zufriedenstellen;Abfindung', pf. naravnanje - ipf. naravnavanje 'Ausgleichen, Abfinden; Abfindung', pf. narušenje - ipf. narušavanje 'Störung, Verletzung'.

Keine Verbalsubstantive sind von folgenden Verben abgeleitet, von denen Substantive anderer wortbildender Kategorien abgeleitet sind: načiniti, napraviti, narikati, nasiliti, navršiti, nazlobiti.

Einige Verbalsubstantive von Verben mit dem Präfix naweisen neben der ursprünglichen Bedeutung eine konkrete bzw. abstrakte auf, und zwar von pf. Verben: namirenje 'Befriedigen, Zufriedenstellen; Abfindung', naravnanje 'Ausgleichen, Abfinden; Abfindung' und von ipf. Verben: naknadjivanje 'Nachholen, Ersetzen; Entschädigung', namirivanje 'Befriedigen, Zufriedenstellen; Abfindung' .

Ableitungen mit dem Formans - $n j(e)$

a) vom pf. Aspekt, 4. vom Stamm des Partizip Präteritum Passiv, der 4. Konjugation

nadoknadjenje 'Ersetzen, Entschädigen', nadraženje

'Reizen, Anreizen', nameštenje 'Zurechtstaldelen'ski-9783954793105 
namirenje 'Beruhigen, Zufriedenstellen; Abfindung', narušenje 'Störung, Verletzung', naslućenje 'Erahnen', naznačenje 'Bezeichnung'

der 5. Konjugation

naravnanje 'Ausgleichen, Abfinden; Abfindung', nazvanje 'Bezeichnung; Name'

b) vom ipf. Aspekt, 4. vom Stamm des Partizip Präteritum Passiv, der 5. Konjugation

nabavljanje 'Besorgen', nagadjanje 'Raten, Mutmassen', nameštanje 'Zurechtstellen', namigavanje 'Zuwinken', napijanje 'Zutrinken', napominjanje 'Erwähnen', naprezanje 'Anstrengen, Anspannung', naravnavanje 'Ausgleichen', naricanje 'Zudenken', narušavanje 'Niederreissen, Zerstören', natiranje 'Zerreiben', naučanje, naučavanje 'Lernen', nazdravljanje 'Zutrinken', nazivanje 'Heissen, Benennen'

der 6. Konjugation

nadoknadjivanje 'Ersetzen, Entschädigen', nadraživanje 'Reizen', najavljivanje 'Benachrichtigen', najaživanje 'Wasserableiten', nakanjivanje 'Vornehmen, Vorhaben', naknadjivanje 'Nachholen, Ersetzen; Entschädigung', namahivanje 'Zuwinken', namamljivanje 'Anlocken', namigivanje 'Zublinzeln', namirivanje 'Befriedigen, Zufriedenstellen; Abfindung', naplaćivanje 'Bezahlen', napućivanje 'Hinweisen', naslućivanje 'Erahnen', nastanjivanje 'Ansiedeln', naznačivanje 'Bezeichnen'

Ableitungen mit dem Formans -ć(e)

a) vom pf. Aspekt, 4. vom Stamm des Partizip Präteritum Passiv, der 2. Konjugation

napregnuće 'Anstrengung, Anspannung'

CD. Verbalsubstantive von Verben mit dem Präfix za- in rein perfektivierender Funktion

a) za- als reihendes Präfix

Die Ableitungsverfahren: I. Suffigierung

Die wortbildenden Typen nach ihren Formantien, ihrer Produktivi- 
tät und den Bedeutungen der Präfixe der ableitenden Verben mit ihrer Häufigkeit:

Neutra: I. $-n j(e)$ (138), Bed.: Rla (12), Rlb (22), Rlc (3), Rld (6), Rle (3), RIf (14), Rlg (2), RIh (9), Rli (3), R2a (5), R2b (51), R2c (4), R3 (4)

Die Ableitungsstämme und die Konjugationen:

Neutra: I. 4. Stamm des Partizip Präteritum Passiv der 5., 6., 4., 3., 1. Konjugation

Der Aspekt der Ableitungsbasis:

Neutra: I. 17 pf. und 121 ipf. Verben

Lediglich durch pf. Verben sind folgende Verbalsubstantive motiviert: zacrnjenje 'Schwarzwerden', zagadjenje 'Verunreinigen', zaklanje 'Schlachten', zaokolišenje 'Herumgehen', zapopljenje 'Ordinieren', zatamnjenje 'Dunkelwerden'.

Verbalsubstantive, die durch den pf. und ipf. Aspekt des ableitenden Verbs motiviert sind: pf. začaranje - ipf. začaravanje 'Bezaubern', pf. zadebljenje - ipf. zadebljavanje 'Verdikkung; Wulst', pf. zagušenje - ipf. zagušavanje, zagušivanje 'Erwürgen; Ersticken', pf. zaledjenje - ipf. zaledjivanje 'Vereisen', pf. zaludjenje - ipf. zaludjivanje 'Irrewerden; Betören', pf. zamračenje - ipf. zamračivanje 'Verdunkeln, Verfinstern', pf. zapamćenje - ipf. zapamćivanje 'Erinnern', pf. zasićenje ipf. zasićivanje 'Sättigen'.

Keine Verbalsubstantive sind von folgenden Verben abgeleitet, von denen Substantive anderer wortbildender Kategorien abgeleitet sind: začešljati, zadaviti, zagrabiti, zagrliti, zamrežiti, zapleniti, zapretati, zašiljiti, zaštedeti, zaštititi, zatonuti, zavrteti, zažariti.

Einige Verbalsubstantive von Verben mit dem Präfix zaweisen neben der ursprünglichen Bedeutung eine konkrete bzw. $a b-$ strakte auf, und zwar von pf. Verben: zadebljenje 'Verdickung; Wulst' und von ipf. Verben: zadebljavanje 'Verdickung; Wulst', zadubljivanje 'Vertiefen; Vertiefung', zamršivanje 'Verwirren; Verwickeltheit, Verworrenheit'.

Ableitungen mit dem Formans $-n j(e)$

Bed.: Ria, a) vom pf. Aspekt, 4. vom Stamm des Partizip Präteritum Passiv, der 4. Konjugation

zaokolišenje 'Herumgehen', zaokruženje 'Umzirkeln, Umkreisen'

b) vom ipf. Aspekt, 4. vom Stamm des Partizip Präteritum 
Passiv, der 5. Konjugation

zamatanje 'Einwickeln', zamotavanje 'Einwickeln, Einrollen', zaokretanje 'Umdrehen, Umkehren', zaokružavanje 'Umzirkeln, Umkreisen, Abrunden', zaošijavanje 'Umschwenken, Hinschleudern', zavraćanje 'Zurückziehen, Aufschlagen'

der 6. Konjugation

zaokruživanje 'Umkreisen', zasukivanje 'Aufkrempeln, Aufschürzen', zavezivanje 'Verbinden, Zubinden'

der 4. Konjugation

zaobilaženje 'Herum-, Umgehen'

Bed.: Rlb, b) vom ipf. Aspekt, 4. vom Stamm des Partizip Präteritum Passiv, der 5. Konjugation

zadevanje 'An-, Aufstecken', zagledanje 'Besehen, Beschauen', zagrtanje 'Umhängen, Uberschlagen', zahvatanje 'Fassen, Ergreifen', zakapčanje, zakopčavanje 'Zuknöpfen', zamakanje 'Eintauchen, Eintunken', zaogrtanje 'Umwerfen, Umhängen', zaparavanje 'Abbrühen', zapasanje 'Umgürten', zapiranje 'Abwaschen', zapljuvavanje 'Bespucken', zaprezanje 'An-, Vorspannen', zarobljavanje 'Gefangennehmen; Versklaven', zaturanje 'Hineinstechen'

der 6. Konjugation

zakučivanje 'Anhängen', zamazivanje 'Beschmieren', zaparivanje 'Abbrühen', zapljuskivanje 'Vollschlagen (von Wellen)', zaprašivanje 'Bestauben', zarobljivanje 'Gefangennehmen', zarubljivanje 'Einsäumen', zatrnjivanje 'Verdornen'

Bed.: Rlc, b) vom ipf. Aspekt, 4. vom Stamm des Partizip Präteritum Passiv, der 5. Konjugation zaranjanje, zaronjavanje 'Eintauchen'

der 6. Konjugation

zaluživanje 'Einlaugen', zaronjivanje 'Eintauchen'

Bed.: Rld, a) vom pf. Aspekt, 4. vom Stamm des Partizip Präteritum Passiv, der 4. Konjugation

zapamćenje 'Erinnern'

b) vom ipf. Aspekt, 4. vom Stamm des Partizip Präteritum Passiv, der 5. Konjugation

zabeležavanje 'Auf-, Verzeichnen, Notieren' 
zacrtavanje 'Aufzeichnen'

der 6. Konjugation

zapamćivanje 'Erinnern', zapisivanje 'Auf-, An-, Einschreiben', zatajivanje 'Verheimlichen'

Bed.: Rle, b) vom ipf. Aspekt, 4. vom Stamm des Partizip Präteritum Passiv, der 5. Konjugation

zadajanje, zadojavanje 'Säugen, Stillen',

zapajanje 'Tränken'

der 6. Konjugation

zahranjivanje 'Ernähren'

Bed.: Rlf, b) vom ipf. Aspekt, 4. vom Stamm des Partizip Präteritum Passiv, der 5. Konjugation

zalemljavanje 'Verlöten', zaprečavanje 'Ver-, Absperren', zasejavanje, zasevanje 'Besäen', zasvodjavanje 'Einwölben', zatapanje 'Zuschmelzen', zatrpavanje 'Ver-, Zuscharren', zaustavljanje 'An-, Zurückhalten', zauzdavanje 'Aufzäumen', zažimanje 'Zudrücken'

der 6. Konjugation

zagaćivanje 'Eindämmen, Eindeichen', zaglibljivanje

'Indenkotversenken; Indiepatschebringen', zajaživanje

'Ab-, Verdämmen', zasadjivanje 'Anpflanzen', zavarivanje 'Schweissen'

Bed.: RIg, b) vom ipf. Aspekt, 4. vom Stamm des Partizip Präteritum Passiv, der 6. Konjugation

zabranjivanje 'Verbieten', zaštićivanje 'Beschützen'

Bed.: Rlh, a) vom pf. Aspekt, 4. vom Stamm des Partizip Präteritum Passiv, der 4. Konjugation

zagušenje 'Erwürgen; Ersticken'

der 1. Konjugation

zaklanje 'Schlachten'

b) vom ipf. Aspekt, 4. vom Stamm des Partizip Präteritum Passiv, der 5. Konjugation

zadiranje 'Zerreissen', zagušavanje 'Erwürgen',

zakidanje 'Abbrechen', zalamanje 'Abbrechen',

zarušavanje 'Niederreissen, Zerstören'

der 6. Konjugation

zagušivanje 'Ersticken', zakidivanje 'Abbrechen' 
Bed.: Rli, b) vom ipf. Aspekt, 4. vom Stamm des Partizip Präteritum Passiv, der 6. Konjugation

zamahivanje 'Einebewegungmachen', zamamljivanje 'An-,

Verlocken', zamenjivanje 'Eintauschen'

Bed.: R2a, b) vom ipf. Aspekt, 4. vom Stamm des Partizip Präteritum Passiv, der 5. Konjugation

zabavljanje 'Verweilen', zanoćavanje 'Ubernachten',

zaostajanje 'Zurück-, Nachbleiben', zaposedanje

'Einnehmen, Besetzen'

der 6. Konjugation

zadanjivanje 'Verweilen'

Bed.: R2b, a) vom pf. Aspekt, 4. vom Stamm des Partizip Präteritum Passiv, der 4. Konjugation

zagadjenje 'Verunreinigen; Verunreinigung', zaledjenje

'Gefrieren', zamračenje 'Verdunkeln, Verfinstern', zamršenje 'Verwirren', zasićenje 'Sättigen; Sättigung'

der 3. Konjugation

zacrnjenje 'Schwarzwerden', zadebljenje 'Verdickung; Wulst', zahladnjenje 'Kaltwerden', zaludjenje 'Irrewerden; Betören', zatamnjenje 'Dunkelwerden'

der 5. Konjugation

začaranje 'Bezaubern, Verhexen; Verhexung'

b) vom ipf. Aspekt, 4. vom Stamm des Partizip Präteritum Passiv, der 5. Konjugation

začadjavanje 'Russigmachen', začaravanje 'Bezaubern, Behexen', zadebljavanje 'Verdickung; Wulst', zagrevanje

'Erwärmen', zakrečavanje 'Weissen', zakržljavanje

'Verkümmern', zamadjijavanje 'Bezaubern; Bezauberung', zamaranje 'Müdemachen', zamrzavanje 'Gefrierenmachen', zamršavanje 'Verwirren, Verwickeln', zanavljanje

'Erneuern', zaobljavanje 'Abrunden; Abrundung', zaoštravanje 'Zuspitzen, Schärfen', zaravnavanje

'Abflachen, Ebenen, Ausgleichen', zasićavanje 'Sättigen', zaslepljavanje 'Blenden', zasoljavanje 'Salzen', zastarevanje 'Veralten; Verjähren', zatrudnjavanje 'Schwangerwerden'

der 6. Konjugation

zabeljivanje 'Weissen', zabunjivanje 'Verlegenmachen, Verwirren', zaceljivanje 'Verheilen', zadubljivanje

'Vertiefen; Vertiefung', zagojaćivanje 'Schmutzund 783954793105 
unordnungmachen', zagušćivanje 'Verdichten', zakuživanje 'Verpesten', zaledjivanje 'Vereisen', zalučivanje 'Absondern, Entwöhnen', zaludjivanje 'Irrewerden', zamagljivanje 'Vernebeln', zamračivanje

'Verdunkeln, Verfinstern', zamršivanje 'Verwirren; Verwickeltheit', zamucivanje 'Trübemachen', zamukivanje

'Verstummen', zasićivanje 'Sättigen', zasladjivanje 'Süssen', zaslepljivanje 'Blenden', zasušivanje

'Vertrocknen', zašiljivanje 'Zuspitzen', zatupljivanje

'Abstumpien'

Bed.: R2c, a) vom pf. Aspekt, 4. vom Stamm des Partizip Präteritum Passiv, der 4. Konjugation

zapopljenje 'Ordinieren'

b) vom ipf. Aspekt, 4. vom Stamm des Partizip Präteritum Passiv, der 5. Konjugation

zadevojčavanje 'Zummädchenmachen', zamomčavanje

'Zumjungenmachen'

der 6. Konjugation

zakaludjerivanje 'Einkleiden'

Bed.: R3, b) vom ipf. Aspekt, 4. vom Stamm des Partizip Präteritum Passiv, der 5. Konjugation

zastrašavanje 'Abschrecken'

der 6. Konjugation

zamesivanje, zamešivanje 'Anrühren', zapaljivanje

'Anzünden', zastrašivanje 'Abschrecken'

b) za- als leeres Präfix

Die Ableitungsverfahren: I. Suffigierung

Die wortbildenden Typen nach ihren Formantien sowie ihre Produktivität :

Neutra: I. $-n j(e)$ (34)

Die Ableitungsstämme und die Konjugationen:

Neutra: I. 4. Stamm des Partizip Präteritum Passiv der 5., 6., 4. Konjugation

Der Aspekt der Ableitungsbasis:

Neutra: I. 8 pf. und 26 ipf. Verben

Lediglich durch pf. Verben sind folgende Verbalsubstantive motiviert: zajamčenje 'Verbürgen', zalečenje 'Heilen, Verheilen'. 
Verbalsubstantive, die durch den pf. und ipf. Aspekt des ableitenden Verbs motiviert sind: pf. zadocnjenje - ipf. zadocnjivanje 'Verspäten; Verspätung', pf. zakašnjenje - ipf. zakašnjavanje, zakašnjivanje 'Verspäten; Verspätung', pf. zamirenje ipf. zamirivanje 'Beschwichtigen', pf. zapaljenje - ipf. zapaljivanje 'Entzünden; Entzündung', pf. zaprepašćenje - ipf. zaprepašćivanje 'Erstaunen', pf. zasvedočenje - ipf. zasvedočavanje 'Bezeugen'.

Einige Verbalsubstantive von Verben mit dem Präfix zaweisen neben der ursprünglichen Bedeutung eine konkrete bzw. abstrakte auf, und zwar von pf. Verben: zadocnjenje 'Verspäten; Verspätung', zakašnjenje 'Verspäten; Verspätung', zapaljenje 'Entzünden; Entzündung' .

Ableitungen mit dem Formans $-n j(e)$

a) vom pf. Aspekt, 4. vom Stamm des Partizip Präteritum Passiv, der 4. Konjugation

zadocnjenje 'Verspäten; Verspätung', zajamčenje 'Verbürgen', zakašnjenje 'Verspäten; Verspätung', zalečenje 'Heilen, Verheilen', zamirenje 'Beschwichtigen', zapaljenje 'Entzünden; Entzündung', zaprepašćenje 'Erstaunen, Erschrecken', zasvedočenje 'Bezeugen'

b) vom ipf. Aspekt, 4. vom Stamm des Partizip Präteritum Passiv, der 5. Konjugation

začikavanje 'Necken, Herausfordern', zadivljavanje 'Begeistern', zadobijanje 'Bekommen, Erlangen', zadocnjavanje 'Verspäten', zakašnjavanje 'Verspäten', zakrštanje 'Bekreuzen', zamiranje 'Sterben', zamišljanje 'Denken', zanovetanje 'Faselei, Gefasel', zapažanje 'Bemerken', zapetljavanje 'Durcheinanderbringen', započinjanje 'Anfangen', zasvedočavanje 'Bezeugen', začaravanje 'Betrügen', zavijanje 'Heulen (langgezogen)', završavanje 'Abschliessen, Vollenden'

der 6. Konjugation

zadocnjivanje 'Verspäten', zahvaljivanje 'Danken', zakašnjivanje 'Verspäten', zalagivanje 'Belügen', zaljeskavanje 'Widerspiegeln', zamirivanje 'Beschwichtigen', zapaljivanje 'Anzünden', zatrudnjivanje 'Belästigen', zavarivanje 'Vortäuschen', završivanje 'Verrichten, Ausüben' 
Schlussbemerkungen

1. Nomina actionis im engeren Sinne

2a) Nomina actionis im engeren Sinne sind mit folgenden in quantitativer Reihenfolge aufgeführten Präfixen in lexikalischer Funktion gebildet: do-, iz-, za-, na-.

Nomina actionis im engeren Sinne sind mit folgenden in quantitativer Reihenfolge aufgeführten Präfixen in modifizierender Funktion gebildet: za-, do-, iz-, na-.

Nomina actionis im engeren Sinne sind mit folgenden in quantitativer Reihenfolge aufgeführten Präfixen in rein perfektivierender Funktion gebildet: a) mit reihenden Präfixen: za-, na-, iz- und b) leeren Präfixen: na-, iz- und za- (letztere mit gleich grosser Belegzahl).

Es kann (s. Tabelle $9 a$ ) in rein quantitativer Hinsicht eine weniger starke Affinität von Verben mit do-, iz- in lexikalischer, dem reihenden Präfix za- und dem leeren na- in rein perfektivierender Funktion, eine schwache von solchen mit za-, nain lexikalischer, den reihenden na-, iz- in rein perfektivierender und za- in modifizierender Funktion und eine sehr schwache von solchen mit den leeren Präfixen iz-, za- in rein perfektivierender und do-, iz-, na- in modifizierender Funktion zu nomina actionis im engeren Sinne festgestellt werden.

2b) Nomina actionis im engeren Sinne sind mit Präfixen in folgenden in quantitativer Reihenfolge aufgeführten Funktionen gebildet: der lexikalischen, rein perfektivierenden mit reihenden Präfixen, rein perfektivierenden mit leeren Präfixen und modifizierenden Funktion.

Es kann (s. Tabelle 10) in rein quantitativer Hinsicht eine weniger starke Affinität von Verben mit Präfixen in lexikalischer Funktion und eine schwache von solchen mit reihenden und leeren Präfixen in rein perfektivierender und von solchen mit Präfixen in modifizierender Funktion zu nomina actionis im engeren Sinne konstatiert werden. Eine ausgeprägte Affinität von Verben mit Präfixen einer bestimmten Funktion kann also zu nomina actionis im engeren Sinne nicht festgestellt werden.

Tabelle 9a: Zahlenmässige Angabe über das Vorkommen der nomina actionis im
Tabelle 9b: Angabe über das Vorkommen der nomina actionis im engeren Sinne nach den 
engeren Sinne nach den

Funktionen und Präfixen

sowie dem Aspekt der

ableitenden Verben

Lexikalische Funktion

Aspekt do- iz- na- za-

$\begin{array}{lllll}\text { pf. } & 16 & 20 & 11 & 8\end{array}$

ipf. $\quad \begin{array}{llll}11 & 4 & 7 & 11\end{array}$

$\begin{array}{lllll}\text { Summe } & 27 & 24 & 18 & 19\end{array}$

Modifizierende Funktion

Aspekt do- iz- na- za-

$\begin{array}{lllll}\text { pf. } & 6 & 4 & 1 & 10\end{array}$

ipf. $21-2$

$\begin{array}{lllll}\text { Summe } & 8 & 5 & 1 & 12\end{array}$
Bedeutungen der Präfixe in Zahlen

$$
\begin{aligned}
& \text { do- L1 (8), L2 (1), L3 (16), } \\
& \text { L4 (2) } \\
& \text { iz- L1 (23), L2 (1) } \\
& \text { na- L1 (18) } \\
& \text { za- L1 (11), L2 (3), L3 (1), } \\
& \text { L4 (4) }
\end{aligned}
$$

do- MI (8)

iz- M1 (5)

na- M1 (1)

za- MI (12)

Rein perfektivierende Funktion

a) reihende Präfixe

Aspekt do-iz- na- za-

pf. $\quad-151126$

ipf. - - 63

Summe $\quad-\begin{array}{lll}15 & 17 & 29\end{array}$

b) leere Präfixe

Aspekt do-iz-na- za-

pf. $\quad 5202$

ipf. - - 33

Summe - 5235

$$
\begin{aligned}
& \text { iz- R1 (5), R2 (10) } \\
& \text { na- RI (5), R2 (12) } \\
& \text { za- R1 (25), R2 (3), R3 (1) }
\end{aligned}
$$

Tabelle 10: Angabe über das Gesamtvorkommen der nomina actionis im engeren Sinne nach den Funktionen der Präfixe in Zahlen und Prozenten

Lexikalische Funktion: Summe Prozent

Modifizierende Funktion:

$$
\begin{aligned}
& 88=42,30 \\
& 26=12,50
\end{aligned}
$$

Rein perfektivierende Funktion:
a) reihende Präfixe:
$61=29,32$
b) leere Präfixe:
$33=15,86$ 


\section{Verbalsubstantive}

2a) Verbalsubstantive sind mit folgenden in quantitativer Reihenfolge aufgeführten Präfixen in lexikalischer Funktion gebildet: iz-, do-, za-, na-.

Verbalsubstantive sind mit folgenden in quantitativer Reihenfolge aufgeführten Präfixen in modifizierender Funktion gebildet: na-, do-, za-, iz-.

Verbalsubstantive sind mit folgenden in quantitativer Reihenfolge aufgeführten Präfixen in rein perfektivierender Funktion gebildet: a) mit reihenden Präfixen: za-, iz-, naund b) leeren Präfixen: na-, za-, iz-.

Es kann (s. Tabelle lla) in rein quantitativer Hinsicht eine sehr starke Affinität von Verben mit dem reihenden Präfix za- in rein perfektivierender Funktion, eine starke von solchen mit izin lexikalischer und dem reihenden iz- in rein perfektivierender Funktion, eine weniger starke von solchen mit do-, za-, na- in lexikalischer, dem reihenden na- und den leeren Präfixen na-, za- in rein perfektivierender und na-, do- in modifizierender Funktion, eine schwache von solchen mit za- in modifizierender und dem leeren Präfix iz- in rein perfektivierender Funktion und eine sehr schwache von solchen mit iz- in modifizierender Funktion $z u$ Verbalsubstantiven festgestellt werden.

2b) Verbalsubstantive sind mit Präfixen in folgenden in quantitativer Reihenfolge aufgeführten Funktionen gebildet: der rein perfektivierenden mit reihenden Präfixen, lexikalischen, modifizierenden und rein perfektivierenden mit leeren Präfixen.

Es kann (s. Tabelle 12) in rein quantitativer Hinsicht eine weniger starke Affinität von Verben mit reihenden Präfixen in rein perfektivierender und von solchen mit Präfixen in lexikalischer Funktion und eine schwache von solchen mit Präfixen in modifizierender und von solchen mit leeren Präfixen in rein perfektivierender Funktion zu Verbalsubstantiven konstatiert werden. Eine ausgeprägte Affinität von Verben mit Präfixen einer bestimmten Funktion kann also $z$ Verbalsubstantiven nicht festgestellt werden.

Tabelle lla: Zahlenmässige Angabe über das Vorkommen der Verbalsubstantive nach den Funktionen und Präfixen
Tabelle 1lb: Angabe über das Vorkommen der Verbalsubstantive nach den Bedeutungen der Präfixe in Zahlen 
sowie dem Aspekt der

ableitenden Verben

Lexikalische Funktion

Aspekt do- iz- na- za-

$\begin{array}{lllll}\text { pf. } & 8 & 15 & 2 & 2\end{array}$

ipf. $\quad \begin{array}{llll}60 & 72 & 28 & 41\end{array}$

$\begin{array}{lllll}\text { Summe } & 68 & 87 & 30 & 43\end{array}$

Modifizierende Funktion

Aspekt do-iz-na- za-

pf. $3-31$

$\begin{array}{lllll}\text { ipf. } \quad 27 & 6 & 28 & 25\end{array}$

Summe $\quad \begin{array}{llll}30 & 6 & 31 & 26\end{array}$

$$
\begin{aligned}
& \text { do- Ll (27), L2 (12), L3 (25), } \\
& \text { L4 (4) } \\
& \text { iz- Ll (81), L2 (6) } \\
& \text { na- Ll (30) } \\
& \text { za- L1 (21), L2 (10), L3 (6), } \\
& \text { I4 (6) }
\end{aligned}
$$

Rein perfektivierende Funktion

a) reihende Präfixe

Aspekt do-iz-na- za-

pf. $\quad-20 \quad 4 \quad 17$

ipf. $\quad-73 \quad 33121$

Summe - $93 \quad 37138$

b) leere Präfixe

Aspekt do- iz- na- za-

pf. $\quad-\quad 5108$

ipf. $\quad-122926$

Summe $\quad-17 \quad 39 \quad 34$ iz- RI (40), R2 (53)

na- R1 (10), R2 (27)

za- RI (74), R2 (60), R3 (4)

Tabelle 12: Angabe über das Gesamtvorkommen der Verbalsubstantive nach den Funktionen der Präfixe in Zahlen und Prozenten

Lexikalische Funktion:

Modifizierende Funktion:

Summe Prozent

Rein perfektivierende Funktion:

a) reihende Präfixe:

$228=33,57$

b) leere Präfixe:

$93=13,69$

$268=39,46$

$90=13,25$ 


\section{ZUSAMMENFASSUNG}

Die vorliegende Arbeit ist eine Abhandlung über substantivische Ableitungen von präfigierten Verben mit den Präfixen do-, iz-, na-, za- in der modernen serbokroatischen Standardsprache. Ihr Ziel ist es, an Hand einer Klassifikation der präfigierten deverbalen Substantive nach onomasiologischen bzw. wortbildenden Kategorien sowie nach den Funktionen und Bedeutungen der Präfixe der zugrunde liegenden Verben festzustellen, ob eine Affinität zwischen den Präfixen der ableitenden Verben und den von ihnen abgeleiteten Substantiven besteht, d.h. ob die Funktionen und Bedeutungen der Präfixe der ableitenden Verben sozusagen eine Prädisposition zur Bildung von Substantiven bestimmter onomasiologischer bzw. wortbildender Kategorien haben.

Im ersten Teil sind die allgemeinen Prinzipien und Ansichten für eine möglichst adäquate Behandlung der gestellten Aufgabe formuliert.

Die Vorstellungen von den Funktionen der Präfixe im Verb werden im Einklang mit den Konzeptionen von Poldauf, Vey, Kopečnł, Grickat u.a. dargelegt. Danach üben Präfixe in präfigierten Verben drei Funktionen aus, und zwar eine lexikalische, eine modifizierende und eine rein perfektivierende.

Unter Präfixen mit lexikalischer Funktion werden solche verstanden, die das spezifizieren, was man das externe Bedeutungspotential des zugrunde liegenden Verbs nennen könnte.

Unter Präfixen mit modifizierender Funktion werden solche verstanden, die den Ablauf in der Zeit spezifizieren, der generell eine interne Komponente der Bedeutung der Wortart Verb darstellt.

Unter Präfixen mit rein perfektivierender Funktion werden solche verstanden, die lediglich rein aspektale Beziehungen zwischen den unpräfigierten imperfektiven Verben und den von ihnen abgeleiteten präfigierten perfektiven Verben herstellen, ohne die lexikalische Bedeutung der ableitenden Verben $z u$ verändern. $\mathrm{Zu}$ den Präfixen mit rein perfektivierender Funktion werden sowohl "reihende", d.h. solche mit semantischem Gehalt als auch "leere" Präfixe gezählt, d.h. solche ohne semantischen Gehalt.

Bei der Bestimmung der Funktionen wird ausschliesslich von den semantischen Beziehungen ausgegangen, die zwischen den Präfixen und den Simplizia herrschen. Das sekundäre Imperfektiv wird 
als Kriterium zur Bestimmung der Funktionen nicht herangezogen.

Es wird eine Auffassung vom Aspekt vertreten, nach der die Resultativität ein Merkmal der Perfektivität im Aspektpaar ist.

Die Klassifikation der von präfigierten Verben abgeleiteten Substantive erfolgt nach der Wortbildungstheorie des tschechischen Linguisten Dokulil, die das wort in seiner Ganzheit als einen Komplex von semantischer und formaler Seite aufasst. Das grundlegende Element dieser Theorie ist der Begriff der onomasiologischen Kategorien, die die Begriffsinhalte generell strukturieren, ganz von der Form des Wortes abstrahiert sind und in gewisser Weise ein Bindeglied zwischen der aussersprachlichen Erscheinung, die benannt werden soll, und der Sprache darstellen, die diese Erscheinung auf eine bestimmte Weise realisieren und ausdrücken soll.

Der Realisierung der onomasiologischen Struktur eines bestimmten Begriffsinhalts im Rahmen einer Einwortbenennung dienen in dem vorliegenden Material die wortbildenden Verfahren der Suffigierung und Konversion.

Der Beschreibung des Begriffs der Konversion liegt die Auffassung von Dokulil zugrunde, die die spezifischen Besonderheiten der slavischen Sprachen berücksichtigt. Unter Konversion wird das Verfahren der Bildung eines neuen wortes auf der Basis eines in der Sprache schon existierenden ohne den Umbau seines Stamms, d.h. allein durch Anderung seines Paradigmas bei möglichen gleichzeitigen Lautalternationen verstanden.

Die eigentliche Klassifizierung des Materials erfolgt nach den wortbildenden Kategorien und Typen sowie deren Unterabteilungen.

Der wortbildende Typ, der der Realisation der onomasiologischen Kategorien auf der wortbildenden Ebene dient, ist nach Dokulil definiert durch eine bestimmte allgemeine onomasiologischsemantische Struktur, eine bestimmte formale wortbildende Struktur und ein bestimmtes Formans.

Durch eine Abstraktion vom Formans erhält man die wortbildende Kategorie.

Im zweiten Teil der Arbeit erfolgt die Klassifizierung des Materials nach wortbildenden Kategorien, wortbildenden Typen sowie deren Unterkategorien und Untertypen sowie nach den Funktionen und Bedeutungen der Präfixe der ableitenden Verben.

Aufgrund der Klassifikation der von präfigierten Verben ab-

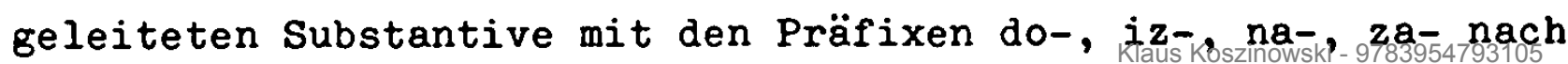


den oben angeführten Prinzipien und in Ubereinstimmung mit den (S. 12ff.) gestellten Fragen nach einer semantisch motivierten und einer rein quantitativ konstatierten Affinität können folgende Feststellungen gemacht werden:

1. Die Frage nach einer semantisch motivierten Affinität ist nur für nomina loci von Verben mit Präfixen in lexikalischer Funktion positiv zu beantworten. Da die überwiegende Mehrzahl der Bedeutungen der Präfixe in lexikalischer Funktion lokalen Charakter haben, kann eine semantisch motivierte Affinität von ihnen zu anderen onomasiologischen bzw. wortbildenden Kategorien nicht konstatiert werden.

2. Die Frage nach einer quantitativ konstatierten Affinität kann wie folgt beantwortet werden:

Es besteht generell die ausgeprägteste Affinität von Verben mit Präfixen in lexikalischer Funktion zu folgenden onomasiologischen bzw. wortbildenden Kategorien in diesen Abstufungen: eine sehr starke Affinität zu nomina loci, eine starke zu nomina instrumenti und nomina agentis, eine weniger starke zu nomina actionis im engeren Sinne und Verbalsubstantiven und eine schwache zu nomina resultativa.

Es besteht generell eine schwache bzw. sehr schwache Affinität von Verben mit Präfixen in modifizierender Funktion zu folgenden onomasiologischen bzw. wortbildenden Kategorien in diesen Abstufungen: eine schwache Affinität zu nomina resultativa, nomina actionis im engeren Sinne, Verbalsubstantiven und eine sehr schwache Affinität zu nomina agentis, nomina loci und nomina instrumenti.

Es besteht generell eine schwache bis weniger starke Affinität von Verben mit reihenden Präfixen in rein perfektivierender Funktion $\mathrm{zu}$ folgenden onomasiologischen bzw. Wortbildenden Kategorien in diesen Abstufungen: eine weniger starke Affinität zu nomina resultativa und Verbalsubstantiven und eine schwache Affinität zu nomina actionis im engeren Sinne, nomina instrumenti, nomina agentis und nomina loci.

Es besteht generell eine schwache Affinität von Verben mit leeren Präfixen in rein perfektivierender Funktion zu folgenden onomasiologischen bzw. wortbildenden Kategorien in diesen Abstufungen: eine schwache Affinität zu nomina actionis im engeren Sinne, Verbalsubstantiven, nomina agentis und eine sehr schwache Affinität zu nomina instrumenti und nomina resultativa; keine Belege sind für nomina loci vorhanden. 
Keine ausgeprägte Affinität in quantitativer Hinsicht kann also von Verben mit Präfixen einer bestimmten Funktion zu nomina actionis konstatiert werden. Bei den nomina actionis, die zum Transpositionstyp gezählt werden, kann a priori aufgrund ihrer primär rein syntaktischen Funktion der Nominalisierung, wobei es zu keiner Anderung der lexikalischen Bedeutung des abgeleiteten Wortes, sondern lediglich zu einem Wechsel der Wortart kommt, kein semantisch bedingter Zusammenhang zur Ableitungsbasis erwartet werden. Dem gegenüber werden bei den dem Mutationstyp angehörenden Ableitungen wortbildender Kategorien neue lexikalischgrammatische Einheiten gebildet. Ableitungsgrundlage und abgeleitetes Wort stehen, entsprechend dem Charakter des ableitenden Wortes, in dem die Funktionen und Bedeutungen der Präfixe besondere Berücksichtigung finden, zueinander in semantischer Relation verschiedener Intensität, die ihren Ausdruck in einer gewissen Affinität von Ableitungen $z u$ bestimmten onomasiologischen bzw. wortbildenden Kategorien findet.

Es kann also gezeigt werden, dass zumindest tendenziell eine gewisse Affinität von den Präfixen der ableitenden Verben zu ihren Ableitungen besteht, ungeachtet der Tatsache, dass Präfixe in diesen Ableitungen keine wortbildende Funktion ausüben.

Die Vermutung, dass sich reihende Präfixe ähnlich verhalten wie lexikalische, da sowohl lexikalische als auch reihende einen semantischen Gehalt haben, wobei allerdings durch erstere ein neues Bedeutungselement dem Inhalt des Simplex hinzugefügt wird, während bei letzteren lediglich eine bestimmte Komponente des Simplexinhalts noch einmal herausgehoben wird, dass also reihende Präfixe zu Ableitungen, die zu onomasiologischen bzw. wortbildenden, eine sehr grosse Affinität zu Präfixen in lexikalischer Funktion (nomina loci, nomina instrumenti) aufweisenden Kategorien gehören, eine entsprechende Affinität zeigen, hat sich nicht bestätigt. Ableitungen von Verben mit reihenden Präfixen sind vielmehr in einem fast gleich hohen Prozentsatz bei allen wortbildenden Kategorien, mit Ausnahme der nomina resultativa, die, wie oben gezeigt wurde, die grösste Affinität zu Verben mit Präfixen in rein perfektivierender Funktion haben, vertreten.

Andererseits jedoch besteht eine gewisse, wenn auch sehr geringe Tendenz, Substantive weniger häufig von Verben mit leeren Präfixen abzuleiten, sofern sie wortbildenden Kategorien angehören, die eine sehr grosse Affinität zu Präfixen in lexikalischer Funktion haben (in Prozent: nomina loci (0), nomina instrumenti 
$(6,84)$, nomina agentis $(12,10)$. Es könnte angenommen werden, dass die geringe Zahl der Ableitungen von Verben mit leeren Präfixen bei wortbildenden Kategorien des genannten Typs, zurückzuführen ist auf ihre teilweise Ersetzung durch Verben mit reihenden Präfixen, entsprechend dem Grad der Affinität der jeweiligen wortbildenden Kategorie zu den lexikalischen Präfixen. Bei dieser Annahme könnte also indirekt von einer grösseren Affinität der reihenden Präfixe zu Ableitungen von Verben mit lexikalischen Präfixen dank ihrer konkreten Eigenschaft gesprochen werden. Allerdings ist der Unterschied hinsichtlich des Prozentsatzes der Ableitungen von leeren Präfixen zwischen den einzelnen wortbildenden Kategorien so gering, dass sich kaum Schlussfolgerungen auf das Verhalten der reihenden Präfixe ziehen lassen. Hinzu kommt, dass nur 3,82 Prozent der nomina resultativa von leeren Präfixen abgeleitet sind, obwohl gerade sie die geringste Affinität $z u$ Präfixen in lexikalischer Funktion aufweisen. Ausserdem müsste die hypothetische Substitution der leeren durch die reihenden Präfixe auf signifikante Weise ihren Ausdruck finden in der Frequenz der Ableitungen von reihenden Präfixen, was sich aber bereits als unzutreffend erwiesen hat.

Zusammenfassend kann festgestellt werden, dass die konkrete Bedeutung der reihenden Präfixe in rein perfektivierender Funktion keinen bzw. nur einen ganz geringen Einfluss auf die zuordnung von Ableitungen $z u$ onomasiologischen bzw. wortbildenden Kategorien hat, dass sich demnach für die Fragestellung nach der Affinität zwischen den Präfixen der ableitenden Verben und den von ihnen abgeleiteten Substantiven die Zweiteilung der Präfixe in rein perfektivierender Funktion in reihende und leere als irrelevant erwiesen hat; denn der Grad der Affinität der Präfixe in rein perfektivierender Funktion, betrachtet als eine Einheit, $\mathrm{zu}$ ihren Ableitungen, ändert sich gar nicht oder nur unwesentlich, addiert man jeweils die Belegzahlen für die Ableitungen von reihenden und leeren Präfixen. 


\section{SIGELVERZEICHNIS}

I. Zeitschriften 222

$\begin{array}{ll}\text { BTJ } & \text { Biuletyn Polskiego Towarzystwa Jęzkoznawczego } \\ \text { CMF } & \text { Casopis pro moderni filologii } \\ \text { CR } & \text { Ceskoslovenská rusistika } \\ \text { FN } & \text { Filologičeskie nauki } \\ \text { IF } & \text { Indogermanische Forschungen } \\ \text { IJSLP } & \text { International Journal of Slavic Linguistics and } \\ & \text { Poetics } \\ \text { JC } & \text { Jazykovedný časopis } \\ \text { JPol } & \text { Jezyk Polski } \\ \text { JF } & \text { Južnoslovenski filolog } \\ \text { NJ } & \text { Naš jezik } \\ \text { PorJ } & \text { Poradnik Jezykowy } \\ \text { PF } & \text { Prace Filologiczne } \\ \text { RES } & \text { Revue des Etudes slaves } \\ \text { RS } & \text { Rocznik Slawistyczny } \\ \text { RJ } & \text { Ruský jazyk } \\ \text { SCSI } & \text { Scandoslavica } \\ \text { SI } & \text { Slavia } \\ \text { SO } & \text { Slavia Occidentalis } \\ \text { SlOr } & \text { Slavia Orientalis } \\ \text { SISl } & \text { Slavica Slovaca } \\ \text { SRL } & \text { Slavistična revija } \\ \text { SR } & \text { Slovenská reč } \\ \text { SS } & \text { Slovo a Slovesnost } \\ \text { TLP } & \text { Travaux linguistiques de Prague } \\ \text { Vja } & \text { Voprosy jazykoznanija } \\ \text { WZUL } & \text { Wissenschaftliche Zeitschrift der Karl-Marx-Uni- } \\ & \text { versität Leipzig. Gesellschafts- und sprachwis- } \\ \text { ZfSl } & \text { Zenschaftliche Reihe. } \\ & \end{array}$

222 Die Abkürzungen erfolgen nach der Konvention des Rocznik Slawistyczny. 
II. Sprachen

$\begin{array}{ll}\text { čech. } & \text { tschechisch } \\ \text { pol. } & \text { polabisch } \\ \text { poln. } & \text { polnisch } \\ \text { russ. } & \text { russisch } \\ \text { skr. } & \text { serbokroatisch }\end{array}$

III. Qualifikatoren

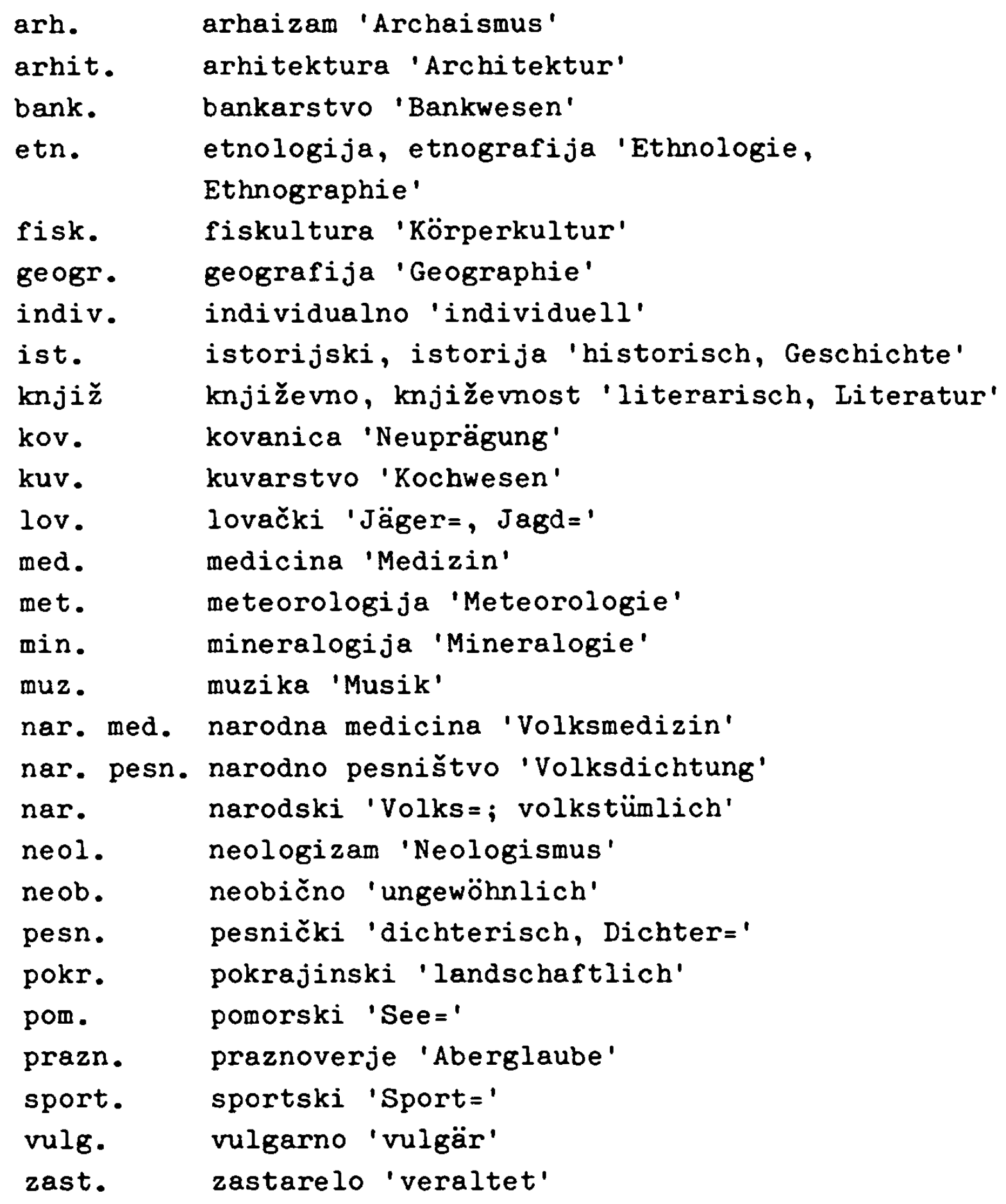


IV. Sonstige Abkürzungen

ipf. imperfektiv

itr. intransitiv

pf. perfektiv

P1. Plural

Sg. Singular

tr. transitiv

I lexikalisch

$M$ modifizierend

$R$ reihend

Il Die Zahlen beziehen sich auf die verschiedenen Präfixbedeutungen

Rla Die Kleinbuchstaben beziehen sich auf die verschiedenen Bedeutungsnuancen 


\section{LITERATURVERZEICHNIS}

I. Wörterbücher

Rečnik srpskohrvatskoga književnog jezika. Bd. 1-4. Matica Srpska-Matica Hrvatska. Novi Sad-Zagreb 1967. Rječnik hrvatskoga ili srpskoga jezika. Jugoslavenska

akademija znanosti $i$ umjetnosti. Zagreb $1880 \mathrm{ff}$. Rečnik srpskohrvatskog književnog i narodnog jezika.

Srpska akademija nauka. Beograd 1959ff.

Grujić B., Zidar J., Rečnik nemačko-srpskohrvatski i srpskohrvatsko-nemački. Beograd 1962.

Iveković F., Broz I., Rječnik hrvatskoga jezika. 2 Bde. Zagreb 1901.

Ristić S., Kangrga J., Rečnik srpskohrvatskog i nemačkog jezika. Beograd 1928.

- Enzyklopädisches deutsch-serbokroatisches Wörterbuch. Zweite wesentlich verbesserte und erweiterte Auflage. München und Beograd 1963.

Tolstoj I. I., Serbsko-chorvatsko-russkij slovar'. Moskva 1957.

Bielfeldt H.H., Russisch-deutsches Wörterbuch. Berlin 1958.

II. Sekundärliteratur

Achmanova 0. S., Očerki po obščej i russkoj leksikologii. Moskva 1957.

Agrell S., Aspektänderung und Aktionsartbildung beim polnischen Zeitworte. Lund 1908.

Apresian Ju. D., Idei $i$ metody sovremennoj strukturnoj lingvistiki. Moskva 1966.

Arutjunova N. D., Nekotorye voprosy obrazovanija $i$ morfologii osnov slova. In: FN 1958, 1, S. 125-137.

Stat'i G. Marčanda po teorii sinchronnogo slovoobrazovanija. In: Vja 1959, 2, S. 127-131.

Babić M., Nomina agentis izvedena sufiksom -10. In: NJ XVI, 1967, S. 84-92.

Bajec A., Besedotvorje slovenskega jezika. IV. Predlogi in predpone. Ljubljana 1959. 
Baláž G., Abstraktné deverbativa $v$ ruštine, slovenčine a češtine. In: Sovětská jazykověda IV, 1954, S. 12-21. Bares R., Die Nomina auf -dio. Meisenheim am Glan 1970. Belić A., Aorist imperfektivnib glagola. In: IF V, 1925/26, S. 171-182.

- O gradjenju glagolskih imenica na -nje i -će. In: NJ I, 1933, S. 262-268.

- 0 jezičkoj prirodi i jezičkom razvitku. Beograd ${ }^{2} 1958$.

- Savremeni srpskohrvatski književni jezik. II. Nauka o gradjenju reči. Beograd 1964.

Bogusławski A., Jeszcze o zagadnieniach budowy wyrazów. In: PorJ 1962, 4, S. 170-175.

- O zasadach analizy morfologicznej. In: BTJ XVIII, 1959, S. 87-95.

- Perfektivnye glagoly $v$ russkom jazyke. In: S1 XXXII, 1963, S. 17-35.

- Prefiksacja czasownikowa we współczesnym języku rosyjskim. Wrocław-Warszawa-Kraków 1963.

Rez.: E. Sekaninová, in: JC XVI, 1965, S. 205-207.

- Prefiksalne pary aspektowe a semantyka prefiksalna czasownika rosyjskiego. In: SIOr IX, 1960, S. 139-175.

- W sprawie synchronii i diachronii w analizie morfologicznej. In: PorJ I960, 7, S. 321-328.

Bondarko A. V., Vid i vremja russkogo glagola (značenie $i$ upotreblenie). Moskva 1971.

Borodič V. V., Genese slovanského systému vidového. In:

Sbornik otvetov na voprosy po jazykoznaniju (k IV Meždunarodnomu s-ezdu slavistov). Moskva 1958, S. 103-106.

- $K$ voprosu o formirovanii soveršennogo $i$ nesoveršennogo vida $v$ slavjanskich jazykach. In: Vja 1953, 6, S. 68-86.

- K voprosu o vidovych otnošenijach staroslavjanskogo glagola. In: Učenye zapiski Instituta Slavjanovedenija AN SSSR IX, 1954, S. 50-138.

Brabec I., Hraste M., Zivković S., Gramatika hrvatskosrpskoga jezika. Zagreb ${ }^{5} 1963$.

Braun M., Grundzüge der slawischen Sprachen. Göttingen $0 . J$. Brodowska-Honowska M., O pojemności znaczeniowej derywatów.

In: JPol XIIV, 1964, S. 193-200.

- Zarys klasyfikacji polskich derywatów. Wrocław-WarszawaKraków 1967. 
Brugmann K., Delbrück B., Grundriss der vergleichenden Grammatik der indogermanischen Sprachen. Strassburg 1913. Buzássyová $K$., Intencia slovesného deja a deverbativna slovotvorná paradigma. In: JC XXI, 1970, S. 113-124.

- K triedeniu koreñových morfém transformačnou metódou.

In: JC XX, 1969, S. 33-49.

Da.ičić J., Osnove srpskoga ili hrvatskoga jezika.

Beograd 1876.

Danilenko V. P., Vlijaet li upotrebitel'nost' slov na produktivnost' slovoobrazovatel'noj modeli? In: Razvitie slovoobrazovanija sovremennogo russkogo jazyka. Moskva 1966,

S. 38-44.

Delbrück B., Vergleichende Syntax der indogermanischen

Sprachen. Bd. 2. Strassburg 1897.

Diels P., Altkirchenslavische Grammatik. Heidelberg ${ }^{2} 1963$. Djordjić P., Iz istorije našeg književnog jezika. Imenice tipa bdenije. In: NJ IV, 1936, S. 100-107.

- Letenje ili lećenje? In: NJ I, 1933, S. 173-174.

- Połabskie rzeczowniki odsłowne. In: SO XII, 1933, S. 165170.

Dobrzýnska T., Wartość aspektowa i czasowa formacji typu pływak. In: PorJ 1969, 1, S. 7-15.

Dokulil M., Kuchař J., K osnovnym voprosam slovoobrazovatel'noj sistemy slavjanskich jazykov. In: Slavjanska filologija. Ezikoznanie VII, Sofija 1965, S. 362-363. Dokulil M., K pojetí morfologické kategorie. In: JC XVIII, 1967, S. 13-36.

- K základnim otázkám tvořeni slov. In: 0 vědeckém poznáni soudobých jazyku. Praha 1958, S. 154-169.

- Ke koncepci porovnávaci charakteristiky slovanských jazykü v oblasti ("tvořeni slov"). In: SS XXIV, 1963, S. 85-105.

- Tvořeni slov v češtině. 1. Teorie odvozování slov. Praha 1962.

Rez.: K. Horálek, in: RS XXIII, 1964, S. 107-111.

Rez.: G. P. Neščimenko, in: Vja 1962, 5, S. 143-148.

Rez.: J. Vachek, in: SS XXIII, 1962, S. 205-211.

- [u.a.], Trořeni slov v češtině. 2. Odvozováni podstatných jmen. Praha 1967.

Rez.: K. Buzássyová, Tvoření slov I, II, Praha 1962, 1967. In: JC XX, 1969, S. 98-103. 
- Zum wechselseitigen Verhältnis zwischen Wortbildung und Syntax. In: TLP I, 1964, S. 215-224.

- Zur Frage der Konversion und verwandter Wortbildungsvorgänge und -beziehungen. In: TLP III, 1968, S. 215-239.

- Zur Frage der Nullableitung. In: Festschrift H. Marchand. 's-Gravenhage 1967, S. 55-64.

- Zur Frage der Stelle der Wortbildung im Sprachsystem. In: SS XXIX, 1968, S. 9-16.

- Zur Theorie der Wortbildung. In: WZUL XVII, 1968, S. 203-211.

Doroszewski W., Kategorie słowotwórcze. (Les catégories fondamentales de la structure des mots). In: Studia $i$ szkice jezykoznawcze. Warszawa 1962, S. 205-222.

- Monografie słowotwórcze. In: PF XIII, 1928, S. 1-261.

- Nomina loci jako kategoria slowotwórcza. In: SI XXXI, 1962, s. 342-347.

- O transformacjach słowotwórczych wyrazów. In: Z polskich studiów slawistycznych. Językoznawstwo III, Warszawa 1968, S. 5-7.

- 0 znaczeniu dokonanym osnów czasownikowych (słownych) w jezyku polskim. In: PF X, 1926, S. 129-309.

- Podstawy gramatyki polskiej. I. Warszawa 21963.

- Syntaktyczne podstawy słowotwórstwa. In: Z polskich studiów slawistycznych. Jezykoznawstwo III, Warszawa 1963, S. 65-78.

Dostál A., Několik kritických poznámek k poslednim pracim

o vidu slovanského slovesa. In: Sl XXVIII, 1959,

S. 326-346.

- Slovanské sloveso. In: 0 vědeckém poznáni soudobých jazyku. Praha 1958, S. 128-132.

- Studie o vidovém systému v staroslověnštině. Praha 1954. Rez.: Ju. S. Maslov, in: Vja 1956, 3, S. 116-124.

Rez.: R. Ružička, in: ZfSI II, 1957, S. 606-611.

Ferens G. F., O tipach slovoobrazovatel'noj formy slov (na materiale sovremennogo nemeckogo jazyka). In: Vja 1957,6 , S. 88-89.

Fleischer W., Wortbildung der deutschen Gegenwartssprache. Leipzig 1969.

Furdik J., 0 súčasných smeroch slovotvorného výskumu.

In: JC XX, 1969, S. 63-78. 
- Slovotvorná analógia a analogická slovotvorba. In: JC XXI, 1970, S. 54-59.

Gabka K., Zur Abgrenzung lexikalischer, morphologischer und syntaktischer Synonymie. In: ZfSI XII, 1967, S. 727734.

Georgieva E., Semantična charakteristika na otglagolnite sǔštestvitelni na -ne i na -nie $v$ bülgarskija knižoven ezik. In: Slavističen sbornik (po slučaj V Meždunaroden kongres na slavistite v Sofija). Sofija 1963, S. 225-233. Grickat I., Nekoliko zapažanja o glagolskom vidu. In:

Pitanja književnosti i jezika IV u. V,B, 1957/58, S. 29-41.

- O nekim vidskim osobenostima srpskohrvatskog glagola. In: JF XXII, 1957, S. 65-130.

- Prefiksacija kao sredstvo gramatičke (čiste) perfektizacije. In: JF XXVII, 1966/67, S. 185-223.

- Sta daje za proučavanje glagolske semantike čista (gramatička) perfektizacija putem prefiksacije.

In: NJ XVI, 1967, S. 119-126. Grigor'ev V. P., $O$ granicach meždu slovosloženiem $i$ affiksaciej. In: Vja 1966, 4, S. 38-52. Grubor Dj., Aspektna značenja. In: Rad Jugoslavenske akademije znanosti i umjetnosti 293, Zagreb 1953, S. 5-234; Aspektna značenja II. In: Rad Jugoslavenske akademije znanosti i umjetnosti 295, Zagreb 1953, S. 81-284. Rez.: J. Vuković, in: Pitanja književnosti i jezika III, 1956, S. 177-195.

Grzegorczykowa R., Czasowniki odimienne we współczesnym jezzyku polskim. Wrocław-Warszawa-Kraków 1969. Grzegorczykowa R., Puzynina I., Słowotwórstwo a "synchroniczny inwentarz elementów semantycznych". In: PorJ 1960, 10 , S. 433-437.

- Z zagadnień słowotwórstwa synchronicznego. In: PorJ 1959, 6-7, S. 241-253.

Günther E. U. K., Die Haupttypen der nominalen und verbalen Wortbildung im Russischen. In: ZfSI V, I960, S. 446-461. Heinz A., Fleksja a derywacja. In: Jpol XLI, 1961, S. 343354.

Hermann E., Objektive und subjektive Aktionsart. In: IF XIV, 1927, S. 207-228. 
Horecký J., O tvoreni slovies predponami. In: SR XXII, 1957, S. 141-155.

- Slovotvorná sústava slovenčiny. Podstatné meno, pridavné meno, sloveso. Bratislava 1959.

Rez.: R. Laskowski, in: RS XXIII, 1964, S. 112-127.

Iljinskij G., Zur slavischen Wortbildung. In: Archiv für slavische Philologie XXIV, 1902, S. 224-228.

Isačenko A. V., Die russische Sprache der Gegenwart. Teil I. Formenlehre. Halle (Saale) 1962.

- Grammatičeskij stroj russkogo jazyka v sopostavlenii s slovackim. Morfologija, II. Bratislava 1960. Rez.: A. V. Bondarko, in: Vja 1962, 5, S. 137-143. Rez.: L'. D'urovič, in CR VII, 1962, S. 228-236.

- Slovesný vid, slovesná akce a obecný charakter slovesného dĕje. In: SS XXI, 1960, S. 9-16.

Ivančev S., Problemi na aspektualnostta v slavjanskite ezici. Sofija 1971.

Ivanova K., Desemantizacijata na glagolnite predstavki v sŭvremennija bŭlgarski knižoven ezik. Sofija 1966.

- Po njakoi vüprosi na glagolnata prefiksacija v bülgarskija ezik. In: Slavističen sbornik (po slučaj $V$ Meždunaroden kongres na slavistite v Sofija). Sofija 1963, S. 193-208.

- Razvoj i upotreba na vtoričnite nesvüršeni glagoli v novobŭlgarskija knižoven ezik. In: Izvestija na Instituta za bülgarski ezik pri BAN XV, Sofija 1968.

- vŭrchu vzaimootnošenieto na glagolnata prefiksacija i kategorijata prechodnost/neprechodnost $v$ süvremennija bülgarski knižoven ezik. In: Slavističen sbornik, Sofija 1968, S. 155-163.

Jacobsohn H., Aspektfragen. In: IF LI, 1933, S. 292-318. Jelínek M., K nominálnimu zpủsobu vyjadrováni. In: Slavica Pragensia IV, 1962, S. 629-634.

- Podstatná jména slovesná se zvratným zájmenem. In: NR 46, 1963, S. 229-236.

Jur'eva E. Ju., K voprosu o prefiksal'nom slovoobrazovanii suščestvitel'nych $\mathrm{v}$ sovremennom francuzskom jazyke.

In: FN 1963, 1, S. 102-111.

Karcevski (Karcevskij) S., Etudes sur le système verbal du russe contemporain. II. Mécanisme des aspects. In: SI I, 1922 , S. $495-523$. 
- Système du verbe russe. Essai de linguistique synchro- nique. Prague 1926.

Kawyn-Kurzowa Z, Kształtowanie sie metod analizy słowotwórczej wyrazu w jezykoznawstwie polskim XX wieku. In: PF XVIII, 1964, S. 223-241.

Ködderitzsch R., Die Nomina auf -išče, -išča, -isko in den ostslavischen Sprachen. Meisenheim am Glan 1969. KölIn H., Die Entstehung des slavischen Verbalaspektes. Die imperfektiven Ableitungen zu präfigierten Verben in ihrem Verhältnis zur Determinationskategorie und zum System der Verbalformen. In: ScSl IV, 1958, S. 308-313. Kolman 0., Još nešto o rečima na -ište. In: NJ II, 1934 , S. 13-19.

Kopečný F., Bemerkungen zu zwei Arbeiten über die schlechthin perfektivierenden Vorsilben im Tschechischen.

In: ZfSl IV, 1959, S. 112-118.

- Dvě nové práce o prostě vidových predponách v češtinĕ. In: SS XVII, 1956, S. 28-35.

- Les fonctions de la préfixation verbale en tchèque moderne. In: RES XXXIII, 1956, S. 84-97.

- Slovesný vid $v$ češtině. Praha 1962.

Rez.: I. Němec, in: SI XXXII, 1963, S. 91-99.

- Základy české skladby. Praha 1958.

Koschmieder E., Nauka o aspektach czasownika polskiego w zarysie. Próba syntezy. Wilno 1934.

- Zeitbezug und Sprache. Ein Beitrag zur Aspekt- und Tempusfrage. Leipzig und Berlin 1929.

- Studien zum slavischen Verbalaspekt. In: Zeitschrift für vergleichende Sprachforschung LVI, 1929, S. 78-105. Kovalyk I.I., Včennja pro slovotvir. (Slovotvorči častyny slova). L'viv 1958.

Koziol H., Wortbildungslehre. Heidelberg 1937.

Křižková H., K problematice podstatných jmen slovesných $v$ ruštině v porovnáni s češtinou. In: RJ IX, 1959, S. 195-203.

Krylov N. A., Tipy osnov v sovremennom russkom jazyke.

In: FN 1963, 2, S. 31-43.

Kubrjakova E. S., Cto takoe slovoobrazovanie. Moskva 1965. Kuchă̌ J., K obščej charakteristike nominacii. In: TLP III, 1968, S. 119-129. 
- Základni rysy struktur pojmenování. In: SS XXIV, 1963, S. $105-114$.

Kuryłowicz J., La genèse d'aspects verbaux slaves. In: PF XIV, 1929, S. 644-657.

- Pochodzenie słowiańskich aspektów czasownikowych. In: Sbornik praci I. Sjezdu slovanských filologu v Praze 1929. II. Přednášky. Praha 1932, S. 572-576. Kyršova M. P., Imennyky $z$ sufiksom -ište $v$ serbochorvats'kij movi. In: Ukrains'ke slov-janoznavstvo VII, 1972 , S. 33-45.

Laskowski R., Wróbel H., Użycie paradygmatu w funkcji formantu słowotwórczego we współczesnej polszczýnie. In: JPol XIIV, 1964, S. 214-220.

Lekov I., Slovoobrazovatelni sklonnosti na slavjanskite ezici. Sofija 1958.

Leskien A., Grammatik der serbo-kroatischen Sprache.

1. Teil: Lautlehre, Stammbildung, Formenlehre.

Heidelberg 1914.

- Handbuch der altbulgarischen Sprache. Heidelberg ${ }^{8} 1962$.

Levkovskaja K. A., O principach strukturno-semantičeskogo analiza jazykovych edinic (na materiale nemeckogo jazyka). In: Vja 1957, 6, S. 4l-55.

- O slovoobrazovanii i ego otnošenii k grammatike. In: Voprosy teorii $i$ istorii jazyka $v$ svete trudov $I . V$. Stalina po jazykoznaniju. Moskva 1952, S. 153-181.

- O specifike prefiksacii v sisteme slovoobrazovanija. In: Voprosy grammatičeskogo stroja. Moskva 1955, S. 299-321.

- Slovoobrazovanie. Moskva 1954.

Lichtman R. I., Suščestruet $l i$ bezaffiksnyj sposob slovoobrazovanija v russkom jazyke? In: Vja 1968, 2, S. 51-59. Lopatin I. S., Uluchanov I. S., Postroenie razdela "Slovoobrazovanie". In: Osnovy postroenija opisatel'noj grammatiki sovremennogo russkogo literaturnogo jazyka. Moskva 1966, S. 50-127.

Lopatin V. V., Substantivacija kak sposob slovoobrazovanija v sovremennom russkom jazyke. In: Russkij jazyk. Grammatičeskie issledovanija. Moskva 1967, S. 205-233. Marchand H., Die Ableitung desubstantivischer Verben mit Nullmorphem im Französischen und die entsprechenden Verhältnisse im Englischen und Deutschen. In: Zeitschrift 
für französische Sprache und Literatur LXXIII, 1963, S. 164-179.

- The Categories and Types of Present-Day English WordFormation. A synchronic-diachronic approach. Wiesbaden 1960.

Rez.: M. Gawełek, in: Kwartalnik neofilologiczny 1968, 1, S. 105-111.

Rez.: E. S. Kubrjakova, I. N. Anackij, in: Vja 1963, 1, S. $135-142$.

Maretić T., Gramatika hrvatskoga ili srpskoga književnog jezika. Zagreb ${ }^{3} 1963$.

- Gramatika i stilistika hrvatskoga ili srpskoga književnog jezika. Zagreb ${ }^{2} 1931$.

Maslov Ju. S., Glagol'nyj vid v sovremennom bolgarskom literaturnom jazyke (značenie $i$ upotreblenie). In: Voprosy grammatiki bolgarskogo literaturnogo jazyka. Moskva 1959, S. 157-312.

- Morfologija glagol'nogo vida v sovremennom bolgarskom literaturnom jazyke. Moskva-Leningrad 1963.

- Po vúprosa za vidovata defektivnost (nesúotnositelnost na glagolite ot svüršen $i$ nesvüršen vid) $v$ bŭlgarskija

i ruskija ezik. In: Bŭlgarski ezik VIII, 1958, S. 499-513.

- Rol' tak nazyvaemoj perfektivacii i imperfektivacii v processe vozniknovenija slavjanskogo glagol'nogo vida. In: Issledovanija po slavjanskomu jazykoznaniju. Moskva 1961, S. 165-195.

- Zur Entstehungsgeschichte des slavischen Verbalaspektes. In: ZfSI IV, 1959, S. 560-568.

Mazon A., Morphologie des aspects du verbe russe. Paris 1908. Meillet A., Etudes sur l'étymologie et le vocabulaire du vieux slave. II. Paris ${ }^{2} 1961$.

- Le slave commun. Paris 1924.

- Linguistique historique et linguistique générale. Paris 1948.

Mel'čuk I. A., K ponjatiju slovoobrazovanija. In: Izvestija AN SSSR. Serija literatury i jazyka XXVI, 1967, 4,

S. 352-362.

Miklosich F., Vergleichende Grammatik der slavischen

Sprachen. Bd. IV. Syntax. Heidelberg 1926.

- Vergleichende Syntax der slavischen Sprachen. Wien 1883. 
Motsch W., Zur Stellung der 'Wortbildung' in einem formalen

Sprachmodell. In: Studia grammatica I, Berlin 1965,

S. 31-50.

Mučnik I. P., 0 vidovych korreljacijach i sisteme sprja-

ženija glagola $\mathrm{v}$ sovremennom russkom jazyke. In: Vja

1956,6 , S. 92-106.

Müller $0 .$, Zur Stellung der Verben mit préverbes vides

im russischen Aspektsystem. In: ZfSI IX, 1964, S. 213-

220.

Němec I., Genese slovanského systému vidového. Praha 1958.

- Vývojové problémy soudobé nauky o vidu. In: SI XXVIII,

1959, S. 301-325.

Neščimenko G. P., Zakonomernosti slovoobrazovanija, seman-

tiki i upotreblenija suščestvitel'nych s suffiksami

sub-ektivnoj ocenki $v$ sovremennom češskom jazyke. In:

Issledovanija po češskomu jazyku. Voprosy slovoobra-

zovanija i grammatiki. Moskva 1963, S. 105-158.

Netteberg K. (Heltberg), Etudes sur le verbe polonais. Copenhague 1953.

- Niektóre problemy derywacji słowiańskiej. In: ScSI IX, 1963, s. 139-152.

- O derywacji i transformacji. In: ScSl VIII, 1963, S. 191200.

- O formacjach przyimkowych i przedrostkowych. In: ScSI V, 1959 , S. 19-29.

- O funkcji konektywnej przyrostków. In: ScSI VII, 1961, S. 286-299.

- O roli przedrostków w derywacji. In: ScSI XIV, 1968, S. 117-129.

- O typach derywacji zależnej i niezależnej z sufiksem -ina. In: ScSl VI, 1960, S. 132-143.

Nikolić S., Nomina agentis u staroslovenskom jeziku. In:

JF XXVII, 1966/67, S. 1-84.

Oravec J., Významová štruktúra prvotných predložiek.

In: JC XIX, 1968, S. 41-49.

Orzechowska H., Orzeczeniowe formacje odsłowne w jezykach

południowosłowiańskich. Wrocław-Warszawa-Kraków 1966.

Pauliny E., Odvodzovanie slovies podl'a slovesného vidu.

In: Slovo a tvar IV, 1950, S. 88-93.

Peciar S., Funkcie slovesnej predpony na- v slovenčine.

In: JC XVIII, 1967, S. 138-150. 
- K problému čisto vidových predpôn. In: JC XIX, 1968, S. 216-230.

Peškovskij A. M., Russkij sintaksis $v$ naučnom osveščenii. Moskva 1934.

Poldauf I., Ještě k "prostě vidovým předponám" $v$ češtině. In: SS XVII, 1956, S. 169-175.

- Podil mluvnice a nauky o slovniku na problematice slovesného vidu. In: Sb. Studie a práce linguistické. I. K šedesátým narozeninám ak. B. Havránka. Praha 1954, S. 200-223.

- Spojováni s predponami při tvoření dokonavych sloves v češtině. In: SS XV, 1954, S. 49-65.

- Trořeni slov. In: 0 vědeckém poznáni soudobých jazykú. Praha 1958, S. 143-153.

Pomianowska W., Klasyfikacja rzeczowników odrzeczownikowych. Wrocław-Warszawa-Kraków 1963.

Puzynina J., Kategoria aspektu w polskich nazwach czynności. In: PF XIX, 1969, S. 99-107.

- Pojecie regularnej $i$ nieregularnej konstrukcji morfemowej a fakty słowotwórcze. In: BTJ XXV, 1967, S. 91-102. Regnéll C. G., Uber den Ursprung des slawischen Verbalaspektes. Lund 1944.

Rozwadowski J., 0 dwuczłonowości wyrazów. In: 0 zjawiskach i rozwoju jezyka. Wydanie II, pomnożone. Kraków 1950, S. 143-155.

Rusek J., Ze studiów nad nazwami czynności w jezyku bułgarskim i macedońskim. In: Zeszyty naukowe uniwersytetu jagiellońskiego XVII, Filologia 4, Kraków 1958, S. 203234.

Ružička R., Einführung in die Flexion und Aspektbildung des russischen Verbs. Leipzig 1954.

Sanskij N. M., Očerki po russkomu slovoobrazovaniju i leksikologii. Moskva 1959.

Rez.: A. Bogusławski, in: S10r III, I960, S. 511-515. Rez.: V. V. Lopatin, I. S. Uluchanov, in: FN 1961, 1, S. 135-141.

Saussure de F., Grundfragen der allgemeinen Sprachwissenschaft. Paris ${ }^{2} 1967$.

Schippan Th., Die Verbalsubstantive der deutschen Sprache der Gegenwart. Habil.-Schr. Leipzig 1967. 
Schmidt W., Lexikalische und aktuelle Bedeutung. Berlin 1963.

Schooneveld van C. H., The so-called "Préverbes Vides" and

Neutralization. In: Dutch Contributions to the Fourth

International Congress of Slavicists, Moscow 1958.

's-Gravenhage, S. 159-161.

Schütz J., Das serbokroatische augmentative Suffix -uština.

In: ZfSI II, 1957, S. 391-393.

Sekaninová E., Analł́za sémantiky komponentov $\mathrm{v}$ predponovom slovese. In: Kapitoly ze srovnávací mluvnice ruské a české. III. Praha 1968, S. 232-286.

- Miesto prefixácie vo vidovom systéme slovanského slovesa. In: Sisl v, 1970, S. 17-33.

- Nové pohl'ady na kategóriu slovesného vidu. In: JC XXIII, 1972, S. 192-197.

- Slovesná predpona do- $v$ ruštine a slovenčine. In: CR XVI, 1971, S. 193-199.

- Strukturálno-sémantická analýza slovies s predponou nav slovenčine. In: JC XXI, 1970, S. 26-35.

Sieczkowski A., $\mathrm{Z}$ metodyki badán porównawczych nad słowotwórstwem słowiańskim. In: BTJ XXI, 1962, S. 171-180. Skok P., Supstantiviranje infinitiva u slovenačkom. In: Casopis za Slovenski jezik, književnost in zgodovino VII, Ljubljana 1928, S. 156-157.

Słoński St., Funkcje prefiksów werbalnych w jezjku starosłowiańskim (starobułgarskim). Warszawa 1937.

- Funkcje prefiksu werbalnego do- w jezyku starosłowiańskim. In: PF XIV, 1929, S. 86-93.

- Funkcje prefiksu werbalnego na- w jezyku starosłowiańskim. In: PF XIV, 1929, S. 129-153.

Smilauer V., Novočeské tvořeni slov. Praha 1971.

- Slovesný vid a zpưsob slovesného děje. Prvni hovory o českém jazyce. Praha 1940.

Smirnickij A. I., Leksikologija anglijskogo jazyka. Moskva 1956.

- Po povodu konversii $\mathrm{v}$ anglijskom jazyke. In: Inostrannye jazyki v škole 1954, 3, S. 12-24.

- Tak nazyvaemaja konversija $i$ čeredovanie zvukov $v$ anglijskom jazyke. In: Inostrannye jazyki v škole 1953, 5, S. 21-31. 
Soboleva P. A., Ob osnovnom i proizvodnom slove pri slovoobrazovatel'nych otnošenijach po konversii. In: Vja 1959, 2, S. 91-95.

Stender-Petersen A. I., 0 funkcijach glagol'nych pristavok $v$ russkom jazyke. In: SI XII, 1933, S. 321-334.

Stepanova M. D., O vnešnej $i$ vnutrennej valentnosti slova. In: Inostrannye jazyki $v$ škole 1967,3 , S. 13-19.

- "Slovoobrazovanie, orientirovannoe na soderžanie", $i$ nekotorye voprosy analiza leksiki. In: Vja 1966, 6, S. 48-59.

- Slovoobrazovanie sovremennogo nemeckogo jazyka. Moskva 1953.

Rez.: K. A. Levkovskaja, in: Vja 1955, 4, S. 145-152. Stevanović M., Savremeni srpskohrvatski jezik. Beograd 1964. Stiebitz F., Vid a zpúsob slovesného děje. In: Listy

filologické LV, 1928, S. 1-14. Stojanović Lj., O značenju i upotrebi glagolskih oblika

u rečenicama. In: JF II, 1929, S. 187-189.

Stolc J., K syntaxi činitel'ských a dejových podstatných mien. In: Slovo a tvar II, 1948, S. 6-10. Strakova V., Primečanija k razdelu "Slovoobrazovanie".

In: CR XII, 1967, S. 74-75.

Sverdlov L. G., Semantika otglagol'nych suščestvitel'nych na -nije, -tije v russkom jazyke. In: FN 1961, 2, S. 23-35.

Szymański T., Słowotwórstwo rzeczownika w bułgarskich tekstach XVII-XVIII wieku. Wrocław-Warszawa-Kraków 1968. Tichonov A. N., Cistovidovye pristavki v sisteme russkogo vidovogo formoobrazovanija. In: Vja 1964, I, S. 42-52.

- O semantičeskoj sootnositel'nosti proizvodjaščich i proizvodnych osnov. In: Vja 1967, 1, S. 113-120.

- Zametki o vtoričnoj imperfektivacii glagolov s čisto vidovymi pristavkami. In: Trudy Uzbekskogo gosudarstvennogo universiteta imeni Ališera Navoi. Novaja serija № 92. Slavjanskij sbornik. Samarkand 1958. Trávniček F., Mluvnice spisovné češtiny. I. Hláskoslovi tvořeni slov - tvaroslovi. Praha ${ }^{3} 1951$.

- Studie o českém vidu slovesném. Praha 1923. Trnka B., O podstatě vidu. In: CMF XIV, 1928, S. 193-197. Trypućko J., 0 pewnej nie dostrzeżonej funkcji przedrostków czasownikowych w jezyku rosyjskim. In: SRL III 1950,2 
S. 327-342.

Ugrinova-Skalovska R., Značenjata na glagolskite prefiksi vo makedonskiot jazik. Skopje 1960.

Vey M., Les préverbes "vides" en tchèque moderne. In: RES XXIX, 1952, S. 82-107.

Rez.: F. Kopečný, in: SS XVIII, 1956, S. 28-35. Vinogradov V. V., Slovoobrazovanie v ego otnošenii k grammatike $i$ leksikologii (na materiale russkogo $i$ rodstvennych jazykov). In: Voprosy teorii $i$ istorii jazyka v svete trudov J. V. Stalina po jazykoznaniju. Moskva 1952, S. 99-152.

- Sovremennyj russkij jazyk. Morfologija. Moskva 1952.

- Russkij jazyk. Moskva-Leningrad 1947.

Vinokur G. 0., Zametki po russkomu slovoobrazovaniju. In:

Izvestija AN SSSR. Otdelenie literatury i jazyka V, 1946, S. 315-322.

Volockaja Z. M., K probleme sinchronnogo slovoobrazovanija.

In: Lingvističeskie issledovanija po obščej i slavjans-

koj tipologii. Moskva 1966, S. 231-236.

- Ob odnom podchode $k$ opisaniju slovoobrazovatel'noj sistemy. In: Lingvističeskie issledovanija po obščej

i slavjanskoj tipologii. Moskva 1966, S. 51-62.

Vondrák W., Vergleichende slavische Grammatik. I-II. Göttingen 21924-1928.

Vuković J., Glagolske imenice na -nje i -će. In: Pitanja savremenog književnog jezika I, Sarajevo 1949, S. 40-53.

- Glagolske imenice na -nje i -će. In: Pitanja savremenog književnog jezika II, Sarajevo 1950, S. 149-171.

Wierzchowski J., System leksykalny a słowotwórstwo polskie. In: IJSLP VII, 1963, S. 58-71.

- Uwagi słowotwórczo-leksykologiczne. In: BTJ XVIII, 1959, S. 223-229.

Wijk van N., Sur l'origine des aspects du verbe slave.

In: RES IX, 1929, S. 237-252.

- Zur Vorgeschichte der slavischen Aspekte. In: IF LIII, 1935, S. 196-206.

Witkowski W., Sufiksy nomina agentis $w$ jezyku rosyjskim.

In: Studia z filologii polskiej i słowiańskiej I,

Warszawa 1955, S. 486-520.

Zemskaja E. A., Ponjatija proizvodnosti, oformlennosti i členimosti osnov. In: Razvitie slovoobrazovanija 
sovremennogo russkogo jazyka. Akademija nauk SSSR. Moskva 1966, S. 3-12.

- Tipy odnovidovych pristavočnych glagolov v sovremennom russkom jazyke. In: Issledovanija po grammatike russkogo literaturnogo jazyka. Moskva 1955, S. 5-4l.

- Zametki po sovremennomu musskomu slovoobrazovaniju. In: Vja 1965, 3, S. 102-110.

Zirmunskij V. M., O granicach slova. In: Vja 1961, 3, S. 3-21.

Zwoliński P., Wspólne tendencje słowotwórcze (derywacjjne) jezyków słowiańskich. In: Z polskich studiów slawistycznych III, Warszawa 1968, S. 89-99. 


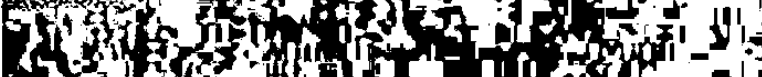

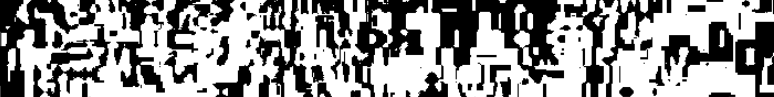
4 stim 4 ibin 134 y

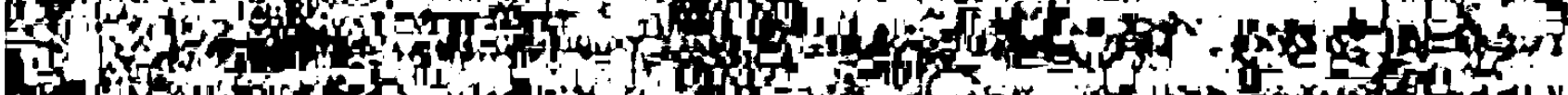

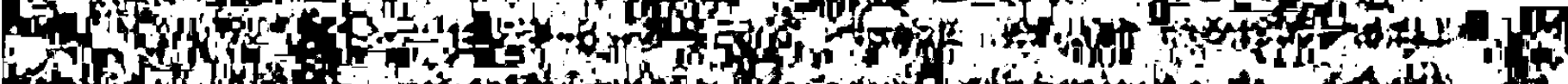
The

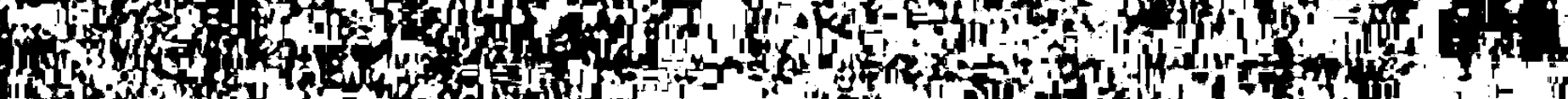

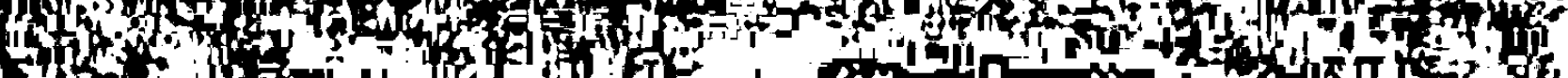

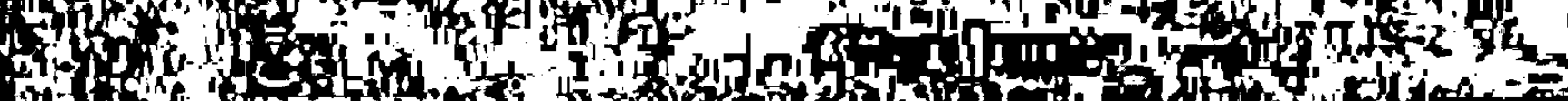

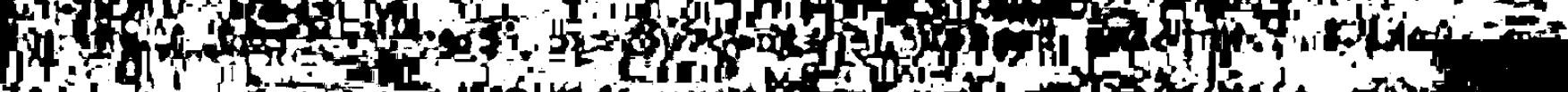

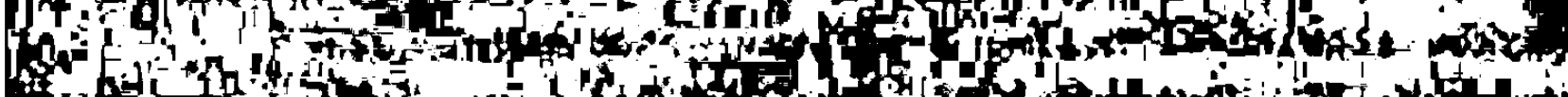

50 (2) of

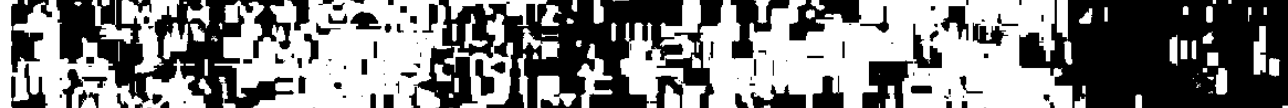
of

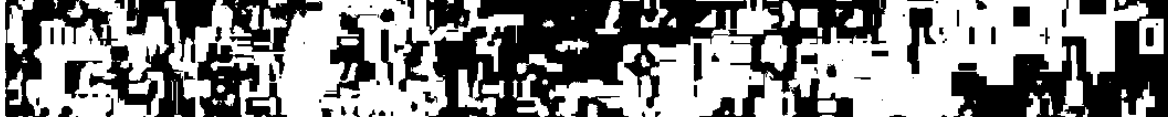

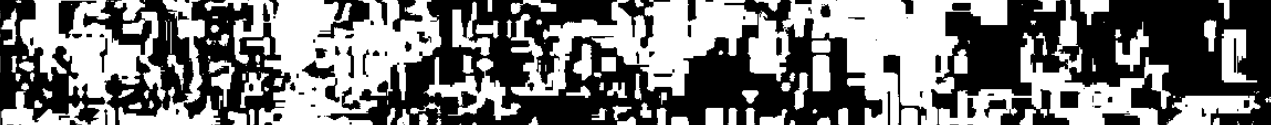

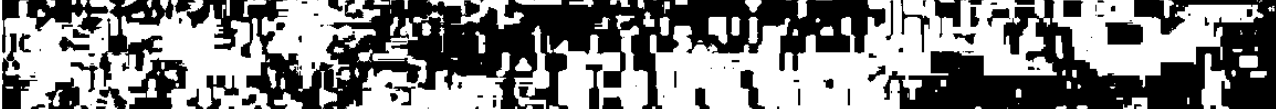
-

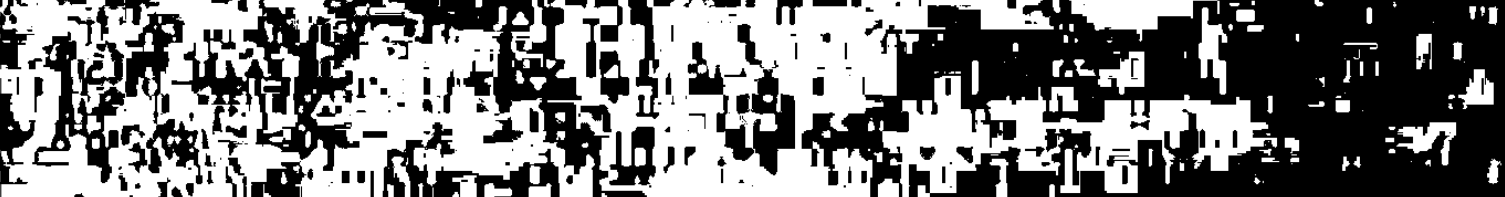
A

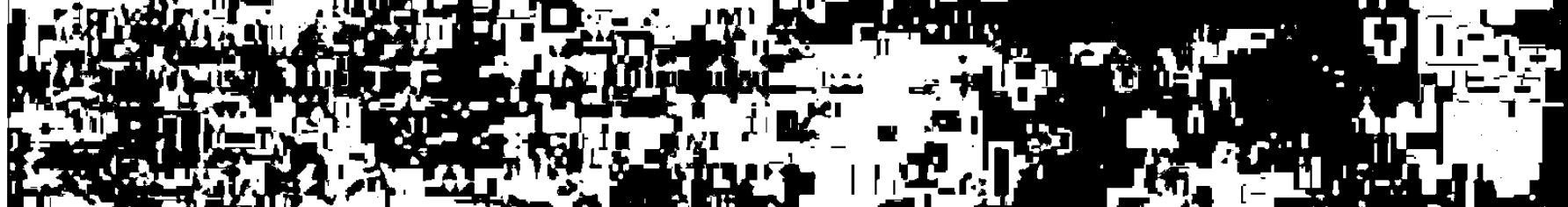

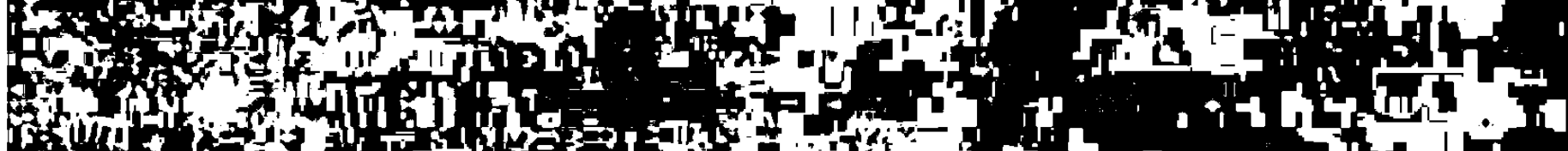

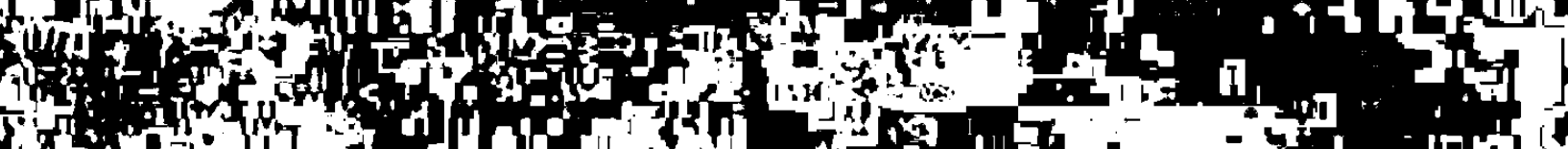
(1) (n) $\therefore$ and (n) Q1. Hing a - in the 


\section{NACHWORT}

Die vorliegende Arbeit wurde im Wintersemester 1973/74 von der Philosophischen Fakultät der Universität Regensburg als Dissertation angenommen.

Herrn Prof. Dr. Karl-Heinz Pollok danke ich für die Betreuung dieser Arbeit.

Herr Dr. Gunter Spiess M.A., Regensburg, hat in uneigennütziger Weise zur Entstehung der Arbeit durch Anregungen, Ratschläge und Hinweise beigetragen, wofür ihm an dieser Stelle ganz besonders herzlich gedankt sei. 
Klaus Koszinowski - 9783954793105

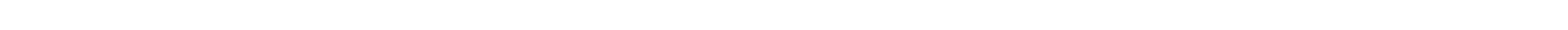


83. Baumann, W.: Die Sage von Heinrich dem Löwen bei den Slaven. 1975. $185 \mathrm{~s}$.

84. Everts-Grigat, S.: V. V. Majakovskij: Pro éto. Ubersetzung und Interpretation. 1975. $262 \mathrm{~S}$.

85. Mirsky, S.: Der Orient im Werk Velimir Chlebnikovs. 1975. VIII, $112 \mathrm{~S}$.

86. Ditterich, M.: Untersuchungen zum altrussischen Akzent anhand von Kirchengesangshandschriften. 1975. $147 \mathrm{~S}$.

87. Cummins, G. M.: The Language of the Old Czech Legenda o svate Katetine. 1975. VIII, $371 \mathrm{~S}$.

88. Földeak, H.: Neuere Tendenzen der sowjetischen Science Fiction. 1975. VI, $208 \mathrm{~S}$.

89. Drews, P.: Devétsil und Poetismus. Künstlerische Theorie und Praxis der tschechischen literarischen Avantgarde am Beispiel Vitézslav Nezvals, Jaroslav Seiferts und Jifí Wolkers. 1975. $330 \mathrm{~s}$.

90. Schönle, P. W.: zur Wortbildung im modernen Russisch. 1975. VIII, 195 S.

91. Okuka, M.: Sava Mrkalj als Reformator der serbischen Kyril1iza. Mit einem Nachdruck des Salo debeloga jera libo Azbukoprotres. 1975. $123 \mathrm{~S}$.

92. Neuhäuser, R.: The Romantic Age in Russian Literature: Poetic and Esthetic Norms. An Anthology of Original Texts (18001850). 1975. VIII, $300 \mathrm{~S}$.

93. Döring, J. R. (Hrg.) : Literaturwissenschaftliches Seminar: Zur Analyse dreier Erzählungen von Vl. I. Dal'. Mit einem methodologischen Geleitwort von Johannes Holthusen.1975. $203 \mathrm{~S}$.

94. Alexander, R.: Torlak Accentuation. 1975. XVI, 806 S.

95. Schenkowitz, G.: Der Inhalt sowjetrussischer Vorlesestoffe für Vorschulkinder. Eine quantifizierende Corpusanalyse unter Benutzung eines Computers. 1976. $767 \mathrm{~S}$.

96. Kitch, F. C. M.: The Literary Style of Epifanij Premudryj. Pletenije sloves. 1976. 298 S.

97. Eschenburg, B.: Linguistische Analyse der Ortsnamen der ehemaligen Komitate Bács und Bodrog von der ungarischen Landnahme (896) bis zur Schlacht von Mohács (1526). 1976. $156 \mathrm{~s} .3 \mathrm{Kt}$.

98. Lohse, H.: Die Ikone des hl. Theodor Stratilat zu Kalbensteinberg. Eine philologisch-historische Untersuchung. 1976.XX,242 S.

99. Erbsibh, G.: "Pobeda nad solncem". Ein futuristisches Drama von A. KruCenych. Ubersetzung und Kommentar. (Mit einem Nachdruck der Originalausgabe.) 1976. $121 \mathrm{~S}$.

100. Koszinowski, K.: Die von präfigierten Verben abgeleiteten Substantive in der modernen serbokroatischen standardsprache. Eine Untersuchung zu den Präfixen do, iz, na, za. 1976. $271 \mathrm{~S}$.

101. Leitner, A.: Die Erzählungen Fedor Sologubs. 1976. 249 S. 